BRUNO LUÍS DAMINELI

\title{
ESTUDO DE MÉTODOS PARA CARACTERIZAÇÃO DE PROPRIEDADES FÍSICAS DE AGREGADOS GRAÚDOS DE RESÍDUOS DE CONSTRUÇÃO E DEMOLIÇÃO RECICLADOS
}

Dissertação apresentada à Escola Politécnica da Universidade de São Paulo para obtenção do título de Mestre em Engenharia. 
BRUNO LUÍS DAMINELI

\section{ESTUDO DE MÉTODOS PARA CARACTERIZAÇÃO DE PROPRIEDADES FÍSICAS DE AGREGADOS GRAÚDOS DE RESÍDUOS DE CONSTRUÇÃO E DEMOLIÇÃO RECICLADOS}

Dissertação apresentada à Escola Politécnica da Universidade de São Paulo para obtenção do título de Mestre em Engenharia.

Área de concentração:

Engenharia de Construção Civil e Urbana

Orientador:

Prof. Dr. Vanderley Moacyr John 
Este exemplar foi revisado e alterado em relação à versão original, sob responsabilidade única do autor e com a anuência de seu orientador.

São Paulo, 06 de julho de 2007.

Assinatura do autor

Assinatura do orientador

FICHA CATALOGRÁFICA

Damineli, Bruno Luís

Estudo de métodos para caracterização de propriedades físicas de agregados graúdos de resíduos de construção e demolição reciclados / B.L. Damineli. -- ed.rev. -- São Paulo, 2007. $107 \mathrm{p}$.

Dissertação (Mestrado) - Escola Politécnica da Universidade de São Paulo. Departamento de Engenharia de Construção Civil.

1.Resíduos de construção 2.Agregados (Reciclagem) 3.Absorção 4.Controle da qualidade 5 .Usinas de reciclagem de resíduos urbanos 6.Concreto I.Universidade de São Paulo. Escola Politécnica. Departamento de Engenharia de Construção Civil II.t. 
Dedico este trabalho:

A minha esposa Milena, que confiou no meu potencial e me inspirou com sua garra invejável, a quem amo demais.

A meus pais, Mário e Selene, que me deram meios e ensinamentos para a formação dos meus valores, não tenho como agradecê-los por terem feito tudo tão certo.

À Eliana, que ajudou a me criar, a quem estimo como a uma mãe.

A meus irmãos, Lígia, Guilherme e Beatriz, que conviveram comigo diferentes e importantes fases de minha vida. Ainda vamos enfrentar muitas juntos...

E a Deus, que guia minha vida em direção ao trabalho útil. Vocês são inestimáveis para mim. 


\section{AGRADECIMENTOS}

Este trabalho, em momento algum, foi realizado individualmente. Há muita gente a agradecer... mas, em especial, há três pessoas para quem palavras de agradecimento são pouco para expressar o que fizeram por mim.

A primeira é o meu orientador, Prof. Dr. Vanderley Moacyr John. Em encontros às vezes de minutos mas com rendimento inacreditável, aprendi que grandes profissionais e homens se fazem com doses exatas de trabalho e exigência mas também bom-humor, compreensão e humildade, tudo em tempo e linhas reduzidas. "O tempo é o bem mais precioso e escasso que temos na vida" (JOHN, reunião sobre o mestrado).

A segunda é a Profa. Dra. Maria Elena dos Santos Taqueda. O planejamento experimental deste (e dos meus próximos) trabalhos deveu-se (ou dever-se-ão) às competentes tramas estatísticas aprendidas com ela, sempre a muito custo... para arquitetos, e para engenheiros (5 homens, me incluindo, não resolveram UM exercício proposto em três dias!). Seus auxílios ao planejamento dos experimentos laboratoriais e à análise dos resultados foram fundamentais.

A terceira é o Dr. Sérgio Cirelli Angulo, com quem poderia até mesmo dividir a autoria deste trabalho, pois o acompanhou com disposição invejável a discussões e retirada de dúvidas, auxiliando-me desde o início na elaboração de planos experimentais, compreensão de métodos de cálculos e de ensaios, adaptação ao laboratório, correção de textos... enfim, em tudo o que um arquiteto recém-chegado à Escola Politécnica precisa sofrer.

Agradeço também a todos os professores das disciplinas cursadas. Paulo Helene, Antônio Figueiredo, Maria Alba, Sílvia Selmo, Kay, além do prof. Vanderley e da profa. Maria Elena, saibam que, em cada uma de suas disciplinas, aprendi conteúdos valiosos ao meu projeto.

Agradeço aos técnicos do laboratório, Adilson, Reginaldo, Renata e Talita, que tanto me auxiliaram nas necessidades da pesquisa. Em especial agradeço ao Ismael, pela concepção do cilindro para aplicação do vácuo, e ao Mário, que, além de se tornar um grande amigo e me ajudar no laboratório, teve atuação decisiva na etapa final, quando faltavam poucos ensaios e a central de vácuo quebrou... e ainda me ajudou nos ensaios de picnometria...

Obrigado aos bibliotecários, que sempre me atenderam com paciência, à Sarah, que revisou a bibliografia, à Fátima, que sempre auxiliou nos problemas de ordem burocrática, e à Engrácia, que cuidou dos problemas burocráticos envolvendo recursos para a pesquisa.

Agradeço a todos os mestrandos que cursaram disciplinas comigo e me ajudaram em diversos momentos, destacando os Srs. Flávio Munhoz e Fernando Montija, que cursaram comigo a maioria das disciplinas e agüentaram com grande paciência muitas dúvidas sobre engenharia elementar (e não-elementar!), repetidas diversas vezes...

Devo ainda agradecer à minha família pela grande paciência e apoio durante todo o processo. Minha esposa Milena, obrigado por me incentivar e ficar ao meu lado, para que eu pudesse enfrentar tudo com coragem e tranqüilidade. Meu pai Mário, mãe Selene, Eliana e vó Maria, obrigado por tudo o que fizeram por mim, sua dedicação e ensinamentos me permitem entender as dificuldades como aprendizados e desafios a serem vencidos. Meus irmãos Lígia, Guilherme e Beatriz, obrigado por participarem da minha vida, me ajudando a pensar sempre no futuro e em nossos crescimentos pessoais. Obrigado a todos, por me compreenderem nos momentos difíceis e em minhas eventuais ausências... mas saibam que tudo valeu a pena.

Enfim, a todos que ajudaram de alguma forma a fazer do mestrado na Poli (para um arquiteto!) mais do que uma dura prova de fogo matemático-lógico-estatístico-químico, principalmente um grandioso aprendizado de vida. 


\section{RESUMO}

O baixo consumo de agregados de Resíduos de Construção e Demolição (RCD) deve-se, atualmente, à sua variabilidade natural e à falta de controle de sua qualidade, que limitam sua utilização em aplicações de maiores demandas, tais como concretos. Uma maneira usual de controle de agregados para concretos se dá por meio da determinação de sua porosidade, expressa pelas propriedades físicas de massa específica e absorção. O método utilizado para medir estas propriedades é a NM 53, norma derivada da ASTM C127. Porém, foi originalmente concebida para caracterizar agregados naturais, não sendo adequada sobre agregados de RCD reciclados.

Nesse sentido, o objetivo deste trabalho é estabelecer um método rápido e preciso para controle de qualidade e triagem de agregados reciclados em usinas de reciclagem, o que poderia ampliar as possibilidades de campos para sua utilização.

Para isso, foram estudados comparativamente três métodos distintos - NM 53, massa submersa no tempo e secagem - para determinação das propriedades físicas absorção e massa específica aparente (MEA) dos agregados reciclados. Os planejamentos experimentais basearamse em modelos estatísticos do tipo fatorial completo, que permitem melhorias do processo selecionado, de acordo com necessidades estabelecidas, através de análises de variáveis de possível significância às respostas. A adequação da NM 53 para utilização sobre agregados reciclados depende de: 1) aumento da saturação dos poros das amostras; 2) diminuição da perda de massa durante os ensaios; e 3) aumento da rapidez das determinações.

Após a execução dos planejamentos experimentais, pôde-se propor um novo método para determinação da absorção e MEA de agregados graúdos de RCD reciclados. Tal método aumentou estatisticamente os valores de absorção medidos (aumento da saturação de poros), diminuiu a perda de massa das amostras durante a execução dos ensaios e ainda reduziu o tempo de caracterização de 48 horas (mínimo dispensado pela NM 53) para aproximadamente 4 horas. O método utiliza equipamentos simples e de baixo custo, possuindo potencial real para ser implantado para controle de qualidade de agregados de RCD reciclados em usinas de reciclagem.

Palavras-chave: resíduos de construção; agregados (reciclagem); absorção; massa específica; controle da qualidade; concreto. 


\section{ABSTRACT}

The low comsumption of Construction and Demolition Waste (CDW) recycled aggregates happens, nowadays, because its natural variability and quality control absence that limit its use in applications with larger demands, such as concretes. One way of concrete aggregates control is done by determining its porosity, express by physical properties absorption and relative density. The method that measures its properties is the NM 53, standard derived from ASTM C127. But this standard was conceived to characterize natural aggregates, and is not appropriate on CDW recycled aggregates.

In this way, the purpose of this work is to establish a quick and accurate method for quality control and selection of recycled aggregates in recycling plants, which could increase the possibilities of fields for its use.

Thus, this work comparatively studied three distinct methods - NM 53, submerged mass in time and drying - for determining physical properties absorption and relative density of recycled aggregates. The experimental plannings were based on statistical models type Design of Experiments (DOE) that allow improvement on a selected process, in accordance with established needs, through analysis of possible significant variables for results. The adaption of NM 53 to recycled aggregates characterization depends on: 1) increase of sample pores saturation; 2) decrease of mass loss during the tests; and 3) increase of determination speed.

After execution of experimental plannings, a new method for determining CDW coarse recycled aggregates physical properties could be proposed. This method statistically increased the measured absorption values (pores saturation increase), decreased mass loss during tests executions and reduced the characterization time from 48 hours (minimum used by NM 53) to approximately 4 hours. The method uses simple and low costs equipment, having real potential to be implemented for quality control of CDW recycled aggregates on recycling plants.

Keywords: construction waste; aggregates (recycling); absorption; relative density; quality control; concrete. 


\section{SUMÁRIO}

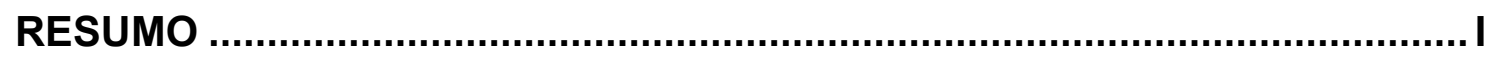

ABSTRACT

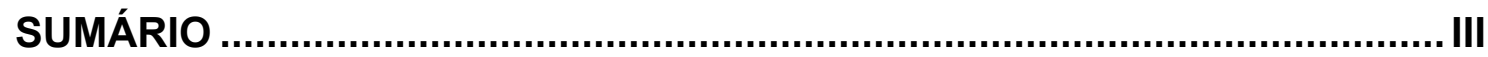

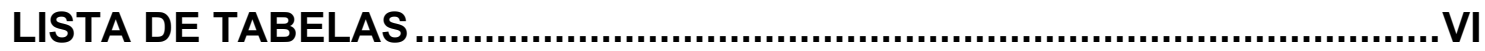

LISTA DE FIGURAS

LISTA DE SÍMBOLOS E ABREVIAÇÕES ……..........................................III

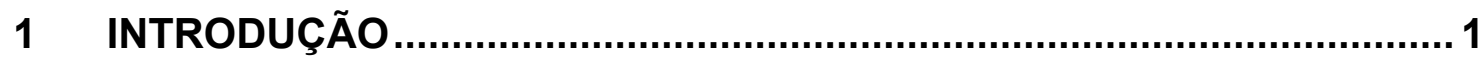

2 CONTROLE DAS PROPRIEDADES FÍSICAS DOS AGREGADOS DE RCD RECICLADOS

2.1 Definição, quantificação e problemas ambientais gerados pelos resíduos de construção e demolição.

...4

2.2 Produção e aplicação de agregados de RCD reciclados ................................................. 5

2.3 Definição de porosidade, absorção de água e massa esp. de agregados porosos ................ 8

2.4 Importância da porosidade dos agregados para o concreto .................................................9

2.5 Métodos para determinação da porosidade de agregados graúdos .................................. 13

2.5.1 Determinação das propriedades pela NM 53 .......................................................... 13

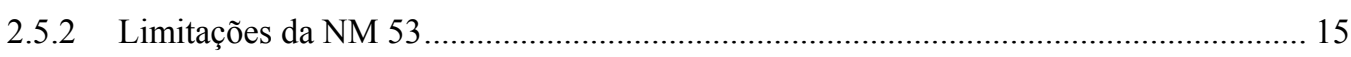

2.6 Métodos alternativos ................................................................................................................... 17

2.6.1 Massa submersa ao longo do tempo e aplicação de vácuo.......................................... 17

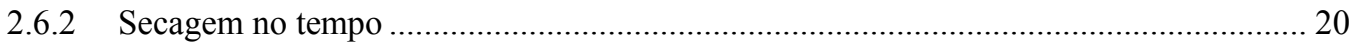

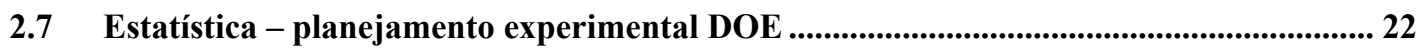

\section{ESTUDO EXPERIMENTAL SOBRE AGREGADOS DE BAIXA}

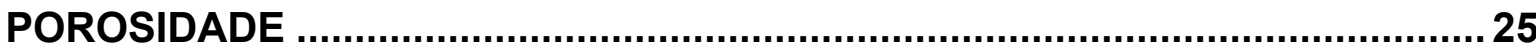

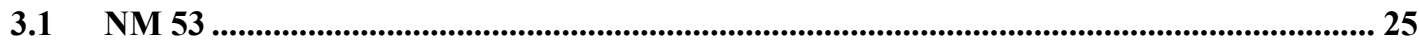

3.1.1 Planejamento experimental, materiais e métodos …............................................. 25

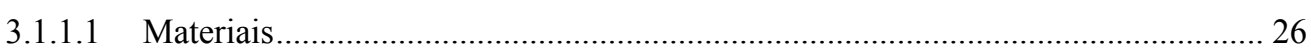

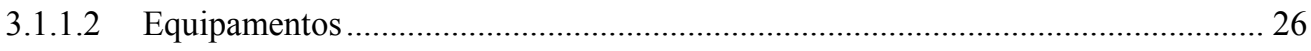

3.1.1.3 Descrição dos procedimentos de ensaio e cálculos ........................................... 27

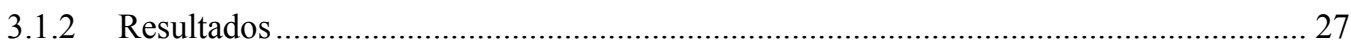

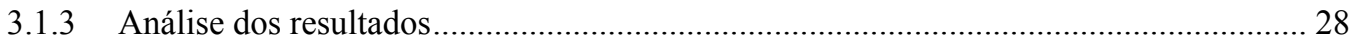

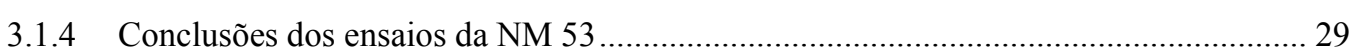




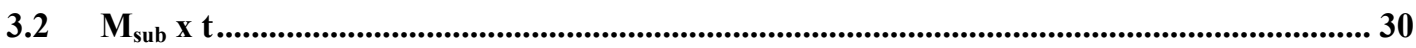

3.2.1 Planejamento experimental, materiais e métodos ………………………………....... 30

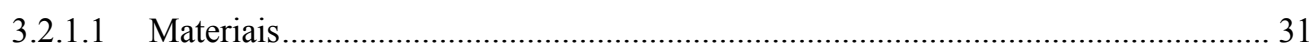

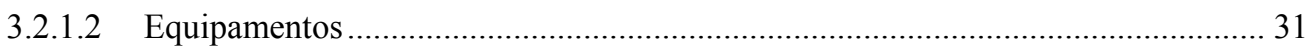

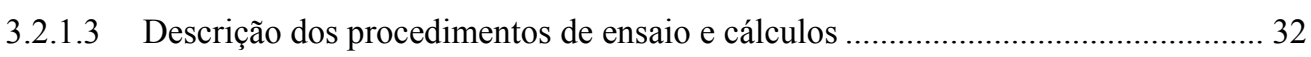

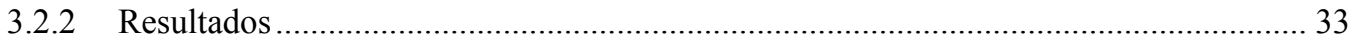

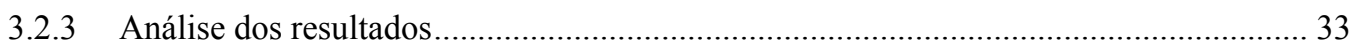

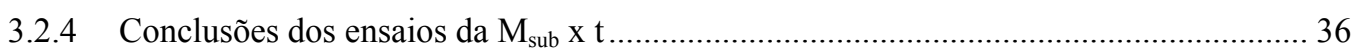

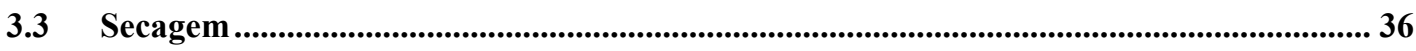

3.3.1 Planejamento experimental, materiais e métodos ........................................................ 36

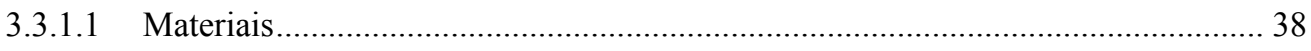

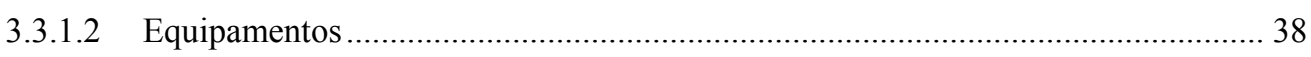

3.3.1.3 Descrição dos procedimentos de ensaio e cálculos ................................................ 38

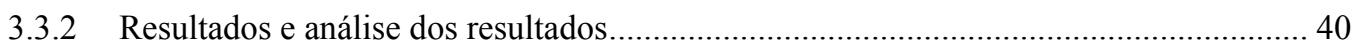

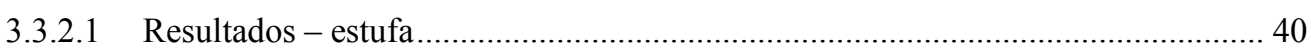

3.3.2.2 Análise dos resultados - estufa...................................................................... 42

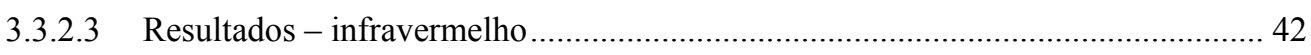

3.3.2.4 Análise dos resultados - infravermelho.................................................................... 44

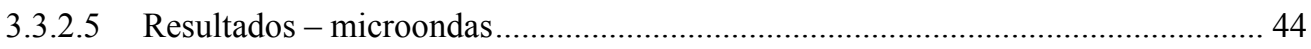

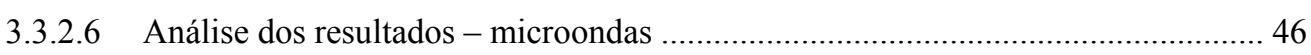

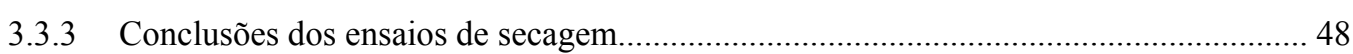

\section{ESTUDO DE MÉTODO RÁPIDO PARA DETERMINAÇÃO DE PROPRIEDADES FíSICAS DE AGREGADOS DE ALTA POROSIDADE.}

4.1 Planejamento experimental, materiais e métodos ................................................................... 49

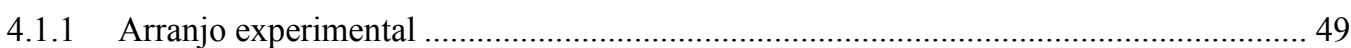

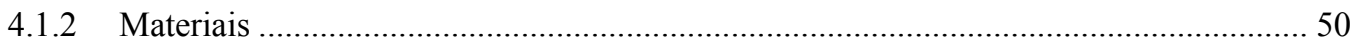

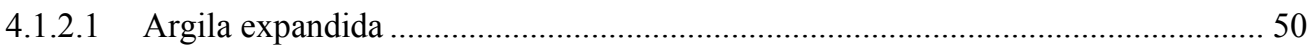

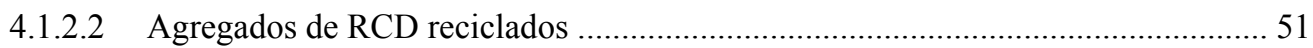

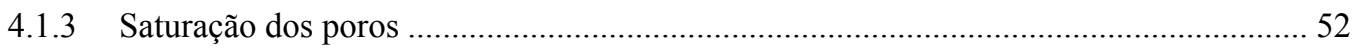

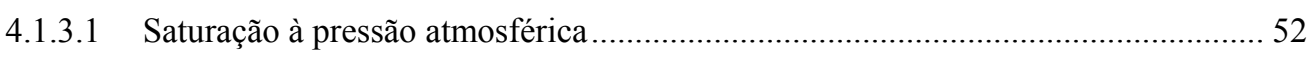

4.1.3.2 Saturação a vácuo ......................................................................................... 52

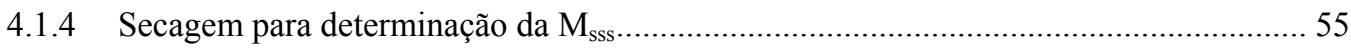

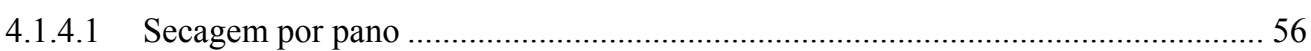

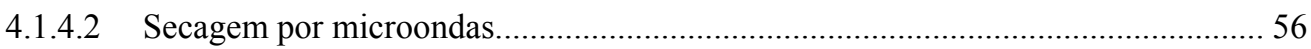

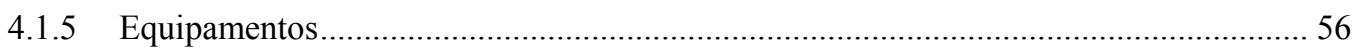

4.1.6 Procedimentos de ensaio e cálculos .................................................................................. 57

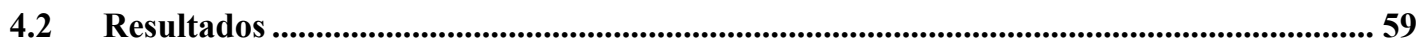




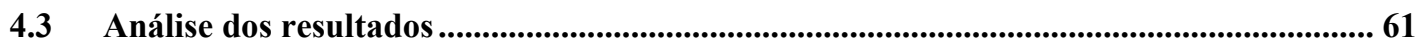

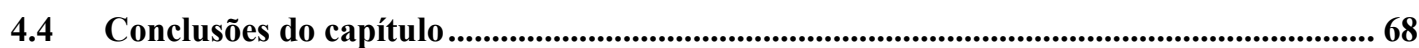

5 EFEITO DO MÉTODO DE SECAGEM E DA REPETIÇÃO DO ENSAIO SOBRE A PERDA DE MASSA DE AGREGADOS DE RCD RECICLADOS .......70

5.1 Planejamento experimental, materiais e métodos ................................................................. 70

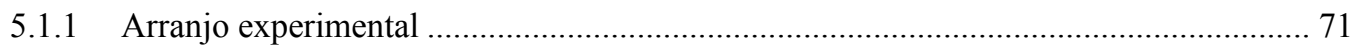

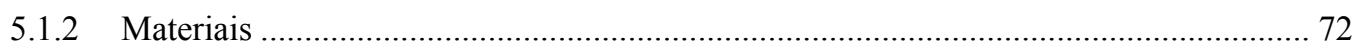

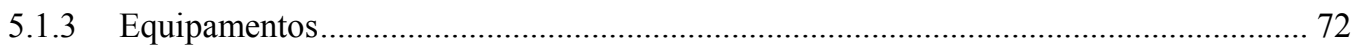

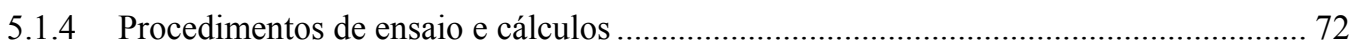

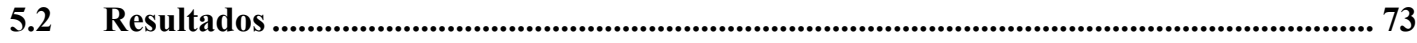

$5.3 \quad$ Análise dos resultados .......................................................................................................... 74

5.4 Conclusões do capítulo ............................................................................................................... 79

6 COMPARAÇÃO ENTRE DETERMINAÇÃO DA MASSA SECA EM ESTUFA E MICROONDAS ......................................................................... 80

6.1 Planejamento experimental, materiais e métodos ..................................................................... 80

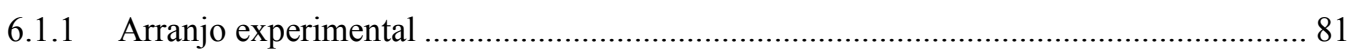

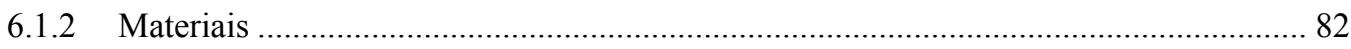

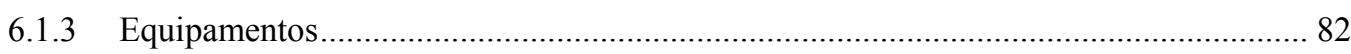

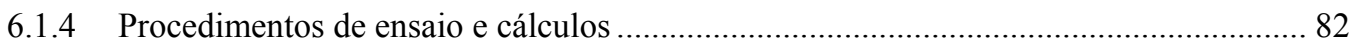

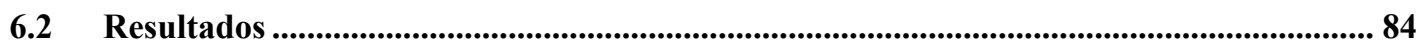

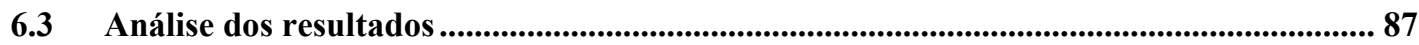

6.4 Conclusões do capítulo ..............................................................................................................90

7 PROPOSTA DE MÉTODO ................................................................ 91

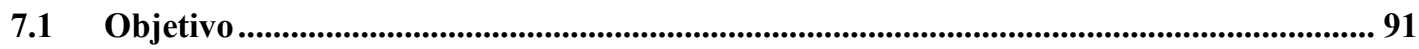

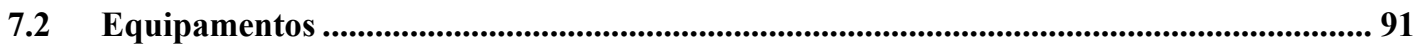

$7.3 \quad$ Procedimentos de ensaio e cálculos ............................................................................................92

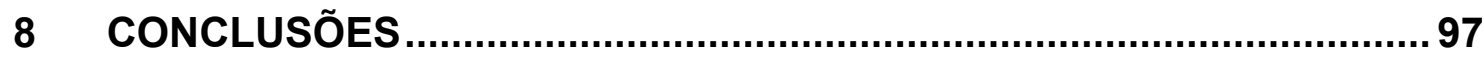

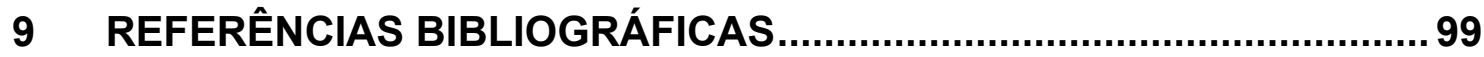

APÊNDICES A a I....................................................................... CD-ROM 


\section{LISTA DE TABELAS}

Tabela 2.1 - Classificação e destinação dos agregados de RCD reciclados segundo a

Danish Concrete Association 13

Tabela 3.1 - Planejamento fatorial $2^{2}$ dos ensaios para a NM 53 - esferas de vidro 26

Tabela 3.2 - Composição granulométrica dos agregados de vidro - porcentagem retida acumulada nas peneiras

Tabela 3.3 - Resultados dos ensaios do método NM 53 - esferas de vidro.

Tabela 3.4 - Determinação do erro experimental do planejamento de esferas de vidro para as respostas de absorção

Tabela 3.5 - Estudo de significância das variáveis dos ensaios da NM 53 para esferas de vidro para respostas de absorção.

Tabela 3.6 - Planejamento fatorial $2^{3}$ dos ensaios para a Msub x $\mathrm{t}$ - esferas de vidro .........31

Tabela 3.7 - Resultados dos ensaios do método Msub x t - esferas de vidro

Tabela 3.8 - Determinação do erro experimental dos ensaios do método Msub x t esferas de vidro

Tabela 3.9 - Estudo de significância das variáveis dos ensaios da Msub x t para esferas de vidro para respostas de absorção

Tabela 3.10 - Codificação variáveis utilizadas para o método secagem - esferas de vidro 37

Tabela 3.11 - Planejamento fatorial $2^{2}$ dos ensaios para secagem em estufa - esferas de vidro.

Tabela 3.12 - Planejamento fatorial $2^{2}$ dos ensaios para secagem com infravermelho esferas de vidro.

Tabela 3.13 - Planejamento fatorial $2^{2}$ dos ensaios para secagem em microondas esferas de vidro

Tabela 3.14 - Resultados dos ensaios do planejamento do método de secagem em estufa - esferas de vidro.

Tabela 3.15 - Resultados dos ensaios do método secagem em infravermelho - esferas de vidro

Tabela 3.16 - Resultados dos ensaios do método secagem em microondas - esferas de vidro

Tabela 3.17 - Cálculo do erro sistemático detectado para os ensaios de secagem de esferas de vidro em microondas 
Tabela 3.18 - Determinação do erro experimental dos ensaios do método secagem em microondas - esferas de vidro

Tabela 3.19 - Estudo de significância das variáveis dos ensaios de secagem em microondas para esferas de vidro

Tabela 4.1 - Planejamento fatorial $2^{3}$ completo dos ensaios sobre agregados de alta porosidade

Tabela 4.2 - Composição granulométrica dos agregados de argila expandida porcentagem retida acumulada nas peneiras

Tabela 4.3 - Composição granulométrica dos agregados reciclados - porcentagem retida acumulada nas peneiras

Tabela 4.4 - Planejamento preliminar fatorial $2^{3}$ completo dos ensaios sobre agregados 1,9 a $2,2 \mathrm{~kg} / \mathrm{dm}^{3}$, respostas em diferentes tempos $\mathrm{t}$ de cada ensaio e proporções entre absorções destes diferentes tempos

Tabela 4.5 - Estudo de significância das variáveis do planejamento preliminar sobre agregados 1,9 a $2,2 \mathrm{~kg} / \mathrm{dm}^{3}$

Tabela 4.6 - Resultados dos ensaios do planejamento experimental $2^{3}$ realizado sobre os agregados porosos

Tabela 4.7 - Determinação do erro do planejamento de agregados porosos para as respostas de absorção

Tabela 4.8 - Estudo de significância das variáveis do planejamento de agregados porosos para respostas de absorção.

Tabela 4.9 - Determinação do erro do planejamento de agregados porosos para respostas de perda de massa

Tabela 4.10 - Estudo de significância das variáveis do planejamento de agregados porosos para respostas de perda de massa

Tabela 5.1 - Planejamento fatorial $2^{2}$ completo dos ensaios sobre agregados reciclados densidade $1,9<\mathrm{d}<2,2 \mathrm{~kg} / \mathrm{dm}^{3}$.

Tabela 5.2 - Resultados do planejamento $2^{2}$ realizado sobre agregados reciclados $1,9<\mathrm{d}<2,2 \mathrm{~kg} / \mathrm{dm}^{3}$

Tabela 5.3 - Determinação do erro experimental do planejamento para as respostas de absorção

Tabela 5.4 - Estudo de significância das variáveis do planejamento para as respostas de absorção 
Tabela 5.5 - Determinação erro experimental do planejamento para as respostas de perda de massa.

Tabela 5.6 - Estudo de significância das variáveis do planejamento para as respostas de

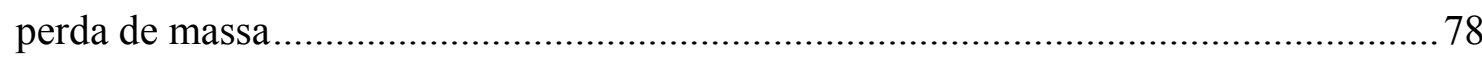

Tabela 6.1 - Planejamento fatorial $2^{1}$ completo dos ensaios sobre agregados reciclados densidade $1,9<\mathrm{d}<2,2 \mathrm{~kg} / \mathrm{dm}^{3}$

Tabela 6.2 - Resultados do planejamento $2^{1}$ realizado sobre agregados reciclados $1,9<\mathrm{d}<2,2 \mathrm{~kg} / \mathrm{dm}^{3}$

Tabela 6.3 - Determinação do erro experimental do planejamento para as respostas de massa seca

Tabela 6.4 - Estudo de significância das variáveis do planejamento para as respostas de massa seca 89

Tabela 6.5 - Determinação erro experimental do planejamento para as respostas de absorção 89

Tabela 6.6 - Estudo de significância das variáveis do planejamento para as respostas de absorção 


\section{LISTA DE FIGURAS}

Figura 2.1 - a) Chegada dos RCD à usina, momento da triagem; b) Pilhas com RCD cinzas e vermelhos. .06

Figura 2.2 - Equipamento para britagem dos RCD, transformando-os em agregados .06

Figura 2.3 - a) Peneiramento dos agregados de RCD gerados; b) Granulometrias distintas destes agregados 06

Figura 2.4 - Distribuição de massa em intervalos de densidade para agregados graúdos de RCD reciclados: IT V (Itaquera Vermelho), IT C (Itaquera cinza) e VI V (Vinhedo vermelho) - classificação que leva em conta a usina de reciclagem de sua coleta e a preponderância de materiais vermelhos (cerâmicos) ou cinzas (cimentícios) (ANGULO, 2005)

Figura 2.5 - Resistência à compressão dos concretos em função da massa específica aparente dos agregados de RCD reciclados utilizados na sua fabricação, para cada relação a/c (ANGULO, 2005; CARRIJO, 2005).

Figura 2.6 - Desprendimento de bolhas de ar de amostras de agregados reciclados de

faixas de grande porosidade. Fotos: Bruno Luís Damineli 16

Figura 2.7 - Etapas de secagem. 20

Figura 2.8 - Determinação da absorção no ponto de intersecção entre fases de secagem I e II

Figura 3.1 - Esferas de vidro utilizadas no trabalho 26

Figura 3.2 - Fluxograma dos ensaios do planejamento experimental do método NM 53 ...27

Figura 3.3 - Efeito das variáveis: a) massa; e b) método de secagem, sobre as respostas de absorção ..... .28

Figura 3.4 - Ilustração da variação do comprimento L de acordo com a variação da massa de agregados 30

Figura 3.5 - Fluxograma dos ensaios do método da $\mathrm{M}_{\text {sub }}$ ao longo do tempo 32

Figura 3.6 - Efeito das variáveis: a) massa; e b) vácuo, sobre as respostas de absorção..... 34

Figura 3.7 - Efeito da variável ciclos de vácuo, sobre as respostas de absorção ................. 34

Figura 3.8 - Fluxograma dos ensaios do método da secagem ao longo do tempo. 39

Figura 3.9 - Secagem de esferas de vidro em estufa, amostra de: a) $1 \mathrm{~kg}$, temperatura $\left.110^{\circ} \mathrm{C}(--) ; b\right) 4,5 \mathrm{~kg}$, temperatura de $110^{\circ} \mathrm{C}(+-)$. 40 
Figura 3.10 - Secagem de esferas de vidro em estufa, amostra de: a) $1 \mathrm{~kg}$, temperatura de $140^{\circ} \mathrm{C} \mathrm{(-+);} \mathrm{b)} 4,5 \mathrm{~kg}$, temperatura de $140^{\circ} \mathrm{C}(++)$.

Figura 3.11 - Secagem de esferas de vidro em estufa, amostra $2,75 \mathrm{~kg}$ e temperatura $125^{\circ} \mathrm{C}$ (ponto central): a) repetição 1 ; b) repetição 2 ; e c) repetição 3.

Figura 3.12 - Secagem de esferas de vidro em infravermelho, amostra de: a) $1 \mathrm{~kg}$, altura camada de agregado baixa (- -); b) 4,5kg, altura camada de agregado baixa (+-)

Figura 3.13 - Secagem de esferas de vidro em infravermelho, amostra de: a) $1 \mathrm{~kg}$, altura da camada de agregado alta (-+); b) 4,5kg, altura da camada de agregado alta (++).... 43

Figura 3.14 - Secagem de esferas de vidro em infravermelho, amostra de $2,75 \mathrm{~kg}$ e altura da camada de agregado média (ponto central): a) repetição 1 ; b) repetição 2 ; e c) repetição 3

Figura 3.15 - Secagem de esferas de vidro em microondas, amostra de massa: a) $1 \mathrm{~kg}$, potência $2(--)$; b) $2 \mathrm{~kg}$, potência $2(+-)$

Figura 3.16 - Secagem de esferas de vidro em microondas, amostra de massa: a) $1 \mathrm{~kg}$, potência $8(-+)$; b) $2 \mathrm{~kg}$, potência $8(++)$. .45

Figura 3.17 - Secagem de esferas de vidro em microondas, amostra de massa 1,5kg e potência 5 (ponto central): a) repetição 1 ; b) repetição 2 ; e c) repetição 3 45

Figura 3.18 - Efeito das variáveis: a) massa; e b) potência do microondas, sobre as respostas de absorção 47

Figura 4.1 - Agregados de argila expandida utilizados no trabalho ..... 50

Figura 4.2 - a) Detalhe dos agregados densidade $<1,9 \mathrm{~kg} / \mathrm{dm}^{3}$; b) Detalhe dos agregados densidade $>2,5 \mathrm{~kg} / \mathrm{dm}^{3}$ .51

Figura 4.3 - Efeito das variáveis: a) massa; e b) vácuo, sobre as respostas de absorção..... 54 Figura 4.4 - Efeito da variável ciclos de vácuo, sobre as respostas de absorção ..................54 Figura 4.5 - Correlação entre absorção aos 30 min e absorções medidas a $24 \mathrm{~h}$ e $72 \mathrm{~h}$ de ensaio: a) independentemente do vácuo utilizado; b) para o vácuo $-500 \mathrm{mmHg}$. .55

Figura 4.6 - Percentual de absorção atingido em 30 minutos em relação a: 1) 72 horas; e

2) 24 horas de ensaio, sob diferentes depressões aplicadas. .55

Figura 4.7 - Fluxograma de ensaio do planejamento experimental dos agregados de alta porosidade.

Figura 4.8 - Ensaios --+ (argila expandida, saturação ambiente 24h, microondas): a) repetição 1 ; b) repetição 2

Figura 4.9 - Ensaios +-+ (agregado reciclado, saturação ambiente 24h, microondas): a) repetição 1 ; b) repetição 2 
Figura 4.10 - Ensaios -++ (argila expandida, saturação vácuo 30 min, microondas): a) repetição 1 ; b) repetição 2

Figura 4.11 - Ensaios +++ (agregado reciclado, saturação vácuo $30 \mathrm{~min}$, microondas): a) repetição 1 ; b) repetição 2

Figura 4.12 - Exemplo de determinação dos limites dos períodos de taxa de secagem constante (linhas verdes) e taxa linearmente decrescente (linhas laranjas), sobre o ensaio -++ , repetição 1

Figura 4.13 - Efeito da variável agregado sobre as respostas de: a) absorção; e b) perda de massa

Figura 4.14 - Efeito da variável método de saturação sobre as respostas de: a) absorção; e b) perda de massa 64

Figura 4.15 - Efeito da variável método de secagem sobre as respostas de: a) absorção; e b) perda de massa .65

Figura 5.1 - Fluxograma de ensaio do planejamento experimental dos agregados reciclados densidade $1,9<\mathrm{d}<2,2 \mathrm{~kg} / \mathrm{dm}^{3}$

Figura 5.2 - Ensaios de secagem da amosta M1: a) $1^{\circ}$ ensaio, microondas (-+1); b) $2^{\circ}$ ensaio, microondas $(++1)$. 73

Figura 5.3 - Ensaios de secagem da amostra M2: a) $1^{\circ}$ ensaio, microondas (-+2); b) $2^{\circ}$ ensaio, microondas $(++2)$ .73

Figura 5.4 - Ensaios de secagem da amostra M3: a) $1^{\circ}$ ensaio, microondas $(-+3)$; b) $2^{\circ}$ ensaio, microondas $(++3)$. 74

Figura 5.5 - Efeito das variáveis: a) repetição do ensaio; e b) método de secagem, sobre as respostas de absorção

Figura 5.6 - Efeito das variáveis: a) repetição do ensaio; e b) método de secagem, sobre as respostas de perda de massa 76

Figura 6.1 - Fluxograma de ensaio do planejamento experimental dos agregados reciclados densidade $1,9<\mathrm{d}<2,2 \mathrm{~kg} / \mathrm{dm}^{3}$ 82

Figura 6.2 - Esquema dos períodos de secagem obtidos através dos dados de secagem em microondas (linhas vermelhas) e do método de determinação da $\mathrm{M}_{\mathrm{s}}$ (linha verde) ........84

Figura 6.3 - Determinação da $\mathrm{M}_{\mathrm{s}}$ através dos dados de secagem em microondas, para a amosta: a) A1; e b) A2

Figura 6.4 - Determinação da $\mathrm{M}_{\mathrm{s}}$ através dos dados de secagem em microondas, para a amosta: a) A3; e b) A4. 
Figura 6.5 - Ensaios de secagem da amosta A1, considerando a $\mathrm{M}_{\mathrm{s}}$ obtida em: a) estufa (1); e b) microondas $(+1)$ 86

Figura 6.6 - Ensaios de secagem da amosta A2, considerando a $\mathrm{M}_{\mathrm{s}}$ obtida em: a) estufa (-

2); e b) microondas $(+2)$ 86

Figura 6.7 - Ensaios de secagem da amosta A3, considerando a $\mathrm{M}_{\mathrm{s}}$ obtida em: a) estufa (-

3); e b) microondas $(+3)$. 86

Figura 6.8 - Ensaios de secagem da amosta A4, considerando a $\mathrm{M}_{\mathrm{s}}$ obtida em: a) estufa (4); e b) microondas (+4) .87

Figura 6.9 - Efeito da variável método de obtenção da massa seca sobre as respostas de:

a) massa seca; e b) absorção 88

Figura 7.1 - Fluxograma do ensaio criado para caracterização de propriedades físicas de agregados reciclados de alta porosidade.

Figura 7.2 - Ilustração dos equipamentos e procedimento utilizados para saturação das amostras 93

Figura 7.3 - Ilustração dos equipamentos e procedimento utilizados para secagem das amostras em microondas

Figura 7.4 - Esquema dos períodos de secagem obtidos através dos dados de secagem em microondas (linhas vermelhas) e do método de determinação da Ms (linha verde) ...... 95 Figura 7.5 - Esquema da determinação da absorção (A) no ponto de intersecção entre fases de secagem I e II 


\section{LISTA DE SÍMBOLOS E ABREVIAÇÕES}

RCD - Resíduos de Construção e Demolição.

CDW - Construction and Demolition Waste.

NBR - Norma Brasileira.

NM - Norma Mercosul.

SIERESP - Sindicato das Empresas Removedoras de Entulho do Estado de São Paulo.

CONAMA - Conselho Nacional do Meio Ambiente.

ABNT - Associação Brasileira de Normas Técnicas.

ASTM - American Society of Testing Materials.

RILEM - International Union of Laboratories and Experts in Construction Materials, Systems and Structures.

NEN - Nederlands Normalisatie- instituut.

DIN - Deutsche Institut für Normung.

IT C - Fração mineral de RCD do tipo cinza proveniente da usina de Itaquera.

IT V - Fração mineral de RCD do tipo vermelho proveniente da usina de Itaquera.

VI V - Fração mineral de RCD do tipo vermelho proveniente da usina de Vinhedo.

DOE - Design of Experiments.

1 - litro.

$\mathrm{dm}^{3}$ - decímetro cúbico.

$\mathrm{cm}^{3}$ - centímetro cúbico.

$\mathrm{kg}$ - quilograma.

$\mathrm{mmHg}$ - milímetros de Mercúrio.

$\mathrm{g}$ - grama ou gravidade.

MEA - massa específica aparente dos agregados graúdos de RCD reciclados

$\left(\mathrm{kg} / \mathrm{dm}^{3}\right)$, que considera os poros abertos no volume da partícula.

MER - massa específica real dos agregados graúdos de RCD reciclados $\left(\mathrm{kg} / \mathrm{dm}^{3}\right)$, que considera apenas os poros fechados no volume da partícula.

Ms - massa seca.

Msss - massa em estado saturado com superfície seca.

Msub - massa submersa.

$\min -$ minuto.

$\mathrm{s}-$ segundo.

$\mathrm{t}$ - intervalo de tempo.

$\mathrm{T}$ - temperatura.

$\mathrm{m}$ - massa.

$\mathrm{v}$ - vácuo.

cv - ciclos de vácuo.

$\mathrm{h}-$ altura. 


\section{INTRODUÇÃO}

Ao longo de toda a história a humanidade vem se desenvolvendo, em número populacional e em termos de conhecimento. Este avanço, porém, implica em grande utilização de matérias-primas para a manutenção de níveis cada vez maiores de conforto a número cada vez maior de pessoas.

A indústria da construção civil, por sua vez, consome a maior parte dos recursos naturais do planeta, gerando grande quantidade de resíduos, os Resíduos de Construção e Demolição - ou RCD. Estes resíduos possuem potencial para reutilização ou reciclagem, atividades que configuram a solução para problemas ambientais por eles causados como deposições em aterros ou locais irregulares da malha urbana.

Estudos mostram que a fração mineral dos RCD compõe, em média, até $90 \%$ da massa total dos mesmos. Isto demonstra que estratégias de gerenciamento destes resíduos devem ser focadas na reciclagem massiva desta fração mineral, sob a forma de agregados reciclados, para que possam surtir efeitos benéficos ao meio ambiente.

Porém, um dos entraves para a reciclagem intensiva da fração mineral dos RCD é o mercado escasso para assimilação dos agregados de RCD reciclados provenientes de sua reciclagem. A variabilidade natural destes agregados e a sua grande porosidade em relação a agregados naturais faz com que eles atualmente sejam usados principalmente em obras de pavimentação - incapazes de apresentar demanda suficiente ao total aproveitamento do material -, sendo sua utilização em concretos limitada por normas restritivas, quando não vetada por falta de segurança comprovada. Para que os agregados de RCD reciclados possam ser adequados a alguns tipos de concretos, é necessário que passem por um processo de controle de qualidade mais rigoroso do que os agregados naturais, mais homogêneos e menos porosos. Este controle baseia-se fundamentalmente na medição de sua porosidade, propriedade física inversamente proporcional à resistência mecânica e à durabilidade dos materiais, a qual pode ser determinada através das medidas físicas de absorção e massa específica aparente. A porosidade dos agregados (matéria-prima) determina a qualidade final de concretos (produto) com eles produzidos.

Mas os métodos usualmente utilizados para caracterização da absorção e massa específica de agregados, como a NM 53 (Mercosul), que é uma tradução da ASTM C127 
(EUA) foram desenvolvidos para agregados naturais, e podem apresentar erros experimentais não previstos e não quantificados adequadamente quando aplicados a agregados reciclados, como perda de massa da amostra e saturação incompleta de poros sob condições normais.

Já há, na Europa, diversos estudos normativos sobre agregados de RCD reciclados para uso em concreto, o que demonstra que a preocupação dada a estes agregados é diferenciada da ministrada aos agregados de rochas naturais, e que as atuais normas de caracterização não se aplicam de forma satisfatória sobre os reciclados, que devem ser tratados particularmente (SCHOUENBORG et al., 2003).

Assim, este trabalho tem por objetivo estudar de forma sistemática novos métodos rápidos e precisos de medida da absorção, massa específica aparente e massa específica real dos agregados de RCD reciclados. Ressalta-se que não são abordadas todas as propriedades físicas dos agregados, mas especificamente as três acima citadas.

Métodos mais rápidos e precisos para caracterização de agregados reciclados deverão permitir a identificação rápida de lotes de agregados de melhor qualidade na usina de reciclagem, que possam ser destinados a aplicações mais nobres - como concretos. Seu mercado, hoje restrito, seria expandido, a reciclagem seria realizada em maior escala, e problemas ambientais seriam minimizados.

Três métodos serão analisados: a NM 53, atual método de determinação da absorção e massa específica aparente de agregados graúdos em geral, para se estudar as dimensões dos erros apontados em bibliografia de sua utilização sobre agregados reciclados; a massa submersa ao longo do tempo, desenvolvido por Ramalho et al (2004); e a secagem ao longo do tempo, baseado em propriedades conhecidas de secagem de sólidos porosos. A secagem será realizada em três equipamentos: estufa, infravermelho ou microondas. Para aumentar a quantidade e rapidez de saturação dos poros das amostras será estudada a possibilidade da aplicação de pressão de vácuo durante o período de sua saturação.

Três materiais serão utilizados: vidro - sólido de baixa porosidade com absorção, MEA e MER conhecidas, usado como referência; argila expandida - sólido poroso com baixos níveis de perda de massa no manuseio; e agregado de RCD reciclado de densidade menor do que $1,9 \mathrm{~kg} / \mathrm{dm}^{3}$ e densidade $1,9<\mathrm{d}<2,2 \mathrm{~kg} / \mathrm{dm}^{3}$ - sólido poroso com altos níveis de perda de massa no manuseio, correspondente às faixas densitárias de maior porosidade e grande ocorrência dentre os agregados provenientes da reciclagem da fração mineral dos $\mathrm{RCD}$, o pior caso dentro do campo de variabilidade possível em uma usina de reciclagem. 
Algumas variáveis de possível significância aos ensaios serão consideradas, como: massa da amostra; pressão de vácuo a ser aplicada; número de ciclos de pressão aplicados; altura da camada de agregado; temperatura de secagem; meio para minoração da desagregação da amostra; meio para determinação da $\mathrm{M}_{\mathrm{sss}}$ e da $\mathrm{M}_{\mathrm{s}}$, entre outras.

As análises serão realizadas baseadas em cálculos estatísticos dos tipos ANOVA e DOE fatorial completo, aplicados sobre planejamentos experimentais desenvolvidos de acordo com a estatística a ser utilizada em cada caso.

O estudo está dividido em sete capítulos, sendo que o um é esta introdução.

O capítulo 2 contém a revisão bibliográfica do trabalho, que apresenta: definição e quantificação dos RCD e dos problemas gerados por eles; definição das propriedades físicas estudadas e importância da sua correta determinação; problemas encontrados em aplicações anteriores da NM 53 sobre agregados de RCD reciclados; e a conceituação teórica dos métodos a serem pesquisados experimentalmente.

O capítulo 3 apresenta os resultados e discussões dos planejamentos experimentais realizados sobre os agregados de porosidade baixa (vidro).

Os capítulos 4, 5 e 6 apresentam os resultados e discussões de planejamentos experimentais realizado sobre os agregados de alta porosidade (reciclados e argila expandida), criados na seqüência requerida pelas conclusões que foram surgindo no andamento dos trabalhos, buscando sempre ajustar o método para a eliminação de falhas do método atual e o alcance da maior precisão e do menor tempo de execução possíveis.

O capítulo 7 apresenta uma proposta de método para a determinação rápida e precisa das propriedades físicas citadas dos agregados estudados, baseando-se nas análises dos planejamentos experimentais estudados nos capítulos anteriores.

O capítulo 8 é a conclusão, onde se discute o trabalho como um todo: os objetivos atingidos, os benefícios mais importantes do novo método e seu papel social no auxílio à reciclagem dos resíduos de construção, na busca de uma cadeia produtiva da construção civil mais sustentável.

No final do trabalho é ainda apresentado um CD-ROM contendo os apêndices de A a I, correspondentes aos dados na íntegra dos ensaios realizados nos planejamentos dos capítulos 3 a 6 . Os apêndices correspondentes a cada planejamento são citados oportunamente nos resultados de cada um. 


\section{CONTROLE DAS PROPRIEDADES FíSICAS DOS AGREGADOS DE RCD RECICLADOS}

Este capítulo é uma revisão bibliográfica sobre o tema da pesquisa e tem como objetivos: 1) sistematizar conhecimentos básicos sobre os materiais estudados, como definição, quantificação, origem, problemas ambientais gerados e produção dos agregados de RCD reciclados; 2) conceituar as grandezas físicas de agregados que serão estudadas e a importância de sua correta determinação para a utilização destes agregados em concretos; 3 ) discutir os possíveis problemas detectados para a aplicação do método atual (NM 53) para caracterização destas propriedades nos agregados de RCD reciclados; 4) expor os métodos alternativos que serão investigados neste trabalho; e 5) apresentar os conceitos estatísticos empregados para análise dos resultados dos planejamentos experimentais executados.

\subsection{DEFINIÇÃO, QUANTIFICAÇÃO E PROBLEMAS AMBIENTAIS GERADOS PELOS RESÍDUOS DE CONSTRUÇÃO E DEMOLIÇÃO}

Os Resíduos de Construção e Demolição, ou RCD, são os provenientes de construções, reformas, reparos e demolições de obras de construção civil, e os resultantes da preparação e da escavação de terrenos (CONAMA, 2002). Não se incluem nesta definição os resíduos gerados na produção dos materiais de construção (resíduos industriais), e tampouco os resíduos residenciais sólidos urbanos (lixo residencial).

Os RCD são compostos por concretos, argamassas, rochas, blocos de alvenaria, tijolos, telhas, azulejos, solos, areia, asfalto, argila, metais, madeiras, plásticos, borrachas e papéis ou papelão. Além dos resíduos de reformas e demolições compostos por materiais já utilizados, existem materiais novos nos RCD, provenientes dos desperdícios em canteiro de obra (ANGULO, 2000).

A composição, quantidade e características dos RCD diferem muito em função de variáveis como: a) indústria local; b) qualidade e treinamento da mão-de-obra; c) clima local, pois influem nas características das edificações e, portanto, nas técnicas de construção e demolição adotadas; d) programas de redução de perdas ou reutilização em canteiros de obra; e) obras especiais na região (exemplo: metrô); f) matéria-prima disponível na região; e g) momento de coleta da amostra. 
Sendo a cadeia da construção civil a maior consumidora de recursos naturais da sociedade atual - extração de 14 a 50\% dos recursos naturais totais mundiais (SJOSTROM, 1996 apud JOHN, 2000), também gera grande quantidade de RCD. Esta geração é estimada em 600 a 918 kg/hab.ano na Europa (JOHN, 2000) e em 500kg/hab.ano no Brasil (PINTO, 1999). São valores da ordem de 125 milhões de toneladas anuais nos EUA, 15 milhões na Holanda (KOWALCZYK, 2000) e 68,5 milhões no Brasil (PINTO, 1999). Estas grandes quantidades de RCD gerados trazem problemas ao meio ambiente: esgotamento gradual de áreas para aterro; assoreamento de rios e córregos; deposições irregulares com grandes custos para as prefeituras e comprometimento da qualidade de vida urbana, entre outros (CARNEIRO; CASSA; BRUM, 2001).

A melhoria destes aspectos ambientais só pode ocorrer com a reciclagem ou reutilização massiva dos RCD gerados na construção civil.

\subsection{PROdUÇÃo e APLICAÇÃo dE AGREGADOS DE RCD RECICLADOS}

A fração mineral dos RCD compõe em torno de $90 \%$ da massa total dos mesmos (FERRAZ et al, 2001), fato que faz com que estratégias de gerenciamento destes resíduos devam ser baseadas na reciclagem massiva desta fração mineral, sob a forma de agregados reciclados, para que possam melhorar os aspectos ambientais citados (ANGULO, 2005).

As características dos agregados de RCD reciclados estão diretamente relacionadas à forma com que são fabricados, e principalmente às características da fração mineral dos RCD disponível para sua fabricação: concreto, blocos, argamassas, cerâmicas, rochas e outros.

O processo de produção dos agregados de RCD reciclados a partir da fração mineral dos RCD é realizado pelas seguintes etapas:

a) triagem na chegada dos resíduos à central de reciclagem para separação de RCD minerais com predominância de materiais cinzas (elementos de origem cimentícia) ou vermelhos (elementos de origem cerâmica), conforme Figuras 2.1 (a) e (b);

b) catação manual para retirada de elementos não-minerais e contaminantes dos montantes totais de RCD de origem mineral, cinzas ou vermelhos;

c) britagem dos RCD por compressão (britador de mandíbula) ou impacto (britador de impacto), gerando agregados reciclados, conforme Figura 2.2;

d) eventual retirada de resíduos metálicos dos agregados com separador magnético; 
e) peneiramento dos agregados gerados, que são divididos em faixas granulométricas conforme Figuras 2.3 (a) e (b).

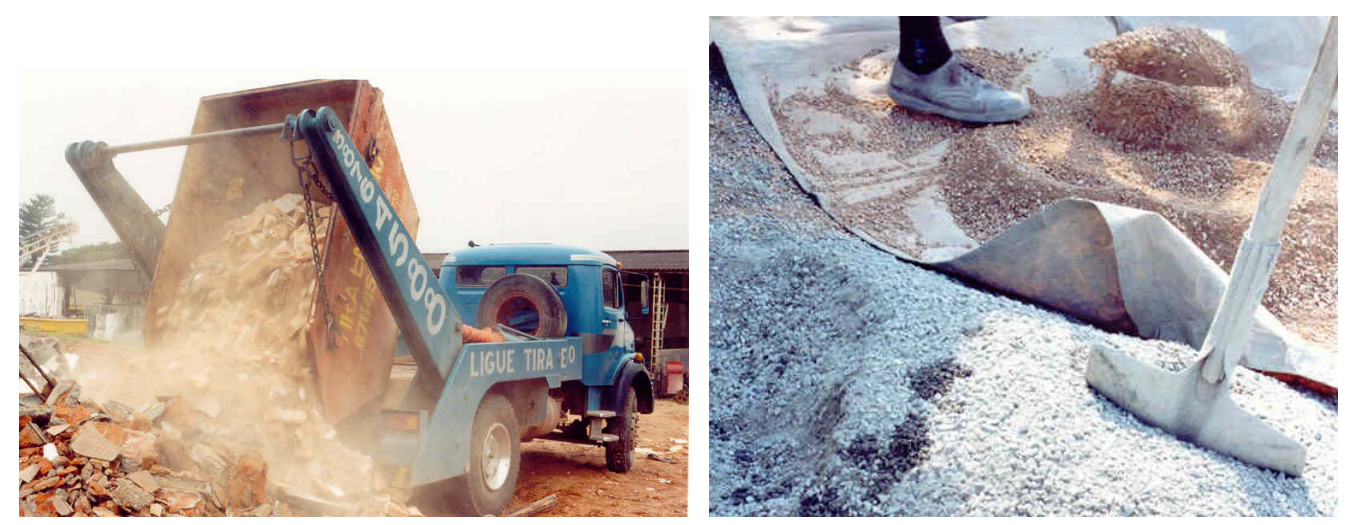

Figura 2.1 - a) Chegada dos RCD à usina, momento da triagem; b) Pilhas com RCD cinzas e vermelhos.

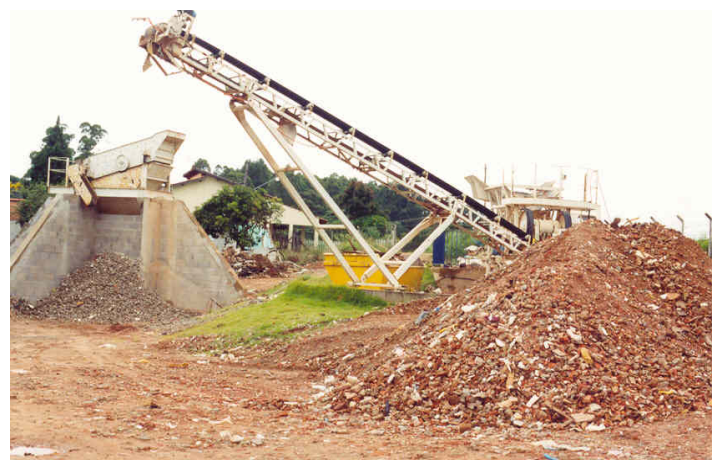

Figura 2.2 - Equipamento para britagem dos RCD, transformando-os em agregados.
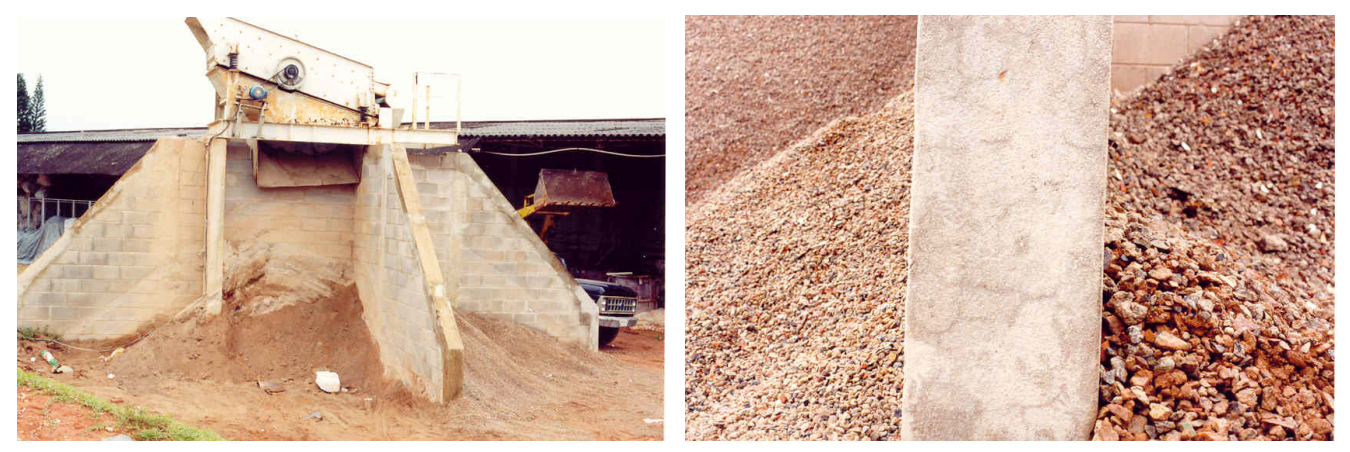

Figura 2.3 - a) Peneiramento dos agregados de RCD gerados; b) Granulometrias distintas destes agregados.

As técnicas de demolições têm papel importante para o aumento do percentual de resíduos passíveis de serem reciclados. Demolições convencionais misturam fases de resíduos, contaminando-as entre si ou com resíduos perigosos ou não recicláveis (JOHN; ANGULO, 2003). A desconstrução (demolição seletiva ou desmontagem), que já é praticada em muitos países da Europa (HENDRIKS, 2000), não mistura resíduos distintos, aumentando consideravelmente sua reciclabilidade por reduzir a necessidade de triagem de frações de 
resíduos perigosos e contaminantes, com diminuição da variabilidade dos lotes e dos custos de reciclagem (KIBERT; CHINI, 2000).

No Brasil o sistema de desconstrução do edifício é aplicado a alguns elementos arquitetônicos, como portas, janelas, pisos, louças sanitárias, telhas, madeiras, pias, vidros, canos, equipamentos elétricos e ferragens do concreto, separadas por maçarico após quebra das estruturas. Sobram a estrutura e a alvenaria - justamente a fração mineral que corresponde a 90\% da massa dos RCD, classificada predominantemente como categoria A de resíduos pela Resolução CONAMA 307 -, que ainda não são demolidas seletivamente, o que aumenta sua variabilidade natural e sua contaminação.

Assim, a reciclagem intensiva da fração mineral ainda não ocorre porque a sua variabilidade (e, portanto, dos agregados reciclados dela originados), unida à maior porosidade destes agregados em relação aos naturais, limitam a sua utilização em concretos, gerando a "reciclagem de baixo valor" (HENDRIKS, 2000). Segundo este conceito, estes agregados são aplicados em locais de menores exigências técnicas do que poderiam, pois sua variabilidade faz com que sejam classificados segundo os requisitos técnicos mais restritivos. Usos comuns como pavimentação seriam capazes de absorver até $50 \%$ destes agregados se $100 \%$ dos RCD fossem reciclados; a outra metade ficaria à espera de novos mercados (ANGULO et al, 2002), o que desestimula a reciclagem dos RCD e, por conseqüência, a sua demolição seletiva.

Sob este enfoque, a difusão de tecnologia eficaz de controle de qualidade de agregados de RCD reciclados tem o papel de impulsionar a demolição seletiva e a reciclagem destes resíduos (SCHOUENBORG et al, 2003). Uma melhor triagem de agregados na usina de reciclagem pode classificá-los de acordo com padrões mais rígidos de qualidade, ampliando seus mercados e diminuindo os montantes a serem dispostos em aterros.

Resultados experimentais de Carrijo (2005) e Angulo (2005) encontraram bons resultados em concretos confeccionados com agregados de RCD reciclados classificados de acordo com a densidade. Como a densidade de um agregado está diretamente relacionada à sua porosidade e esta determina sua absorção de água, os lotes de agregados podem ser certificados de acordo com estas propriedades físicas. 


\subsection{DEFINIÇÃO DE POROSIDADE, ABSORÇÃO DE ÁGUA E MASSA ESPECÍFICA DE AGREGADOS POROSOS}

Segundo Mehta (1994), tamanho, volume e continuidade dos poros na estrutura do sólido determinam a sua estrutura de porosidade e, assim, a sua permeabilidade e absorção, que é a quantidade de água passível de ser incorporada aos poros permeáveis.

Poros permeáveis são definidos, segundo a norma NBR 9935/1987, como as descontinuidades ligadas à superfície externa do agregado passíveis de reterem água - os poros cujo acesso da água é possível. Há também poros não-permeáveis na configuração física de muitos corpos sólidos, como os agregados estudados, que são cavidades ou falhas internas não diretamente acessíveis à água. Estes não compõem a estrutura contínua de poros, estando isolados no interior da estrutura física do sólido. Seu volume pode ser medido através de métodos específicos, que incluem cominuição a pó das amostras, de forma a destruí-los. Embora afetem as propriedades físicas dos agregados, estes poros não-permeáveis não serão abrangidos por este estudo.

O Comitê C9 da ASTM define absorção na norma C 125 (Termos relativos a concreto e agregados para concretos) como "Processo pelo qual um líquido penetra e preenche os poros permeáveis em um corpo sólido poroso", com conseqüente aumento de massa do corpo sólido. Assim, a absorção está diretamente relacionada à estrutura de porosidade do corpo, sendo uma proporção da quantidade de água possível de ser retida nestes poros em relação à massa seca do material. Sua determinação pode ser considerada como uma quantificação indireta da porosidade, da resistência mecânica e da durabilidade de corpos porosos, uma vez que a ciência dos materiais correlaciona estas grandezas (CALLISTER, 2000; VAN VLACK, 1970). Estudos de Angulo (2005) e Carrijo (2005) trazem relações diretas entre a porosidade dos agregados reciclados e a resistência de concretos.

A massa específica é uma propriedade que pode ser definida como a massa do material por unidade de volume (NM 53; ASTM C 127). Este volume, porém, apresenta-se de diversas formas, podendo ou não incluir os poros internos das partículas e até mesmo os vazios entre as partículas (SVAROVSKY, 1987). Assim, existem três tipos de massa específica utilizados para medidas de porosidade de corpos sólidos:

- Massa específica aparente dos grãos (MEA): razão da massa pelo volume do agregado, determinado de forma a incluir os poros permeáveis das partículas mas não os vazios entre elas. Corresponde à densidade do volume ocupado pelo sólido na forma em que 
pode ser visualizado, daí o nome aparente. Quando se observa a olho nu um corpo sólido, normalmente seus poros, se existirem, não são visualizados. Estes poros, para a massa específica aparente, são considerados integrantes do volume do material. Deve-se notar, contudo, que a diferenciação entre poro interno e rugosidade da superfície do material é subjetiva, pois alguns trechos da superfície da partícula possuem cavidades que, dependendo do ponto de vista, podem ser classificadas como poros ou superfície.

- Massa específica real (MER): razão da massa pelo volume do agregado, determinado de forma a excluir os poros permeáveis. Corresponde à densidade do material sólido que compõe a partícula, daí a designação real. Porém, os poros não-permeáveis podem ou não ser excluídos do volume considerado, o que depende do método utilizado para a medição, pois sua determinação necessita de ensaios mais específicos e destrutivos com cominuição a pó das amostras.

- Massa específica unitária: razão da massa pelo volume do agregado, determinado de forma a incluir os poros permeáveis das partículas e também os vazios entre elas. Corresponde, assim, à densidade do volume total ocupado pelo sólido, incluindo-se todos os vazios entre eles, ou seja, o volume do recipiente em que se encontram. Esta massa específica não interessa a este trabalho.

As propriedades de massa específica aparente e absorção estão relacionadas à estrutura porosa permeável do corpo, sendo medidas indiretas da porosidade dos agregados. Esta porosidade pode ser definida como a porcentagem de vazios no volume total do corpo, e pode ser calculada pela fórmula:

$$
\text { Porosidade }=\left[1-\left(\frac{M E A}{M E R}\right)\right] \times 100
$$

\subsection{IMPORTÂNCIA DA POROSIDADE DOS AGREGADOS PARA O CONCRETO}

Se a porosidade de um sólido é inversamente proporcional à sua resistência mecânica (CALLISTER, 2000; VAN VLACK, 1970), a correta determinação desta porosidade é um controle eficaz do desempenho mecânico do sólido. Os agregados naturais já são controlados desta forma, pois as medidas físicas de absorção e massa específica aparente refletem a sua porosidade (NM 53; ASTM C 127-01).

Os agregados reciclados de materiais cimentícios possuem pasta aderida aos grãos, de forma que sua porosidade é maior do que a dos agregados naturais (CHEN; YEN; CHEN, 
2003; LO; GAO; JEARY, 1999). Sua porosidade depende da quantidade de pasta aderida ao agregado original e da porosidade desta pasta (idade e relação água/cimento do concreto ou argamassa que a originou) (PEDROZO; LEITE; DAL MOLIN, 2000).

Por sua vez, agregados reciclados de materiais cerâmicos possuem porosidades diversas, relacionadas, em geral, às variações (que dependem da cerâmica a ser obtida em cada caso) adotadas nos processos de produção das peças cerâmicas, como: teor de compactação da matéria-prima utilizada; quantidade de água adicionada à matéria-prima; pressão de prensagem; velocidade e temperatura da secagem para eliminação do excesso de água presente nos poros formados; temperatura e tempo de queima; acabamento; e outros. Estes fatores podem aumentar ou diminuir o tamanho e a quantidade de poros dos componentes cerâmicos fabricados, e mesmo gerar defeitos em sua estrutura química (Van Vlack, 1973; Askeland, 1990). Porém, a baixa qualidade das cerâmicas produzidas no Brasil faz com que, em média, os agregados reciclados de origem cerâmica possuam teores de porosidade também superiores a agregados naturais.

Coerentemente, estudos de Angulo (2005) e Carrijo (2005) demonstraram que agregados de RCD reciclados apresentam em geral menores densidades em relação aos agregados naturais. A maioria dos agregados reciclados estudados pelos autores encontra-se nas faixas superiores a $1,7 \mathrm{~kg} / \mathrm{dm}^{3}$, sendo os intervalos principais os de 1,9 a $2,2 \mathrm{~kg} / \mathrm{dm}^{3}$, de 2,2 a $2,5 \mathrm{~kg} / \mathrm{dm}^{3}$ e $>2,5 \mathrm{~kg} / \mathrm{dm}^{3}$, conforme a Figura 2.4. Sabe-se, por outro lado, que agregados de origem em rochas naturais apresentam valores de densidade em torno de $2,5 \mathrm{~kg} / \mathrm{dm}^{3}$ ou superior (MEHTA, 1994; HELENE, 1992).

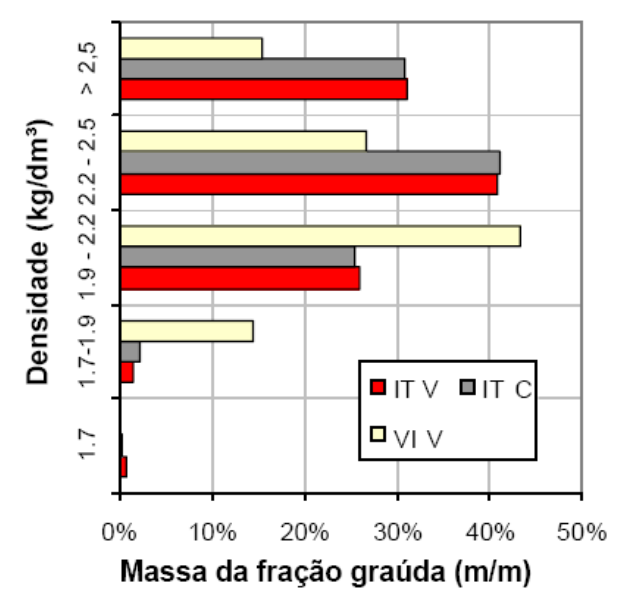

Figura 2.4 - Distribuição de massa em intervalos de densidade para agregados graúdos de RCD reciclados: IT V (Itaquera Vermelho), IT C (Itaquera cinza) e VI V (Vinhedo vermelho) - classificação que leva em conta a usina de reciclagem de sua coleta e a preponderância de materiais vermelhos (cerâmicos) ou cinzas (cimentícios) (ANGULO, 2005). 
Conforme a Figura 2.4, os agregados reciclados se encontram dentro de um amplo campo de distribuição de porosidade, o que lhes proporciona grande variabilidade de propriedades físicas, diferenciando-os dos agregados de rochas naturais. Estes últimos, além de menores valores de porosidade, possuem um campo de distribuição de porosidade menor, sendo portanto mais homogêneos.

A porosidade do concreto é definida por alguns fatores, como: relação a/c (água/cimento); falhas de compactação; quantidade de ar incorporado; e porosidade dos agregados. A porosidade dos agregados (matéria-prima), assim, ajuda a determinar a porosidade e, portanto, a qualidade final de concretos (produto) com eles produzidos.

Como mais de $75 \%$ do volume total do concreto é preenchido pelos agregados, os agregados de RCD reciclados passam, por sua alta porosidade, a influenciar de forma relevante a resistência dos concretos com eles confeccionados (ANGULO, 2005; CARRIJO, 2005), diferentemente dos agregados naturais. Passam a configurar uma região de especial atenção dentro do concreto, pois podem se tornar pontos de rupturas, diminuindo a resistência (WASSERMAN; BENTUR, 1996). A Figura 2.5 prova a importância da porosidade dos agregados de RCD reciclados sobre a resistência dos concretos com eles confeccionados, pois percebe-se que a diminuição da porosidade do agregado (aumento da MEA) gera aumento da resistência do concreto (ANGULO, 2005; CARRIJO, 2005).

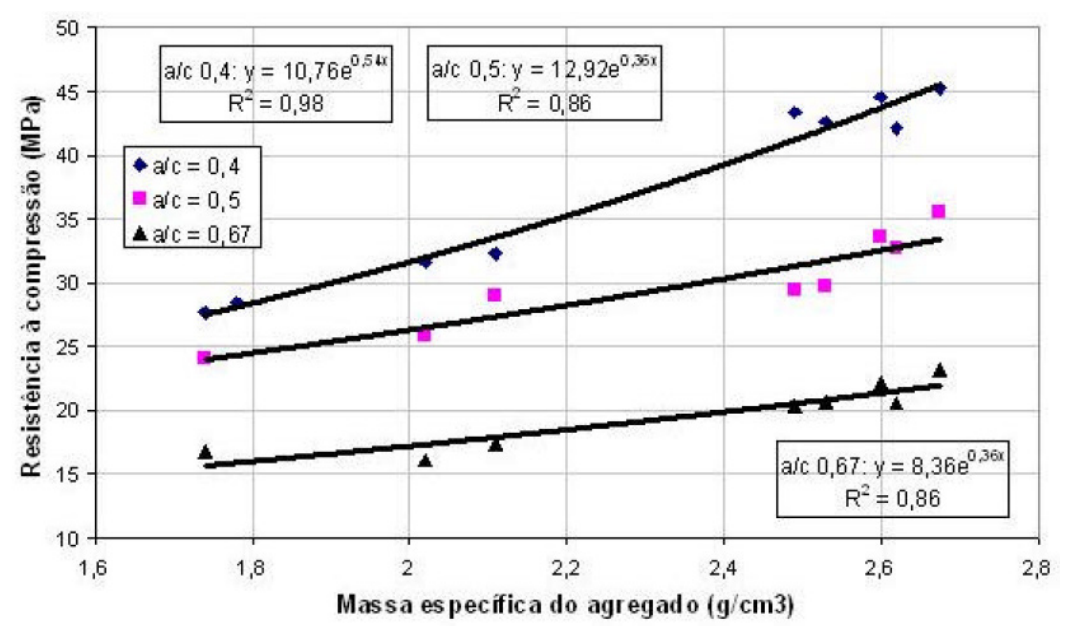

Figura 2.5 - Resistência à compressão dos concretos em função da massa específica aparente dos agregados de RCD reciclados utilizados na sua fabricação, para cada relação a/c (ANGULO, 2005; CARRIJO, 2005).

A maior porosidade dos agregados de RCD reciclados também vai aumentar a absorção de parte da água livre da pasta de cimento do concreto. Desta forma, os agregados de RCD reciclados são, em alguns casos, pré-saturados antes da colocação do cimento (PEDROZO; LEITE; DAL MOLIN, 2000). Leite (2001) mostra que esta pré-saturação ocorre 
normalmente por um período de 10 minutos, tempo no qual o agregado reciclado quase satura. Também demonstra que, de forma geral, há maior perda de consistência nos tempos iniciais para os concretos frescos que contêm os agregados reciclados, devido às maiores taxas de absorção destes. Lo; Gao; Jeary (1999) realizaram experimentos onde também houve pré-saturação dos agregados leves utilizados nas misturas de concreto, conseguindo minimizar o efeito da absorção dos agregados sobre a quantidade de água disponível para hidratação da zona de interface entre os agregados e o cimento durante o processo de hidratação do concreto.

O conhecimento da cinética de absorção dos agregados de RCD reciclados também torna possível a correção de valores de água adicionados à mistura, se não for realizada a présaturação dos agregados. Resultados experimentais de Poon et al (2004) demonstraram que os teores de água a serem adicionados em misturas de concretos confeccionados com agregados graúdos naturais ou reciclados são diferentes entre si para se atingir a mesma relação a/c efetiva. O teor de água a ser adicionado é maior conforme aumenta a proporção dos agregados reciclados - é influenciado pelo aumento da porosidade -, devendo-se somar ao total a quantidade de água que será absorvida pelo agregado. Sem levar em consideração a absorção, os agregados de RCD reciclados, durante o período de hidratação do concreto, absorvem água disponibilizada para fazer parte da pasta de concreto, resultando em relações a/c reais menores do que as calculadas, com modificações do abatimento do tronco de cone (POON et al, 2004).

Devido à importância demonstrada das propriedades físicas de absorção e massa específica de agregados de RCD reciclados para aplicação em concretos, comitês normativos europeus sobre o assunto, como a RILEM, já abordam e especificam valores limites para estas propriedades. Algumas normas já são encontradas, como a NEN 5905:1997, na Holanda, que especifica os agregados reciclados segundo critérios de qualidade como: formato das partículas, porcentagem de miúdos, distribuição granulométrica, massa específica e absorção, entre outros (HENDRICKS et al., 1998). Na Alemanha, há a DIN-1045 - "Concrete and Reinforced Concrete", que regulamenta a utilização de agregados reciclados em concretos. A Danish Concrete Association (Dinamarca) também traz recomendações envolvendo agregados reciclados de concreto. Os agregados reciclados são divididos em duas classes, conforme apresentado na Tabela 2.1, notando-se que mencionam diretamente as massas específicas dos agregados a serem utilizados, relacionando-as à resistência dos concretos produzidos: 
Tabela 2.1 - Classificação e destinação dos agregados de RCD reciclados segundo a Danish Concrete Association (GLAVIND; HAUGAARD, 1998 apud CARRIJO, 2005).

\begin{tabular}{|l|l|l|l|}
\hline CLASSE & \multicolumn{1}{|c|}{ ORIGEM } & MASSA ESPECÍFICA & \multicolumn{1}{|c|}{ DESTINO } \\
\hline GP 1 & $\begin{array}{l}\text { resíduos de concreto com } \\
\text { pequena quantidade de alvenaria }\end{array}$ & $\begin{array}{l}\text { concreto armado ou não-armado, } \\
\text { em ambientes pertencentes à } \\
\text { classe passiva ou moderada com } \\
\text { resistências de até 40 MPa }\end{array}$ \\
\hline GP 2 & $\begin{array}{l}\text { resíduos de concreto e alvenaria } 2,2 \mathrm{~kg} / \mathrm{dm}^{3} \\
\text { ou somente alvenaria }\end{array}$ & $\begin{array}{l}\text { concreto armado ou não-armado } \\
\text { em ambientes pertencentes à } \\
\text { classe passiva com resistências de } \\
\text { até 20 MPa }\end{array}$ \\
\hline
\end{tabular}

Aplicando controle de qualidade sobre os agregados de RCD reciclados conforme indicações de normas como as acima citadas, alguns estudos já comprovaram ser tecnicamente possível e interessante a utilização destes agregados para a produção de concretos, atingindo-se resistências de até 40 MPa em alguns casos (LEVY, 1997; ZORDAN, 1997; ANGULO, 2005; CARRIJO, 2005).

\subsection{MÉtodos PARA DETERMINAÇÃo dA POROSIDADE DE AGREGAdOS GRAÚDOS}

Os métodos atualmente utilizados no Brasil para a determinação das propriedades físicas de absorção de água e massa específica de agregados em geral (naturais ou reciclados) são descritos pela NM 53 (ABNT, 2003). Os procedimentos adotados por esta norma, de ensaios e cálculos, são semelhantes aos da norma americana ASTM C 127-01.

\subsubsection{DETERMINAÇÃO DAS PROPRIEDADES PELA NM 53}

A NM 53 baseia-se no princípio de Arquimedes para determinar a absorção e massas específicas aparente e real, a partir da medida de três parâmetros da amostra: massa seca $\left(\mathrm{M}_{\mathrm{s}}\right)$, massa saturada com superfície seca $\left(\mathrm{M}_{\mathrm{sss}}\right)$ e massa submersa $\left(\mathrm{M}_{\mathrm{sub}}\right)$.

A massa seca $\left(\mathrm{M}_{\mathrm{s}}\right)$ do material é a massa excluindo-se qualquer água livre. De acordo com a NM 53, a amostra é secada em estufa a temperatura de $105^{\circ} \mathrm{C}$ por 24 horas e sua massa é medida. Novamente é secada em estufa e a massa medida após mais 24 horas, repetindo-se o processo até que não haja decréscimo de sua massa.

A massa no estado saturado superfície seca $\left(\mathrm{M}_{\mathrm{sss}}\right)$ do material é a massa na qual todos os poros do sólido estão totalmente preenchidos com água, sem que, no entanto, haja água na superfície do mesmo. A $\mathrm{M}_{\mathrm{sss}}$ configura a soma da massa seca do sólido mais a massa da água dentro de seus poros permeáveis. A $\mathrm{M}_{\mathrm{sss}}$ é determinada, de acordo com a NM 53, deixando-se a amostra em imersão por um período de 24 horas, quando é considerado que sua 
absorção chegou ao limite. É, então, retirada da água, secada por pano até que sua superfície se apresente seca visualmente e pesada.

A massa submersa $\left(\mathrm{M}_{\text {sub }}\right)$, por sua vez, é a massa da amostra imersa em água, logo após sua saturação por 24 horas. Esta medição é realizada com a amostra pendurada em cesto metálico vazado acoplado à balança. $\mathrm{O}$ cesto e a amostra ficam imersos na água no momento da pesagem, de forma que se mede a força resultante do peso da amostra descontando-se o empuxo criado pela água sobre a mesma.

De acordo com o princípio de Arquimedes, um corpo total ou parcialmente mergulhado num fluido recebe deste um empuxo dirigido verticalmente de baixo para cima, igual ao volume deslocado. Assim, a força (F) total resultante deste corpo é igual ao seu peso (P) menos o seu empuxo (E) (HALLIDAY, 1991), conforme a equação 2:

$$
F=P-E
$$

A força $\mathrm{P}$ pode ser calculada pela multiplicação da massa pela aceleração da gravidade, conforme equação 3 (HALIDAY, 1991).

$$
P=M_{\sec a} \times g
$$

O empuxo (E) de um corpo sólido é definido como a multiplicação das grandezas gravidade $(\mathrm{g})$, volume de material deslocado $\left(\mathrm{V}_{\text {deslocado }}\right)$ e densidade do líquido $(\rho)$ (no caso da água sob condições normais de temperatura e pressão, $1 \mathrm{~kg} / \mathrm{dm}^{3}$ ) em que se encontra

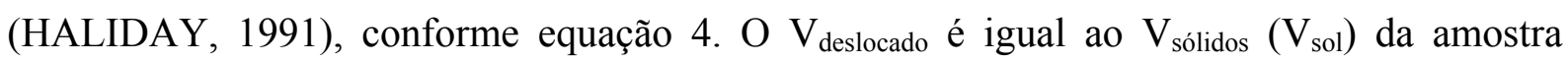
quando a medida é realizada no momento em que todos os poros estão saturados.

$$
E=g \times V_{\text {deslocado }} \times \rho_{\text {agua }}, \text { ou } \quad E=g \times V_{\text {sol }} \times \rho_{\text {água }}
$$

A força $F$ resultante é medida pela equação 5:

$$
F=M_{\text {sub }} \times g
$$

Substituindo as equações 3, 4 e 5 na $2(\mathrm{~F}=\mathrm{P}-\mathrm{E})$, chega-se à equação 6 :

$$
\left(M_{\text {sub }} \times g\right)=\left(M_{\mathrm{sec} a} \times g\right)-\left(g \times V_{\text {sol }} \times \rho_{\text {agua }}\right)
$$

Cortando g e considerando 1 para $\rho$ (densidade da água), tem-se a equação 7:

$$
M_{\text {sub }}=M_{\mathrm{sec} a}-V_{\text {sol }} \quad, \text { ou } \quad V_{\text {sol }}=M_{\mathrm{sec} a}-M_{\text {sub }}
$$


$\mathrm{O} \mathrm{V}_{\text {sol }}$ encontrado na equação 7 permite o cálculo da MER, de acordo com as definições do item 2.1, conforme equação 8 .

$$
M E R=\frac{M_{\mathrm{sec} a}}{V_{\text {sol }}} \quad, \text { ou } \quad M E R=\frac{M_{\mathrm{sec} a}}{M_{\mathrm{sec} a}-M_{\text {sub }}}
$$

Por outro lado, o $\mathrm{V}_{\text {aparente }}\left(\mathrm{V}_{\mathrm{ap}}\right)$ pode ser calculado de acordo com a equação 9:

$$
V_{a p}=V_{\text {sol }}+V_{\mathrm{H}_{2} \mathrm{O}} \quad, \text { ou } \quad V_{a p}=V_{\text {sol }}+V_{\text {poros }}
$$

Substituindo, na equação $9, \mathrm{~V}_{\text {sol }}$ por $\mathrm{M}_{\text {seca }}-\mathrm{M}_{\text {sub }}$ (equação 7 ), e $\mathrm{V}_{\mathrm{H} 2 \mathrm{O}}$ por $\mathrm{M}_{\mathrm{H} 2 \mathrm{O}}$ (densidade da água é 1), tem-se a equação 10 :

$$
V_{a p}=M_{\sec a}-M_{s u b}+M_{H_{2} O}
$$

Se $M_{\text {seca }}+M_{H 2 O}$ corresponde à $M_{\text {sss }}$ do material, pode-se deduzir a equação 11 .

$$
V_{a p}=M_{s s s}-M_{s u b}
$$

Com o $\mathrm{V}_{\mathrm{ap}}$ dos agregados encontrado na equação 11, é possível calcular-se a MEA, de acordo com as definições do item 2.1, conforme equação 12.

$$
M E A=\frac{M_{\sec a}}{V_{a p}} \quad, \text { ou } \quad M E A=\frac{M_{\sec a}}{M_{s s s}-M_{s u b}}
$$

A absorção é a medida percentual de ganho de massa de água do agregado no ponto de $\mathrm{M}_{\text {sss }}$, comparado ao ponto de $\mathrm{M}_{\mathrm{s}}$. Relaciona a quantidade de água retida nos poros do material à sua massa seca, conforme equação 13 .

$$
A(\%)=\frac{M_{s s s}-M_{\sec a}}{M_{\sec a}} \times 100
$$

\subsubsection{LIMITAÇÕES DA NM 53}

Essa norma foi concebida para caracterizar agregados de rochas naturais com pouca porosidade - valores entre 1 a 2,5\% de volume de poros, segundo Leite, 2001 - e agregados leves. É uma norma bem aceita e difundida, pois a história da construção civil tem comumente trabalhado, ao longo do tempo, com agregados destes tipos.

Porém, esta norma apresenta problemas para caracterizar agregados reciclados:

a) tempo de caracterização 
É necessário secar os agregados em estufa por 24 horas para que seja determinada a $\mathrm{M}_{\mathrm{s}}$ da amostra. Este período pode ser acrescido por outros de 24 horas, caso conclua-se que a $\mathrm{M}_{\mathrm{s}}$ ainda não tenha sido atingida (diferença $>0,5 \%$ em relação à medição anterior). Em seguida, a amostra é imersa em água por mais 24 horas para a determinação da $M_{\text {sss }}$ e $M_{\text {sub. }} O$ processo dura, assim, no mínimo 48 horas, tempo que pode inviabilizar uma produção em escala industrial na central de reciclagem.

b) dificuldade de saturação de todos os poros

LEITE (2001) demonstra que os agregados de RCD reciclados não saturam em 24 horas. Os poros, não saturados totalmente, apreendem ar, e este ar aumenta a força empuxo (E) da equação 2, diminuindo conseqüentemente a força $(F)$ resultante, trazendo erro às medidas de $\mathrm{M}_{\text {sub }}$ e $\mathrm{M}_{\text {sss }}$ e, portanto, aos cálculos de MEA, MER e absorção do material. $\mathrm{O}$ ar sendo desprendido das amostras é visualizado na Figura 2.6.
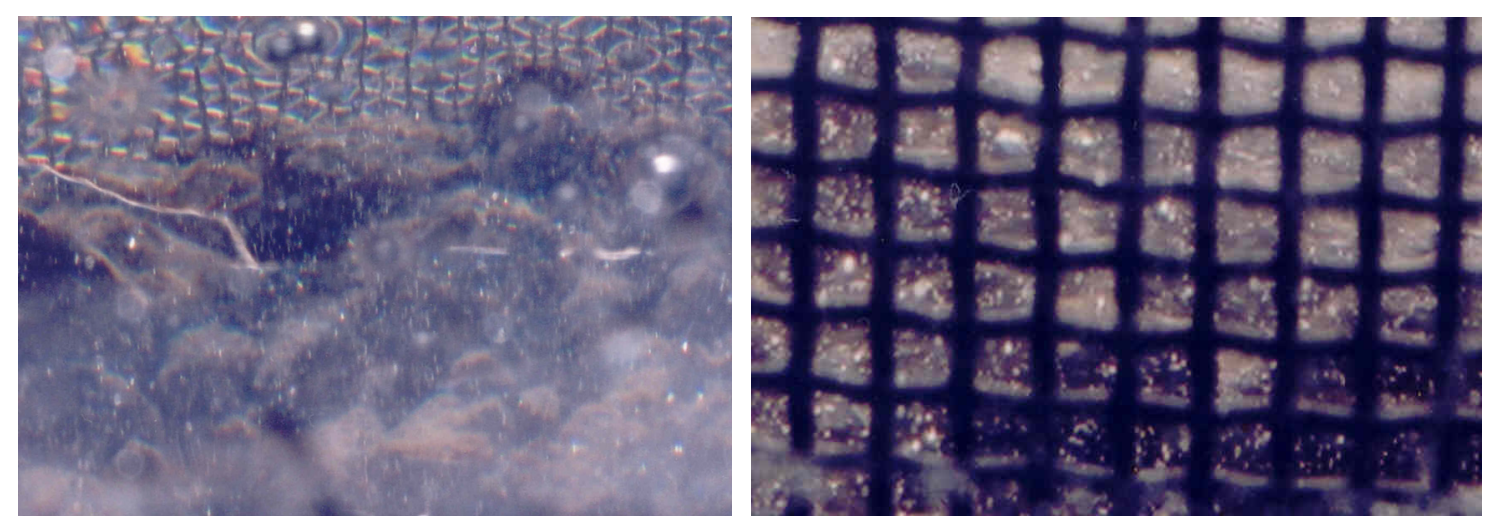

Figura 2.6 - Desprendimento de bolhas de ar de amostras de agregados reciclados de faixas de grande porosidade.

Fotos: Bruno Luís Damineli.

Schouenborg et al (2003) apresentam dados que permitem supor que agregados naturais chegam a seu estado de equilíbrio ("steady-state") de absorção, com massa constante, após 3 meses de imersão em água, ao passo que os muito porosos, como os leves e os reciclados, têm este tempo aumentado para aproximadamente 1 ano. Assim, 24 horas são insuficientes para a saturação total de qualquer agregado, o que traz erros desconhecidos às medidas. Porém, não foram encontradas bibliografias que analisem a importância deste erro.

c) perda de massa do material

Dados de Carrijo (2005) demonstram que, após diversos ciclos de determinação de absorção sobre uma amostra, erros da ordem de $30 \%$ são encontrados devidos à perda de massa do material pela secagem por pano. O erro se acumula quando da utilização da mesma amostra por repetidas vezes, afetando a repetibilidade do ensaio. 
Leite (2001) cita em seu trabalho a perda de massa de agregados de RCD reciclados, quando submetidos ao procedimento de secagem por pano. Esta secagem é ainda dificultada conforme haja diminuição da granulometria das partículas.

É importante notar que faltam dados sobre estudos sistemáticos destes possíveis erros observados por diferentes pesquisadores. Todos os autores pesquisados citam que as normas atuais para caracterização de propriedades físicas devem ser usadas com limitações sobre agregados de RCD reciclados, e a necessidade de se desenvolver novos métodos de quantificação para as propriedades destes materiais.

\subsection{MÉTOdOS ALTERNATIVOS}

Os problemas encontrados para a aplicação da NM 53 a agregados de RCD reciclados têm incentivado autores a propor novos meios de realizar a sua caracterização física. Algumas perspectivas de possível sucesso foram identificadas.

\subsubsection{MASSA SUBMERSA AO LONGO DO TEMPO E APLICAÇÃo DE VÁCUO}

Leite (2001), encontrando as dificuldades mencionadas para a caracterização dos agregados reciclados, propõe novas normas de ensaio para a determinação de suas propriedades físicas. Um método de Neville (1995) é adaptado para a determinação da massa específica. Este procedimento configura evolução nos conceitos de caracterização de agregados reciclados, pois utiliza depressão de vácuo durante 15 minutos sobre a amostra para retirar o ar aprisionado e aumentar a saturação dos poros.

Para a medição da absorção da amostra, monitora-se a sua massa submersa por 24 horas após secagem por 24 horas, com agitação do recipiente a cada momento de leitura, sem depressão de vácuo. Este ensaio melhora a saturação, mas continua utilizando 48 horas. Além disso, a cinética de absorção de agregados porosos é rápida - mais de $60 \%$ ocorre nos primeiros 10 minutos. A agitação manual proposta, mesmo periódica, pode não garantir a retirada do ar aprisionado (ALMEIDA et al, 2003), resultando um processo de saturação ou desprendimento de bolhas lento pela ausência da pressão.

Conclusões de Schouenborg et al (2003) ressaltaram boa repetitividade / reprodutibilidade de ensaios com uso de vácuo sobre o agregado, e boa correspondência entre ensaios rápidos com vácuo e ensaios de absorção de longo prazo (até 1 ano).

Partindo destas considerações, Ramalho et al (2004) deduziram fisicamente um modelo teórico para determinação de propriedades físicas de agregados reciclados, unindo os 
conceitos mais importantes dos ensaios propostos por Leite (2001) e a depressão de vácuo enfatizada por Schouenborg et al (2003), que passa a ser aplicada sobre a amostra enquanto sua $\mathrm{M}_{\text {sub }}$ é monitorada. $\mathrm{O}$ vácuo permanente busca retirar o ar incorporado ao material sem a necessidade de se agitar a amostra e de forma controlada e forçada, possibilitando que maior quantidade de ar seja retirada em tempos menores.

A seguir, está descrito o novo modelo teórico apontado por Ramalho et al (2004). Novamente tem-se as equações 2, 3, 4 e 5, sendo que, nas equações 4 e 5, o $V_{\text {deslocado }}$ e a $M_{\text {sub }}$ medidos não são apenas os finais, mas em vários tempos t.

$$
\begin{aligned}
& F=P-E \\
& P=M_{\text {sec } a} \times g \\
& E_{(t)}=g \times V_{\text {deslocado }(t)} \times \rho_{\text {agua }} \\
& F_{(t)}=M_{\text {sub }(t)} \times g
\end{aligned}
$$

O volume de material deslocado descrito na equação 4 (empuxo) é variável agora, podendo ser calculado a cada momento como a soma do volume de sólidos $\left(\mathrm{V}_{\mathrm{sol}}\right)$ do material com o seu volume de poros totais $\left(\mathrm{V}_{\text {poros }}\right)$, subtraindo-se o volume de poros que estão saturados no instante $\mathrm{t}$ da leitura $\left(\mathrm{V}_{\text {psat }(\mathrm{t})}\right)$, pois este volume já preenchido já não faz parte do volume de material que sofre empuxo. $\mathrm{O} \mathrm{V}_{\text {deslocado }}$ pode ser assim calculado pela equação 14:

$$
V_{\text {deslocado }}=V_{\text {sol }}+V_{\text {poros }}-V_{\text {psat }(t)}
$$

Deste modo, a equação do empuxo (4) pode ser reescrita conforme a equação 15 , substituindo-se o valor de $\mathrm{V}_{\text {deslocado }}$ pela equação 14 :

$$
E=g \times\left(V_{\text {sol }}+V_{\text {poros }}-V_{\text {psat }(t)}\right) \times \rho_{\text {agua }}
$$

Substituindo-se as equações 3, 5 e 15 na equação 2, tem-se agora a equação 16 :

$$
\left[M_{\text {sub }(t)} \times g\right]=\left[M_{\sec a} \times g\right]-\left[g \times\left(V_{\text {sol }}+V_{\text {poros }}-V_{\text {psat }(t)}\right) \times \rho_{\text {agua }}\right]
$$

O agregado é submerso em água após secagem total, e sua $\mathrm{M}_{\text {sub }}$ é acompanhada ao

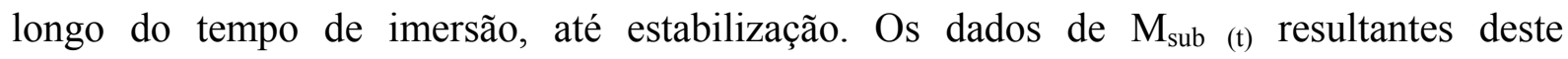
acompanhamento possibilitam cálculo da massa específica e absorção do agregado, pois há dois pontos de grande interesse devido a alguns fatores peculiares que neles ocorrem: 
a) no instante zero, o volume deslocado pelo sólido é o volume aparente das partículas, pois que o líquido ainda não penetrou em seus poros permeáveis;

b) no instante infinito, o volume deslocado pelo sólido é o volume de sólidos das partículas, pois que o líquido já preencheu todos os seus poros permeáveis.

Se a força $\mathrm{P}$ é constante e depende da $\mathrm{M}_{\mathrm{s}}$ do material e da gravidade, a variação da $\mathrm{F}$ resultante depende das variações do empuxo. Por sua vez, a variação do E depende da variação do $\mathrm{V}$ deslocado. Este $\mathrm{V}_{\text {deslocado }}$ pode ser determinado nos dois instantes $\mathrm{t}$ descritos $(0 \mathrm{e}$ $\infty)$ pois sabe-se que, em $\mathrm{t}=0, \mathrm{o} \mathrm{V}_{\mathrm{psat}}=0$, e, em $\mathrm{t}=\infty, \mathrm{V}_{\text {psat }}=\mathrm{V}_{\text {poros. }}$ Tem-se:

1) No instante $\mathbf{t}=\mathbf{z e r o}\left(0 \%\right.$ de absorção), o $\mathbf{V}_{\text {psat }}=\mathbf{0}$, o que faz com seja cortado da equação. A equação 16 transforma-se na equação 17 :

$$
\left[M_{\text {sub }(0)} \times g\right]=\left[M_{\sec a} \times g\right]-\left[g \times\left(V_{\text {sol }}+V_{\text {poros }}\right) \times 1\right]
$$

2) No instante $\mathbf{t}=$ infinito (100\% de absorção), o $\mathbf{V}_{\text {psat }}=\mathbf{V}_{\text {poros }}$, fato que faz estas duas grandezas se anularem. A equação 16 transforma-se na equação 18:

$$
\left[M_{s u b(\infty)} \times g\right]=\left[M_{\sec a} \times g\right]-\left[g \times V_{s o l} \times 1\right]
$$

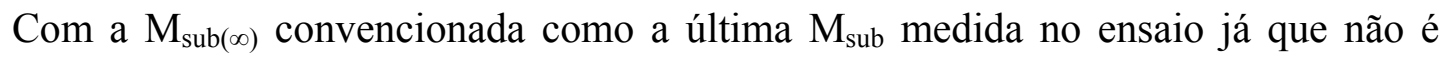

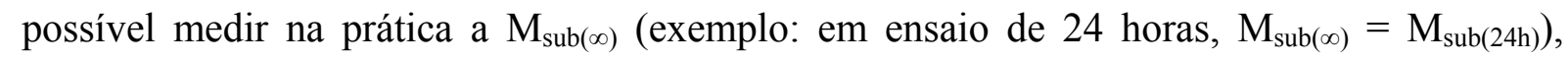
calcula-se, pela equação 18 , o $\mathrm{V}_{\text {sol }}$, já que $\mathrm{M}_{\mathrm{s}}$ e $\mathrm{g}$ são constantes. Aplicando o $\mathrm{V}_{\text {sol }}$ na equação 17, pode-se calcular o $V_{\text {poros }}$, pois a $M_{\text {sub(0) }}$ foi medida. Com $M_{\text {seca }}, M_{\text {sub(0) }}, M_{\text {sub( }())}, V_{\text {poros }}$ e $V_{\text {sol }}$ pode-se calcular as propriedades físicas de absorção, MEA e MER, respectivamente pelas equações 19, 8 e 12, lembrando que, para o cálculo da MEA, o $V_{\text {ap }}$ equivale à soma do $V_{\text {sol }} \mathrm{e}$ do $\mathrm{V}_{\text {poros }}$, conforme a equação 9.

$$
A(\%)=\frac{M_{s u b(\infty)}-M_{s u b(0)}}{M_{\sec a}} \times 100
$$

Este método, além de eliminar o manuseio do material, conforme sugerido por Leite (2001), pode também determinar precisamente o ponto de $\mathrm{M}_{\mathrm{sss}}$ do agregado, que não irá mais depender da inspeção visual do operador.

Porém, a eliminação das bolhas de ar incorporadas é importante para uma correta determinação do empuxo. A presença de bolhas de ar diminui o $\mathrm{V}_{\text {psat }} \mathrm{O}$ vácuo, sendo alternativa para retirar o ar do material de forma forçada, tem grande probabilidade de aumentar este $\mathrm{V}_{\text {psat }}$ e acelerar o ensaio. 


\subsubsection{SECAGEM NO TEMPO}

Dias; Agopyan (2005) e Kropp (2005) também propõem método de ensaio para determinação da absorção de agregados reciclados, baseado em propriedades de secagem conhecidas de corpos sólidos porosos (BROWN et al, 1965; KEEY, 1972; STRONGIN; BORDE, 1986; SCHADLER; KAST, 1986; STRUMILLO; KUDRA, 1986; NONHEBEL; MOSS, 1971; McCABE et al, 1987). A secagem de um material poroso em um ambiente controlado e estável é um processo dividido em 4 etapas, de acordo com a Figura 2.7:

1) Inicial $\left(I_{0}\right)$ : a velocidade de secagem aumenta ou diminui com rapidez, com duração curta. É instável e depende da temperatura inicial do material, sendo o tempo de adequação entre temperaturas e pressões de vapor do sólido e do meio secante.

2) Primeira etapa de secagem (I): a velocidade de secagem é constante, assim como a temperatura na superfície e no interior do sólido. Este período é denominado de estacionário e se prolonga enquanto a umidade perdida para o meio é a umidade livre e que não está no interior dos poros do material, daí a taxa constante de secagem.

3) Segunda etapa de secagem (II): a taxa de secagem passa a ser decrescente, com diminuição da quantidade de água evaporada por unidade de tempo, pois a superfície de evaporação desloca-se para as camadas interiores do sólido. A umidade livre contida dentro dos poros do material começa a ser retirada.

4) Terceira etapa de secagem (III): a velocidade de secagem é decrescente mas diferente do período II, pois diminui proporcionalmente à diminuição da umidade. A evaporação é exclusivamente subsuperficial, estando cada vez mais longe da superfície. O calor necessário à evaporação penetra no interior do material parcialmente seco, o que se torna gradativamente mais difícil e explica a redução da velocidade da secagem.

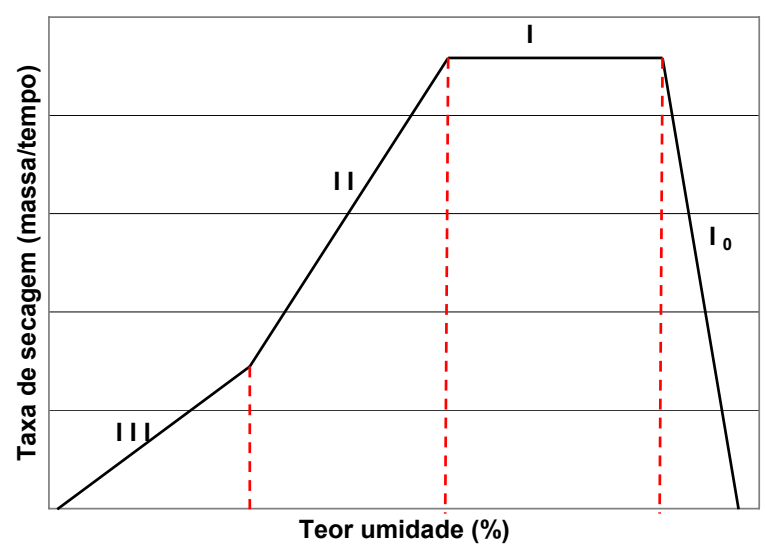

Figura 2.7 - Etapas de secagem. 
5) Finalmente, após a terceira etapa de secagem, a velocidade da secagem chega a zero, indicando que o ponto de umidade de equilíbrio foi atingido.

Experimentalmente, imerge-se a amostra em água até saturação total. A seguir procede-se à secagem do conjunto amostra/água em ambiente constante. Durante esta secagem, são monitorados os valores de massa até se atingir massa constante (amostra seca), em intervalos de tempo definidos. O teor de umidade a cada instante ( $\mathrm{t}$ ) é uma relação entre a massa do conjunto agregado/água no instante ( $\mathrm{t}$ ) e a $\mathrm{M}_{\mathrm{s}}$ inicial, conforme equação 20:

TeorUmidade $(t)(\%)=\frac{M_{\text {conj.agreg } / \text { agua }(t)}-M_{\mathrm{sec} a}}{M_{\mathrm{sec} a}} \times 100$

A taxa de secagem pode ser calculada, em cada instante t, pela subtração da massa do conjunto agregado/água do instante $(\mathrm{t})$ em relação ao instante (t-1) anterior, dividida pelo próprio intervalo de tempo, conforme a equação 21 .

TaxaSecagem $(t)(\mathrm{g} / \mathrm{min})=\frac{\left[M_{\text {conj.agreg } / \text { água }(t-1)}\right]-\left[M_{\text {conj.agreg } / \text { água }(t)}\right]}{(t)-(t-1)} \quad(21)$, onde

Mconj. agreg/água é a massa total, formada pelo agregado mais a umidade total contida no recipiente no instante t.

Deve-se observar que as taxas de secagem utilizadas originalmente nos cálculos de absorção de sólidos porosos são medidas de perda de massa por unidade de tempo por unidade de área superficial do sólido que está sendo secado. Porém, neste trabalho esta taxa foi simplificada, sendo considerada como uma medida de perda de massa por unidade de tempo, eliminando-se a área superficial do sólido. Este procedimento simplifica o ensaio e não traz prejuízo às absorções calculadas, já que a área superficial, mesmo fora dos cálculos, está implícita na taxa, pois se pode dizer que a taxa adotada considera que a perda de massa do conjunto agregado/água está ocorrendo no intervalo de tempo considerado, e para a área superficial total da amostra, que existe mesmo não tendo sido mensurada.

Com os valores de teor de umidade e taxa de secagem de cada instante $t$, faz-se um gráfico de secagem, e nele são identificadas as fases de secagem. Determina-se o ponto de mudança entre as fases 1 (taxa de secagem constante, onde a umidade retirada é externa aos poros) e 2 (taxa de secagem decrescente, quando a evaporação passa ao interior dos poros). Este é o ponto em que o agregado está sob absorção máxima e sem umidade livre excedente aos seus poros permeáveis (o ponto de $\mathrm{M}_{\mathrm{sss}}$ ). Graficamente, é possível determinar a absorção do material, configurada pela projeção deste ponto de transição sobre o eixo x, que contém o teor de umidade. No exemplo da Figura 2.8, a absorção medida seria A. 


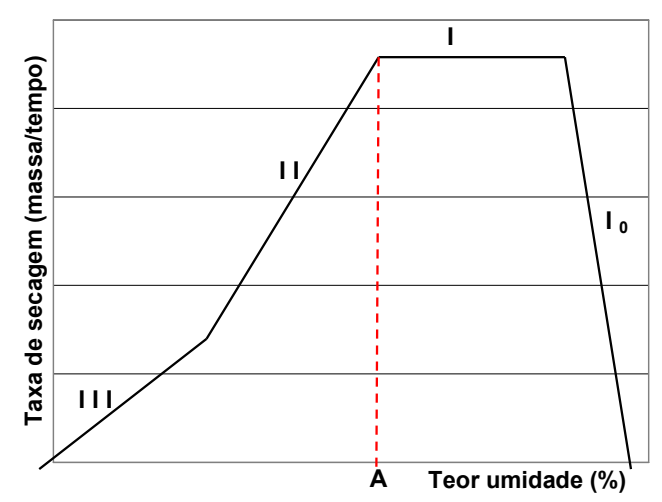

Figura 2.8 - Determinação da absorção no ponto de intersecção entre fases de secagem I e II.

Voltando aos dados, este valor de teor de secagem corresponde a um valor de massa que o originou, que é a $\mathrm{M}_{\text {sss. }}$. Medindo a $\mathrm{M}_{\text {sub }}$ após a saturação e antes do início da secagem, tem-se a $\mathrm{M}_{\text {seca }}, \mathrm{M}_{\mathrm{sss}}$ e $\mathrm{M}_{\text {sub }}$ do agregado, permitindo o cálculo da sua absorção, MER e MEA, de acordo com as equações 13,12 e 8 , respectivamente:

$$
\begin{aligned}
& A(\%)=\frac{M_{s s s}-M_{\sec a}}{M_{\sec a}} \times 100 \\
& M E A=\frac{M_{\sec a}}{M_{s s s}-M_{s u b}} \\
& M E R=\frac{M_{\sec a}}{M_{\sec a}-M_{s u b}}
\end{aligned}
$$

\subsection{ESTATÍSTICA - PLANEJAMENTO EXPERIMENTAL DOE}

O "Design of Experiments", ou DOE, é uma ferramenta estatística que permite a composição de uma seqüência de experimentos, levando em conta as variáveis do procedimento julgadas significantes. Esta seqüência de experimentos tem a propriedade de planejar as combinações possíveis dos níveis de todas as variáveis, sem repetições de ensaios - com exceção do chamado ponto central, repetido algumas vezes sob condições idênticas de forma a oferecer graus de liberdade suficientes para a determinação do erro experimental (BOX; HUNTER; HUNTER, 1978).

A análise estatística sobre os resultados dos planejamentos realizados tem o intuito de criar procedimentos laboratoriais relevantes para cada metodologia estudada, pois possibilita a compreensão das influências das variáveis consideradas sobre as respostas obtidas. Pode-se concluir sobre: a) efeito de cada variável sobre as respostas; b) importância deste efeito, em comparação com o erro experimental; c) correlações e curvaturas do modelo; 
e d) possibilidades da variável aumentar o erro. Com estas análises, pode-se estimar valores ótimos das variáveis dentro de um certo intervalo (BOX; HUNTER; HUNTER, 1978), o que possibilita o ajuste dos métodos para que se chegue à criação de procedimentos padrões com as melhores condições possíveis, tanto em relação à diminuição do tamanho dos erros e incertezas de ensaio como em relação à melhoria da capacidade de aquisição de respostas.

Neste tipo de planejamento experimental, as variáveis são codificadas como $-1,0$ e +1 , sendo que, para cada valor codificado, corresponde um valor real da variável. Por exemplo, ao se estudar o intervalo da massa (variável) dos agregados entre 1 e $4 \mathrm{~kg}$, o ponto 1 corresponde à massa de $1 \mathrm{~kg}$ (menor massa do intervalo), o ponto +1 , à massa de $4 \mathrm{~kg}$ (maior massa) e o ponto 0 , o central, à massa intermediária, de $2,5 \mathrm{~kg}$. Com as variáveis codificadas, o planejamento é definido, de modo que todas as combinações entre os diferentes níveis das variáveis tornem-se ensaios para execução experimental.

Os efeitos das variáveis sobre as respostas medidas podem ser calculados de forma simplificada através da soma e subtração das respostas medidas, em acordo com os sinais de codificação da variável em estudo. Quando a variável está codificada como (-1), o valor da resposta é subtraído; quando está codificada como $(+1)$, o valor da resposta é somado. $\mathrm{O}$ resultado desta conta de soma e subtração das respostas de acordo com os sinais da variável analisada é, então, dividido pela metade do número total de ensaios que participaram do cálculo. Os ensaios do ponto central não entram nos cálculos dos efeitos, já que estão no ponto 0 (sem sinal positivo ou negativo). Maiores detalhes e explicações são obtidos em Box; Hunter; Hunter (1978).

O erro do planejamento é calculado de acordo com os ensaios repetidos, conforme as equações abaixo (BOX; HUNTER; HUNTER, 1978):

1) Cálculo do erro quando há repetição de todos os ensaios do planejamento (diferentes combinações repetidas) e não há ensaios no ponto central:

$$
s^{2}=\frac{\sum d i^{2}}{2 g}
$$

$\mathrm{s}^{2}=$ variância estimada dos ensaios realizados

$\mathrm{di}^{2}=$ diferença entre resultados (duplicatas) ou dos resultados das repetições para a média $\mathrm{g}=\mathrm{n}^{\circ}$ de combinações diferentes de ensaios

$$
V=\frac{4}{N} \sigma^{2}
$$

$\mathrm{V}=$ variância estimada para o efeito

$\sigma^{2}=$ variância real (estimada pelo $\mathrm{s}^{2}$ da equação 22)

$\mathrm{N}=\mathrm{n}^{\circ}$ total de ensaios 


$$
s=\sqrt{V}
$$

(24), onde:

$\mathrm{s}=$ erro estimado

2) Cálculo do erro quando há repetição dos ensaios do ponto central do planejamento (mesma combinação repetida):

$$
s^{2}=\frac{\sum d i^{2}}{(n-1)}
$$

$\mathrm{s}^{2}=$ variância estimada dos ensaios realizados

$\mathrm{di}^{2}=$ diferença dos resultados das repetições para a média

$\mathrm{n}=\mathrm{n}^{\circ}$ de repetições de ensaios no ponto central

$$
s=\sqrt{s^{2}}
$$

(26), onde:

$\mathrm{s}=$ erro estimado

Os efeitos calculados das variáveis sobre a resposta estudada são, então, comparados ao erro calculado para a mesma resposta. Se o valor do efeito for maior do que o dobro do erro, pode-se dizer que há significância estatística da variável considerada, ou seja, a alteração da variável modifica de fato a resposta obtida no ensaio.

Após a verificação dos efeitos das variáveis, a constatação de que alguma variável traz ao ensaio efeitos significantes torna possível a utilização de nova ferramenta estatística: a Superfície de Resposta. Com ela, há a possibilidade de utilizar os dados obtidos para a adoção de direções a serem seguidas por estas variáveis para que haja otimização na captação das respostas do ensaio. Exemplificando, se os pontos da variável massa são: -1 (1 kg), 0 (2,5kg) e +1 (4kg) e houver real significância da sua variação para as respostas obtidas, a Superfície de Resposta pode informar se a massa ideal para a realização do ensaio está próxima de $1 \mathrm{~kg}$, próxima de 2,5kg, próxima de $4 \mathrm{~kg}$, acima de $4 \mathrm{~kg}$, ou, ainda, abaixo de $1 \mathrm{~kg}$, para que seja possível encontrá-la após mais alguns ensaios (BOX; HUNTER; HUNTER, 1978).

É importante ressaltar que o intuito deste trabalho é o de realizar planejamento sistematizado de estudo dos métodos, que só pode ser obtido com a utilização de ferramentas específicas, como o DOE. Este tipo de planejamento coloca as variáveis de ensaio como o fator principal a ser considerado para uma possível melhoria do ensaio, uma vez que só o controle das variáveis implicadas podem dar ao analista uma visão abrangente e sistêmica do que está acontecendo dentro de seu campo de atuação. 


\section{ESTUDO EXPERIMENTAL SOBRE AGREGADOS DE BAIXA POROSIDADE}

O objetivo deste capítulo é a análise preliminar da validade dos métodos utilizados neste trabalho como medidores das propriedades físicas de agregados, principalmente o da secagem para determinação da $M_{\text {sss }}$ e o da $M_{\text {sub }} \times \mathrm{t}$, para que possam ser estudados sobre agregados reciclados. Para isto, realizaram-se ensaios sobre esferas de vidro (bolas de gude), sólido de baixa porosidade com absorção e MEA bem definidas. Assim, são conhecidas as respostas a serem atingidas pelos métodos de ensaio para que sejam considerados aptos à realização da tarefa a que se destinam.

O capítulo está dividido em três partes, que são o estudo da caracterização da porosidade do vidro através da: 1) NM 53 (norma atual para execução desta tarefa); 2) massa submersa ao longo do tempo; e 3) secagem.

\subsection{NM 53}

Este item busca analisar a influência de algumas variáveis na determinação das propriedades físicas dos agregados de vidro pela NM 53 para se verificar se esta norma é passível de adaptação para utilização sobre agregados reciclados, tendo em vista os possíveis problemas detectados com relação à sua utilização sobre estes agregados.

\subsubsection{Planejamento experimental, materiaIS E MÉtodos}

Duas variáveis foram investigadas: a) massa, onde foram adotados valores entre $1 \mathrm{~kg}$ (ponto -1) e 4,5kg (ponto +1 ), já que a norma indica $3 \mathrm{~kg}$ como massa representativa para agregados da faixa granulométrica estudada; e b) método de secagem para determinação da $\mathrm{M}_{\mathrm{sss}}$ - com pano (padrão da NM 53, ponto -1) ou com secador por vento (ponto +1 ), o qual pode diminuir a perda de massa da amostra por evitar seu manuseio direto na secagem.

A Tabela 3.1 apresenta o planejamento experimental fatorial completo $2^{2}$ utilizado para o método da NM 53, segundo o modelo de Box; Hunter; Hunter (1978). 
Tabela 3.1 - Planejamento fatorial $2^{2}$ dos ensaios para a NM 53 - esferas de vidro.

\begin{tabular}{|c|c|c|}
\hline \multicolumn{3}{|c|}{ VARIÁVEIS CODIFICADAS } \\
\hline ENSAIO & MASSA & SECAGEM \\
\hline 1.1 .1 & - & 7 \\
\hline 1.1 .2 & + & - \\
\hline 1.1 .3 & - & + \\
\hline 1.1 .4 & + & + \\
\hline 1.1 .5 & - & - \\
\hline 1.1 .6 & + & - \\
\hline 1.1 .7 & - & + \\
\hline 1.1 .8 & + & + \\
\hline
\end{tabular}

Como este planejamento possui uma variável qualitativa (o método de secagem da amostra - pano ou secador), não há possibilidade de realização de ensaios no ponto central. Assim, os ensaios foram duplicados para a determinação do desvio padrão.

\subsubsection{Materiais}

Os ensaios foram realizados sobre esferas de vidro, ilustradas na Figura 3.1, com faixa granulométrica de 9,5 a 19mm (B $B_{1}$ pela NBR 7211/83). Como este é um material com porosidade desprezível, sua absorção de água tende a $0 \%$. As massas específicas aparente e real, por sua vez, apresentam ambas valor aproximado de $2,5 \mathrm{~kg} / \mathrm{dm}^{3}$ (CALLISTER, 2000).

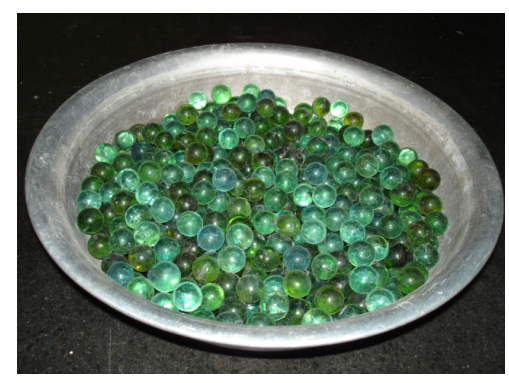

Figura 3.1 - Esferas de vidro utilizadas no trabalho.

A composição granulométrica das esferas de vidro utilizadas está na tabela 3.2.

Tabela 3.2 - Composição granulométrica dos agregados de vidro - porcentagem retida acumulada nas peneiras.

\begin{tabular}{|c|c|c|c|c|}
\hline Peneiras $(\mathrm{mm})$ & $\mathbf{1 9}$ & $\mathbf{1 2 , 5}$ & $\mathbf{9 , 5}$ & $\mathbf{6 , 3}$ \\
\hline \% retida acumulada & 0 & 100 & 100 & 100 \\
\hline
\end{tabular}

\subsubsection{Equipamentos}

Os ensaios do planejamento experimental da norma NM 53 utilizaram-se de:

$\Rightarrow$ Estufa para secagem das amostras, marca FANEM, modelo 320-SE;

$\Rightarrow$ Balança digital Mettler Toledo PB 8001-S, capacidade 8.100g e precisão de 0,1g;

$\Rightarrow$ Recipientes para estocagem, secagem, saturação e medição da $\mathrm{M}_{\text {sub }}$ dos agregados;

$\Rightarrow$ Secador de cabelos, marca Taiff, modelo RS-3. 


\subsubsection{Descrição dos procedimentos de ensaio e cálculos}

O planejamento foi executado de acordo com a seqüência da Figura 3.2.

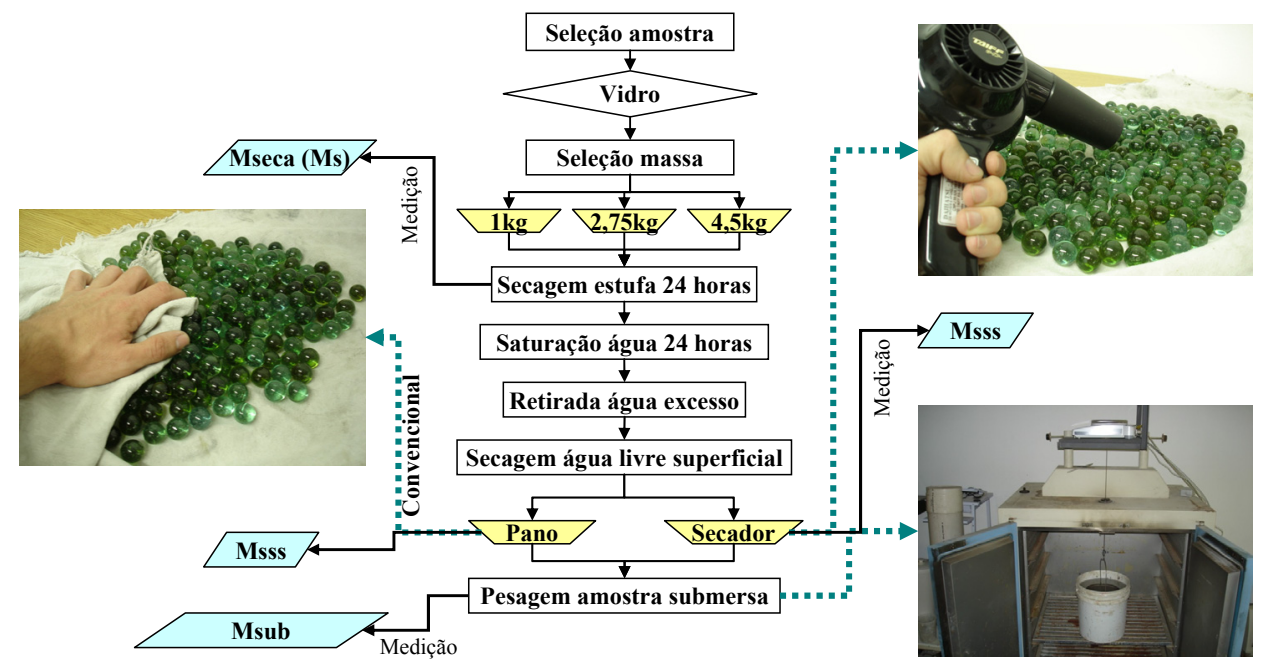

Figura 3.2 - Fluxograma dos ensaios do planejamento experimental do método NM 53.

Com $\mathrm{M}_{\mathrm{s}}, \mathrm{M}_{\mathrm{sss}}$ e $\mathrm{M}_{\text {sub }}$, calcula-se as propriedades de absorção, MEA e MER:

$$
\begin{aligned}
& A(\%)=\frac{M_{\text {sss }}-M_{\mathrm{sec} a}}{M_{\mathrm{sec} a}} \times 100 \\
& M E A=\frac{M_{\mathrm{sec} a}}{M_{s s s}-M_{\text {sub }}} \\
& M E R=\frac{M_{\mathrm{sec} a}}{M_{\mathrm{sec} a}-M_{\text {sub }}}
\end{aligned}
$$

\subsubsection{Resultados}

Os resultados são apresentados na Tabela 3.3. Para a análise estatística, foram estudados os ensaios 1.1.1 a 1.1.8. Algumas análises necessitaram de ensaios extras, utilizando o ponto central da massa $(2,75 \mathrm{~kg})$. São os ensaios 1.1.9 a 1.1.12. Os dados utilizados para o cálculo destes resultados estão no apêndice A.

Tabela 3.3 - Resultados dos ensaios do método NM 53 - esferas de vidro.

\begin{tabular}{|c|c|c|c|c|c|c|}
\cline { 2 - 7 } \multicolumn{1}{c|}{} & VARIÁVEIS & INTERAÇÃO & \multicolumn{3}{c|}{ RESPOSTAS } \\
\hline ENSAO & MASSA & SECAGEM & M x S & ABS $(\%)$ & MER $\left(\mathbf{k g} / \mathbf{d m}^{3}\right)$ & MEA $\left(\mathbf{k g} / \mathbf{d m}^{3}\right)$ \\
\hline 1.1 .1 & - & - & + & 0,060 & 2,51 & 2,50 \\
\hline 1.1 .2 & + & - & - & 0,016 & 2,52 & 2,51 \\
\hline 1.1 .3 & - & + & - & 0,030 & 2,52 & 2,52 \\
\hline 1.1 .4 & + & + & + & 0,009 & 2,51 & 2,51 \\
\hline 1.1 .5 & - & - & + & 0,010 & 2,51 & 2,50 \\
\hline 1.1 .6 & + & - & - & 0,053 & 2,51 & 2,51 \\
\hline 1.1 .7 & - & + & - & 0,000 & 2,51 & 2,51 \\
\hline 1.1 .8 & + & + & + & 0,027 & 2,51 & 2,51 \\
\hline 1.1 .9 & 0 & - & não há & 0,047 & 2,52 & 2,52 \\
\hline 1.1 .10 & 0 & - & não há & 0,023 & 2,51 & 2,51 \\
\hline 1.1 .11 & 0 & + & não há & 0,020 & 2,51 & 2,51 \\
\hline 1.1 .12 & 0 & + & não há & 0,007 & 2,52 & 2,52 \\
\hline
\end{tabular}




\subsubsection{ANÁLISE DOS RESULTADOS}

As análises foram baseadas nos modelos de Box; Hunter; Hunter (1978). Os cálculos estatísticos dos efeitos das variáveis foram feitos pelas médias dos ensaios duplicados, pois, com variáveis qualitativas no planejamento, não houve pontos centrais, sendo as duplicatas necessárias para a determinação do erro padrão.

Conclui-se inicialmente que o método está controlado. A Tabela 3.3 mostra que todas as respostas chegaram a valores muito próximos dos esperados para o vidro: $0 \%$ de absorção e 2,5Kg/dm³ para MER e MEA (CALLISTER, 2000).

As respostas de MER e MEA não serão analisadas estatisticamente, pois, como se pode observar na Tabela 3.3, os resultados destas medidas estão precisos, podendo-se dizer que são estatisticamente iguais devido aos pequenos desvios observados entre eles.

Observando-se a Figura 3.3(a), pode-se afirmar que a variável massa não possuiu efeito significante sobre as respostas de absorção, pois não houve tendência de variação das respostas em função da variação da massa. Porém, nota-se que as respostas apresentaram menores dispersões para massas maiores.

Contudo, em relação ao método de secagem para determinação da $\mathrm{M}_{\mathrm{sss}}$, nota-se uma aparente tendência de diminuição dos valores de absorção medidos com uso do secador em relação à secagem por pano, como observado na Figura 3.3(b). Porém, esta tendência é de amplitude semelhante à da dispersão dos resultados (erro) dos ensaios, de forma que ela pode estar dentro do erro e, assim, não configurar significância real desta variável. Pode-se dizer que, estatisticamente, há dúvida quanto a esta significância. Porém, as reduzidas diferenças entre as respostas obtidas com pano ou secador, bem como sua proximidade a $0 \%$, mostram que não há significado físico relevante conseqüente da alteração do método de secagem.
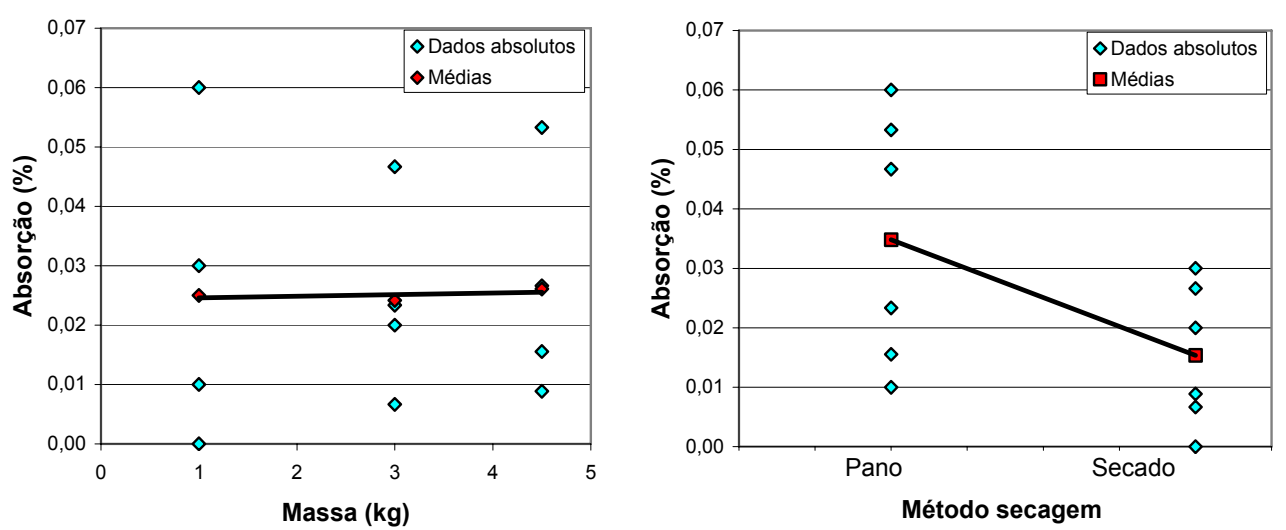

Figura 3.3 - Efeito das variáveis: a) massa; e b) método de secagem, sobre as respostas de absorção. 
Para comprovar estatisticamente estas análises, calcula-se o erro experimental pelos desvios encontrados entre as duplicatas dos ensaios, chegando-se ao valor de 0,018 para as respostas de absorção, conforme a Tabela 3.4.

Tabela 3.4 - Determinação do erro experimental do planejamento de esferas de vidro para as respostas de absorção.

\begin{tabular}{|c|c|c|c|}
\hline \multirow{2}{*}{$\begin{array}{l}\text { Variáveis } \\
\text { ensaio }\end{array}$} & \multicolumn{2}{|c|}{ Repetições } & \multirow{2}{*}{$\begin{array}{l}\text { Diferença entre } \\
\text { réplicas (d) }\end{array}$} \\
\hline & 1 & 2 & \\
\hline-- & 0,06 & 0,01 & 0,05 \\
\hline+ & 0,02 & 0,05 & $-0,04$ \\
\hline-+ & 0,03 & 0,00 & 0,03 \\
\hline++ & 0,01 & 0,03 & $-0,02$ \\
\hline \multicolumn{3}{|c|}{$\sum d^{2}$} & 0,0051 \\
\hline & \multicolumn{2}{|c|}{$s^{2}=$} & 0,0006 \\
\hline & \multicolumn{2}{|c|}{$V=$} & 0,0003 \\
\hline & \multicolumn{2}{|c|}{$s=$} & 0,0179 \\
\hline
\end{tabular}

Calculado o erro, procede-se à sua comparação com os efeitos calculados para cada variável sobre as respostas de absorção, realizada na Tabela 3.5, de acordo com Box; Hunter; Hunter (1978).

Tabela 3.5 - Estudo de significância das variáveis dos ensaios da NM 53 para esferas de vidro para respostas de absorção.

\begin{tabular}{|c|c|c|c|}
\hline Absorção (\%) & Efeito & & Erro padrão \\
\hline média & 0,026 & +- & 0,009 \\
\hline \multicolumn{4}{|c|}{ EFEITOS PRINCIPAIS } \\
\hline efeito massa & 0,001 & +- & 0,018 \\
\hline efeito mét. secagem & $-0,018$ & +- & 0,018 \\
\hline \multicolumn{4}{|c|}{ INTERAÇÕES DOIS FATORES } \\
\hline efeito $\mathrm{m} \times \mathrm{s}$ & 0,002 & +- & 0,018 \\
\hline
\end{tabular}

Observa-se na Tabela 3.5 que não foi detectada significância estatística sobre as variáveis. Encontrou-se apenas tendência à significância do método de secagem, pois o valor calculado para seu efeito aproximou-se do tamanho do erro experimental, o que reafirma a dúvida quanto à significância desta variável.

Para o planejamento experimental do método NM 53, não há a possibilidade de se realizar cheque estatístico de curvatura do modelo, pois não foi possível a realização de ensaios no ponto central. Não há também a necessidade da execução do passo ascendente visando melhorar as respostas, pois o objetivo de verificação da validade do método à tarefa de caracterização de agregados foi cumprido.

\subsubsection{CONCLUSÕES DOS ENSAIOS DA NM 53}

Com os dados dos agregados de vidro para a NM 53, concluiu-se que:

1) os resultados obtidos aproximaram-se dos valores bibliográficos do vidro, o que prova que o método está controlado. Pode servir como base comparativa nos estudos sobre agregados de alta porosidade;

2) a variação da massa não influenciou os resultados obtidos; 
3) a grande dispersão entre as repetições dos ensaios em relação à dispersão das médias dos diferentes ensaios indicou não haver significância da variável método de secagem.

\section{$3.2 M_{S U B} \times T$}

Este item analisa a possibilidade da utilização do método da $\mathrm{M}_{\text {sub }}$ ao longo do tempo para a caracterização de agregados. Para isso, serão estudados efeitos de algumas variáveis deste método na determinação das propriedades físicas de agregados de vidro.

\subsubsection{PlanEJAMENTO EXPERIMENTAL, MATERIAIS E MÉTODOS}

Três variáveis foram constatadas, sendo a primeira a massa, variada entre $1 \mathrm{~kg}$ (ponto -1), 2,75kg (ponto central) e 4,5kg (ponto +1 ), tentando diminuir possíveis oscilações pendulares dos primeiros instantes de imersão das amostras (RAMALHO et al., 2004), que podem dificultar a medição da $\mathrm{M}_{\text {sub(0), }}$, conforme a equação 27 e a Figura 3.4.

$$
T=2 \pi\left(\frac{L}{g}\right)^{1 / 2} \quad \text { (27), onde: }
$$

$\mathrm{T}=$ período - intervalo de tempo para objeto percorrer a trajetória do movimento pendular

$\mathrm{L}=$ comprimento entre nódulo por onde cesto é pendurado e a massa de agregados; $\mathrm{g}$ = aceleração da gravidade

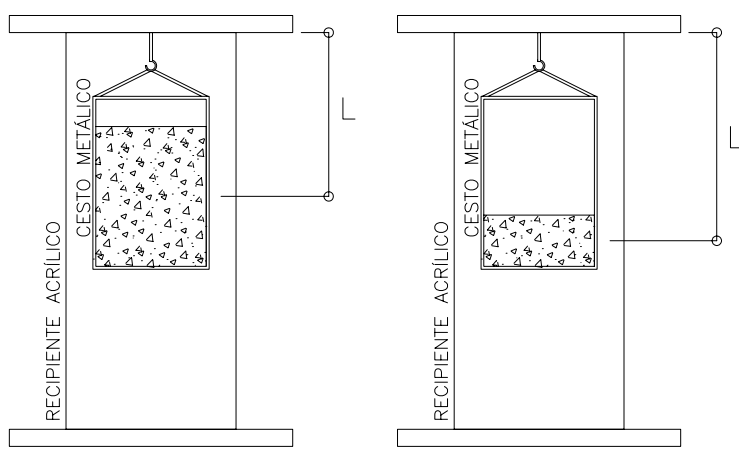

Figura 3.4 - Ilustração da variação do comprimento L de acordo com a variação da massa de agregados.

Como segunda variável empregar-se-á depressão de vácuo para aumentar a quantidade e velocidade de remoção do ar retido nos poros, para sanar um dos possíveis problemas apontados em bibliografia para sua caracterização pela NM 53.

Mas há que se limitar os valores de vácuo a serem aplicados, levando-se em conta a pressão de vapor d'água. É a pressão sob a qual a água entra em estado de vapor para uma dada temperatura. Entre 20 e $30^{\circ} \mathrm{C}$, intervalo de temperatura sob o qual se realizará este estudo, ela varia de $17,54 \mathrm{mmHg}\left(20^{\circ} \mathrm{C}\right)$ até $31,82 \mathrm{mmHg}\left(30^{\circ} \mathrm{C}\right)$. Se a pressão ao nível do mar é de $760 \mathrm{mmHg}$, diminuindo para $674 \mathrm{mmHg}$ à altitude de $1000 \mathrm{~m}$ (altitude aproximada da realização deste estudo), o vácuo máximo a ser aplicado sobre as amostras à temperatura 
ambiente é de $674 \mathrm{mmHg}$ subtraída em $17,54 \mathrm{mmHg}$ para $20^{\circ} \mathrm{C}$, ou subtraída em $31,82 \mathrm{mmHg}$ para $30^{\circ} \mathrm{C}$, o que resulta em um intervalo entre $-642,18$ e $-656,46 \mathrm{mmHg}$ de vácuo máximo. Selecionando-se o pior caso, o vácuo não pode ultrapassar $-642,18 \mathrm{mmHg}$. Desta forma, o vácuo foi variado entre $0 \mathrm{mmHg}$ (ponto -1 ), $-250 \mathrm{mmHg}$ (ponto central) e $-500 \mathrm{mmHg}$ (ponto +1 ), considerando-se, para este último valor, um limite de segurança em relação ao valor máximo encontrado $(-642,18 \mathrm{mmHg})$ para o vácuo a ser aplicado.

Constatou-se preliminarmente que o vácuo aplicado atua sobre a célula de carga, diminuindo os valores de $\mathrm{M}_{\text {sub }}$. Assim, a cada medição o vácuo foi retirado para a realização da leitura da $\mathrm{M}_{\text {sub }}$, padronizando a pressão atmosférica para leitura. A retirada do vácuo com posterior reaplicação configura um ciclo de vácuo. A terceira variável foi então a quantidade de ciclos de vácuo aplicados à amostra durante o ensaio. Os ciclos permitiram que a amostra pudesse ser retirada e reimersa na água enquanto estava sob pressão atmosférica, para a realização do desprendimento de bolhas de ar que aderiam à superfície das partículas de agregado e do cesto metálico durante a ação do vácuo. Este ar atua aumentando o empuxo da amostra, diminuindo os valores da $\mathrm{M}_{\text {sub }}$ medidos, o que poderia gerar erro experimental. Os ciclos foram variados entre 1 ciclo (ponto -1$), 5$ ciclos (central) e 9 ciclos (ponto +1 ).

A Tabela 3.6 apresenta o planejamento experimental fatorial completo $2^{3}$ utilizado para o método da $\mathrm{M}_{\text {sub }} \mathrm{x}$ t, segundo o modelo de Box; Hunter; Hunter (1978).

Tabela 3.6 - Planejamento fatorial $2^{3}$ dos ensaios para a Msub $\mathrm{x} \mathrm{t}$ - esferas de vidro.

\begin{tabular}{|}
\hline \multicolumn{4}{|l|}{ VARIAVEIS CODIFICADAS } \\
\hline ENSAIO & MASSA & VACUO & CICLOS VACUO \\
\hline 1.2 .1 & - & - & - \\
\hline 1.2 .2 & + & - & - \\
\hline 1.2 .3 & - & + & - \\
\hline 1.2 .4 & + & + & - \\
\hline 1.2 .5 & - & - & + \\
\hline 1.2 .6 & + & - & + \\
\hline 1.2 .7 & - & + & + \\
\hline 1.2 .8 & + & + & + \\
\hline 1.2 .9 & 0 & 0 & 0 \\
\hline 1.2 .10 & 0 & 0 & 0 \\
\hline 1.2 .11 & 0 & 0 & 0 \\
\hline 1.2 .12 & 0 & 0 & 0 \\
\hline
\end{tabular}

\subsubsection{Materiais}

Os materiais utilizados são esferas de vidro, apresentadas no item 3.1.1.1.

\subsubsection{Equipamentos}

Os ensaios de absorção no tempo serão realizados com o auxílio de:

$\Rightarrow$ Central de vácuo marca Prismatec, modelo 162-10V, capacidade de deslocamento de 235 litros/min, para aplicação de pressão negativa (vácuo) sobre as amostras; 
$\Rightarrow$ Cilindro de acrílico com tampa de acrílico, calculado para suportar depressão interna;

$\Rightarrow$ Mangueiras $\varnothing=5 / 16$ " e conexões próprias para gases de diâmetros compatíveis às mangueiras, com capacidade de suportar depressão;

$\Rightarrow$ Manômetro com intervalo de 0 a $-700 \mathrm{mmHg}$;

$\Rightarrow$ Célula de carga da marca Alfa, para leitura da $\mathrm{M}_{\text {sub }}$ dentro do cilindro a vácuo;

$\Rightarrow$ Cesto metálico para pendurar a amostra na célula de carga;

$\Rightarrow$ Receptor de dados digital da marca Alfa modelo 3104 B, para captura dos dados.

\subsubsection{Descrição dos procedimentos de ensaio e cálculos}

Os passos da realização dos ensaios deste método estão na Figura 3.5.

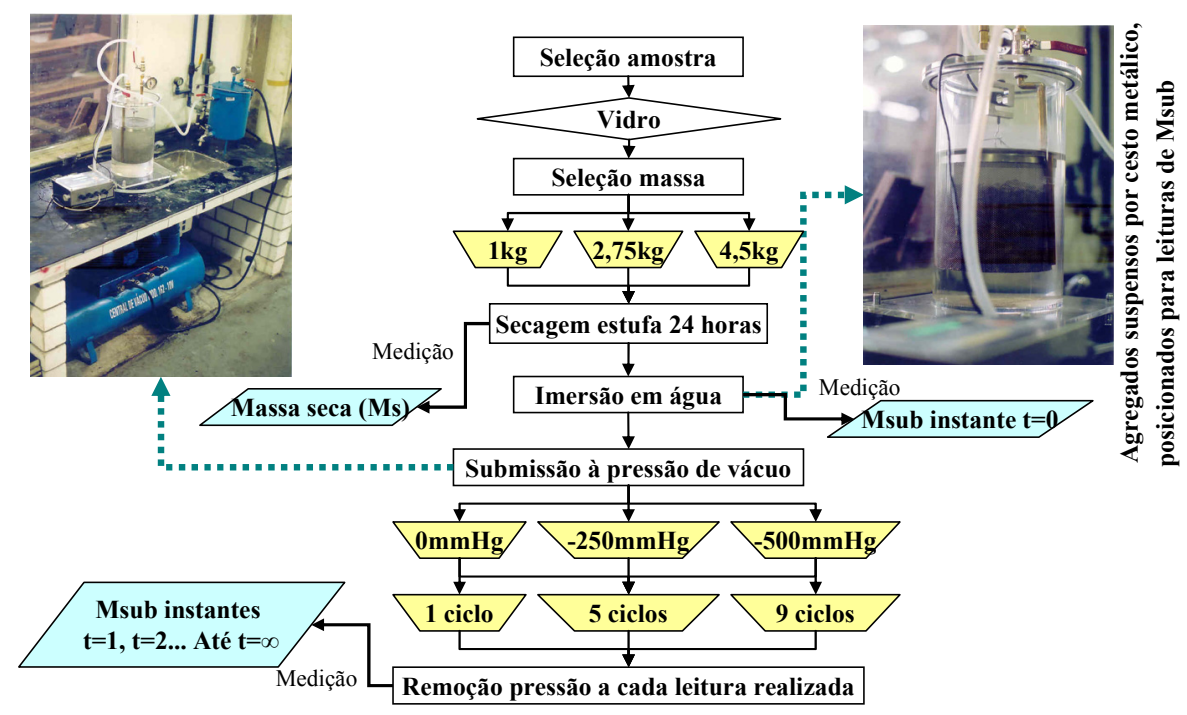

Figura 3.5 - Fluxograma dos ensaios do método da Msub ao longo do tempo.

Com os dados de $\mathrm{M}_{\mathrm{s}}$ e $\mathrm{M}_{\text {sub }}$ dos diferentes tempos de ensaio (inclusive $\mathrm{t}=0$ e $\mathrm{t}=\infty$ ), calcula-se: a) $V_{\text {sol }}$ pela equação 18 ; b) $V_{\text {poros }}$ pela equação 17 ; c) $V_{\text {ap }}$ pela equação 9; e d) MER, a MEA e a absorção pelas equações 8, 12 e 19, respectivamente.

$$
\begin{aligned}
& {\left[M_{\text {sub }(\infty)} \times g\right]=\left[M_{\mathrm{sec} a} \times g\right]-\left[g \times V_{\text {sol }} \times 1\right]} \\
& {\left[M_{\text {sub }(0)} \times g\right]=\left[M_{\mathrm{sec} a} \times g\right]-\left[g \times\left(V_{\text {sol }}+V_{\text {poros }}\right) \times 1\right]} \\
& V_{a p}=V_{\text {sol }}+V_{\text {poros }} \\
& M E R=\frac{M_{\mathrm{sec} a}}{V_{\text {sol }}} \\
& M E A=\frac{M_{\mathrm{sec} a}}{V_{a p}}
\end{aligned}
$$




$$
A(\%)=\frac{M_{\text {sub }(\infty)}-M_{\text {sub }(0)}}{M_{\text {sec } a}} \times 100
$$

\subsubsection{RESULTADOS}

A disposição dos resultados encontra-se na Tabela 3.7. Os dados utilizados para o cálculo destes resultados estão no apêndice B.

Tabela 3.7 - Resultados dos ensaios do método Msub x t - esferas de vidro

\begin{tabular}{|c|c|c|c|c|c|c|c|c|c|c|}
\hline & \multicolumn{3}{|c|}{ VARIÁVEIS } & \multicolumn{4}{|c|}{ INTERAÇÕES } & \multicolumn{3}{|c|}{ RESPOSTAS } \\
\hline ENSAIO & MASSA & VACUO & $\overline{\text { CICLOS V }}$ & $M \times V$ & $\mathrm{M} \times \mathrm{CV}$ & $\overline{V \times C V}$ & $\overline{M \times V \times C V}$ & $\begin{array}{c}\mathrm{ABS} \\
(\%)\end{array}$ & \begin{tabular}{|c}
$\mathrm{MER}$ \\
$\left(\mathrm{kg} / \mathrm{dm}^{3}\right)$
\end{tabular} & \begin{tabular}{|c} 
MEA \\
$\left(\mathrm{kg} / \mathrm{dm}^{3}\right)$
\end{tabular} \\
\hline 1.2 .1 & - & - & - & \pm & + & \pm & - & 0,080 & 2,51 & 2,51 \\
\hline 1.2 .2 & + & - & - & - & - & + & + & 0,035 & 2,50 & 2,50 \\
\hline 1.2 .3 & - & + & - & - & + & - & + & $-0,060$ & 2,51 & 2,51 \\
\hline 1.2 .4 & + & + & - & + & - & - & 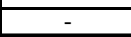 & 0,031 & 2,50 & 2,50 \\
\hline 1.2 .5 & - & - & + & \pm & - & - & \pm & 0,100 & 2,51 & 2,50 \\
\hline 1.2 .6 & + & - & + & 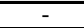 & + & 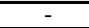 & - & 0,058 & 2,50 & 2,50 \\
\hline 1.2 .7 & & + & + & - & - & + & - & $-0,080$ & 2,50 & 2,51 \\
\hline 1.2 .8 & \pm & \pm & \pm & \pm & \pm & \pm & + & 0,022 & 2,50 & 2,50 \\
\hline 1.2 .9 & $\overline{0}$ & $\overline{0}$ & $\overline{0}$ & não há & não há & não há & não há & 0,040 & 2,51 & 2,50 \\
\hline 1.2 .10 & 0 & 0 & o & não há & não há & não há & não há & 0,033 & 2,51 & 2,51 \\
\hline 1.2 .11 & 0 & 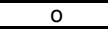 & $\overline{0}$ & não há & não há & não há & não há & 0,013 & 2,51 & 2,51 \\
\hline 1.2 .12 & 0 & 0 & 0 & não há & não há & não há & nåo há & 0,067 & 2,51 & 2,50 \\
\hline
\end{tabular}

\subsubsection{ANÁLISE DOS RESULTADOS}

As análises foram baseadas nos modelos de Box; Hunter; Hunter (1978). Os cálculos dos efeitos das variáveis foram feitos com os ensaios 1.2.1 a 1.2.8, e o erro, através das repetições dos pontos centrais (1.2.9 a 1.2.12), observados na Tabela 3.7.

Este método também está controlado. A Tabela 3.7 mostra que todas as respostas chegaram a valores muito próximos dos esperados para o vidro: $0 \%$ de absorção e $2,5 \mathrm{Kg} / \mathrm{dm}^{3}$ para MER e MEA (CALLISTER, 2000).

As respostas de MER e MEA não serão analisadas estatisticamente, pois, como se pode observar na Tabela 3.7, os resultados destas medidas estão precisos, podendo-se dizer que são estatisticamente iguais devido aos pequenos desvios observados entre eles.

A variável massa não influencia a resposta de absorção, pois, observando-se a Figura 3.6(a), verifica-se leve tendência de aumento da absorção conforme aumento da massa, para as médias das respostas. Porém, as respostas absolutas mostram que as dispersões dos resultados foram bem superiores à dispersão encontrada para as médias, de forma que esta leve tendência de aumento observada está dentro do erro experimental do método. Ainda observa-se que as respostas apresentaram menores dispersões para massas maiores, sendo muito dispersos os resultados com massa $1 \mathrm{~kg}$. Esta dispersão deveu-se à aplicação do vácuo sobre estas amostras, de forma que se pode concluir que há uma interação entre o vácuo e a massa: altas depressões sobre baixas massas geraram grande diferença de respostas. 
Na Figura 3.6(b), mostra-se que houve tendência de diminuição das absorções medidas em função do aumento do vácuo aplicado, ou seja, ocorreu o oposto do que era esperado (aumento da absorção conforme aumento do vácuo). Deve-se salientar, entretanto, que o motivo deste fato também se relaciona à interação entre o vácuo e a massa, pois a variação das respostas de absorção foram causadas pela variação do vácuo sobre as amostras de baixa massa $(1 \mathrm{~kg})$, em especial com diminuição da absorção nos ensaios com aplicação de altos níveis de vácuo $(-500 \mathrm{mmHg})$ sobre $1 \mathrm{~kg}$ de agregados. Ocorre que a célula de carga que recebe as medidas de massa submersa sofre uma pequena deformação quando da utilização do vácuo, e este erro se torna proporcionalmente maior quando a massa é diminuída. Sendo o vidro um material de absorção próxima a zero, o erro fica evidenciado, porém é de proporção desprezível para agregados com maiores valores de absorção, como os agregados reciclados.
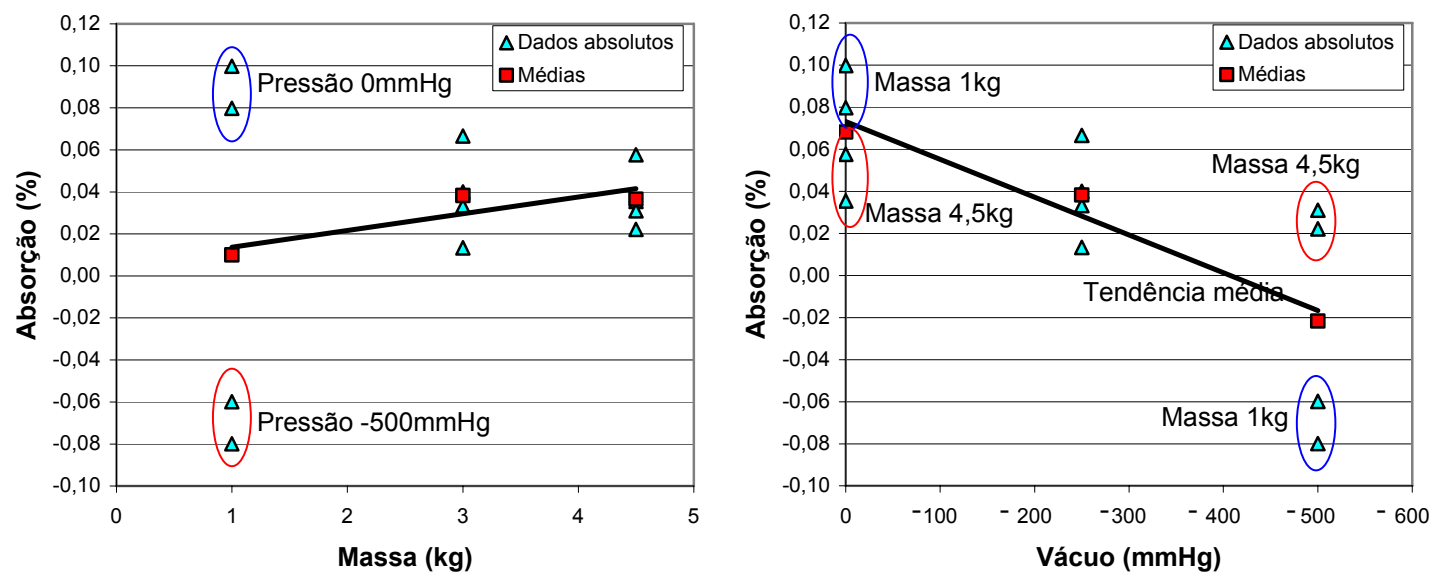

Figura 3.6 - Efeito das variáveis: a) massa; e b) vácuo, sobre as respostas de absorção.

Agora se analisa a variável ciclos de vácuo, na Figura 3.7. Nota-se que não houve tendência de alteração das respostas em função da variação dos ciclos de vácuo.

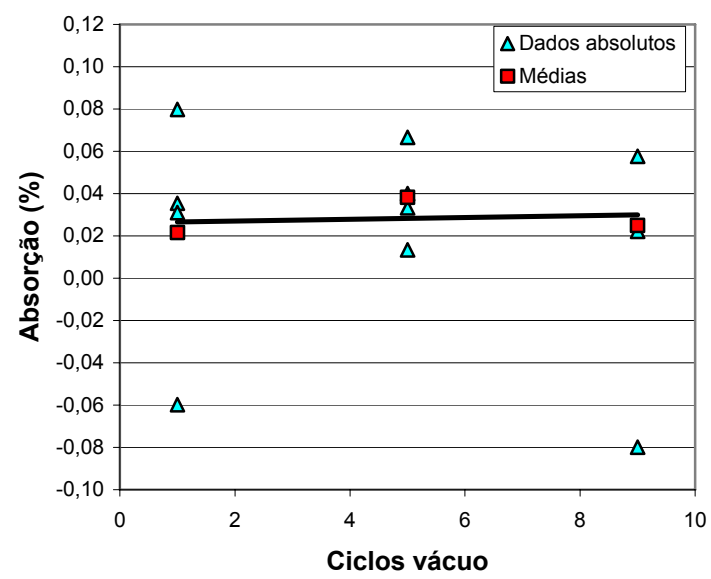

Figura 3.7 - Efeito da variável ciclos de vácuo, sobre as respostas de absorção. 
Para comprovar estatisticamente estas análises, calcula-se o erro experimental pelos desvios entre os pontos centrais, chegando-se ao valor de 0,022 para as respostas de absorção, conforme a Tabela 3.8 .

Tabela 3.8 - Determinação do erro experimental dos ensaios do método Msub x t - esferas de vidro.

\begin{tabular}{|c|c|c|}
\hline $\begin{array}{l}\text { Repetições } \\
\text { ponto central }\end{array}$ & Respostas & $\begin{array}{c}\text { Diferença para } \\
\text { a média (d) }\end{array}$ \\
\hline 1 & 0,04 & 0,002 \\
\hline 2 & 0,03 & $-0,005$ \\
\hline 3 & 0,01 & $-0,025$ \\
\hline 4 & 0,07 & 0,028 \\
\hline Média & 0,038 & 0,0015 \\
\multicolumn{2}{|c|}{$\Sigma \mathrm{d}^{2}$} & 0,0005 \\
& $\mathrm{~s}^{2}=$ & 0,0220 \\
\hline
\end{tabular}

Calculado o erro, procede-se à sua comparação com os efeitos calculados para cada variável sobre as respostas de absorção, realizada na Tabela 3.9, de acordo com Box; Hunter; Hunter (1978).

Tabela 3.9 - Estudo de significância das variáveis dos ensaios da Msub x t para esferas de vidro para respostas de absorção.

\begin{tabular}{|c|c|c|c|}
\hline Absorção (\%) & Efeito & & padrão \\
\hline média & 0,023 & +- & 0,011 \\
\hline \multicolumn{4}{|c|}{ EFEITOS PRINCIPAIS } \\
\hline efeito massa & 0,027 & +- & 0,022 \\
\hline efeito vácuo & $-0,090$ & +- & 0,022 \\
\hline efeito ciclos vácuo & 0,003 & +- & 0,022 \\
\hline \multicolumn{4}{|c|}{ INTERAÇÕES DOIS FATORES } \\
\hline efeito $\mathrm{m} \times \mathrm{v}$ & 0,070 & +- & 0,022 \\
\hline efeito $\mathrm{m} \mathrm{x} \mathrm{cv}$ & 0,003 & +- & 0,022 \\
\hline efeito $v \times c v$ & $-0,018$ & +- & 0,022 \\
\hline \multicolumn{4}{|c|}{ INTERAÇÃO TRÊS FATORES } \\
\hline efeito $\mathrm{m} \times \vee \times c v$ & 0,002 & +- & 0,022 \\
\hline
\end{tabular}

A Tabela 3.9 comprova as conclusões realizadas nas Figuras 3.6 e 3.7. Foram detectadas significâncias estatísticas para a variável vácuo e para a interação vácuo x massa. $\mathrm{O}$ efeito da a massa aproximou-se do erro calculado, permanecendo a dúvida quanto à sua influência isolada sobre as respostas. Todas estas três conclusões estatísticas deveram-se ao fato de que as respostas obtidas com altas massas foram muito próximas, independentemente do vácuo aplicado, ao passo que baixas massas apresentaram resultados muito dispersos em função da alteração do vácuo. A variável ciclos de vácuo não apresentou significância.

O cálculo do cheque de curvatura do modelo apontou que não há curvatura, de modo que as respostas reagem linearmente a modificações lineares das variáveis.

Sendo este capítulo apenas exploratório para a verificação da validade do método, não se realizou a configuração do passo ascendente, pois o objetivo proposto por ora - a validação do novo método para caracterização de agregados, com breve estudo das variáveis que poderiam dificultar esta caracterização - foi atingido. 


\subsubsection{Conclusões dOS ENSAIOS DA $M_{\text {SUB }} \times T$}

Com os dados dos agregados de vidro para o método da $\mathrm{M}_{\text {sub }} \mathrm{x} \mathrm{t}$, concluiu-se:

1) o método funciona e está controlado. Os resultados obtidos aproximaram-se dos valores previstos na bibliografia do vidro, com erro experimental pequeno;

2) as variáveis vácuo e interação massa $\mathrm{x}$ vácuo apresentaram significância sobre as respostas obtidas, e a massa ficou próxima de ser significante. Todas estas significâncias explicam-se pelo fato de que as respostas obtidas com altas massas foram muito próximas, independentemente do vácuo aplicado, ao passo que baixas massas apresentaram resultados muito dispersos em função da alteração do vácuo;

3) não houve significância da variável ciclos de vácuo aplicados.

\subsection{SECAGEM}

O método de secagem acompanhada no tempo tem sido objeto de estudo de alguns pesquisadores, como Dias; Agopyan (2005) e Kropp (2005) para caracterização de agregados

reciclados. É um método de grande potencial para sanar um dos erros levantados da aplicação da NM 53 sobre os agregados porosos, pois não há manuseio da amostra como na secagem por pano da NM 53 (LEITE, 2000; CARRIJO, 2005), o que pode diminuir a perda de massa do material e a subjetividade da determinação do ponto de $\mathrm{M}_{\mathrm{sss}}$ (inspeção visual). Este item, portanto, estuda os efeitos de algumas variáveis deste método na caracterização das propriedades físicas dos agregados de vidro.

\subsubsection{Planejamento eXPERIMENTAL, MATERIAIS E MÉtodos}

As variáveis consideradas nos ensaios de secagem foram quatro, sendo a primeira a massa, variada entre $1 \mathrm{~kg}$ (ponto -1 ), $2,75 \mathrm{~kg}$ (ponto central) e $4,5 \mathrm{~kg}$ (ponto +1 ) em alguns casos, e entre $1 \mathrm{~kg}$ (ponto -1), 1,5kg (ponto central) e $2 \mathrm{~kg}$ (ponto +1 ) em outros.

A altura da camada de agregado foi a segunda variável, pois a secagem não é homogênea. Agregados dispostos nas partes inferiores do recipiente secam posteriormente aos superiores, pois a água posiciona-se no fundo do recipiente e os agregados superiores funcionam como obstáculo à evaporação da água que vem de baixo. A altura da camada de agregados foi variada em: a) espessura baixa (ponto -1) - agregados dispostos ocupando maior área para evitar que se sobreponham; b) espessura alta (ponto +1) - área menor, mesmo que se sobreponham; e c) espessura média (ponto central) - meio termo entre as anteriores. 
A terceira variável é a temperatura de secagem, pois seu aumento pode acelerar os ensaios mas também aumentar a pressão da água sobre os poros capilares dos agregados, causando micro-rupturas e maior destruição das amostras. Temperaturas baixas, por outro lado, podem tornar os ensaios longos e aumentar a heterogeneidade de secagem entre agregados de camadas inferiores e superiores. A temperatura de secagem também influencia diretamente o ponto de umidade de equilíbrio dos agregados para dada umidade relativa do ar, uma vez que, para cada material e para cada temperatura distintos, há curvas isotermas que relacionam diretamente a umidade relativa do ar às umidades livre e de equilíbrio daquele material (McCABE et al, 1987).

Houve mais uma variável estudada: a origem da energia (ou o equipamento) de secagem. A secagem dos agregados foi realizada com: 1) estufa; 2) lâmpadas infravermelho; ou 3) forno de microondas, pois Naik; Ramme (1987) comprovaram que, para determinação da relação a/c de misturas de concretos e argamassas em estado fresco através de secagem, este aparelho é útil, podendo disponibilizar dados precisos em ensaios realizados no intervalo de 15 a 30 minutos.

No microondas, a temperatura de secagem foi controlada indiretamente pela potência, com menores temperaturas quando da utilização de baixas potências e maiores temperaturas resultantes do uso de altas potências.

Os planejamentos fatoriais foram realizados separadamente para cada método de secagem, pois esta variável é a única deste método não quantitativa, mas sim qualitativa.

A Tabela 3.10 apresenta as variáveis utilizadas, com seus valores reais e sua codificação em pontos -1 (menor), 0 (central) e +1 (maior).

Tabela 3.10 - Codificação das variáveis utilizadas para o método secagem - esferas de vidro.

\begin{tabular}{|c|c|c|c|c|c|}
\hline \multicolumn{2}{|c|}{ VARIAVEIS SECAGEM ESTUFA } & \multicolumn{2}{|c|}{ VARIAVEIS SECAGEM INFRAVERMELHO } & \multicolumn{2}{|c|}{ VARIAVEIS SECAGEM MICROONDAS } \\
\hline VALOR CODIFICADO & VALOR ORIGINAL & VALOR CODIFICADO & VALOR ORIGINAL & VALOR CODIFICADO & VALOR ORIGINAL \\
\hline VARIÁVEL MASSA & & VARIÁVEL MASSA & & VARIÁVEL MASSA & \\
\hline - & $1 \mathrm{~kg}$ & - & $1 \mathrm{~kg}$ & - & $1 \mathrm{~kg}$ \\
\hline 0 & $2,75 \mathrm{~kg}$ & 0 & $2,75 \mathrm{~kg}$ & 0 & $1,5 \mathrm{~kg}$ \\
\hline+ & $4,5 \mathrm{~kg}$ & + & $4,5 \mathrm{~kg}$ & + & $2 \mathrm{~kg}$ \\
\hline \multicolumn{2}{|c|}{ VARIÁVEL TEMPERATURA } & \multicolumn{2}{|c|}{ VARIÁVELL H AGREGADO } & \multicolumn{2}{|l|}{ VARIÁVEL POTÊNCIA } \\
\hline - & $110^{\circ} \mathrm{C}$ & - & h baixa & - & 2 (baixa) \\
\hline 0 & $125^{\circ} \mathrm{C}$ & 0 & h média & 0 & 5 (média) \\
\hline+ & $140^{\circ} \mathrm{C}$ & + & $\mathrm{h}$ alta & + & 8 (alta) \\
\hline
\end{tabular}

As Tabelas 3.11, 3.12 e 3.13 apresentam os planejamentos experimentais fatoriais completos $2^{2}$ utilizados para o método da secagem, respectivamente, em estufa, infravermelho e microondas, segundo o modelo de Box; Hunter; Hunter (1978). 
Tabela 3.11 - Planejamento fatorial $2^{2}$ dos ensaios para secagem em estufa - esferas de vidro.

\begin{tabular}{|c|c|c|}
\hline \multicolumn{3}{|l|}{ VARIÁVEIS CODIFICADAS } \\
\hline ENSAIO & MASSA & TEMP. $\left({ }^{\circ} \mathrm{C}\right)$ \\
\hline 1.3 .1 .1 & - & - \\
\hline 1.3 .1 .2 & + & - \\
\hline 1.3 .1 .3 & - & + \\
\hline 1.3 .1 .4 & + & + \\
\hline 1.3 .1 .5$. & 0 & 0 \\
\hline 1.3 .1 .6$. & 0 & 0 \\
\hline 1.3 .1 .7$. & 0 & 0 \\
\hline
\end{tabular}

Tabela 3.12 - Planejamento fatorial $2^{2}$ dos ensaios para secagem com infravermelho - esferas de vidro.

\begin{tabular}{|}
\hline VARIÁVEIS CODIFICADAS \\
\hline ENSAIO & MASSA & H AGREGADO \\
\hline 1.3 .2 .1 & - & - \\
\hline 1.3 .2 .2 & + & - \\
\hline 1.3 .2 .3 & - & + \\
\hline 1.3 .2 .4 & + & + \\
\hline 1.3 .2 .5$. & 0 & 0 \\
\hline 1.3 .2 .6$. & 0 & 0 \\
\hline 1.3 .2 .7$. & 0 & 0 \\
\hline
\end{tabular}

Tabela 3.13 - Planejamento fatorial $2^{2}$ dos ensaios para secagem em microondas - esferas de vidro.

\begin{tabular}{|c|c|c|}
\hline \multicolumn{3}{|c|}{ VARIÁVEIS CODIFICADAS } \\
\hline ENSAIO & MASSA & POTÉNCIA \\
\hline 1.3 .3 .1 & - & - \\
\hline 1.3 .3 .2 & + & - \\
\hline 1.3 .3 .3 & - & + \\
\hline 1.3 .3 .4 & + & + \\
\hline 1.3 .3 .5$. & 0 & 0 \\
\hline 1.3 .3 .6$. & 0 & 0 \\
\hline 1.3 .3 .7$. & 0 & 0 \\
\hline
\end{tabular}

\subsubsection{Materiais}

Os materiais utilizados são esferas de vidro, apresentadas no item 3.1.1.1.

\subsubsection{Equipamentos}

Para os ensaios de secagem, serão utilizados os seguintes equipamentos:

$\Rightarrow$ Estufa para secagem, marca FANEM, modelo 320-SE (figura 5.2);

$\Rightarrow$ Forno de microondas, marca Panasonic, modelo NN S-65, 35 litros, 1000W, 110V;

$\Rightarrow$ Duas lâmpadas de infravermelho marca GE, 250W, 220V;

$\Rightarrow$ Balança digital Mettler Toledo PB 8001-S, capacidade $8.100 \mathrm{~g}$ e precisão de $0,1 \mathrm{~g}$;

$\Rightarrow$ Recipientes metálicos para estocagem, secagem e saturação dos agregados;

$\Rightarrow$ Microcomputador terminal para aquisição de dados de massa da balança Mettler;

$\Rightarrow$ Software WinWedge32, especializado em captação de dados de periféricos.

\subsubsection{Descrição dos procedimentos de ensaio e cálculos}

O fluxograma apresentado na Figura 3.8 resume os procedimentos laboratoriais utilizados no desenvolvimento dos ensaios de secagem. 


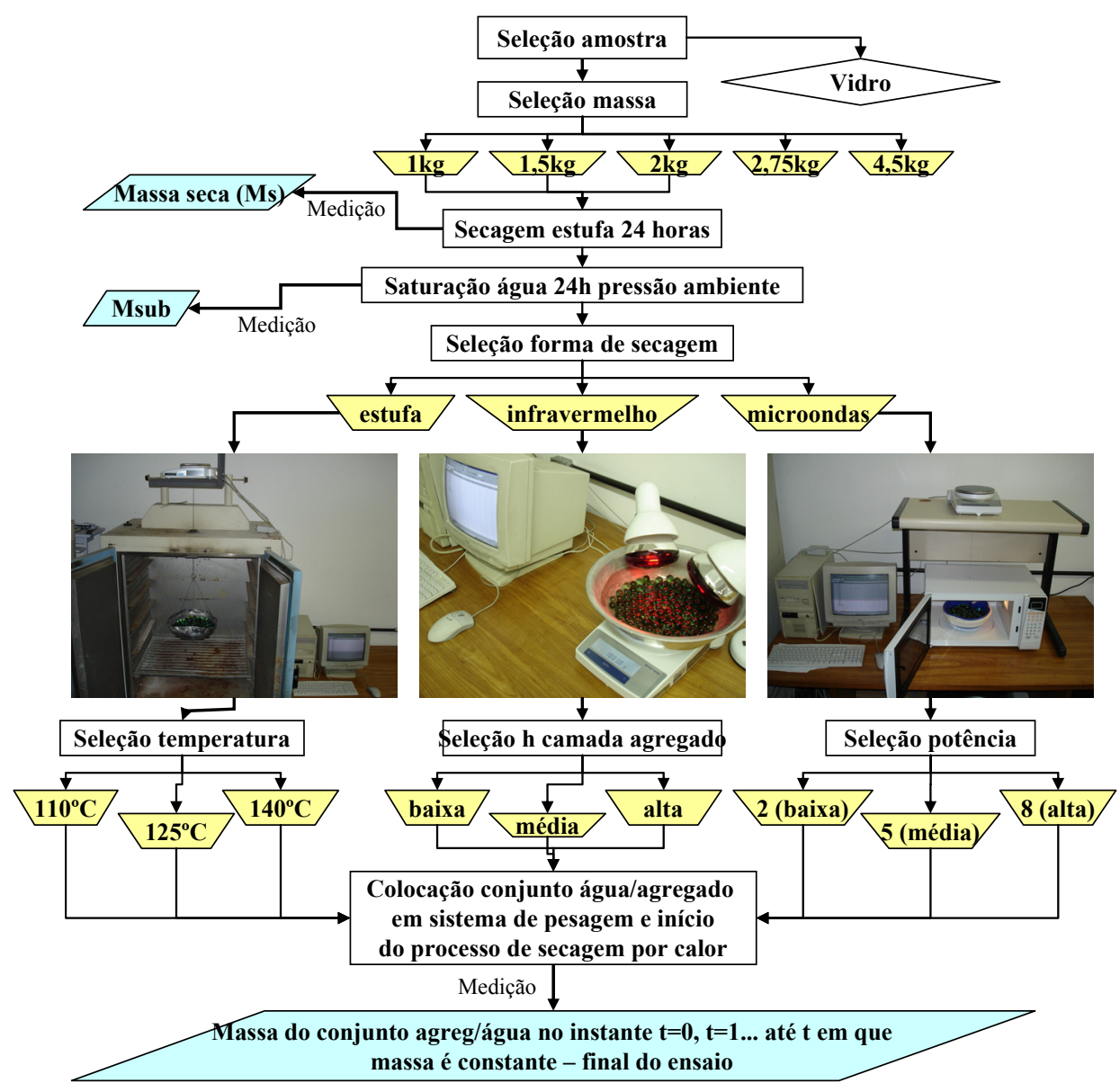

Figura 3.8 - Fluxograma dos ensaios do método da secagem ao longo do tempo.

A colocação do conjunto agregado/água para secagem (início do ensaio) é feita com água em excesso cobrindo os agregados, até atingir temperatura constante. Chegada esta temperatura, é retirada a água em excesso, de forma que as partículas estão úmidas, antes do ponto de $\mathrm{M}_{\mathrm{sss}}$. Deixa-se aproximadamente 6\% de água quente (em relação à massa seca dos agregados) para configurar um período de secagem constante, necessário à determinação da absorção, e a secagem continua. Este procedimento visa homogeneizar ao máximo a secagem dos agregados, pois agregados das camadas inferiores secam mais lentamente do que os superiores por ficarem em contato com água por mais tempo.

Com os dados coletados, formula-se uma tabela contendo 4 colunas: 1) tempo t (período de leitura); 2) massa medida neste tempo t; 3 ) teor de umidade relativo a este tempo t; e 4) taxa de secagem relativa ao tempo t, lembrando que:

$$
\begin{aligned}
& \text { TeorUmidade }(t)(\%)=\frac{M_{\text {conj.agreg } / \text { agua }(t)}-M_{s}}{M_{\mathrm{sec} a}} \times 100 \\
& \operatorname{TaxaSecagem}(t)(\mathrm{g} / \mathrm{min})=\frac{\left[M_{\text {conj.agreg } / \text { água }(t-1)}\right]-\left[M_{\text {conj.agreg } / \text { água }(t)}\right]}{(t)-(t-1)}
\end{aligned}
$$


Realiza-se gráfico do teor de umidade $\mathrm{x}$ taxa de secagem do agregado durante os tempos $\mathrm{t}$ do ensaio. Identificadas as fases de secagem, é feito cálculo por regressão linear do ponto de intersecção entre as fases de secagem 1 (constante) e 2 (decrescente linear), o qual indica exatamente a absorção do agregado medida pelo ensaio.

Com o valor de absorção determinado, volta-se aos dados de massa coletados nos instantes $\mathrm{t}=1$ até $\mathrm{t}=\infty$ e verifica-se, no instante $(\mathrm{t})$ em que esta absorção ocorreu, a massa do conjunto agregado/água correspondente. Esta é a $\mathrm{M}_{\text {sss. }}$.

Pode-se enfim calcular as propriedades físicas de absorção. MEA e MER:

$$
\begin{aligned}
& A(\%)=\frac{M_{s s s}-M_{\sec a}}{M_{\sec a}} \times 100 \\
& M E A=\frac{M_{\sec a}}{M_{s s s}-M_{s u b}} \\
& M E R=\frac{M_{\sec a}}{M_{\sec a}-M_{s u b}}
\end{aligned}
$$

\subsubsection{RESULTADOS E ANÁLISE DOS RESULTADOS}

Os intervalos de tempo para coleta de dados variaram entre os meios secantes, já que os diferentes meios secantes apresentam princípios e taxas de secagem distintas.

\subsubsection{Resultados - estufa}

Para os ensaios de secagem das esferas de vidro em estufa o intervalo de coleta dos dados foi de 1 minuto. Os gráficos resultantes estão nas Figuras 3.9 a 3.11. Os dados utilizados para a confecção dos gráficos e para os cálculos dos resultados estão no apêndice C.
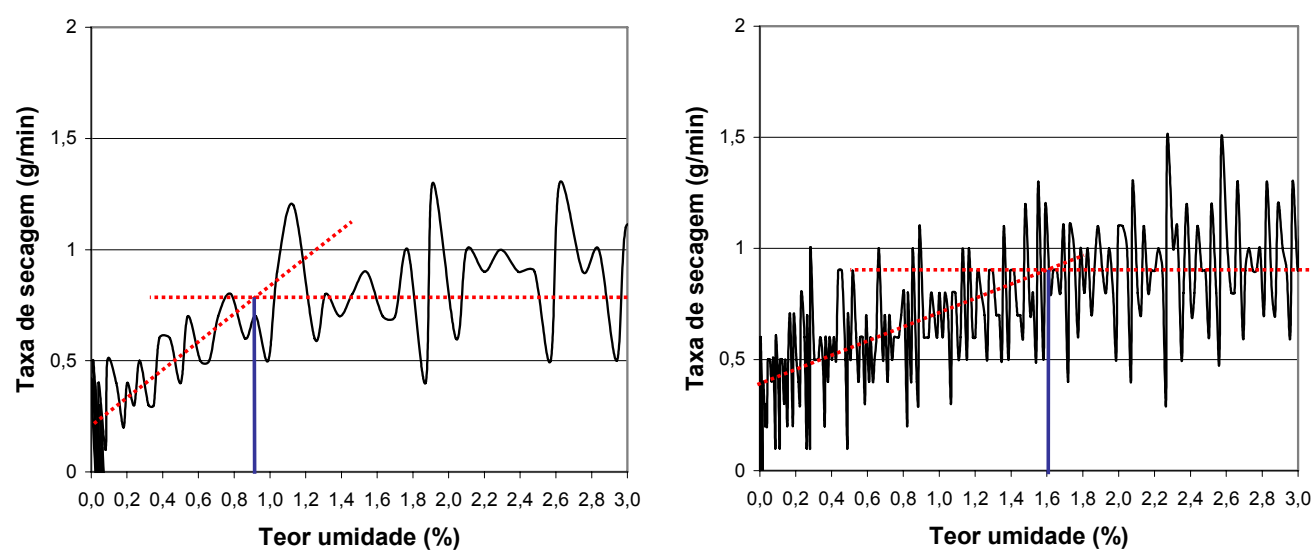

Figura 3.9 - Secagem de esferas de vidro em estufa, amostra de: a) $1 \mathrm{~kg}$, temperat. $110^{\circ} \mathrm{C}(--)$; b) $4,5 \mathrm{~kg}$, temperat. $110^{\circ} \mathrm{C}(+-)$. 

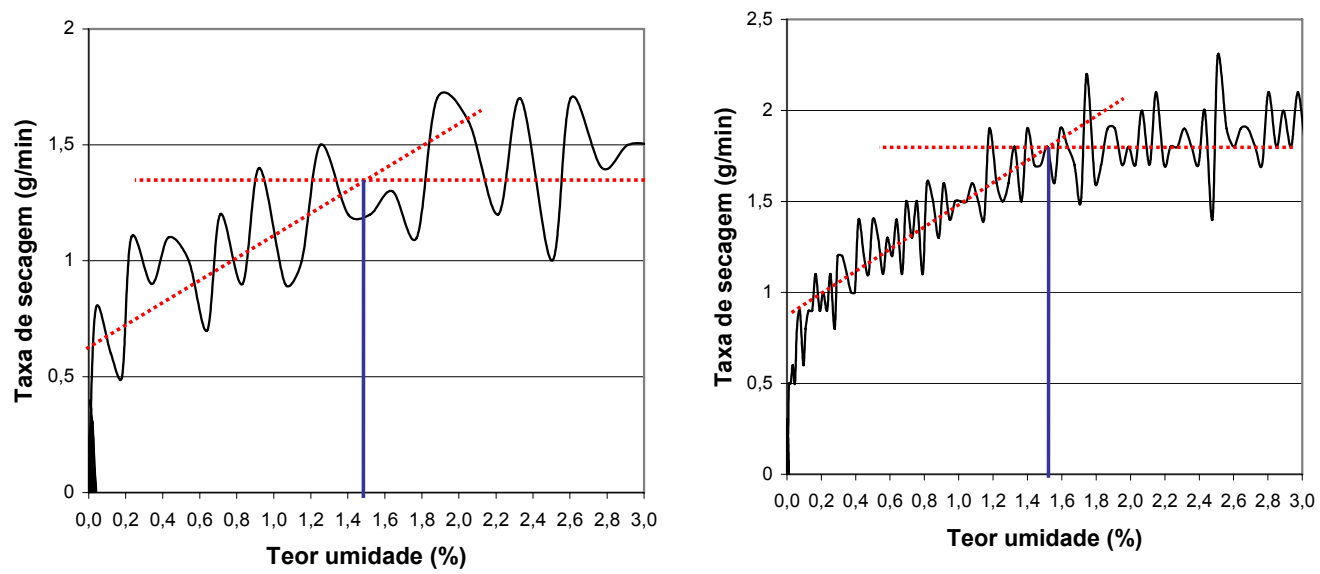

Figura 3.10 - Secagem de esferas de vidro em estufa, amostra de: a) $1 \mathrm{~kg}$, temperatura de $140^{\circ} \mathrm{C}(-+)$; b) $4,5 \mathrm{~kg}$, temperatura de $140^{\circ} \mathrm{C}(++)$.
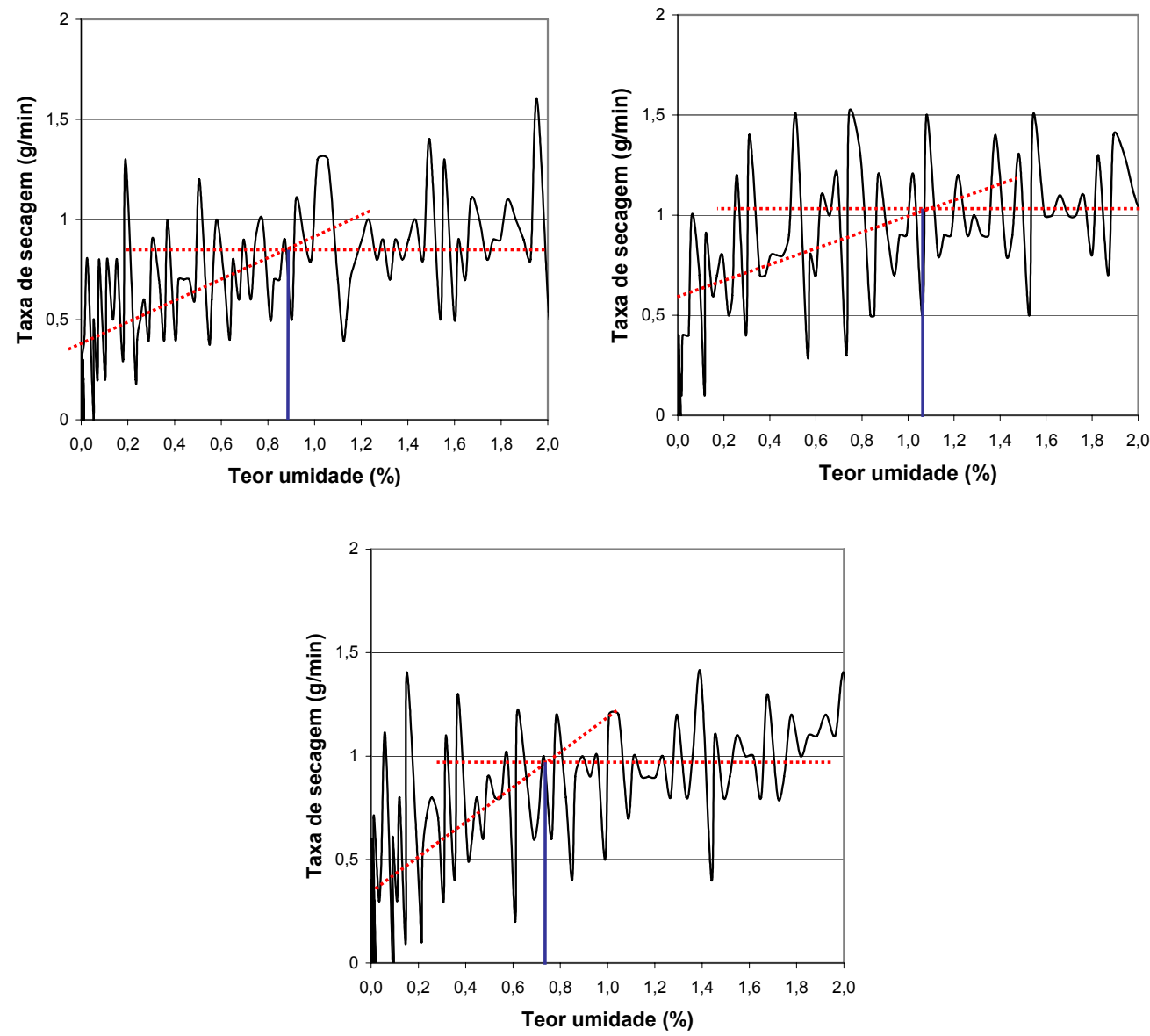

Figura 3.11 - Secagem de esferas de vidro em estufa, amostra $2,75 \mathrm{~kg}$ e temperatura $125^{\circ} \mathrm{C}$ (ponto central): a) repetição 1 ; b) repetição 2; e c) repetição 3 .

Os resultados são apresentados na Tabela 3.14. 
Tabela 3.14 - Resultados dos ensaios do planejamento do método de secagem em estufa - esferas de vidro.

\begin{tabular}{|c|c|c|c|c|c|c|}
\hline \multirow[b]{2}{*}{ ENSAO } & \multicolumn{2}{|c|}{ VARIÁVEIS } & \multirow{2}{*}{$\begin{array}{c}\text { INTERAÇÃO } \\
M \times T\end{array}$} & \multicolumn{3}{|c|}{ RESPOSTAS } \\
\hline & MASSA & TEMPERATURA & & ABS $(\%)$ & MER $\left(\mathrm{kg} / \mathrm{dm}^{3}\right)$ & MEA $\left(\mathrm{kg} / \mathrm{dm}^{3}\right)$ \\
\hline $\begin{array}{l}1.3 .1 .1 \\
\end{array}$ & - & - & + & 0,90 & 2,51 & 2,46 \\
\hline 1.3.1.2 & + & - & - & 1,60 & 2,51 & 2,42 \\
\hline 1.3.1.3 & - & + & - & 1,45 & 2,51 & 2,42 \\
\hline 1.3 .1 .4 & + & + & + & 1,50 & 2,51 & 2,42 \\
\hline 1.3.1.5. & 0 & 0 & não há & 0,87 & 2,52 & 2,46 \\
\hline 1.3.1.6. & 0 & 0 & não há & 1,05 & 2,51 & 2,45 \\
\hline 1.3.1.7. & 0 & 0 & não há & 0,73 & 2,51 & 2,47 \\
\hline
\end{tabular}

\subsubsection{Análise dos resultados - estufa}

As Figuras 3.9 a 3.11 (secagem em estufa) apresentaram grande variabilidade, com amplitude das curvas em relação ao eixo da taxa de secagem de até $1,5 \mathrm{~g} / \mathrm{min}$ de um tempo $\mathrm{t}$ em relação ao tempo $t$ subseqüente $(t+1)$. Esta amplitude tornou imprecisa a medição da absorção, pois as taxas de secagem foram baixas, da ordem de 0,5 a $2 \mathrm{~g} / \mathrm{min}$. Percebe-se que a amplitude de variabilidade (erro) chegou a valores da mesma ordem de grandeza das taxas de secagem, o que fez com que o ponto de mudança de regime de secagem se confundisse com o erro experimental de flutuação da amplitude da taxa de secagem, em todos os ensaios. As respostas, portanto, tiveram pouca confiabilidade, sendo duvidosas quanto à sua precisão.

Os tempos de execução dos ensaios de secagem em estufa também foram longos, entre 6 e 11 horas de secagem. Sendo este método impreciso e demorado, não se aplica ao objetivo deste trabalho, que leva em conta a rapidez e precisão do ensaio. A secagem em estufa não será estudada sobre os agregados reciclados.

\subsubsection{Resultados - infravermelho}

Nos ensaios de secagem das esferas de vidro em infravermelho, o intervalo de coleta dos dados foi 5 minutos. Os gráficos resultantes estão nas Figuras 3.12 a 3.14. Os dados utilizados para confecção dos gráficos e para os cálculos dos resultados estão no apêndice D.
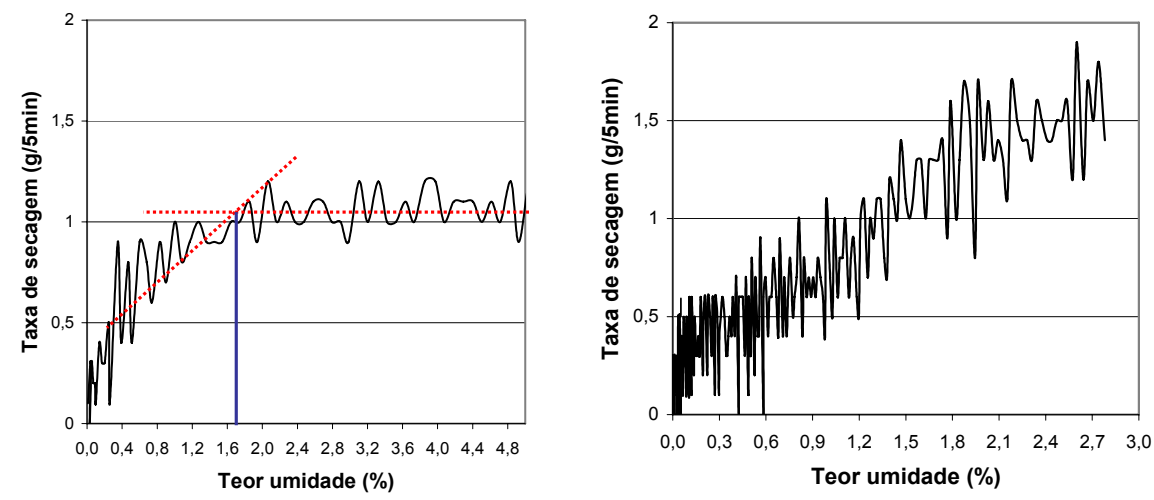

Figura 3.12 - Secagem de esferas de vidro em infravermelho, amostra de: a) $1 \mathrm{~kg}$ e altura da camada de agregado baixa (- -); b) $4,5 \mathrm{~kg}$ e altura da camada de agregado baixa (+-). 

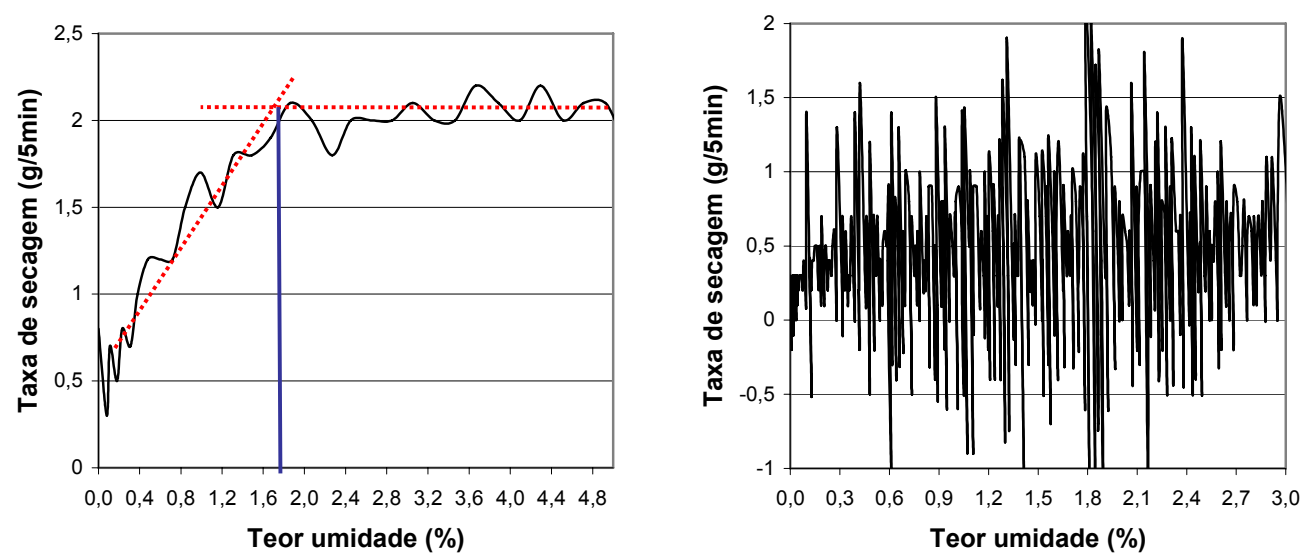

Figura 3.13 - Secagem de esferas de vidro em infravermelho, amostra de: a) $1 \mathrm{~kg}$ e altura da camada de agregado alta (-+); b) $4,5 \mathrm{~kg}$ e altura da camada de agregado alta $(++)$.
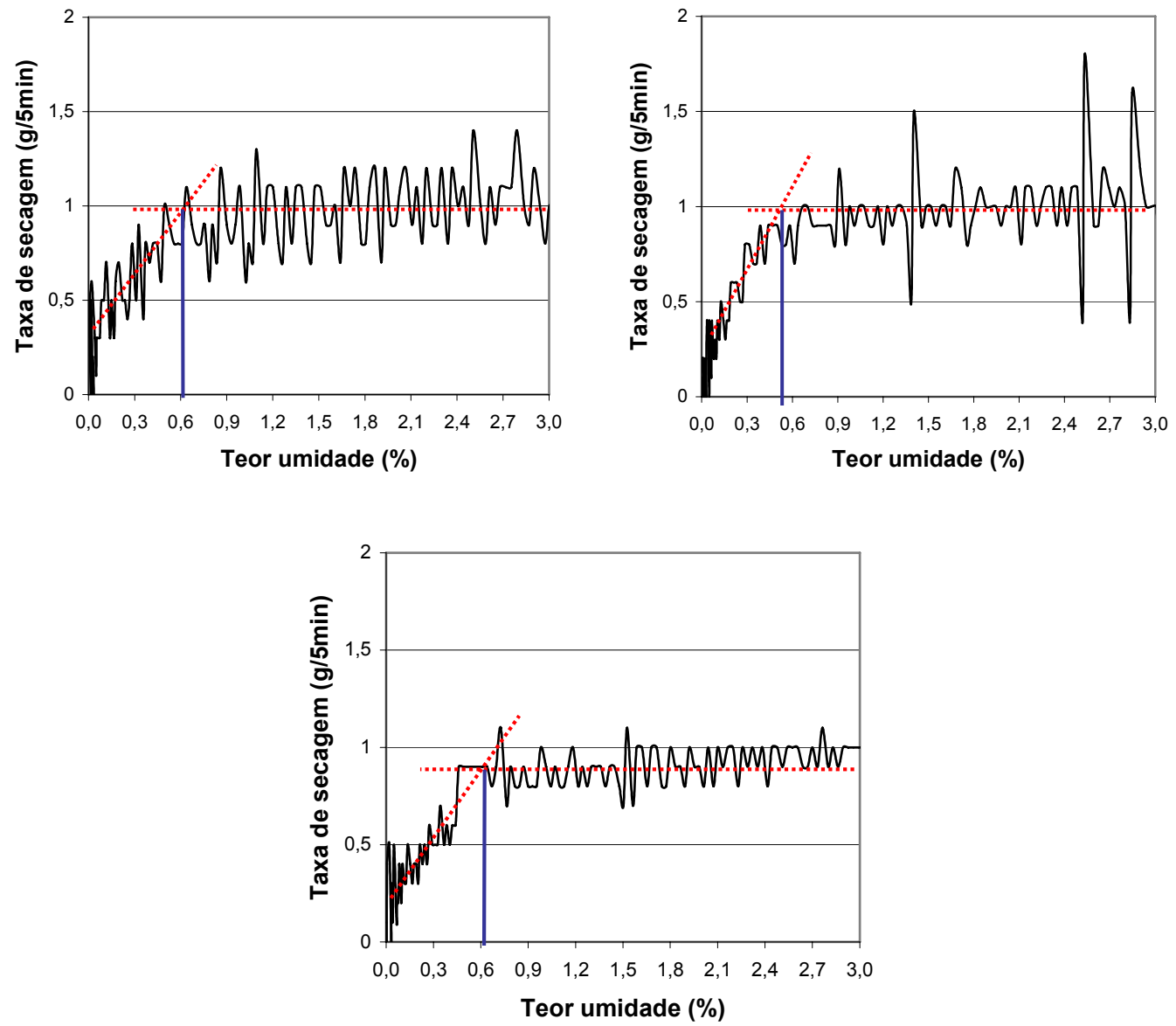

Figura 3.14 - Secagem de esferas de vidro em infravermelho, amostra de 2,75kg e altura da camada de agregado média (ponto central): a) repetição 1 ; b) repetição 2 ; e c) repetição 3 .

Os resultados são apresentados na Tabela 3.15. 
Tabela 3.15 - Resultados dos ensaios do método secagem em infravermelho - esferas de vidro

\begin{tabular}{|c|c|c|c|c|c|c|}
\cline { 2 - 7 } \multicolumn{2}{c|}{} & \multicolumn{2}{l|}{ VARIÁVEIS } & INTERAÇÃO & \multicolumn{3}{c|}{ RESPOSTAS } \\
\hline ENSAO & MASSA & H AGREG & M x H AGR & ABS $(\%)$ & MER $\left(\mathbf{k g} / \mathbf{d m}^{3}\right)$ & MEA $\left(\mathbf{k g} / \mathbf{d m}^{3}\right)$ \\
\hline 1.3 .2 .1 & - & - & + & 1,70 & 2,52 & 2,41 \\
\hline 1.3 .2 .2 & + & - & - & imensurável & 2,51 & imensurável \\
\hline 1.3 .2 .3 & - & + & - & 1,75 & 2,51 & 2,41 \\
\hline 1.3 .2 .4 & + & + & + & imensurável & 2,51 & imensurável \\
\hline 1.3 .2 .5$. & 0 & 0 & não há & 0,60 & 2,52 & 2,48 \\
\hline 1.3 .2 .6$. & $\mathrm{O}$ & $\mathrm{O}$ & não há & 0,51 & 2,52 & 2,49 \\
\hline 1.3 .2 .7$. & $\mathrm{O}$ & $\mathrm{O}$ & não há & 0,60 & 2,52 & 2,48 \\
\hline
\end{tabular}

\subsubsection{Análise dos resultados - infravermelho}

Os ensaios de secagem com utilização de lâmpadas de infravermelho apresentaram altos tempos de execução, entre 18 e 30 horas de secagem. Os ensaios com grandes massas apresentaram impossibilidade de mensuração da absorção, devido aos gráficos apresentarem instabilidade da taxa de secagem. Assim, este método também não se adequou ao objetivo deste trabalho, que busca rapidez e precisão na determinação das propriedades dos agregados estudados, e não será mais utilizado.

\subsubsection{Resultados - microondas}

Nos ensaios de secagem das esferas de vidro em microondas o intervalo de coleta dos dados foi 20 segundos. Os gráficos resultantes estão nas Figuras 3.15 a 3.17. Os dados utilizados para confecção dos gráficos e para os cálculos dos resultados estão no apêndice E.
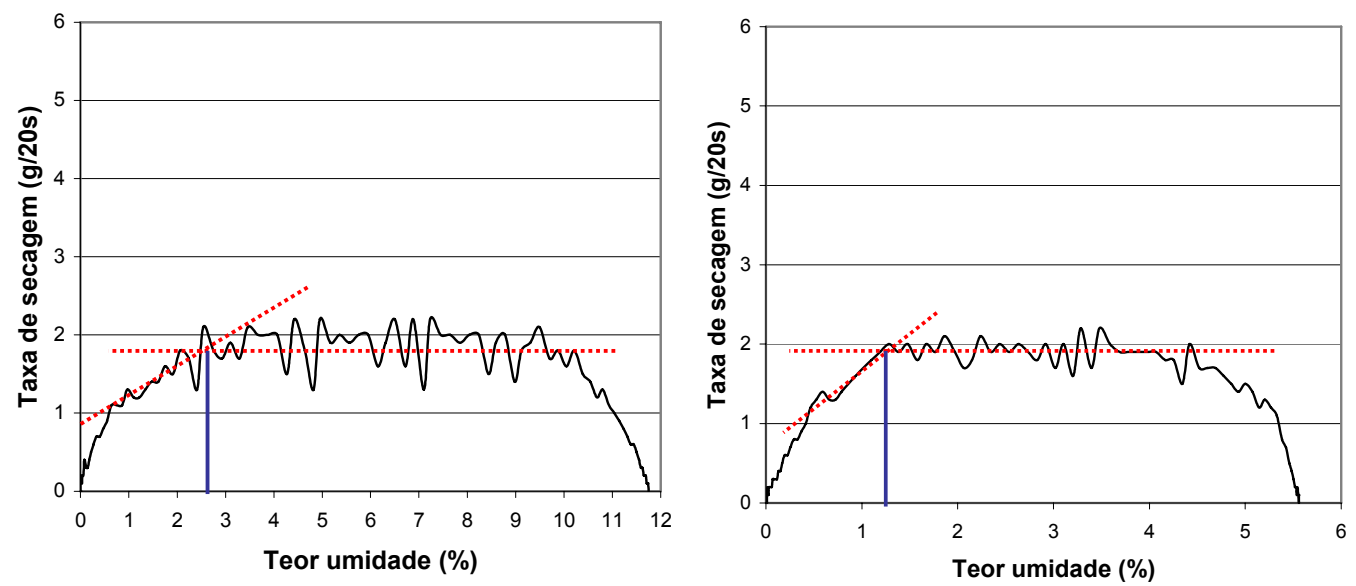

Figura 3.15 - Secagem de esferas de vidro em microondas, amostra de massa: a) 1kg, potência 2 (--); b) 2kg, potência 2 (+-). 

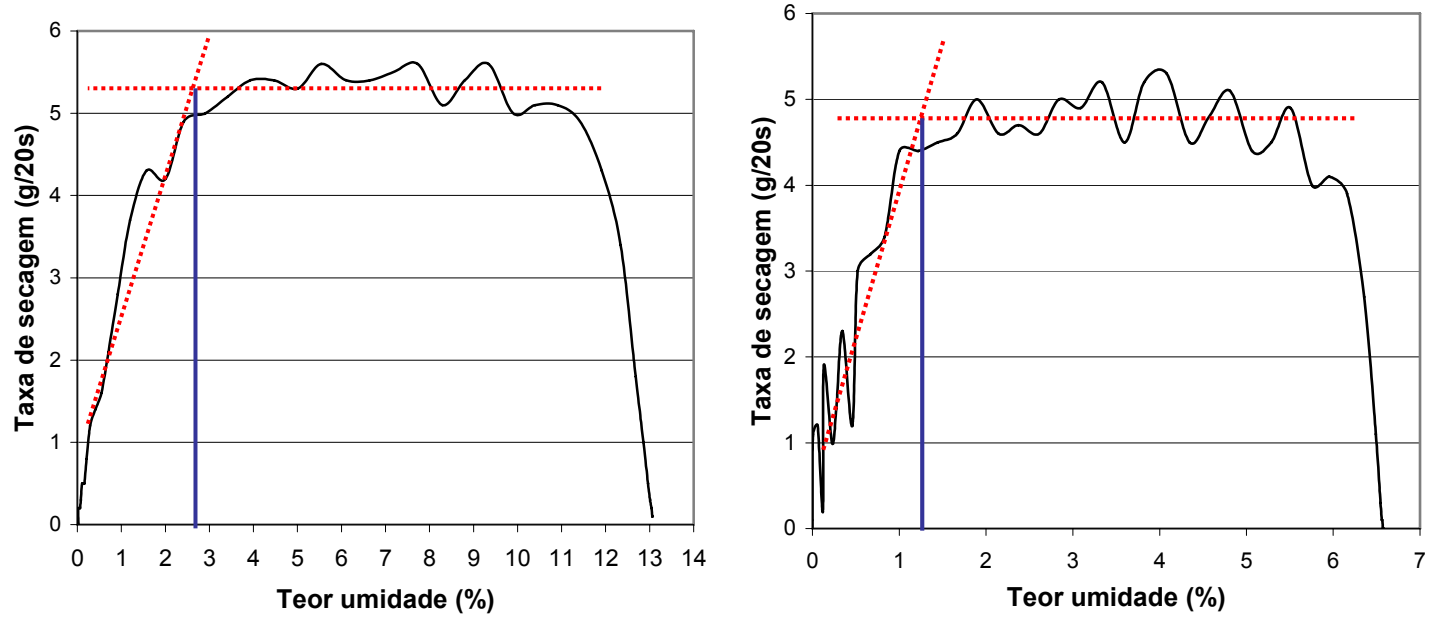

Figura 3.16 - Secagem de esferas de vidro em microondas, amostra de massa: a) $1 \mathrm{~kg}$, potência $8(-+)$; b) $2 \mathrm{~kg}$, potência 8 $(++)$.
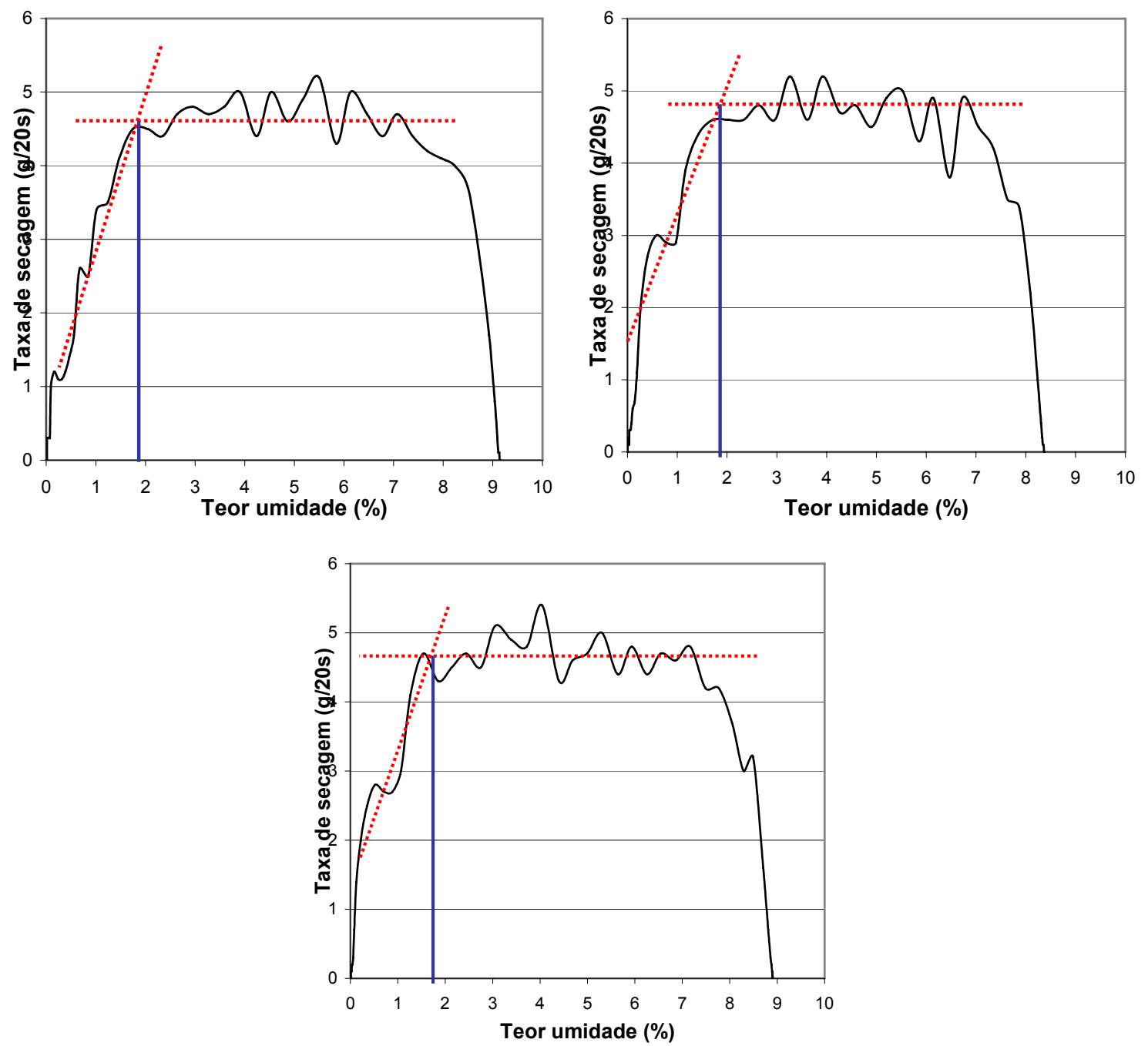

Figura 3.17 - Secagem de esferas de vidro em microondas, amostra de massa 1,5kg e potência 5 (ponto central): a) repetição 1 ; b) repetição 2 ; e c) repetição 3 . 
Os resultados são apresentados na Tabela 3.16.

Tabela 3.16 - Resultados dos ensaios do método secagem em microondas - esferas de vidro

\begin{tabular}{|c|c|c|c|c|c|c|}
\cline { 2 - 7 } \multicolumn{1}{c|}{} & \multicolumn{2}{c|}{ VARIÁVEIS } & INTERAÇÃO & \multicolumn{3}{c|}{ RESPOSTAS } \\
\hline ENSAIO & MASSA & POTÊNCIA & $\mathbf{M} \times \mathbf{P}$ & ABS $(\%)$ & MER $\left(\mathbf{k g} / \mathbf{d m}^{3}\right)$ & MEA $\left(\mathbf{k g} / \mathbf{d m}^{3}\right)$ \\
\hline 1.3 .3 .1 & - & - & + & 2,60 & 2,51 & 2,35 \\
\hline 1.3 .3 .2 & + & - & - & 1,25 & 2,51 & 2,43 \\
\hline 1.3 .3 .3 & - & + & - & 2,65 & 2,51 & 2,36 \\
\hline 1.3 .3 .4 & + & + & + & 1,25 & 2,51 & 2,43 \\
\hline 1.3 .3 .5$. & 0 & 0 & não há & 1,85 & 2,51 & 2,40 \\
\hline 1.3 .3 .6$. & 0 & 0 & não há & 1,85 & 2,51 & 2,40 \\
\hline 1.3 .3 .7$. & 0 & O & não há & 1,75 & 2,51 & 2,40 \\
\hline
\end{tabular}

\subsubsection{Análise dos resultados - microondas}

A análise dos resultados dos ensaios de secagem de esferas de vidro em microondas aponta a possibilidade de obtenção de respostas em tempo reduzido em relação à estufa e ao infravermelho. Os ensaios, em geral, tiveram duração de 20 a 40 minutos, atingindo taxas de secagem da ordem de 2 a 5 gramas a cada 20 segundos, de modo que o intervalo de tempo para as medições foi padronizado em 20 segundos.

Observando-se os gráficos de secagem em microondas (Figuras 3.15 a 3.17), nota-se que os ensaios apresentaram bom controle, pois as amplitudes de oscilação das taxas de secagem foram pequenas em relação à magnitude dos valores das taxas de secagem, o que diminuiu o erro experimental e aumentou a precisão das respostas.

Constatou-se decréscimo da taxa de secagem após certo período de andamento do ensaio, em desacordo com a teoria de secagem, pois a taxa deveria ser constante durante todo o ensaio para agregados de porosidade desprezível (vidro). Assim, conforme a Tabela 3.16, as respostas da secagem em microondas atingiram valores superiores à bibliografia $-0 \%$ de absorção para o vidro. Esta diferença (absorção medida para a real) configura um erro experimental que tem origem no mecanismo de secagem de sólidos de baixa porosidade (McCABE, 1987), pois ao final da secagem a água passa a encontrar maior dificuldade para se desprender devido aos caminhos formados por entre os corpos, os quais configuram obstáculos à sua evaporação. Isto pode gerar diminuição da taxa de secagem (não se mantém necessariamente constante durante a secagem). Este erro pode ser mensurado pela diferença entre as respostas obtidas e as reais (as que deveriam ter sido atingidas - 0\%), ou a diferença entre a $M_{s s s}$ e $M_{s}$, pois estas devem ser iguais para que a absorção seja $0 \%$. A Tabela 3.17 demonstra que o erro é sistemático, sendo uma quantidade fixa de água que encontra maior dificuldade para ser evaporada ao final do ensaio. Os valores do erro foram, em média, $26,34 \mathrm{~g}$, e todos os ensaios resultaram em erros $\left(\mathrm{M}_{\mathrm{sss}}-\mathrm{M}_{\mathrm{s}}\right)$ próximos. 
Tabela 3.17 - Cálculo do erro sistemático detectado para os ensaios de secagem de esferas de vidro em microondas.

\begin{tabular}{l}
\begin{tabular}{|c|c|c|c|}
\hline Ensaio & Msss & Ms & Erro (Msss-Ms) \\
\hline-- & 1025,9 & 999,9 & 26,0 \\
\hline+- & 2025,6 & 2000,5 & 25,1 \\
\hline-+ & 1026,5 & 1000 & 26,5 \\
\hline++ & 2024,9 & 1999,9 & 25,0 \\
\hline o o 1 & 1528,2 & 1500,5 & 27,7 \\
\hline o o 2 & 1528,2 & 1500,4 & 27,8 \\
\hline o o 3 & 1526,4 & 1500,1 & 26,3 \\
\hline
\end{tabular} Erro (Msss-Ms) médio, em massa (g) \\
\hline
\end{tabular}

O erro, sendo sistemático, assume proporções diferentes conforme a massa da amostra, e então a Figura 3.18(a) aponta a variável massa significante às respostas de absorção. A Figura 3.18(b) mostra que a potência não influenciou as respostas.
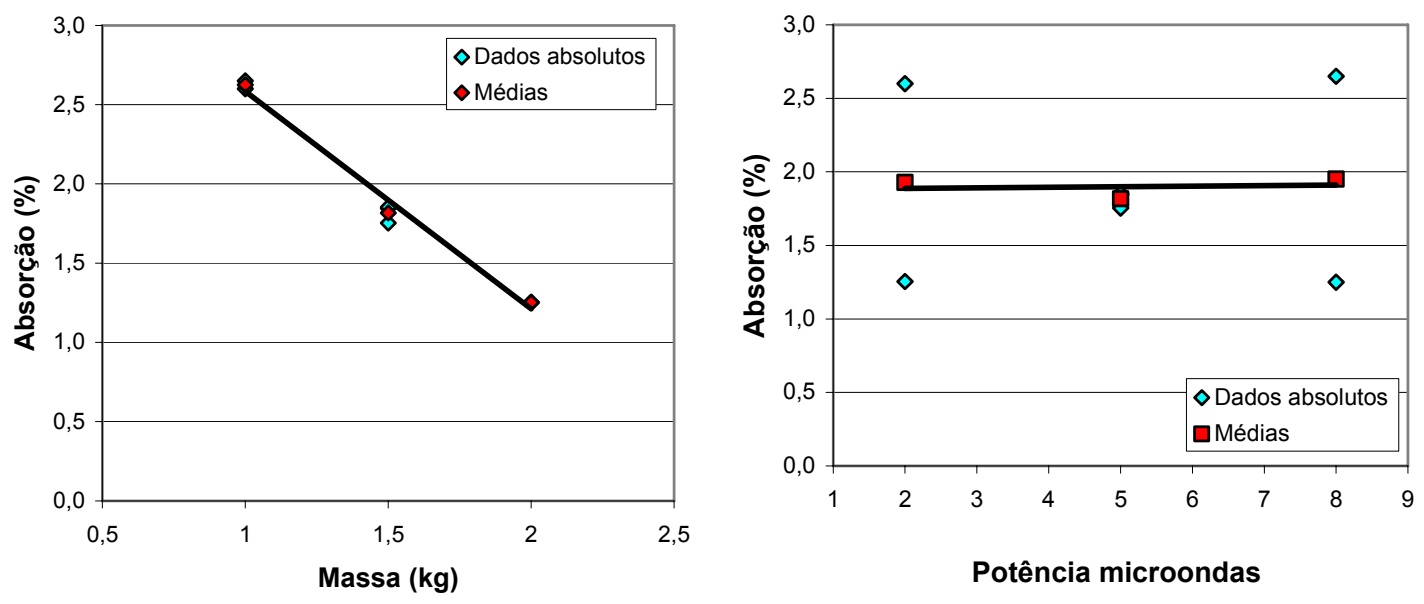

Figura 3.18 - Efeito das variáveis: a) massa; e b) potência do microondas, sobre as respostas de absorção.

Comprovando estas análises, numa análise de efeitos segundo Box; Hunter; Hunter (1978), o erro foi determinado na tabela 3.18, e a massa seria apontada como significante, conforme a Tabela 3.19 .

Tabela 3.18 - Determinação do erro experimental dos ensaios do método secagem em microondas - esferas de vidro.

\begin{tabular}{|c|c|c|}
\hline $\begin{array}{l}\text { Repetições } \\
\text { ponto central }\end{array}$ & Respostas & $\begin{array}{c}\text { Diferença para } \\
\text { a média (d) }\end{array}$ \\
\hline 1 & 1,85 & 0,029 \\
\hline 2 & 1,85 & 0,035 \\
\hline 3 & 1,75 & $-0,064$ \\
\hline \multicolumn{3}{|l|}{ Média } \\
\hline & $\sum d^{2}$ & 0,0062 \\
\hline & $\mathrm{s}^{2}=$ & 0,0021 \\
\hline & $\mathrm{s}=$ & 0,0454 \\
\hline
\end{tabular}

Tabela 3.19 - Estudo de significância das variáveis dos ensaios de secagem em microondas para esferas de vidro.

\begin{tabular}{|c|c|c|c|}
\hline Absorção (\%) & Efeito & & Erro padrão \\
\hline média & 1,939 & +- & 0,023 \\
\hline \multicolumn{4}{|c|}{ EFEITOS PRINCIPAIS } \\
\hline efeito massa & $-1,373$ & +- & 0,0454 \\
\hline efeito potência & 0,023 & +- & 0,0454 \\
\hline \multicolumn{4}{|c|}{ INTERAÇOES DOIS FATORES } \\
\hline efeito $\mathrm{m} \times \mathrm{T}$ & $-0,027$ & +- & 0,0454 \\
\hline
\end{tabular}


Porém, como analisado anteriormente, o efeito da massa deveu-se exclusivamente ao erro sistemático detectado na Tabela 3.17, igual para todos os ensaios e assumindo proporções diferentes para cada um em relação à massa de agregados, que foi variada.

A rapidez dos ensaios e a precisão dos gráficos obtidos fizeram com que o método fosse levado a estudo sobre os agregados de alta porosidade. A teoria de secagem não apresenta erros de variação da taxa de secagem quando da secagem de materiais porosos (McCabe, 1987), de forma que o erro aqui encontrado e discutido não influencia resultados obtidos sobre os agregados de alta porosidade que serão utilizados.

Não há necessidade, nesta etapa, de se fazer o cheque de curvatura ou o passo ascendente, pois o objetivo - avaliar a validade do método - foi realizado.

\subsubsection{ConCLUSÕES DOS ENSAIOS DE SECAGEM}

Com os dados dos agregados de vidro para a secagem, concluiu-se que:

1) os gráficos do teor de umidade da amostra $x$ taxa de secagem em estufa apresentaram grandes oscilações das taxas de secagem, o que trouxe imprecisão aos ensaios. Os ensaios também foram demorados, de forma que este método não será estudado sobre agregados reciclados por não se adequarem aos objetivos deste trabalho - rapidez e precisão;

2) os gráficos do teor de umidade da amostra $x$ taxa de secagem em infravermelho apresentaram também grandes oscilações das taxas de secagem, causando imprecisão. Com ensaios muito demorados, este método também não apresenta potencial para caracterizar agregados de RCD reciclados;

3) o método de secagem em microondas apresentou erro sistemático sobre as respostas de absorção, o qual, adquirindo proporções distintas em relação às diferentes massas usadas, fez com que esta variável apresentasse significância. Este erro era esperado, pois se deve ao mecanismo de evaporação da umidade de materiais não-porosos ou de baixa porosidade, mas não afeta a aplicação do método sobre agregados de alta porosidade;

4) finalmente, os gráficos do teor de umidade da amostra $x$ taxa de secagem em microondas apresentaram pequenas variações da taxa de secagem e proporcionaram uma determinação fácil e precisa do ponto de queda da taxa de secagem, além de terem sido gerados através de ensaios muito rápidos. O microondas, portanto, será estudado sobre agregados porosos. 


\section{ESTUDO DE MÉTODO RÁPIDO PARA DETERMINAÇÃO DE PROPRIEDADES FÍSICAS DE AGREGADOS DE ALTA POROSIDADE}

Tendo em vista os resultados e análises obtidas sobre os agregados de baixa porosidade (vidro) no capítulo anterior, o presente capítulo busca realizar estudo sobre agregados de alta porosidade, incluindo agregados de RCD reciclados. O objetivo é tentar minimizar os problemas detectados em bibliografia para aplicação do método atual (NM 53) na caracterização destes agregados, através da utilização de novos procedimentos de ensaios, para que o objetivo final - o desenvolvimento de método rápido e preciso para caracterização dos agregados de RCD reciclados - seja atingido.

\subsection{Planejamento experimental, materiaIs e mÉtodos}

Os possíveis problemas da aplicação da NM 53 sobre agregados de alta porosidade encontrados em bibliografia foram: a) perda de massa da amostra; b) saturação incompleta de poros por aprisionamento de ar nos poros; e c) altos tempos totais para execução dos ensaios. Assim, foi realizado planejamento experimental que permitisse a abordagem de variáveis possíveis de utilização para correção destes erros. Porém, como os ensaios sobre o vidro demonstraram que a NM 53 vale para agregados de baixa porosidade, a norma serviu, neste planejamento, como base para análises comparativas.

\subsubsection{ARRANJO EXPERIMENTAL}

A Tabela 4.1 apresenta o planejamento experimental $2^{3}$ utilizado para os estudos sobre os agregados de alta porosidade, segundo o modelo de Box; Hunter; Hunter (1978). O planejamento foi duplicado, com o intuito de se determinar o erro experimental. As três variáveis utilizadas foram: 1) o agregado de alta porosidade, argila expandida (ponto -1) ou agregados reciclados densidade $<1,9 \mathrm{~kg} / \mathrm{dm}^{3}$ (ponto +1 ); 2) o método de saturação dos poros, sob pressão ambiente por 24 horas (-1) ou sob depressão de vácuo $-500 \mathrm{mmHg}$ por 30 minutos $(+1)$; e 3) o método de secagem da amostra para determinação da $M_{\text {sss }}$, com pano (-1) ou microondas $(+1)$. 
Tabela 4.1 - Planejamento fatorial $2^{3}$ completo dos ensaios sobre agregados de alta porosidade.

\begin{tabular}{|c|c|c|c|c|c|c|c|}
\hline & \multicolumn{3}{|c|}{ VARIAVEIS CODIFICADAS } & \multicolumn{4}{|c|}{ VARIAVEIS CODIFICADAS } \\
\hline ENSAIO & AGREGADO & SATURAÇÁOO & SECAGEM & ENSAIO & AGREGADO & SATURAÇÁO & SECAGEM \\
\hline 2.2 .1 & - & - & - & 2.2 .9 & - & - & - \\
\hline 2.2 .2 & + & - & - & 2.2 .10 & + & - & - \\
\hline 2.2 .3 & - & + & - & 2.2 .11 & - & + & - \\
\hline 2.2 .4 & + & + & - & 2.2 .12 & + & + & - \\
\hline 2.2 .5 & - & - & + & 2.2 .13 & - & - & + \\
\hline 2.2 .6 & + & - & + & 2.2 .14 & + & - & + \\
\hline 2.2 .7 & - & + & + & 2.2 .15 & - & + & + \\
\hline 2.2 .8 & + & + & + & 2.2 .16 & + & + & + \\
\hline
\end{tabular}

\subsubsection{MATERIAIS}

Conforme Tabela 4.1, a primeira variável do planejamento foram os agregados de alta porosidade utilizados: argila expandida ou agregados de RCD reciclados.

\subsubsection{Argila expandida}

Foi utilizada argila expandida nos estudos, ilustrada na Figura 4.1, com a finalidade de comparação em relação aos agregados de $\mathrm{RCD}$ reciclados. É um agregado de alta porosidade com baixos níveis de desgaste superficial por manuseio, o que traz a possibilidade de análise das diferenças de perda de massa em relação aos agregados de RCD (altas taxas de desgaste superficial por manuseio) durante os ensaios de acordo com o método utilizado.

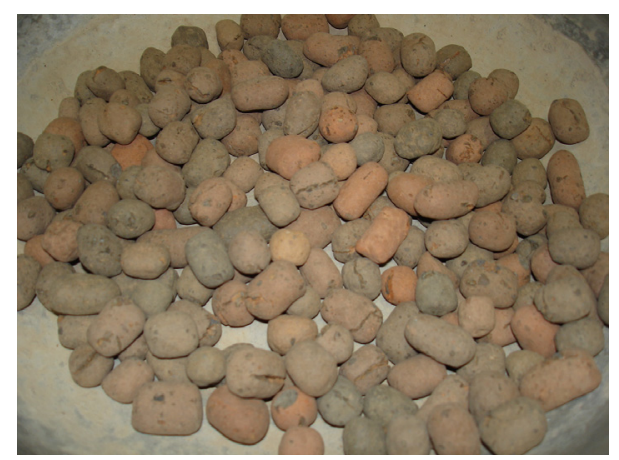

Figura 4.1- Agregados de argila expandida utilizados no trabalho.

Os agregados de argila da amostra padrão para o planejamento foram escolhidos por catação, selecionando-se os mais esféricos e menos dotados de fendas. Também foi detectada a necessidade de separá-los por densidade, pois muitos flutuavam na água (densidade

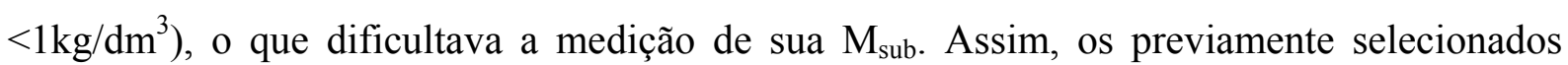
foram secos em estufa e jogados na água. Os que flutuaram foram excluídos, e a amostra foi feita a partir apenas dos que afundaram imediatamente, com densidade, portanto, $>1 \mathrm{~kg} / \mathrm{dm}^{3}$.

Estes agregados foram caracterizados dentro da faixa granulométrica de 9,5 a 19mm, de acordo com a NBR 7211/83, que é a granulometria considerada como $\mathrm{B}_{1}$. A composição granulométrica da argila expandida utilizada neste trabalho está apresentada na tabela 4.2. 
Tabela 4.2 - Composição granulométrica dos agregados de argila expandida - porcentagem retida acumulada nas peneiras.

\begin{tabular}{|c|c|c|c|c|}
\hline Peneiras $(\mathrm{mm})$ & $\mathbf{1 9}$ & $\mathbf{1 2 , 5}$ & $\mathbf{9 , 5}$ & $\mathbf{6 , 3}$ \\
\hline \% retida acumulada & 0 & 94,1 & 100 & 100 \\
\hline
\end{tabular}

\subsubsection{Agregados de $R C D$ reciclados}

As amostras de agregados de RCD reciclados graúdos estudadas neste trabalho são as mesmas usadas por Angulo (2005) e Carrijo (2005). Foram coletadas na central de reciclagem de Itaquera, localizada no município de São Paulo.

Coletadas as amostras, foi realizado peneiramento mecânico em laboratório com malha 9,5 mm, para retirada do excesso de finos. Após, realizou-se uma britagem secundária, pois parte da amostra não se encontrava na faixa granulométrica de interesse ao trabalho. Uma vez britada, a amostra foi novamente peneirada, para adequar-se à faixa granulométrica de 9,5 a $19 \mathrm{~mm}$, considerada como $\mathrm{B}_{1}$ pela NBR 7211/83.

A amostra foi, então, dividida em quatro faixas de densidade aparente: $<1,9 \mathrm{Kg} / \mathrm{dm}^{3}$, 1,9 a $2,2 \mathrm{Kg} / \mathrm{dm}^{3}, 2,2$ a $2,5 \mathrm{Kg} / \mathrm{dm}^{3}$ e $>2,5 \mathrm{Kg} / \mathrm{dm}^{3}$, através de separação por líquidos densos, segundo metodologia de Angulo (2005). As faixas de densidade fornecem informações mais detalhadas sobre a variabilidade dos agregados reciclados. Após a separação densitária os agregados foram lavados, para retirar excessos de finos. A composição granulométrica das faixas densitárias dos agregados reciclados utilizados está apresentada na tabela 4.3.

Tabela 4.3 - Composição granulométrica dos agregados reciclados - porcentagem retida acumulada nas peneiras.

\begin{tabular}{|c|c|c|c|c|}
\cline { 2 - 5 } \multicolumn{1}{c|}{} & \multicolumn{4}{c|}{ Peneiras (mm) } \\
\hline Densidades & $\mathbf{1 9}$ & $\mathbf{1 2 , 5}$ & $\mathbf{9 , 5}$ & $\mathbf{6 , 3}$ \\
\hline $\mathrm{d}<1,9$ & 0 & 66,7 & 99,8 & 100 \\
\hline $1,9<\mathrm{d}<2,2$ & 0 & 81,2 & 99,9 & 100 \\
\hline
\end{tabular}

Nos ensaios deste planejamento foram usadas amostras da faixa de densidade $<1,9$ $\mathrm{kg} / \mathrm{dm}^{3}$, pois apresenta maior porosidade comparada às outras faixas, conforme visualizado nas Figuras 4.2.a) e 4.2.b), com altas taxas de absorção e desgaste superficial por manuseio.
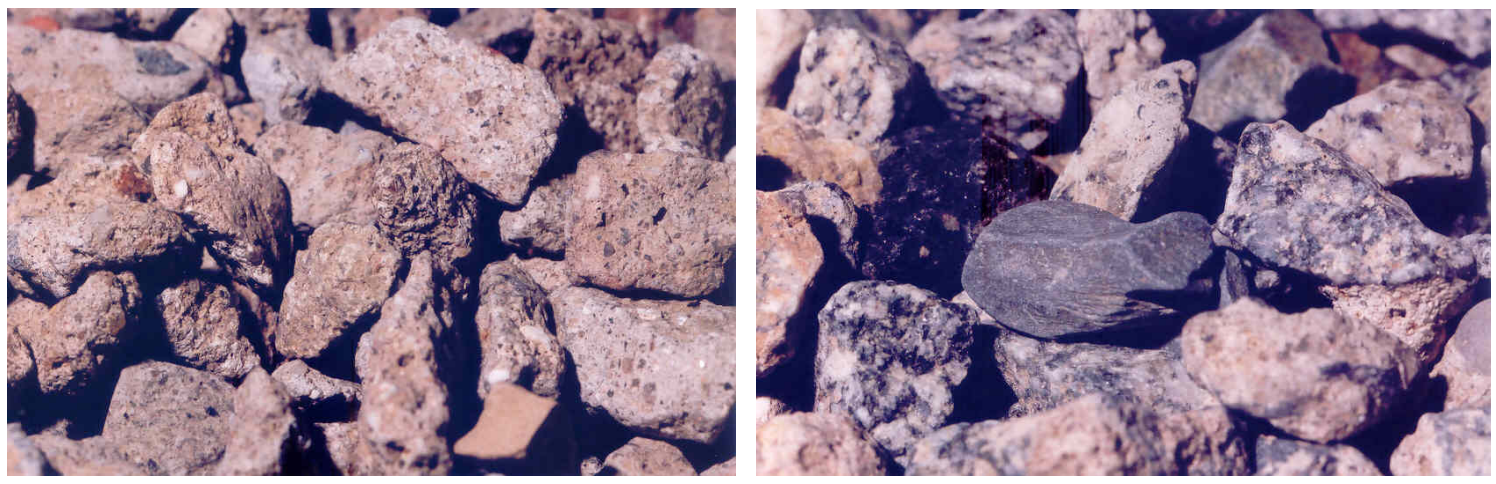

Figura 4.2 - a) Detalhe dos agregados densidade $<1,9 \mathrm{~kg} / \mathrm{dm}^{3}$; b) Detalhe dos agregados densidade $>2,5 \mathrm{~kg} / \mathrm{dm}^{3}$. 


\subsubsection{SATURAÇÃO DOS POROS}

A segunda variável do planejamento experimental, conforme a Tabela 4.1, foi o método de saturação dos poros. Como visto no capítulo 3 (agregados de vidro), a variação da depressão aplicada à amostra altera as respostas de absorção, de forma que foi adotada como variável para o estudo de sua influência sobre a saturação dos poros das amostras de alta porosidade. Foram utilizadas pressão ambiente e depressão de vácuo.

\subsubsection{Saturação à pressão atmosférica}

A norma NM 53 impõe saturação da amostra por 24 horas, sob pressão atmosférica. Porém, diversos estudos apontaram que este método é ruim para aplicação sobre agregados de alta porosidade, pois o ensaio torna-se longo e não proporciona saturação completa dos poros, trazendo erros aos valores de absorção (LEITE, 2001; SCHOUENBORG et al, 2003; RAMALHO et al, 2004). A saturação à pressão atmosférica por $24 \mathrm{~h}$ será utilizada por ser o procedimento padrão da NM 53, valendo como comparação em relação aos métodos e tempos de saturação propostos para agregados porosos.

\subsubsection{Saturação a vácuo}

A bibliografia apontou a depressão por vácuo como forma alternativa à NM 53 para saturação de poros de agregados porosos em maior velocidade e quantidade (LEITE, 2001; SCHOUENBORG et al, 2003; RAMALHO et al, 2004). Porém, perante dúvidas sobre a massa ideal da amostra, a depressão de vácuo ideal a ser utilizada e o tempo ideal para sua aplicação, foi realizado planejamento experimental preliminar considerando-se estas variáveis. A massa foi variada em $1 \mathrm{~kg}$ (ponto -), 2,5kg (ponto central) ou $4 \mathrm{~kg}$ (ponto + ); o vácuo em $0 \mathrm{mmHg}(-),-250 \mathrm{mmHg}$ (central) ou $-500 \mathrm{mmHg}(+)$; e os ciclos de vácuo, em 1 ciclo (-), 5 (central) ou 9 ciclos (+). Foram usados agregados de RCD reciclados densidade 1,9 a $2,2 \mathrm{~kg} / \mathrm{dm}^{3}$ (ANGULO, 2005), e o método da $\mathrm{M}_{\text {sub }}$ x t (RAMALHO et al, 2004), por ser apropriado a se medir absorção no tempo.

A Tabela 4.4 apresenta o planejamento fatorial $2^{3}$ (BOX; HUNTER; HUNTER, 1978) e as respostas de absorção após 30 minutos, 24 horas e 72 horas de ensaio. Também traz proporções entre estas absorções, demonstrando o percentual de absorção aos 30 minutos em relação à absorção de $24 \mathrm{~h}$ e à de $72 \mathrm{~h}$. Os dados utilizados para o cálculo destes resultados estão no apêndice F. 
Tabela 4.4 - Planejamento preliminar fatorial $2^{3}$ completo dos ensaios sobre agregados $1,9 \mathrm{a} 2,2 \mathrm{~kg} / \mathrm{dm}^{3}$, respostas em diferentes tempos $\mathrm{t}$ de cada ensaio e proporções entre absorções destes diferentes tempos.

\begin{tabular}{|c|c|c|c|c|c|c|c|c|c|c|c|}
\hline \multirow[b]{2}{*}{ ENSAIO } & \multicolumn{3}{|c|}{ VARIÁVEIS CODIFICADAS } & \multicolumn{2}{|c|}{ RESPOSTAS $\left(\mathrm{kg} / \mathrm{dm}^{3}\right)$} & \multicolumn{3}{|c|}{ RESPOSTAS ABSORÇÃO (\%) } & \multicolumn{3}{|c|}{ PROPORÇÕES ABSORÇÃO DIFERENTES TEMPOS } \\
\hline & MASSA & VÁCUO & CICLOS V & MEA & MER & $30 \mathrm{~min}$ & $24 \mathrm{~h}$ & $72 \mathrm{~h}$ & $30 \mathrm{~min} / 24 \mathrm{~h}(\%)$ & $30 \mathrm{~min} / 72 \mathrm{~h}(\%)$ & $24 \mathrm{~h} / 72 \mathrm{~h}(\%)$ \\
\hline 2.1 .1 & - & - & - & 2,15 & 2,54 & 5,96 & 6,86 & 7,17 & 86,90 & 83,19 & 95,73 \\
\hline 2.1 .2 & + & - & - & 2,13 & 2,53 & 6,18 & 7,03 & 7,35 & 87,82 & 84,04 & 95,69 \\
\hline 2.1 .3 & - & + & - & 2,15 & 2,63 & 7,57 & 8,18 & 8,48 & 92,56 & 89,23 & 96,41 \\
\hline 2.1 .4 & + & + & - & 2,16 & 2,63 & 7,42 & 8,04 & 8,37 & 92,23 & 88,63 & 96,10 \\
\hline 2.1 .5 & - & - & + & 2,14 & 2,56 & 6,29 & 7,08 & 7,63 & 88,86 & 82,49 & 92,84 \\
\hline 2.1 .6 & + & - & + & 2,13 & 2,54 & 6,41 & 7,37 & 7,71 & 86,99 & 83,13 & 95,56 \\
\hline 2.1 .7 & - & + & + & 2,15 & 2,64 & 7,72 & 8,25 & 8,68 & 93,56 & 88,94 & 95,06 \\
\hline 2.1 .8 & + & + & + & 2,12 & 2,61 & 7,85 & 8,42 & 8,76 & 93,24 & 89,55 & 96,05 \\
\hline 2.1 .9 & 0 & 0 & 0 & 2,13 & 2,59 & 7,06 & 7,91 & 8,31 & 89,20 & 84,92 & 95,20 \\
\hline 2.1 .10 & 0 & 0 & 0 & 2,13 & 2,58 & 6,95 & 7,64 & 8,13 & 90,99 & 85,54 & 94,02 \\
\hline 2.1 .11 & 0 & 0 & 0 & 2,16 & 2,59 & 6,60 & 7,46 & 7,82 & 88,44 & 84,39 & 95,42 \\
\hline 2.1 .12 & 0 & 0 & 0 & 2,15 & 2,60 & 6,69 & 7,52 & 7,92 & 88,95 & 84,55 & 95,06 \\
\hline
\end{tabular}

A partir das respostas de absorção após 72 horas de ensaio apresentadas na Tabela 4.4, pode-se criar a Tabela 4.5, que estuda a significância estatística das variáveis, conforme Box; Hunter; Hunter (1978).

Tabela 4.5 - Estudo de significância das variáveis do planejamento preliminar sobre agregados 1,9 a 2,2kg/dm ${ }^{3}$.

\begin{tabular}{|c|c|c|c|}
\hline Absorção (\%) & Efeito & & Erro padrão \\
\hline média & 8,020 & +- & 0,110 \\
\hline \multicolumn{4}{|c|}{ EFEITOS PRINCIPAIS } \\
\hline efeito massa & 0,058 & +- & $\overline{0,219}$ \\
\hline efeito vácuo & 1,110 & +- & 0,219 \\
\hline efeito ciclos vácuo & 0,352 & +- & 0,219 \\
\hline \multicolumn{4}{|c|}{ INTERAÇÕES DOIS FATORES } \\
\hline efeito $\mathrm{m} \times \mathrm{v}$ & $-0,075$ & +- & $\overline{0,219}$ \\
\hline efeito $\mathrm{m} \mathrm{x} \mathrm{cV}$ & 0,024 & +- & 0,219 \\
\hline efeito $v \times c v$ & $-0,056$ & +- & 0,219 \\
\hline \multicolumn{4}{|c|}{ INTERAÇÃO TRÊS FATORES } \\
\hline efeito $\mathrm{m} \times \mathrm{x} \times \mathrm{cv}$ & 0,073 & +- & 0,219 \\
\hline
\end{tabular}

A análise das Tabelas 4.4 e 4.5, juntamente com as Figuras 4.3 e 4.4 (geradas a partir da Tabela 4.4), permite concluir que:

1) as respostas de MEA não são influenciadas por nenhuma variável, pois são estatisticamente iguais para todos os ensaios;

2) a variável massa não influencia as respostas de absorção mas sua diminuição aumenta a dispersão de resultados, conforme a Figura 4.3.a). Assim, para o planejamento principal esta variável foi fixada de acordo com a NM 53, que adota $3 \mathrm{~kg}$ para agregados de baixa porosidade para a granulometria de agregados estudada. Para os agregados de alta porosidade será utilizada quantidade equivalente em volume, o que significa aproximadamente a mesma quantidade de partículas e massa um pouco menor;

3) a variável vácuo possui significância sobre as respostas de absorção, pois seu efeito calculado é bem superior ao dobro do erro (Tabela 4.5). A Figura 4.3.b) aponta graficamente o aumento da absorção em função do aumento do vácuo utilizado nos ensaios. 
Pôde-se então fixar a depressão de vácuo a ser utilizada no planejamento principal em $500 \mathrm{mmHg}$, pois depressões menores apresentam diminuição da absorção medida e portanto da saturação da amostra, em relação linearmente proporcional;
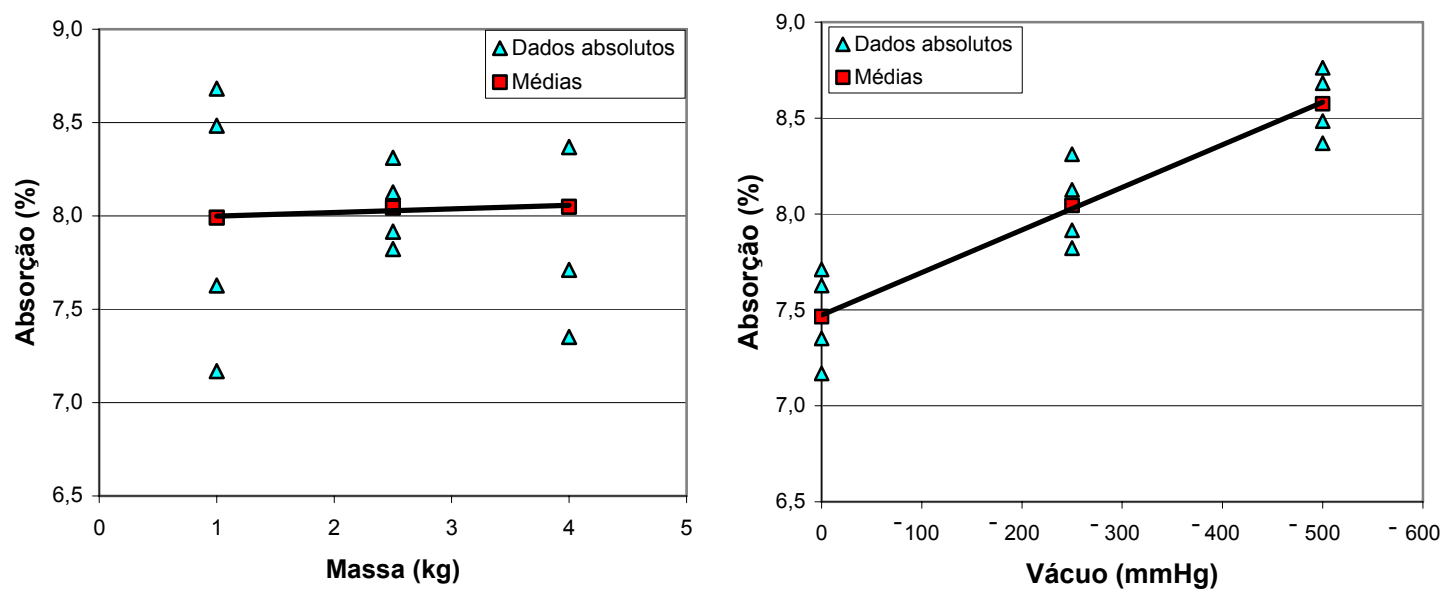

Figura 4.3 - Efeito das variáveis: a) massa; e b) vácuo, sobre as respostas de absorção.

4) os ciclos de vácuo não apresentaram significância sobre a absorção, mas houve leve tendência de aumento destas respostas conforme aumento do número de ciclos aplicados, conforme Tabela 4.5 e Figura 4.4. Assim, no planejamento principal foram fixados o máximo de ciclos possíveis para retirada do ar aderido à superfície da amostra através de retirada e reimersão da amostra na água;

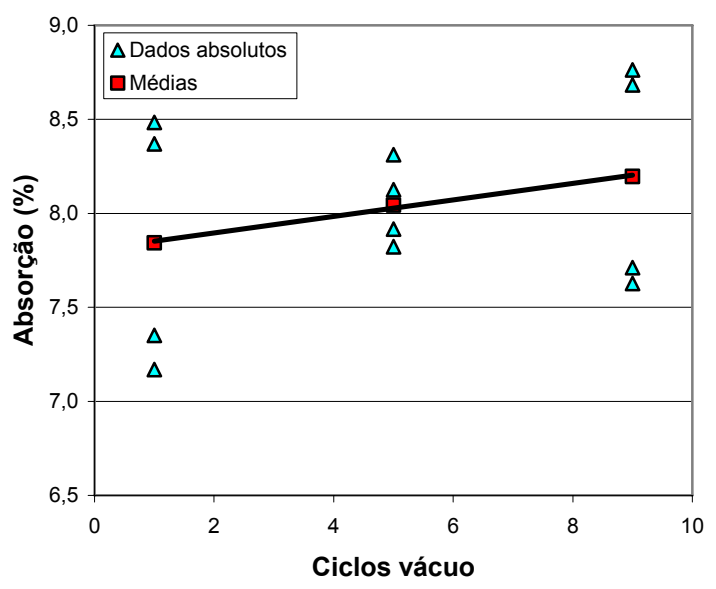

Figura 4.4 - Efeito da variável ciclos de vácuo, sobre as respostas de absorção.

5) o tempo de aplicação da depressão de vácuo sobre a amostra não precisa ser de 24h, pois há correlação linear de grande precisão entre os valores de absorção medidos após 30 minutos de ensaio em relação às absorções determinadas às $24 \mathrm{e} 72$ horas, conforme pode ser visto nas Figuras 4.5(a) e (b). 

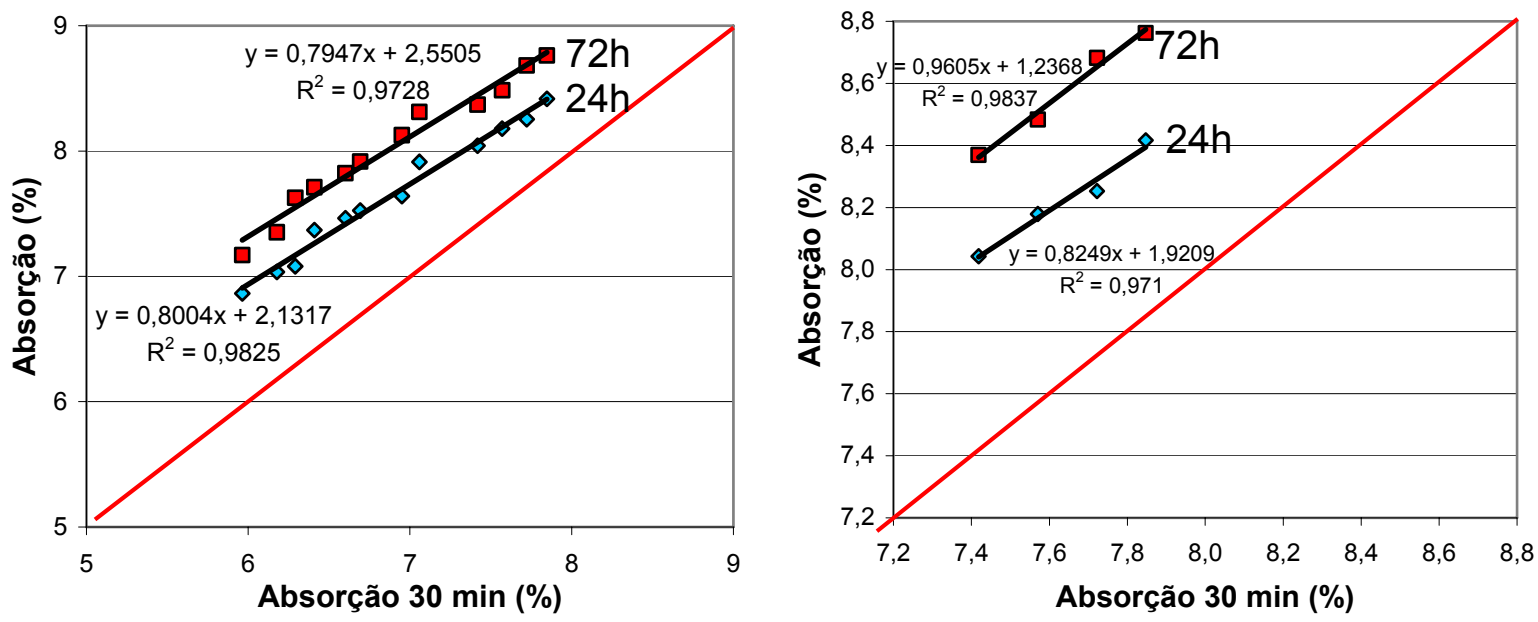

Figura 4.5 - Correlação entre absorção aos 30 min e absorções medidas a 24h e 72h de ensaio: a) independentemente do vácuo utilizado; b) para o vácuo $-500 \mathrm{mmHg}$.

Em especial, o aumento do vácuo aumenta o percentual de saturação de poros aos 30 minutos em relação à saturação a 24 ou 72 horas, conforme a Tabela 4.4 e a Figura 4.6. Chega-se a atingir, em 30 minutos de ensaio sob vácuo $-500 \mathrm{mmHg}$, valores da ordem de 88 a $90 \%$ da saturação após $72 \mathrm{~h}$. O tempo de aplicação do vácuo, então, será fixado em 30 minutos. A saturação sob depressão de vácuo $-500 \mathrm{mmHg}$ por $30 \mathrm{~min}$ será comparada à saturação sob pressão ambiente 24h (NM 53).

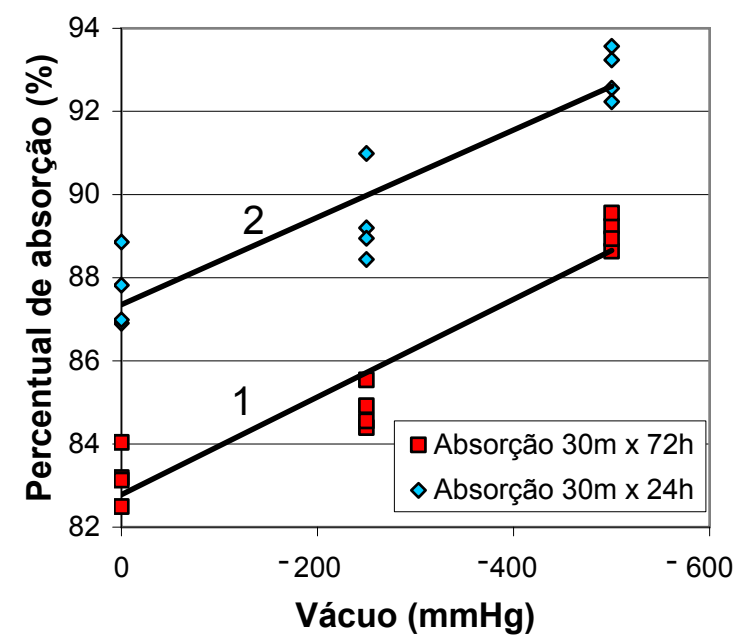

Figura 4.6 - Percentual de absorção atingido em 30 minutos em relação a: 1) 72 horas; e 2) 24 horas de ensaio, sob diferentes depressões aplicadas.

\subsubsection{SECAGEM PARA DETERMINAÇÃo DA $M_{\text {SSS }}$}

O equipamento de secagem da amostra para determinação de sua $\mathrm{M}_{\mathrm{sss}}$ foi, conforme observado na Tabela 4.1, a terceira variável do planejamento experimental adotado, sendo utilizada secagem da amostra por pano ou por microondas. 


\subsubsection{Secagem por pano}

A norma NM 53 padroniza a medição da $\mathrm{M}_{\text {sss }}$ por secagem manual da amostra com pano até constatação de que esteja com sua superfície seca. Estudos apontaram problemas para a aplicação deste método sobre agregados reciclados, pois há perda de massa da amostra (LEITE, 2001; RAMALHO et al, 2004). A secagem por pano será utilizada por ser o padrão da NM 53, servindo como comparação em relação aos métodos propostos para determinação da $\mathrm{M}_{\mathrm{sss}}$ de agregados de alta porosidade.

\subsubsection{Secagem por microondas}

O método da secagem de sólidos descrito no capítulo 2 pode ser usado para determinação da $\mathrm{M}_{\mathrm{sss}}$ em substituição à secagem por pano da NM 53 (BROWN et al, 1965; McCABE, 1987). Nos ensaios com esferas de vidro, a estufa e as lâmpadas de infravermelho apresentaram altos tempos de ensaio e grande imprecisão (ruídos), não se adequando ao objetivo deste estudo. Porém, a secagem em microondas apresentou precisão satisfatória e baixos tempos de execução, o que fez com que o método fosse estudado em comparação à secagem por pano, buscando-se o melhor método de determinação da $\mathrm{M}_{\mathrm{sss}}$ dos agregados de alta porosidade em relação: 1) à precisão das respostas de absorção medidas; e 2) à perda de massa ocorrida durante os ensaios. A potência do microondas foi fixada em 2 (baixa), pois se constatou nos ensaios com vidro que sua variação não altera os resultados mas altas potências diminuem a sensibilidade por imporem altas taxas de secagem aos agregados.

\subsubsection{EQUIPAMENTOS}

Os ensaios realizados neste estudo utilizaram-se de:

$\Rightarrow$ Estufa para secagem das amostras, marca FANEM, modelo 320-SE;

$\Rightarrow$ Balança digital Mettler Toledo PB 8001-S, capacidade $8.100 \mathrm{~g}$ e precisão de $0,1 \mathrm{~g}$;

$\Rightarrow$ Recipientes para estocagem, secagem, saturação e medição da $\mathrm{M}_{\text {sub }}$ dos agregados;

$\Rightarrow$ Central de vácuo marca Prismatec, modelo 162-10V, capacidade de deslocamento de 235 litros/min, para aplicação da pressão de vácuo sobre as amostras;

$\Rightarrow$ Cilindro de acrílico com tampa de acrílico, calculado para suportar pressão interna;

$\Rightarrow$ Mangueiras $\varnothing=5 / 16$ " e conexões para gases de diâmetros compatíveis às mangueiras, com capacidade de suportar pressão;

$\Rightarrow$ Manômetro com intervalo de 0 a $-700 \mathrm{mmHg}$;

$\Rightarrow$ Célula de carga da marca Alfa, para leitura da $\mathrm{M}_{\text {sub }}$ dentro do cilindro sob vácuo; 
$\Rightarrow$ Receptor de dados digital da marca Alfa modelo 3104 B, para captura dos dados;

$\Rightarrow$ Panos para secagem dos agregados;

$\Rightarrow$ Forno microondas Panasonic, modelo NN S-65, capacidade de 35 litros, potência máxima de $1000 \mathrm{~W}$, tensão $110 \mathrm{~V}$, com furo na face superior;

$\Rightarrow$ Microcomputador terminal para aquisição de dados de massa da balança Mettler;

$\Rightarrow$ Software WinWedge32, especializado em captação de dados de periféricos.

\subsubsection{Procedimentos de ensaio e cálculos}

Os ensaios foram realizados de acordo com os passos da Figura 4.7.

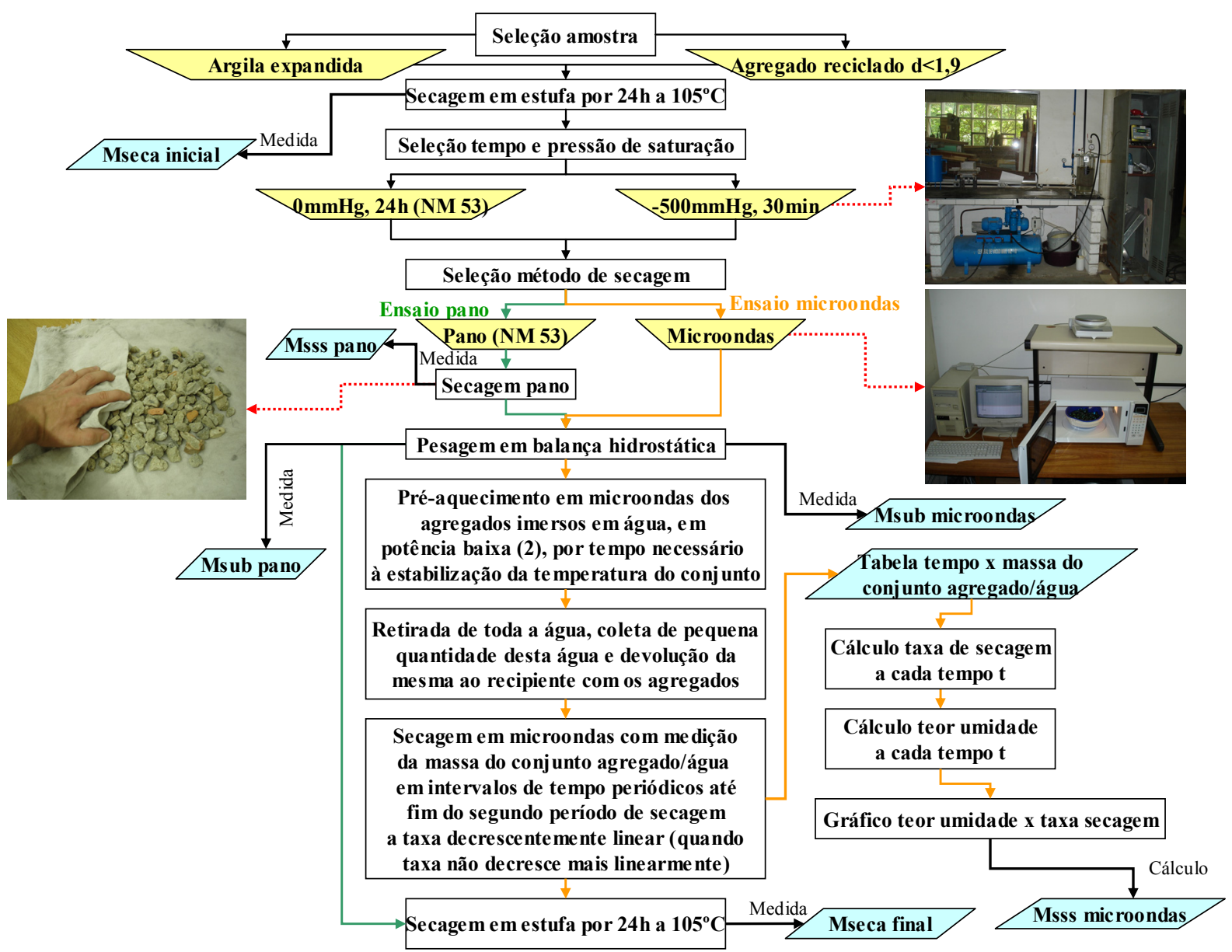

Figura 4.7 - Fluxograma de ensaio do planejamento experimental dos agregados de alta porosidade.

Para os ensaios cuja secagem para determinação da $M_{s s s}$ foi realizada com microondas, a colocação do conjunto agregado/água para secagem (início do ensaio) foi feita com água cobrindo os agregados até atingir temperatura constante (taxa de secagem constante). Chegada a temperatura, foi retirada a água em excesso, de forma que as partículas estavam úmidas, antes do ponto de $\mathrm{M}_{\mathrm{sss}}$. Deixou-se aproximadamente $6 \%$ de água quente (em relação à massa seca dos agregados) para configurar um período de secagem constante, 
necessário à determinação da absorção, e a secagem continuou. Este procedimento visou homogeneizar ao máximo a secagem, pois agregados das camadas inferiores secam mais lentamente do que os superiores por ficarem em contato com água por mais tempo. Os dados foram coletados em intervalos de 20 segundos.

Com os dados coletados em cada ensaio, formulou-se tabela contendo 4 colunas: 1) tempo $\mathrm{t}$ (período de leitura); 2) massa medida neste tempo $\mathrm{t}$; 3 ) teor de umidade relativo a este tempo t; e 4) taxa de secagem relativa ao tempo t, lembrando:

$$
\begin{aligned}
& \text { TeorUmidade }(t)(\%)=\frac{M_{\text {conj.agreg } / \text { água }(t)}-M_{\mathrm{sec} a}}{M_{\mathrm{sec} a}} \times 100 \\
& \operatorname{TaxaSecagem}(t)(\mathrm{g} / \mathrm{min})=\frac{\left[M_{\text {conj.agreg } / \text { água }(t-1)}\right]-\left[M_{\text {conj.agreg } / \text { água }(t)}\right]}{(t)-(t-1)}
\end{aligned}
$$

Com estes dados foi construída a curva do teor de umidade $\mathrm{x}$ taxa de secagem do agregado. Identificadas as fases de secagem, foi feito cálculo por regressão linear do ponto de intersecção entre as fases de secagem 1 (constante) e 2 (decrescente linear), o qual indica o instante em que ocorre a condição saturada superfície seca do agregado, de acordo com a Figura 2.8 do capítulo 2. A determinação da $\mathrm{M}_{\text {sss }}$ por pano foi realizada conforme a NM 53 .

Com $M_{\mathrm{s} 0 \text { (inicial), }} \mathrm{M}_{\mathrm{sf} \text { (final), }} \mathrm{M}_{\mathrm{sss}}$ e $\mathrm{M}_{\text {sub }}$, calcula-se as propriedades absorção (A), massa específica aparente (MEA), massa específica real (MER) e perda de massa:

$$
\begin{aligned}
& A(\%)=\frac{M_{s s s}-M_{\sec a}}{M_{\sec a}} \times 100 \\
& M E A=\frac{M_{\sec a}}{M_{s s s}-M_{s u b}} \\
& M E R=\frac{M_{\sec a}}{M_{\sec a}-M_{s u b}} \\
& \operatorname{PerdaMassa}(\%)=\left(\frac{M_{s 0}-M_{s f}}{M_{s 0}}\right) x 100
\end{aligned}
$$

Importa ainda ressaltar que todos os ensaios foram realizados sob umidade relativa do ar padronizada em $50+-4 \%$. O motivo deste cuidado foi o fato de que cada material possui curvas isotermas próprias (uma para cada temperatura distinta), relacionando diretamente a umidade relativa do ar (eixo $\mathrm{x}$, em porcentagem) ao conteúdo de água total (eixo y, em porcentagem). O gráfico de cada curva isoterma é capaz de apontar, para a dada temperatura e 
sob determinada umidade relativa do ar, a umidade de equilíbrio do material em questão. Esta umidade de equilíbrio é a umidade que, apesar de não estar combinada, não pode ser retirada por evaporação devido ao equilíbrio da umidade do conjunto com a umidade relativa do ar. Assim, a umidade retirada pelos ensaios de secagem é apenas a umidade livre, equivalente à umidade total do conjunto subtraída da umidade de equilíbrio configurada para a temperatura e a umidade relativa do ar correspondentes às condições de realização do processo de secagem (McCABE, 1987). Deste modo, a padronização das condições de umidade relativa do ar evita que ocorra retirada de teores distintos de umidade em ensaios diferentes, o que poderia incutir em erro experimental.

\subsection{Resultados}

As Figuras 4.8, 4.9, 4.10 e 4.11 apresentam os gráficos de secagem em microondas obtidos no planejamento realizado. Os dados utilizados para a confecção dos gráficos e para os cálculos dos resultados estão no apêndice G.
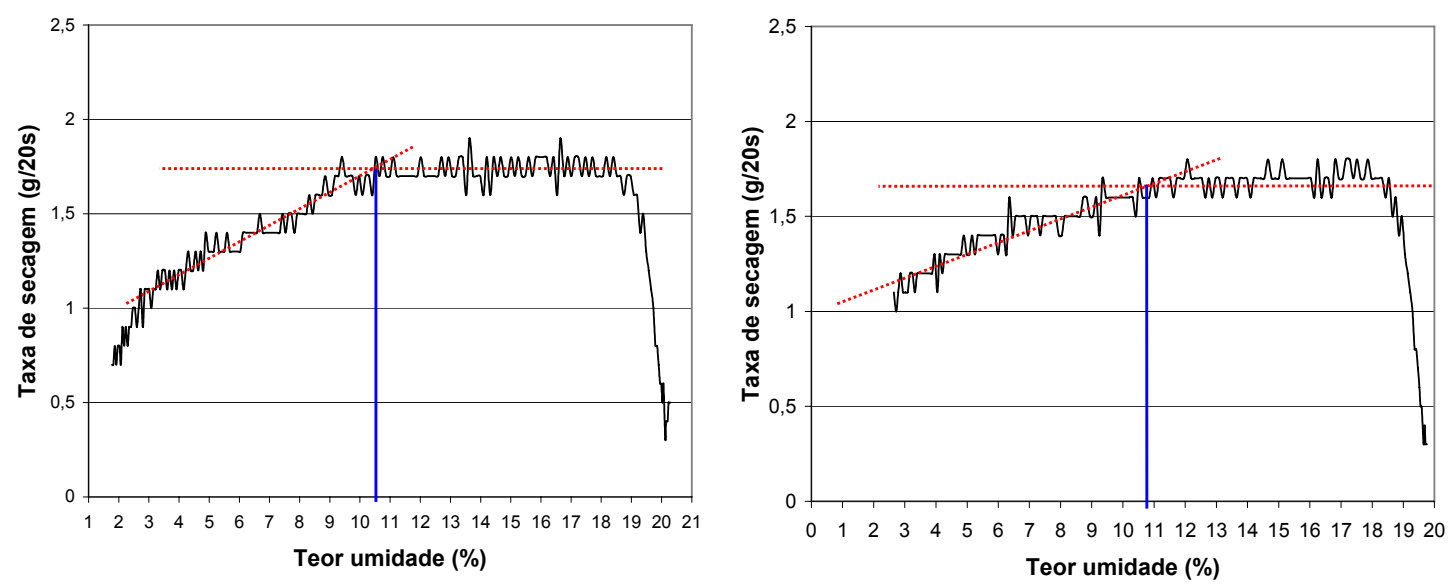

Figura 4.8 - Ensaios --+ (argila expandida, saturação ambiente 24h, microondas): a) repetição 1; b) repetição 2.
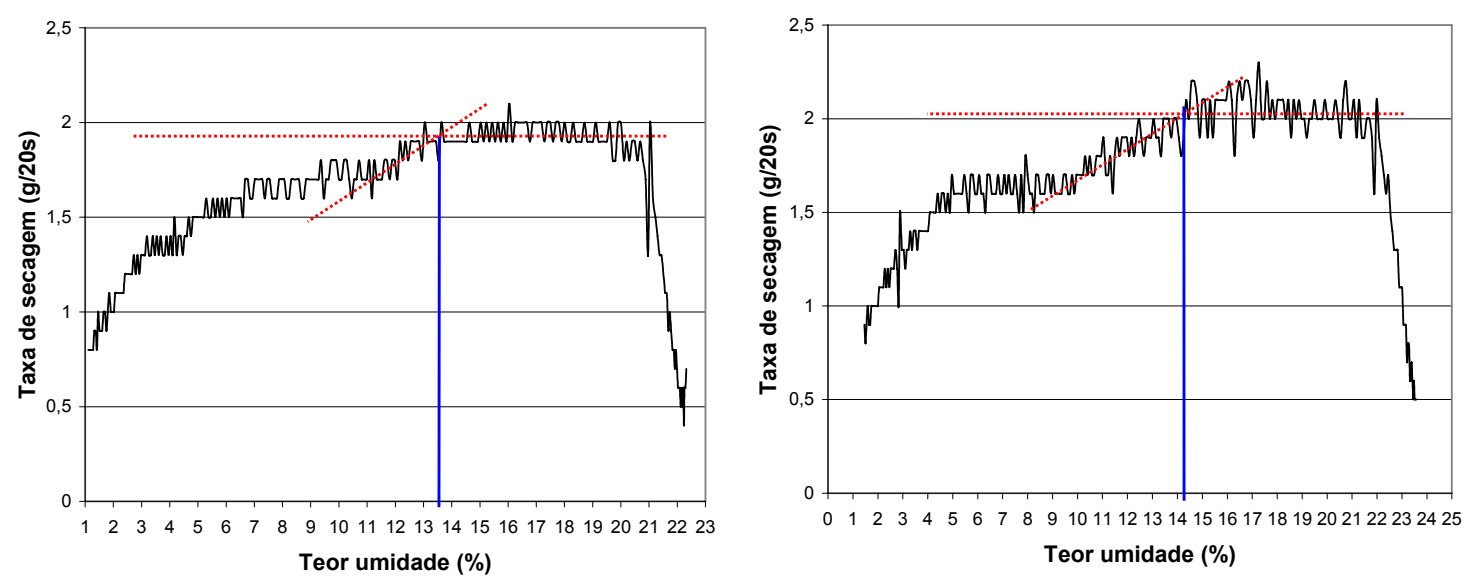

Figura 4.9 - Ensaios +-+ (agregado reciclado, saturação ambiente 24h, microondas): a) repetição 1; b) repetição 2. 

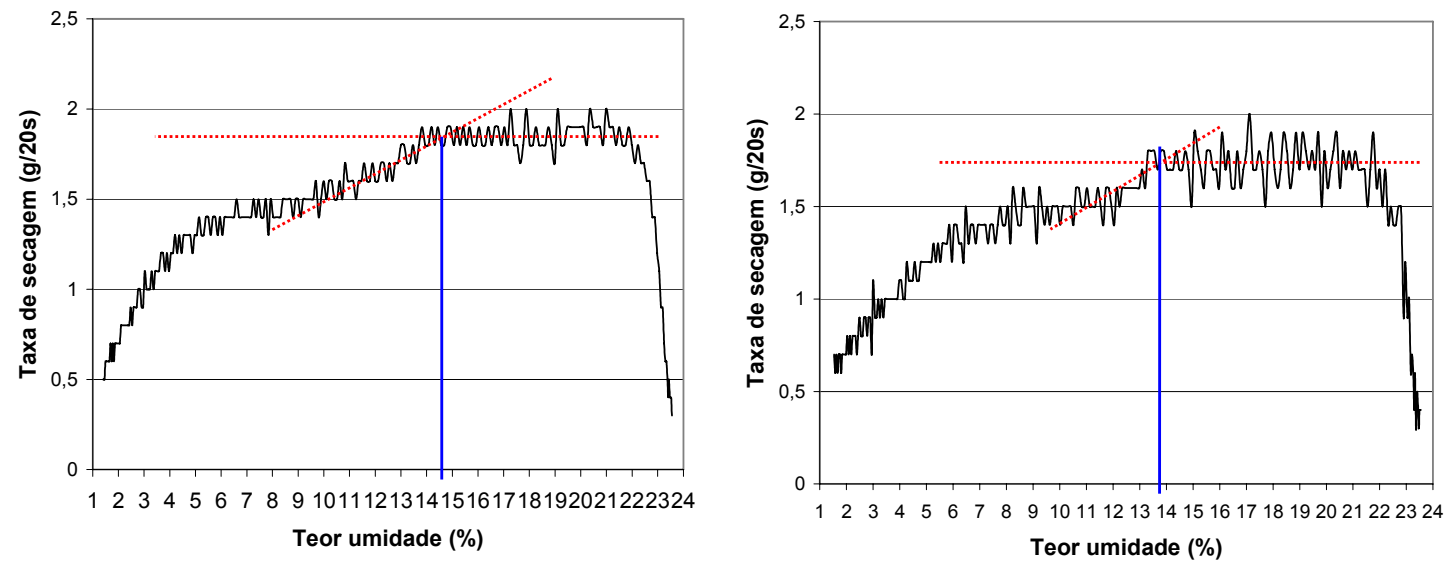

Figura 4.10 - Ensaios -++ (argila expandida, saturação vácuo 30 min, microondas): a) repetição 1; b) repetição 2.
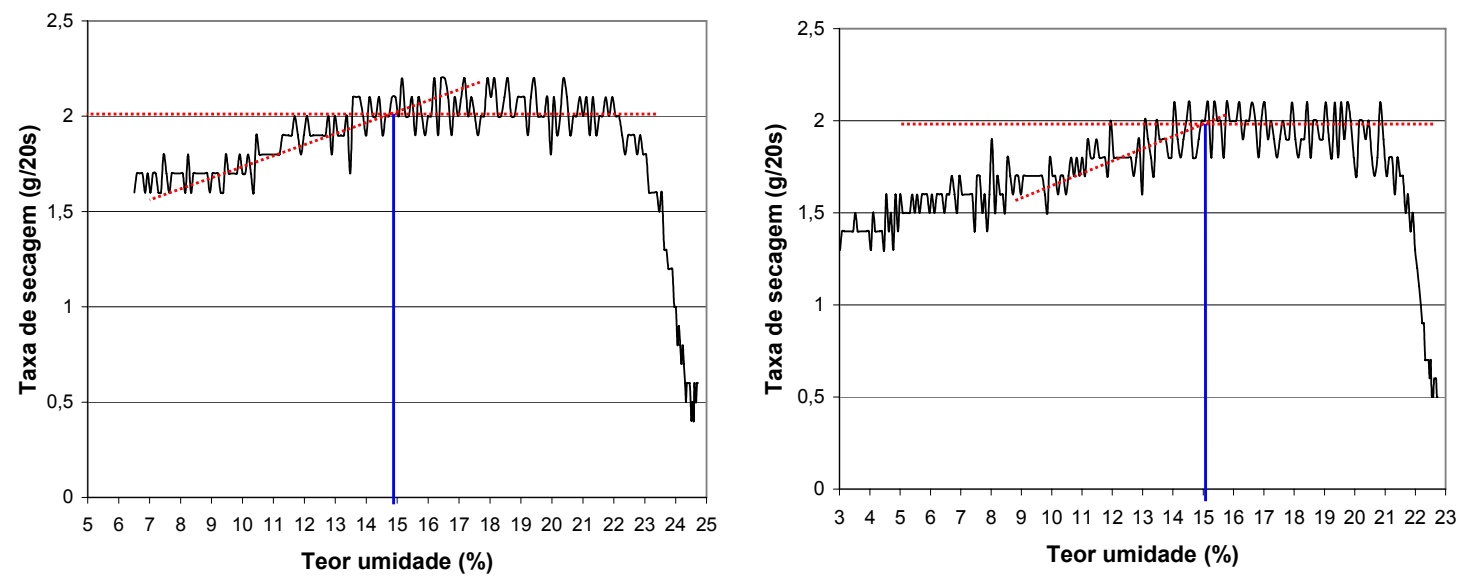

Figura 4.11 - Ensaios +++ (agregado reciclado, saturação vácuo 30 min, microondas): a) repetição 1; b) repetição 2.

A reta vertical indica a umidade que corresponde ao ponto de $\mathrm{M}_{\mathrm{sss}}$, calculada com regressão por mínimos quadrados do ponto de transição da taxa de secagem constante para a linearmente decrescente. A seleção dos dados correspondentes aos períodos de secagem constante e decrescentemente linear, a serem utilizados nos cálculos de regressão, foi realizada visualmente em cada gráfico, adotando-se, para cada período, os pontos inicial e final como sendo os limítrofes destes períodos mas dentro do trecho de cada um deles em que se houvesse certeza de sua linearidade, ou seja, certeza de que estariam dentro do trecho. Os ensaios de secagem, portanto, também apresentam alguma subjetividade, porém em proporções muito pequenas e que podem ser desconsideradas pelo fato de que as diferenças de medidas que podem ocorrer são muitas vezes menores do que o erro experimental do método. A Figura 4.12 ilustra um exemplo da determinação visual do início e final de cada período de secagem do ensaio (taxa constante ou linearmente decrescente). 


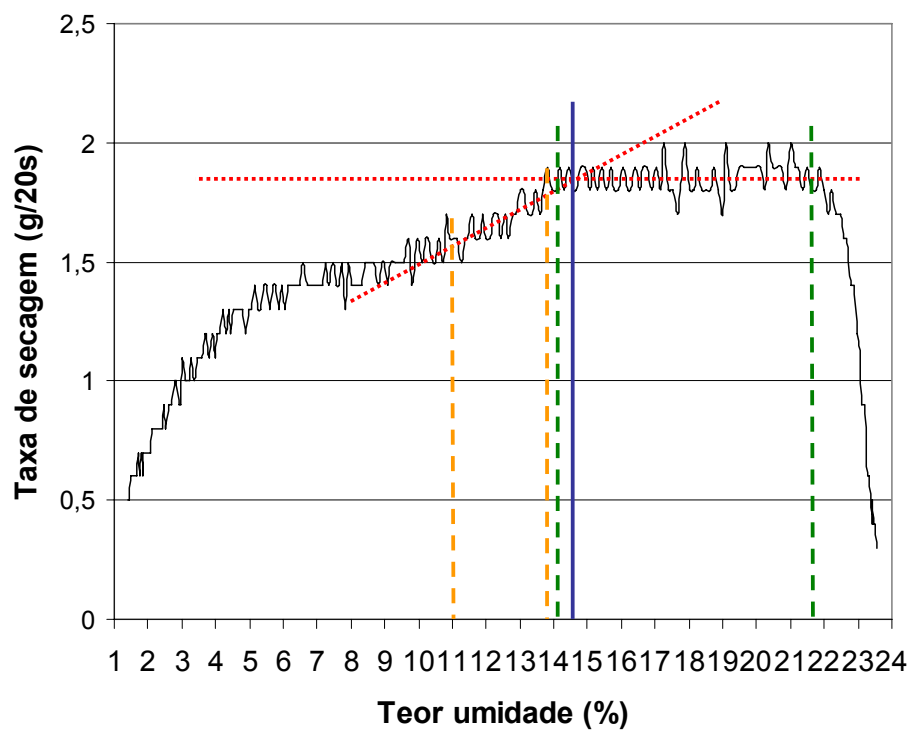

Figura 4.12 - Exemplo de determinação dos limites dos períodos de taxa de secagem constante (linhas verdes) e taxa linearmente decrescente (linhas laranjas), sobre o ensaio -++, repetição 1.

Para análise dos resultados com base em modelos estatísticos DOE fatorial, a sua disposição foi realizada na Tabela 4.6, conforme Box; Hunter; Hunter (1978).

Tabela 4.6 - Resultados dos ensaios do planejamento experimental $2^{3}$ realizado sobre os agregados porosos.

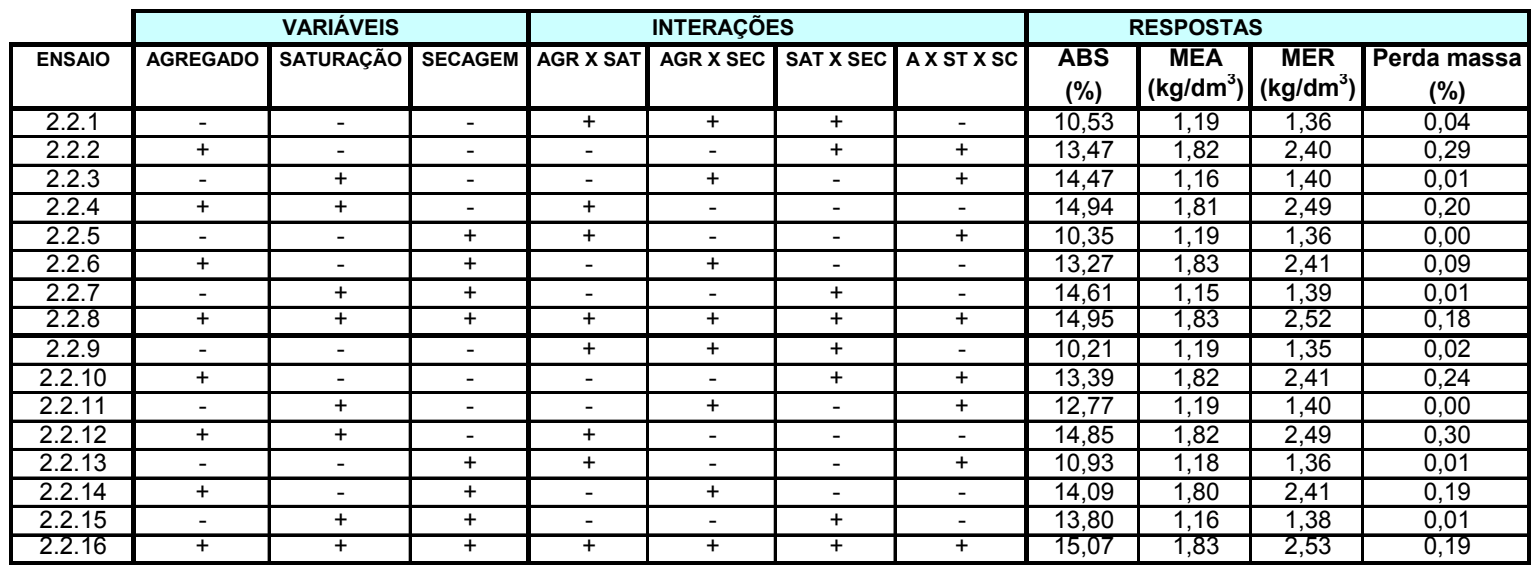

\subsection{ANÁLISE DOS RESULTADOS}

As análises de dados foram baseadas em modelos estatísticos de Box; Hunter; Hunter (1978), e contam com o auxílio dos softwares Excel e Minitab 14. Os cálculos estatísticos dos efeitos das variáveis sobre as respostas foram feitos pelas médias dos ensaios duplicados, pois, com variáveis qualitativas no planejamento, não foi possível a adoção de pontos centrais, de modo que as duplicatas foram necessárias para a determinação do erro padrão.

Segundo Moravia et al (2006), a MER de agregados graúdos de argila expandida apresenta valor aproximado de $2,57 \mathrm{~kg} / \mathrm{dm}^{3}$ quando determinada por picnometria de Hélio 
sobre amostra moída - para que no resultado não haja influência dos poros não-permeáveis, que ocorrem em grande quantidade neste material, pois a matriz porosa da argila, quando moída, não mais existe. Este valor aproxima-se dos resultados obtidos por Angulo (2005) em ensaios de picnometria de Hélio sobre agregados reciclados, que estão em torno de $2,6 \mathrm{~kg} / \mathrm{dm}^{3}$.

Apesar disso, Holm; Ooi, Bremmer (2004) mostram que a dinâmica de absorção de água de agregados de argila expandida é muito lenta, sendo que após 1 ano imerso este agregado atingiu absorção de 30\% mas com apenas $88 \%$ dos poros preenchidos por água. Após 1 dia de imersão foi medida absorção de água de 10,5\% (com 31\% dos poros preenchidos), valor semelhante aos obtidos no presente estudo, que variaram entre 10,21 e $10,92 \%$ (ver Tabela 4.6) para saturação por imersão em água à pressão ambiente por 24 horas, enquanto imersão sob vácuo em 30 minutos levou a absorções de 12,77 a 14,61\%, atingida pelos autores somente após 3 dias de imersão. Deve-se lembrar que a absorção dos agregados de RCD reciclados apresenta dinâmica bem mais veloz.

Devido à lentidão da dinâmica de absorção de água da argila expandida, que ocorre devido ao seu sistema de poros que apresenta maior dificuldade de ser preenchido pela água e à maior quantidade de poros não-permeáveis presentes, as respostas de MER do material medidas no presente trabalho, como pode ser observado na Tabela 4.6, variaram entre 1,36 e $1,40 \mathrm{~kg} / \mathrm{dm}^{3}$. São valores baixos, pois deveriam ter se aproximado do valor de $2,57 \mathrm{~kg} / \mathrm{dm}^{3}$ encontrado por Moravia et al (2006), já que se sabe que a MER não depende da porosidade ou sistema de poros do material mas sim de sua composição química (ANGULO, 2005), de forma que argilas expandidas devem apresentar MER semelhantes entre si independentemente de sua porosidade. Para se analisar melhor o fenômeno, mediu-se por picnometria de Hélio a MER da amostra de argila expandida utilizada neste estudo, obtendo-se, quando não-moída, $1,97 \mathrm{~kg} / \mathrm{dm}^{3}$ em média, com desvio-padrão de 0,027 sobre 5 repetições, e, quando moída, $2,48 \mathrm{~kg} / \mathrm{dm}^{3}$, com desvio-padrão de 0,075 sobre 5 amostras, valor muito próximo ao determinado por Moravia et al (2006).

Pode-se concluir então que, além dos poros não-permeáveis de agregados de argila expandida não poderem ser medidos sem a moagem da amostra (mesmo no caso da picnometria de Hélio), sua medição é difícil e demorada por ensaios de imersão em água, mesmo com aplicação de vácuo por $30 \mathrm{~min}$. Neste material, a determinação da massa especifica real deve ser feita em amostra moída por métodos picnométricos.

Por outro lado, o método utilizado no planejamento deste estudo produziu resultados consistentes para a MER dos agregados reciclados. Ao contrário dos agregados de argila 
expandida, os ensaios com saturação por água preencheram de forma conveniente os poros dos agregados de RCD reciclados, pois obtiveram respostas de MER variando de 2,40 a $2,41 \mathrm{~kg} / \mathrm{dm}^{3}$ com saturação à pressão ambiente, e de 2,49 a $2,53 \mathrm{~kg} / \mathrm{dm}^{3}$ com saturação à pressão de vácuo (ver Tabela 4.6), todas próximas ao valor de $2,6 \mathrm{~kg} / \mathrm{dm}^{3}$ obtido por Angulo (2005) através de picnometria de Hélio. Assim, pode-se concluir: 1) a saturação com água é adequada à determinação da porosidade de agregados de RCD reciclados; e 2) na saturação por água, o uso do vácuo sobre os agregados reciclados aumenta a proximidade das respostas de MER em relação às respostas obtidas nos ensaios de picnometria.

Como este é um estudo sobre melhoria de métodos de determinação de propriedades físicas, o erro encontrado sobre as MER dos agregados de argila expandida não influencia as análises. Deve-se apenas ser ressaltado que o método com saturação por água é conveniente para a determinação de propriedades físicas de agregados de RCD reciclados, encontrando respostas de MER próximas ao valor real deste material $-2,6 \mathrm{~kg} / \mathrm{dm}^{3}-$, mas pode gerar problemas para a determinação destas propriedades sobre agregados de argila expandida, que possuem maior quantidade de poros não-permeáveis.

Iniciando as análises de efeitos das variáveis sobre os resultados obtidos, não há sentido em se analisar o efeito dos agregados sobre as respostas, pois é esperado que diferentes agregados atinjam diferentes respostas de absorção, MEA, MER e perda de massa, o que fica claro na Tabela 4.6. Em especial as respostas de MEA foram alteradas apenas pela variação do agregado, atingindo em todos os ensaios entre 1,15 e $1,19 \mathrm{~kg} / \mathrm{dm}^{3}$ para a argila expandida, e entre 1,80 e $1,83 \mathrm{~kg} / \mathrm{dm}^{3}$ para os agregados de RCD reciclados, independentemente de alterações nas variáveis pressão de saturação e meio de secagem. Assim, os efeitos das variáveis sobre a MEA não serão avaliados, pois já se pode afirmar que todas as variações propostas com relação ao meio de saturação e ao método de secagem das amostras são válidas para a medição da MEA de agregados de alta porosidade.

A variação do tipo de agregado neste planejamento teve o intuito de validar as conclusões obtidas para agregados porosos de diferentes naturezas, e, através da Figura 4.13, comprova-se que os dois utilizados neste estudo são de alta porosidade e de naturezas diferentes por possuírem níveis de perda de massa muito diferentes. 

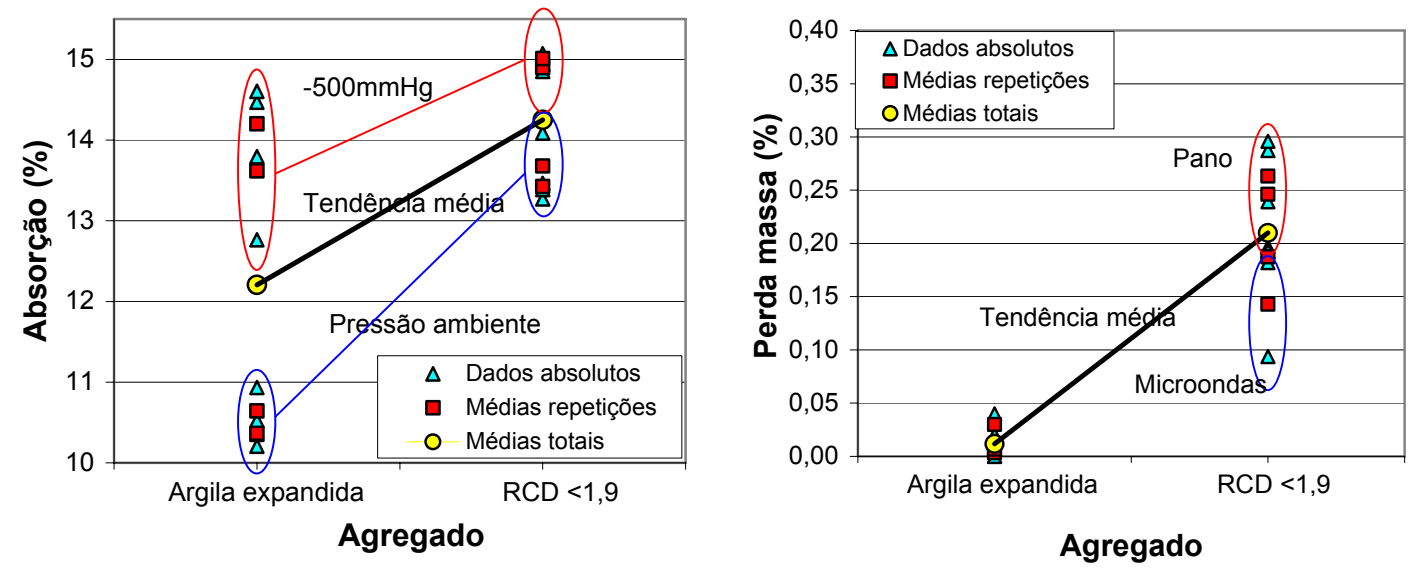

Figura 4.13 - Efeito da variável agregado sobre as respostas de: a) absorção; e b) perda de massa.

A Figura 4.14 realiza a análise da influência da segunda variável, o método de saturação (vácuo 0 ou $-500 \mathrm{mmHg}$ ), sobre as respostas de absorção e perda de massa.
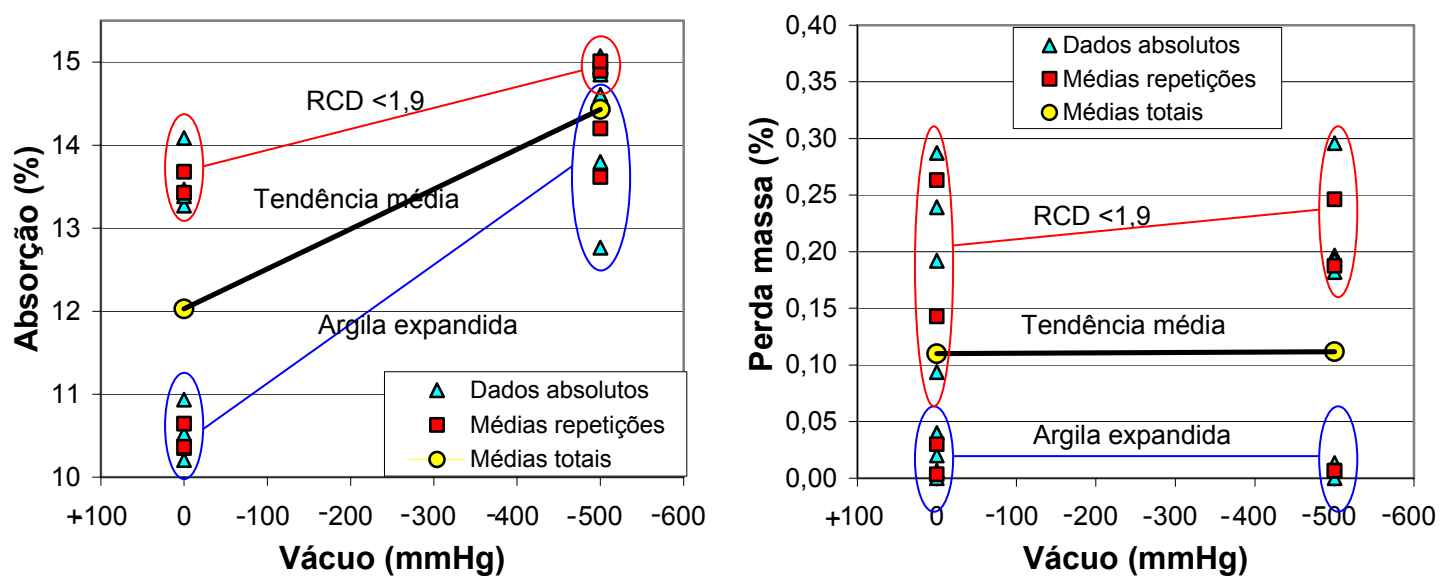

Figura 4.14 - Efeito da variável método de saturação sobre as respostas de: a) absorção; e b) perda de massa.

Há grande aumento da resposta de absorção com a aplicação da depressão de vácuo, independentemente das demais variáveis, como se pode ver na Figura 4.14(a). O fato é relevante, pois prova que a aplicação do vácuo realmente aumenta a saturação dos poros de agregados de alta porosidade em relação ao procedimento da NM 53. Mais ainda, com o vácuo $-500 \mathrm{mmHg}$, além de respostas mais precisas quanto à saturação de poros, obtém-se também redução do tempo de ensaio, pois não são utilizadas 24 horas para saturação mas apenas 30 minutos. Como a tendência apresentada está muito acima do erro experimental (dispersão dos resultados), pode-se afirmar que o vácuo permite a obtenção de melhores resultados em tempos bem menores, comparado à saturação proposta pela norma. No entanto, deve-se lembrar que, mesmo com o vácuo, a argila expandida não satura todos os poros. 
Já a Figura 4.14(b) demonstra que, se por um lado a saturação por vácuo traz os benefícios citados, por outro não aumenta a perda de massa da amostra durante o ensaio, o que poderia ser um problema já que o vácuo força a entrada da água nos poros do material. Esta saturação é, portanto, mais eficiente e bem mais rápida do que a da norma, e sua aplicação não apresenta outros problemas.

A Figura 4.15 analisa a significância do método de secagem para obtenção da $M_{\text {sss }}$ sobre as respostas de absorção e perda de massa.
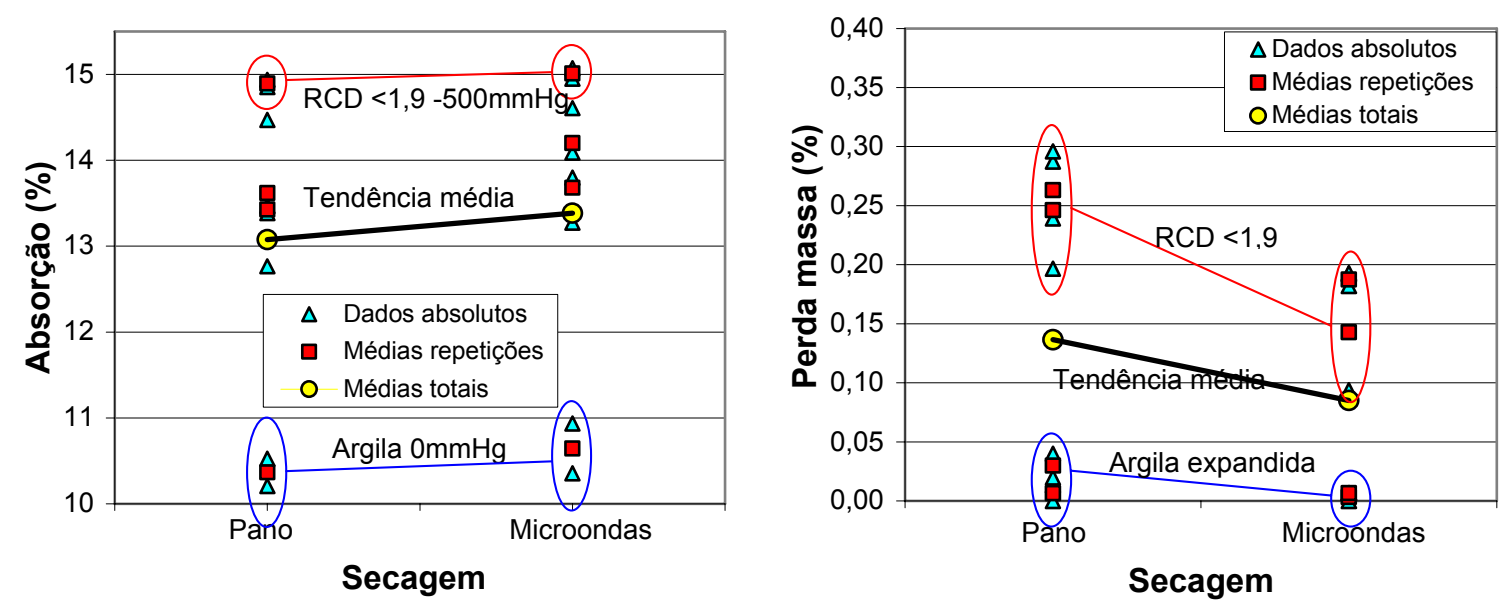

Figura 4.15 - Efeito da variável método de secagem sobre as respostas de: a) absorção; e b) perda de massa.

Sabe-se que o método de secagem por pano (NM 53) tem sido objeto de críticas quanto à sua aplicação sobre agregados reciclados, já que aplica manuseio com pressão sobre a amostra, causando-lhe desgaste superficial. Ainda há o fato de que é um método subjetivo, pois a inspeção visual do operador determina o ponto de $\mathrm{M}_{\mathrm{sss}}$.

Quanto à resposta de absorção, pode-se comprovar, porém, que a secagem por pano (padrão da NM 53) ou por microondas obtêm resultados estatisticamente iguais, conforme a Figura 4.15(a). Assim, a secagem por pano pode ser substituída com sucesso pela secagem por microondas. Resta saber se o novo método ajuda a diminuir os níveis de perda de massa dos agregados, o que era esperado por não haver manuseio da amostra durante os ensaios.

Conforme pode ser analisado na Figura 4.15(b), há uma real tendência de diminuição da perda de massa das amostras de agregados de RCD reciclados com a utilização do microondas em relação ao pano. Mas este ganho foi relativamente pequeno, pois todos os ensaios apresentaram baixas perdas: com o pano estas variaram entre 0,20 e $0,30 \%$, e com o microondas seus valores oscilaram entre 0,09 a $0,19 \%$. 
Para comprovar estatisticamente estas análises, calcula-se o erro experimental pelos desvios encontrados entre as duplicatas dos ensaios, chegando-se ao valor de 0,262 para as respostas de absorção, conforme a Tabela 4.7.

Tabela 4.7 - Determinação do erro do planejamento de agregados porosos para as respostas de absorção.

\begin{tabular}{|c|c|c|c|}
\hline & \multicolumn{2}{|l|}{ Repetições } & \multirow{2}{*}{$\begin{array}{l}\text { Diferença entre } \\
\text { réplicas }(d)\end{array}$} \\
\hline Variaveis ensaio & 1 & 2 & \\
\hline--- & 10,53 & 10,21 & 0,32 \\
\hline+-- & 13,47 & 13,39 & 0,08 \\
\hline-+- & 14,47 & 12,77 & 1,71 \\
\hline++ & 14,94 & 14,85 & 0,09 \\
\hline--+ & 10,35 & 10,93 & $-0,58$ \\
\hline+-+ & 13,27 & 14,09 & $-0,81$ \\
\hline-++ & 14,61 & 13,80 & 0,81 \\
\hline+++ & 14,95 & 15,07 & $-0,12$ \\
\hline \multicolumn{3}{|c|}{$\sum d^{2}$} & 4,694 \\
\hline & \multicolumn{2}{|c|}{$\mathrm{s}^{2}=$} & 0,293 \\
\hline & \multicolumn{2}{|c|}{$V=$} & 0,073 \\
\hline & \multicolumn{2}{|c|}{$s=$} & 0,2708 \\
\hline
\end{tabular}

O erro é então comparado aos efeitos de cada variável sobre as respostas de absorção, conforme a Tabela 4.8, de acordo com Box; Hunter; Hunter (1978).

Tabela 4.8 - Estudo de significância das variáveis do planejamento de agregados porosos para respostas de absorção.

\begin{tabular}{|c|c|c|c|}
\hline Absorção (\%) & Efeito & & Erro padrão \\
\hline média & 13,230 & +- & 0,135 \\
\hline \multicolumn{4}{|c|}{ EFEITOS PRINCIPAIS } \\
\hline efeito agregado & 2,046 & +- & 0,271 \\
\hline efeito saturação & 2,402 & +- & 0,271 \\
\hline efeito secagem & 0,307 & +- & 0,271 \\
\hline \multicolumn{4}{|c|}{ INTERAÇÕES DOIS FATORES } \\
\hline efeito agr x sat & $-1,002$ & +- & 0,271 \\
\hline efeito agr $\times$ sec & $-0,123$ & +- & 0,271 \\
\hline efeito sat $\times$ sec & 0,042 & +- & 0,271 \\
\hline \multicolumn{4}{|c|}{ INTERAÇÃO TRÊS FATORES } \\
\hline efeito $a \times s t \times s c$ & $-0,111$ & +- & 0,271 \\
\hline
\end{tabular}

Os mesmos cálculos foram realizados para as respostas de perda de massa, chegando-se ao erro experimental de 0,019 demonstrado na Tabela 4.9, e comparando-o aos efeitos das variáveis sobre as respostas de perda de massa, na Tabela 4.10.

Tabela 4.9 - Determinação erro do planejamento de agregados porosos para respostas de perda de massa.

\begin{tabular}{|c|c|c|c|}
\hline & \multicolumn{2}{|c|}{ Repetições } & \multirow{2}{*}{\begin{tabular}{|} 
Diferença entre \\
réplicas (d)
\end{tabular}} \\
\hline Variáveis ensaio & 1 & 2 & \\
\hline-- & 0,04 & 0,02 & \\
\hline+-- & 0,29 & 0,24 & 0,05 \\
\hline-+- & 0,01 & 0,00 & 0,01 \\
\hline++- & 0,20 & 0,30 & $-0,10$ \\
\hline--+ & 0,00 & 0,01 & $-0,01$ \\
\hline+-+ & 0,09 & 0,19 & $-0,10$ \\
\hline-++ & 0,01 & 0,01 & 0,00 \\
\hline+++ & 0,18 & 0,19 & $-0,01$ \\
\hline \multirow{2}{*}{\multicolumn{3}{|c|}{$\sum d^{2}$}} & 0,0226 \\
\hline & & & 0,0014 \\
\hline & \multicolumn{2}{|c|}{$\begin{array}{l}\mathrm{s}^{2}= \\
\mathrm{V}=\end{array}$} & 0,0004 \\
\hline & \multicolumn{2}{|c|}{$\mathrm{s}=$} & 0,0188 \\
\hline
\end{tabular}


Tabela 4.10 - Estudo de significância das variáveis do planejamento de agregados porosos para respostas de perda de massa.

\begin{tabular}{|c|c|c|c|}
\hline Perda massa (\%) & Efeito & & Erro padrão \\
\hline média & 0,111 & +- & 0,009 \\
\hline \multicolumn{4}{|c|}{ EFEITOS PRINCIPAIS } \\
\hline efeito agregado & 0,198 & +- & 0,019 \\
\hline efeito saturação & 0,002 & +- & 0,019 \\
\hline efeito secagem & $-0,051$ & +- & 0,019 \\
\hline \multicolumn{4}{|c|}{ TNTERAÇOES DOIS FATORES } \\
\hline efeito agr $x$ sat & 0,012 & +- & 0,019 \\
\hline efelto agr $\times$ sec & $-0,038$ & +- & 0,019 \\
\hline efeito sat $x$ sec & 0,022 & +- & 0,019 \\
\hline \multicolumn{4}{|c|}{ TNTERAÇAO TRES FATORES } \\
\hline efeito a $x$ st $x$ sc & 0,009 & +- & 0,019 \\
\hline
\end{tabular}

Observa-se, nas Tabelas 4.8 e 4.10, que se comprova estatisticamente a significância da variável agregado sobre as respostas de absorção e de perda de massa - o que é lógico, visto que são agregados distintos.

A Tabela 4.8 mostra que a variável método de saturação apresenta significância sobre as respostas de absorção, comprovando o aumento da saturação de poros com o uso da pressão de vácuo $-500 \mathrm{mmHg}$ por 30 minutos em relação à saturação ambiente por 24 horas, afirmação que possibilita a execução do ensaio com maior precisão e economia de 23,5 horas. Na mesma tabela se verifica também que o método de secagem não apresenta significância sobre as respostas de absorção (resultados do pano iguais aos do microondas, o que possibilita a utilização de ambos para a determinação da absorção dos agregados).

Ainda é possível observar, na Tabela 4.10, que o método de saturação não influencia as medidas de perda de massa, de forma que a saturação forçada pela pressão não destrói a amostra, como poderia ser cogitado. Também nesta tabela verifica-se que realmente o método de secagem apresenta significância sobre as respostas de perda de massa, de forma que o uso do microondas melhora o ensaio em relação ao uso do pano, mas em nível menor do que o esperado. Na prática, devido às pequenas diferenças entre as perdas de massa encontradas com pano e com microondas, o uso do microondas parece não apresentar melhora muito significativa em relação à minoração da perda de massa da amostra.

Quanto a este aspecto, deve ser lembrado que os ensaios deste planejamento foram executados todos com a mesma amostra de agregados de RCD reciclados, ou de argila expandida. A adoção de uma única amostra de cada agregado tem importância fundamental para as medições de absorção e MEA, pois pequenas variações de amostras distintas, se fossem adotadas, poderiam indicar significâncias estatísticas erradas para as variáveis adotadas, visto os pequenos desvios encontrados entre as respostas obtidas com os dois níveis da variável método de secagem. 
Porém, para a determinação da perda de massa, a adoção de uma amostra única pode resultar em erro, especialmente no caso dos agregados de RCD reciclados. As partículas destes agregados apresentam, em sua camada exterior, baixos níveis iniciais de atração atômica, o que se deve em parte ao processo de britagem sofrido na usina de reciclagem. Assim, nos primeiros ensaios realizados com uma amostra de agregados reciclados, esta camada externa desprende-se com relativa facilidade, o que gera altos índices de perda de massa. Os próximos ensaios são marcados por gradual diminuição das camadas externas fracamente ligadas ao núcleo, com conseqüente diminuição das perdas de massa medidas.

Após a execução deste planejamento, portanto, restou uma dúvida quanto à dimensão real da influência da variável método de secagem em relação à perda de massa da amostra pode ser maior do que a encontrada aqui. Esta hipótese deu origem ao próximo capítulo.

Para o planejamento experimental realizado, não há sentido em se realizar cheque estatístico de curvatura do modelo, pois duas variáveis (agregados e meio de secagem) são qualitativas. O mesmo vale para o passo ascendente - etapa de cálculo de novas configurações de ensaios visando otimização das respostas. Este passo ascendente poderia indicar no máximo a otimização das respostas através da variação da depressão de vácuo a valores superiores a -500mmHg, impróprios aos ensaios realizados.

\subsection{ConClusões do CAPÍtulo}

Sobre o planejamento experimental realizado com os agregados de alta porosidade, concluiu-se que:

1) Há correlação linear entre saturação de poros de agregados de RCD reciclados realizada sob vácuo $-500 \mathrm{mmHg}$ por 30 minutos, $24 \mathrm{~h}$ ou 72 horas, demonstrando que, sob esta depressão, a amostra absorve aproximadamente entre 88 e $90 \%$ de sua absorção em 72 horas nos primeiros 30 minutos;

2) As respostas de MEA e MER podem ser obtidas com sucesso para qualquer um dos agregados porosos utilizados, com pressão ambiente 24 horas ou vácuo $-500 \mathrm{mmHg}$ por 30 minutos para saturação de poros, e com pano ou microondas para secagem - sua determinação independe das variáveis;

3) A aplicação de vácuo $-500 \mathrm{mmHg}$ por 30 minutos sobre a amostra aumenta a quantidade de poros saturados de forma significativa em relação à quantidade de poros saturados sob pressão ambiente por 24 horas (NM 53), ainda economizando 23,5 horas de ensaio, o que 
se comprova pelo fato da variável método de saturação ter apresentado significância sobre as respostas de absorção no planejamento executado;

4) A saturação dos poros da amostra sob vácuo $-500 \mathrm{mmHg}$ (forçada) não destrói a amostra, pois a variável método de saturação não apresentou significância sobre as respostas de perda de massa;

5) A secagem para determinação da $\mathrm{M}_{\mathrm{sss}}$ com o microondas determina a absorção da amostra de forma análoga à utilização do pano (NM 53), pois a variável método de secagem não apresentou significância sobre as respostas de absorção;

6) A secagem por microondas diminui a perda de massa da amostra quando comparada à secagem com o pano (NM 53), o que se comprova pelo fato de que a variável método de secagem apresentou significância sobre as respostas de perda de massa;

7) Dúvidas sobre a real dimensão da significância da forma de secagem sobre as respostas de perda de massa foram levantadas pelo fato da amostra utilizada no planejamento ter sido a mesma para todos os ensaios (uma amostra de agregados reciclados e uma de argila expandida), pois é provável que maiores taxas de perda de massa ocorram nos primeiros ensaios. Isto tornou necessário novo planejamento experimental utilizando-se de amostras novas a cada ensaio, apresentado no próximo capítulo. 


\section{EFEITO do MÉTOdo dE SECAGEM E DA}

\section{REPETIÇÃO DO ENSAIO SOBRE A PERDA DE MASSA DE AGREGADOS DE RCD RECICLADOS}

O capítulo anterior demonstrou possibilidade de determinação de propriedades físicas de agregados porosos com sucesso através da alteração de dois procedimentos da NM 53: a) a saturação à pressão ambiente por $24 \mathrm{~h}$, substituída por saturação sob vácuo $-500 \mathrm{mmHg}$ por 30 min, o que diminui 23,5 horas de ensaio e aumenta a saturação de poros da amostra; e b) a secagem por pano para determinação da $M_{\text {sss }}$, que pode ser obtida através de secagem por microondas. Porém, foi detectado que o planejamento pode ter gerado subestimação da diferença de perda de massa das amostras de agregados de RCD reciclados entre as duas formas de secagem - pano e microondas.

O presente capítulo, assim, busca analisar a real significância desta variável sobre as respostas de perda de massa, com objetivo de verificar a conclusão constatada de que o microondas gera realmente menor perda de massa do que a secagem por pano, mas com ganho muito pequeno, de baixa relevância prática.

\subsection{Planejamento experimental, materiaIS e mÉtodos}

A dúvida quanto ao possível erro de determinação da perda de massa dos agregados de RCD reciclados teve origem no fato de que as amostras utilizadas no planejamento do capítulo anterior precisaram ser as mesmas em todos os ensaios, pois só assim as conclusões sobre as variáveis consideradas não sofreriam influências das pequenas diferenças que sempre existem entre amostras distintas. Conseqüentemente, as amostras utilizadas sofreram repetidos ciclos de molhagem-secagem -8 ensaios sobre os agregados de argila expandida e 8 ensaios sobre os agregados reciclados, portanto 8 ciclos de molhagem-secagem sobre cada amostra -, e a perda de massa pode ter sido maior no primeiro ciclo em relação aos posteriores. Assim, os ensaios subseqüentes podem ter sido marcados por diminuição da perda das camadas superficiais e conseqüente diminuição da perda de massa. O presente planejamento experimental visou estudar se este erro ocorre de fato, e se realmente resultou na subestimação da diferença de perda de massa da amostra entre ensaios com secagem por pano ou microondas no planejamento do capítulo 4 . 


\subsubsection{ARRANJO EXPERIMENTAL}

A Tabela 5.1 mostra o planejamento fatorial $2^{2}$ utilizado para as verificações sobre a desagregação da amostra, segundo modelo de Box; Hunter; Hunter (1978).

Tabela 5.1 - Planejamento fatorial $2^{2}$ completo dos ensaios sobre agregados reciclados densidade $1,9<\mathrm{d}<2,2 \mathrm{~kg} / \mathrm{dm}^{3}$.

\begin{tabular}{|c|c|c|c|c|c|}
\hline \multicolumn{3}{|c|}{ VALORES ORIGINAIS DAS VARIÁVEIS } & \multicolumn{2}{|c|}{ VALORES CODIFICADOS } & \multirow[b]{2}{*}{ AMOSTRA } \\
\hline ENSAIO & ENSAIO & SECAGEM & ENSAIO & SECAGEM & \\
\hline 2.3 .1 & primeiro & pano & - & - & \multirow{2}{*}{$\begin{array}{c}\text { Pano } 1 \\
\text { P1 }\end{array}$} \\
\hline 2.3 .2 & segundo & pano & + & - & \\
\hline 2.3 .3 & primeiro & microondas & - & + & \multirow{2}{*}{$\begin{array}{c}\text { Micro } 1 \\
\text { M1 } \\
\end{array}$} \\
\hline 2.3 .4 & segundo & microondas & + & + & \\
\hline 2.3 .5 & primeiro & pano & - & - & \multirow{2}{*}{$\begin{array}{c}\text { Pano } 2 \\
\text { P2 } \\
\end{array}$} \\
\hline 2.3 .6 & segundo & pano & + & - & \\
\hline 2.3 .7 & primeiro & microondas & - & + & \multirow{2}{*}{$\begin{array}{c}\text { Micro } 2 \\
\text { M2 }\end{array}$} \\
\hline 2.3 .8 & segundo & microondas & + & + & \\
\hline 2.3 .9 & primeiro & pano & - & - & \multirow{2}{*}{$\begin{array}{c}\text { Pano } 3 \\
\text { P3 }\end{array}$} \\
\hline 2.3 .10 & segundo & pano & + & - & \\
\hline 2.3 .11 & primeiro & microondas & - & + & \multirow{2}{*}{$\begin{array}{c}\text { Micro } 3 \\
\text { M3 }\end{array}$} \\
\hline 2.3.12 & segundo & microondas & + & + & \\
\hline
\end{tabular}

O planejamento $2^{2}$, conforme a Tabela 5.1, foi repetido três vezes para se determinar o erro experimental, sendo os ensaios 2.3 .1 a 2.3 .4 a primeira repetição; 2.3 .5 a 2.3 .8 a segunda; e 2.3.9 a 2.3.12 a terceira. As repetições foram realizadas com amostras distintas provenientes de um mesmo lote, sendo, para cada repetição, duas amostras, uma para dois ensaios com pano e outra para dois ensaios com microondas, totalizando seis amostras.

A primeira variável do planejamento foi o número de ciclos molhagem-secagem da amostra em ordem cronológica, sendo o ponto (-1) o primeiro ensaio realizado sobre a amostra, e o ponto $(+1)$ o segundo ensaio. Buscou-se, assim, averiguar-se a diferença de perda de massa entre o primeiro e o segundo ciclo de molhagem-secagem da mesma amostra, para os dois métodos de secagem estudados (pano e microondas), dúvida que gerou este planejamento experimental.

O método de secagem da amostra para determinação da $\mathrm{M}_{\mathrm{sss}}$ foi, conforme a Tabela 5.1, a segunda variável do planejamento, sendo secagem por pano (ponto -1) ou por microondas (ponto +1 ), uma vez que foi esta variável que gerou dúvidas no planejamento do capítulo 4 em relação às respostas de perda de massa. Sua inclusão no planejamento permitiu a avaliação da diferença de perda de massa real - no primeiro ensaio - entre os métodos de secagem por pano e por microondas. Detalhes da secagem com pano ou microondas estão descritos no capítulo 4.

Este planejamento experimental ainda tornou possível a análise da diferença entre ensaios idênticos com pano ou microondas, realizados sobre amostras diferentes mas de mesmas características de porosidade (mesma faixa de densidade). 
O método de saturação da amostra, variável no planejamento do capítulo anterior, foi agora fixado em saturação sob depressão de vácuo $-500 \mathrm{mmHg}$ por 30 minutos, método comprovadamente mais rápido e eficiente do que a saturação $24 \mathrm{~h}$ à pressão ambiente.

\subsubsection{MATERIAIS}

Os agregados, uma das variáveis do planejamento do capítulo 4, foram agora fixados, pois as conclusões sobre sua significância foram satisfatórias. Foram adotados agregados de RCD reciclados de densidade $1,9<\mathrm{d}<2,2 \mathrm{~kg} / \mathrm{dm}^{3}$, (alta porosidade), lembrando que as amostras estudadas neste trabalho são as mesmas utilizadas por Angulo (2005) e Carrijo (2005). Detalhes destas amostras estão no capítulo 4.

\subsubsection{EQUIPAMENTOS}

Os ensaios deste planejamento utilizaram-se dos mesmos equipamentos do planejamento do capítulo 4, pois os ensaios foram idênticos em termos de execução.

\subsubsection{Procedimentos de ensaio e cálculos}

Os ensaios foram realizados de acordo com os passos da Figura 5.1.

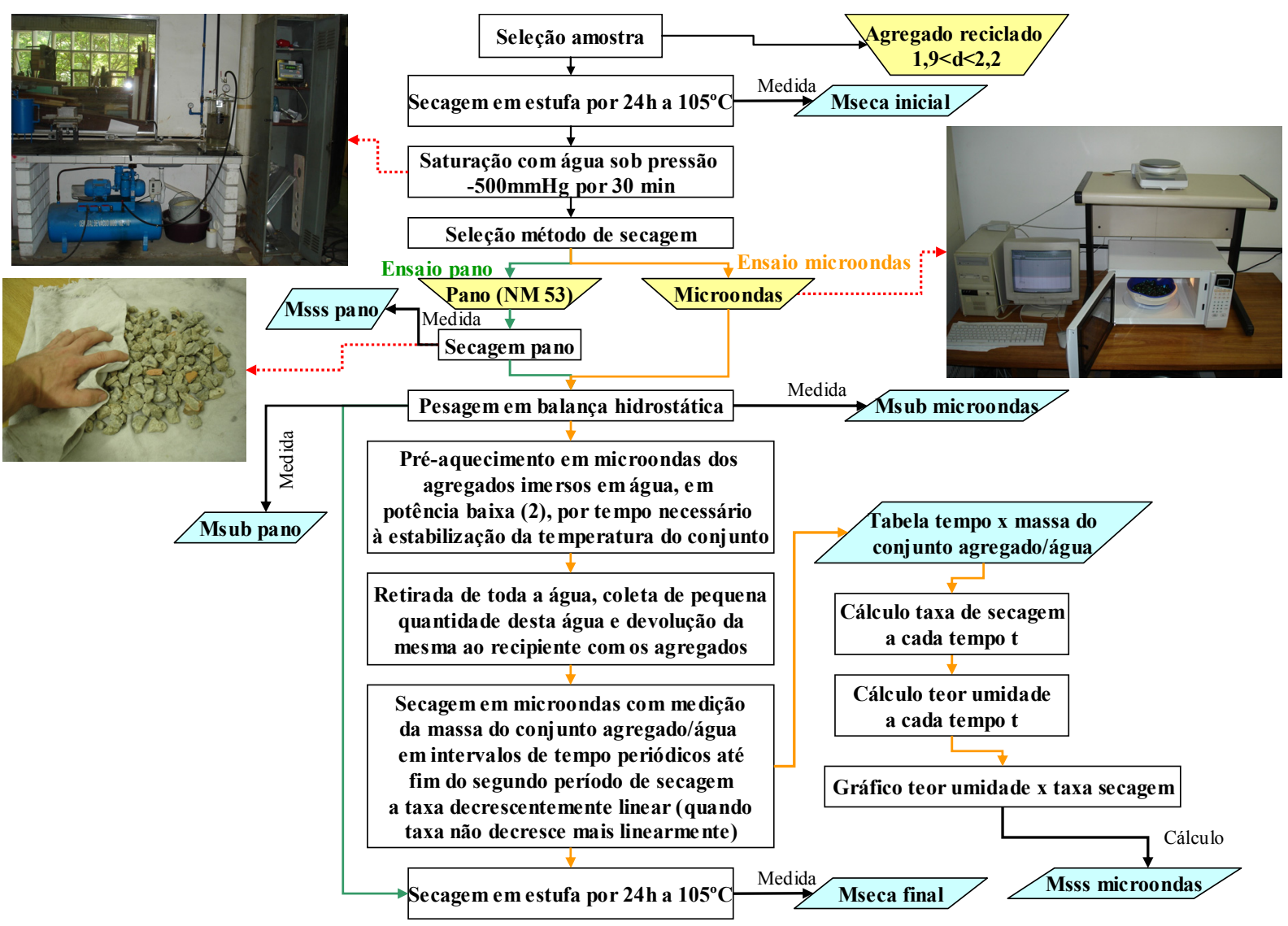

Figura 5.1 - Fluxograma de ensaio do planejamento experimental dos agregados reciclados densidade $1,9<\mathrm{d}<2,2 \mathrm{~kg} / \mathrm{dm}^{3}$. 
Os ensaios em microondas seguiram os mesmos cuidados e meios de aquisição de respostas descritos no item 4.1.6 do capítulo 4, pois foram idênticos aos do planejamento experimental daquele capítulo, com modificações apenas nas amostras de agregados. Os cálculos das respostas também foram realizados de forma análoga à dos ensaios do capítulo 4.

Também como nos ensaios do planejamento do capítulo 4, aqui os ensaios foram realizados sob umidade relativa do ar controlada em 50+-4\%, pelos mesmos motivos descritos no item 4.1.6. A padronização das condições de umidade relativa do ar evita que ocorra retirada de teores distintos de umidade em ensaios diferentes, o que poderia incutir em erro experimental, de acordo com McCabe (1987).

\subsection{Resultados}

As Figuras 5.2 a 5.4 apresentam os gráficos de secagem em microondas obtidos. Os dados usados para confecção dos gráficos e para cálculos dos resultados estão no apêndice H.
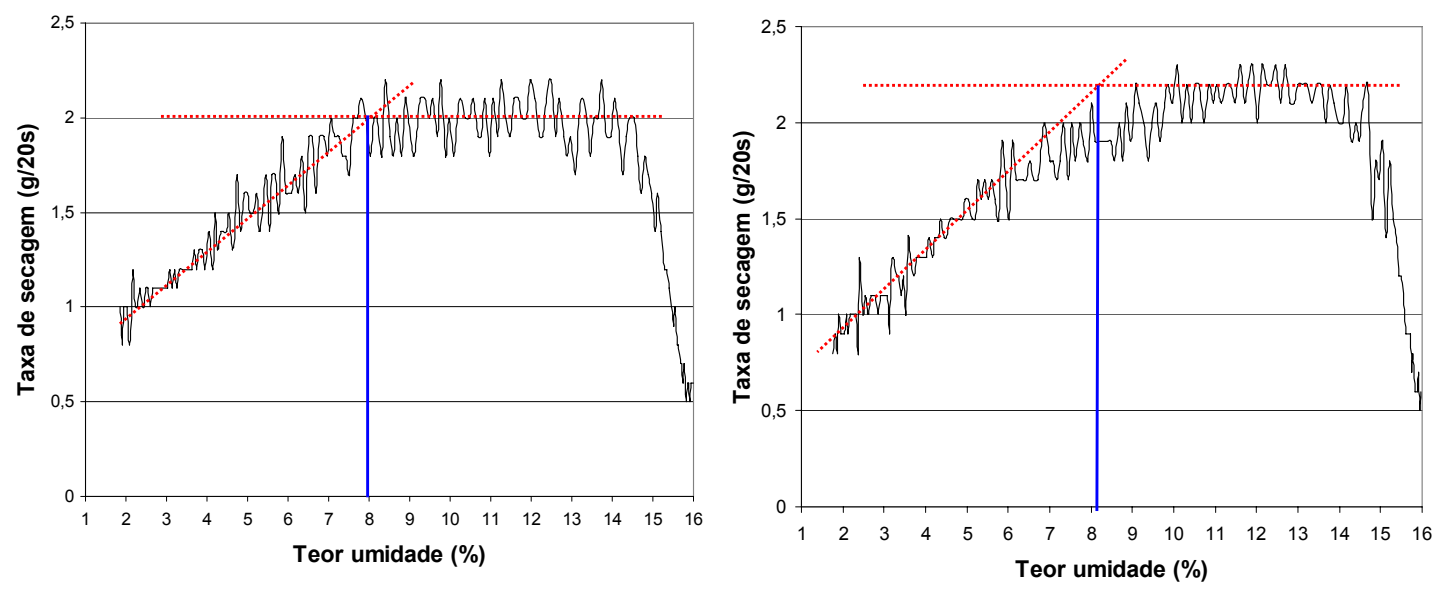

Figura 5.2 - Ensaios de secagem da amosta M1: a) $1^{\circ}$ ensaio, microondas (-+1); b) $2^{\circ}$ ensaio, microondas $(++1)$.
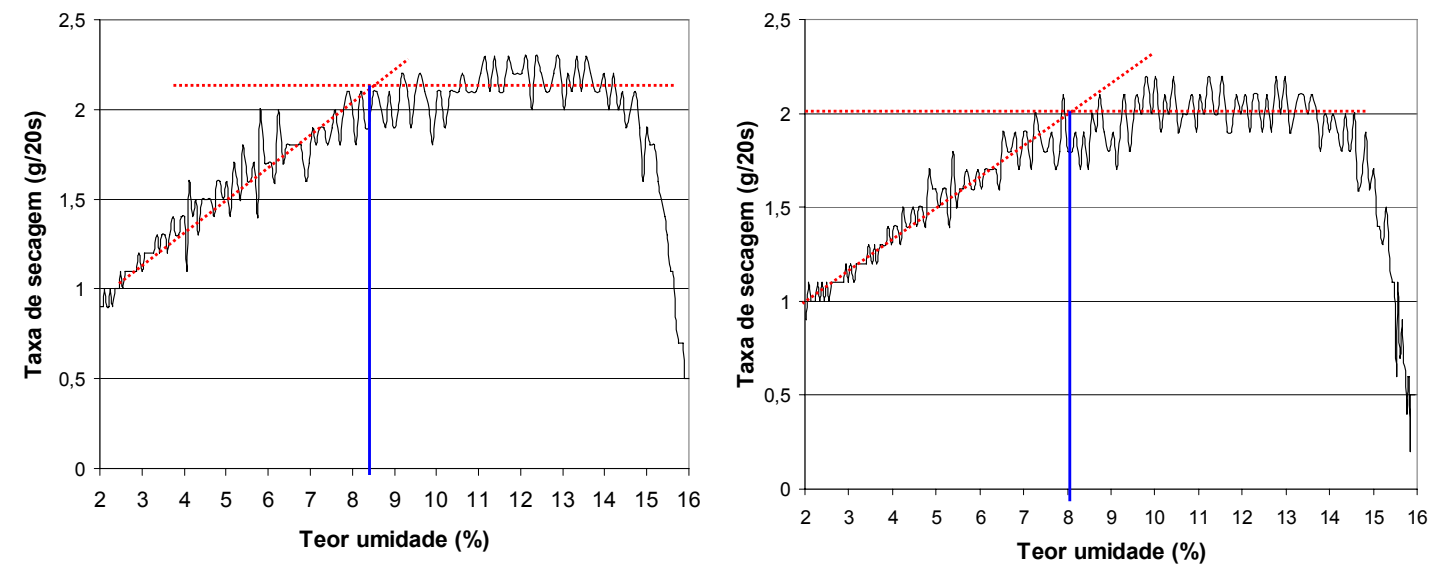

Figura 5.3 - Ensaios de secagem da amostra M2: a) $1^{\circ}$ ensaio, microondas (-+2); b) $2^{\circ}$ ensaio, microondas (++2). 

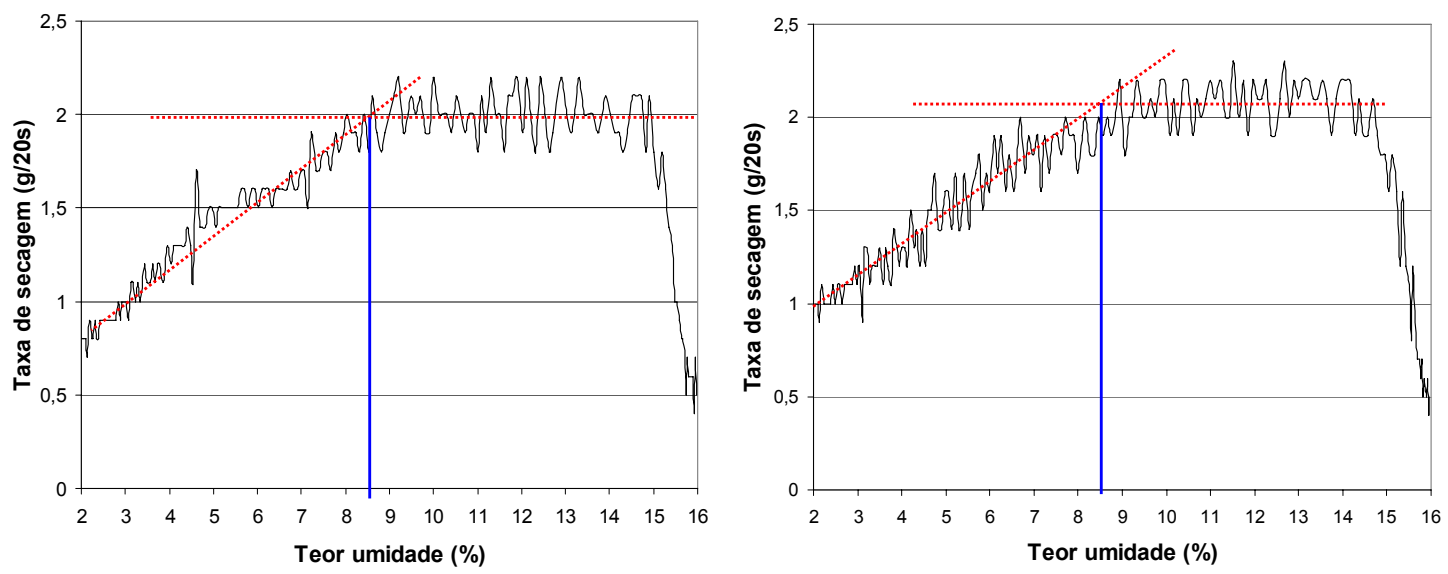

Figura 5.4 - Ensaios de secagem da amostra M3: a) $1^{\circ}$ ensaio, microondas (-+3); b) $2^{\circ}$ ensaio, microondas $(++3)$.

A reta vertical indica a umidade que corresponde ao ponto de $\mathrm{M}_{\mathrm{sss}}$, calculada com regressão por mínimos quadrados do ponto de transição da taxa de secagem constante para a linearmente decrescente. A seleção dos dados correspondentes aos períodos de secagem constante e decrescentemente linear, utilizados nos cálculos de regressão, foi realizada de forma análoga à descrita no item 4.2 do capítulo 4 .

Para análise dos resultados com base em modelos estatísticos DOE fatorial completo, a sua disposição foi realizada na Tabela 5.2.

Tabela 5.2 - Resultados do planejamento $2^{2}$ realizado sobre agregados reciclados $1,9<\mathrm{d}<2,2 \mathrm{~kg} / \mathrm{dm}^{3}$.

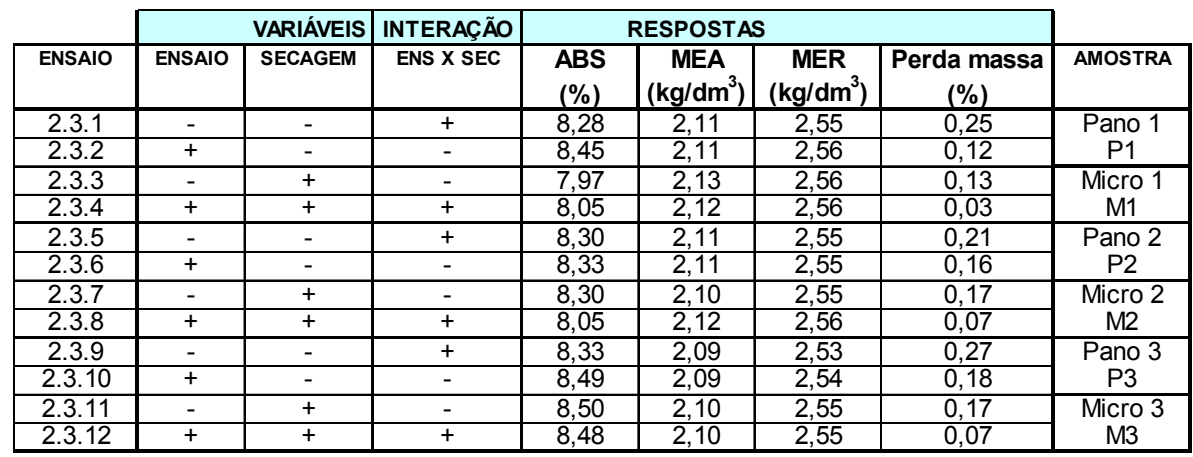

\subsection{ANÁlise doS RESULTADOS}

As análises de dados foram baseadas nos modelos de Box; Hunter; Hunter (1978), com auxílio dos softwares Excel e Minitab 14. As análises físicas e estatísticas dos efeitos das variáveis sobre as respostas foram feitas pelas médias dos ensaios triplicados. O cálculo do erro do planejamento, por sua vez, foi realizado a partir dos desvios entre os ensaios repetidos, lembrando que foram repetidos sobre amostras distintas. Deste modo, o erro expressa também a variabilidade entre as diferentes amostras mas de mesma faixa de porosidade (densidade $1,9<\mathrm{d}<2,2 \mathrm{~kg} / \mathrm{dm}^{3}$ ). 
As resposta de MEA, como ocorrido no planejamento do capítulo 4, atingiram valores muito próximos em todos os ensaios, variando entre 2,09 e $2,13 \mathrm{~kg} / \mathrm{dm}^{3}$, independentemente de alterações das amostras ou nas variáveis número de ciclos molhagemsecagem sobre mesma amostra e método de secagem. Assim, os efeitos das variáveis sobre a MEA não serão avaliados, pois já se pode afirmar que todas as variações aqui propostas sobre os ensaios são válidas para a medição da MEA de agregados de RCD reciclados. O mesmo pode-se dizer sobre as respostas de MER, que variaram muito pouco - de 2,53 a $2,56 \mathrm{~kg} / \mathrm{dm}^{3}$ entre todos os ensaios realizados.

As Figuras 5.5(a) e 5.5(b) apresentam a correlação entre as respostas de absorção obtidas e as variáveis ensaio e método de secagem, respectivamente.
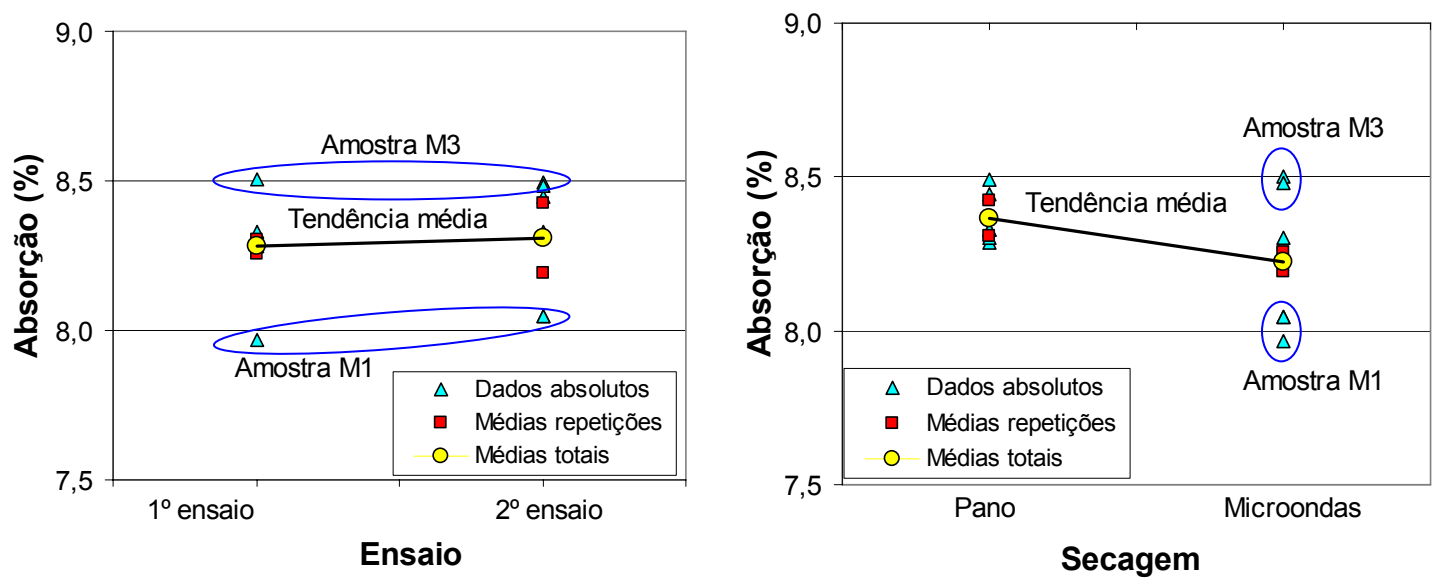

Figura 5.5 - Efeito das variáveis: a) repetição do ensaio; e b) método de secagem, sobre as respostas de absorção.

O intuito do presente planejamento não é a análise das variáveis estudadas sobre as respostas de absorção, visto que no capítulo 4 já foi comprovado que a secagem por pano e por microondas resultam em resultados estatisticamente iguais de absorção. Porém, a Figura 5.5(b) comprova novamente esta análise. A maior dispersão dos resultados de microondas em relação ao pano, visualizada nesta figura, que poderia inicialmente ser interpretada como um maior erro das medidas obtidas com este método de secagem, na realidade deve-se à utilização de amostras distintas, que não possuem os mesmos valores de absorção. A dispersão real dos resultados obtidos com microondas deve ser avaliada pelas diferenças entre absorções medidas sobre mesmas amostras, que, como pode ser observado na Tabela 5.2 e nas Figuras 5.5(a) e (b), são pequenas.

A Figura 5.5(a) ainda demonstra que as respostas de absorção medidas não sofrem alterações quando da aplicação de ensaios sucessivos sobre uma mesma amostra, independentemente do método de secagem. 
Há também o fato de que nestes ensaios foram utilizadas diversas amostras e de faixa de densidade distinta à das amostras do planejamento do capítulo 4. Este fato demonstra que a substituição do pano pela secagem em microondas pode ser generalizada a amostras de alta porosidade em geral, não ficando as conclusões mais restritas a ensaios realizados sobre amostra específica e de faixa de densidade específica, como era o caso do planejamento do capítulo 4.

A Figura 5.6 realiza a análise da influência das variáveis: a) repetição do ensaio; e b) método de secagem, sobre as respostas de perda de massa.
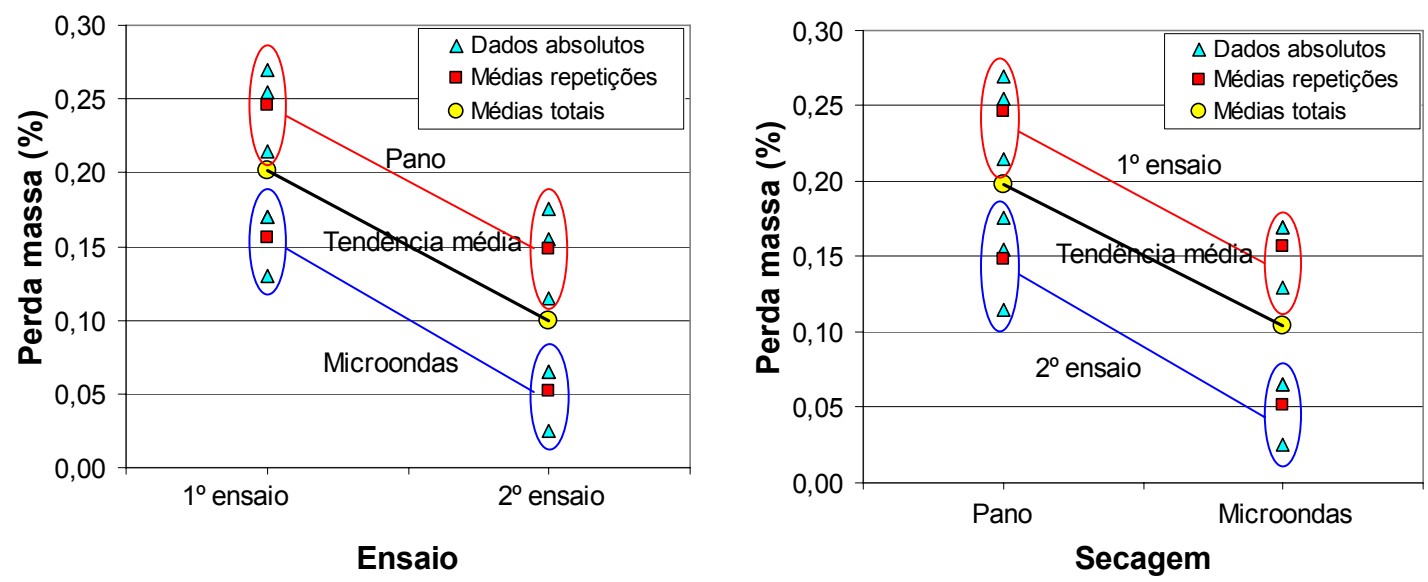

Figura 5.6 - Efeito das variáveis: a) repetição do ensaio; e b) método de secagem, sobre as respostas de perda de massa.

Analisando-se a Figura 5.6(a), percebe-se que há tendências bem definidas de diminuição da perda de massa entre o primeiro e o segundo ensaios realizados sobre uma mesma amostra com mesmo método de secagem. Esta tendência de decréscimo foi encontrada em proporções semelhantes (inclinações de reta parecidas), tanto para os ensaios com secagem por pano como por microondas, para todas as amostras. Por outro lado, na Figura 5.6(b) também se verificou tendência definida de diminuição da perda de massa quando da comparação dos resultados obtidos com o pano em relação aos obtidos com o microondas, também em proporções (inclinação de reta) semelhantes, tanto para os primeiros ensaios realizados sobre as amostras como para os segundos.

Assim, conclui-se que há maior perda de massa da amostra nos primeiros ensaios realizados sobre a mesma, e também há diminuição da perda de massa das amostras quando da substituição da secagem com pano por secagem em microondas. Observa-se que para todas as análises realizadas as tendências discutidas ficaram em níveis bem acima das dispersões dos resultados, que indicam o erro experimental, o que faz com que tais tendências não estejam dentro do erro mas sim sejam significantes às respostas. 
Para comprovar estatisticamente estas análises, calcula-se o erro experimental pelos desvios encontrados entre as triplicatas dos ensaios, chegando-se ao valor de 0,110 para as respostas de absorção, conforme a Tabela 5.3. É importante notar que as três repetições idênticas das combinações de variáveis adotadas foram realizadas sobre amostras distintas, por motivos discutidos no planejamento experimental, de forma que o erro aqui encontrado também inclui as diferenças entre as amostras.

Tabela 5.3 - Determinação do erro experimental do planejamento para as respostas de absorção.

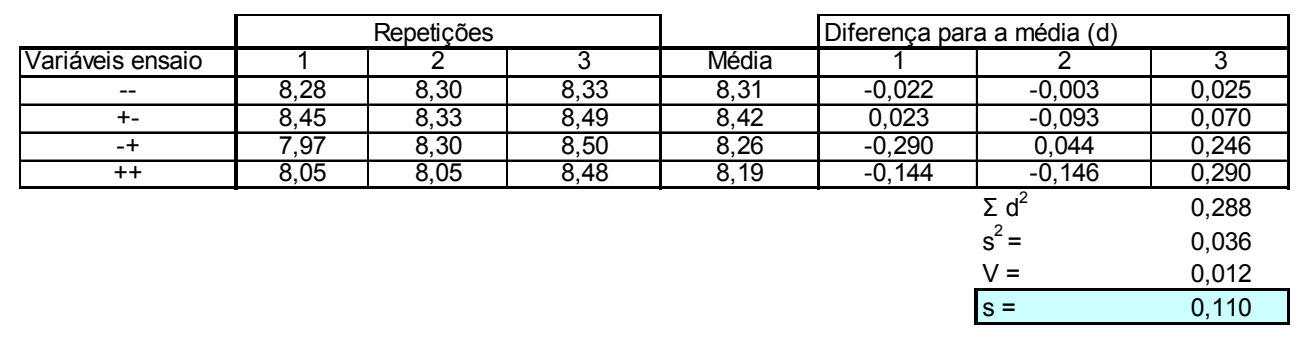

Calculado o erro, procede-se à sua comparação com os efeitos de cada variável sobre as respostas de absorção, na Tabela 5.4, conforme Box; Hunter; Hunter (1978).

Tabela 5.4 - Estudo de significância das variáveis do planejamento para as respostas de absorção.

\begin{tabular}{l|ccc|}
\hline \multicolumn{1}{|l}{ Absorção (\%) } & Efeito & & Erro padrão \\
\cline { 2 - 4 } & 8,294 & +- & 0,055 \\
\hline média & & & \\
\hline EFEITOS PRINCIPAIS & 0,026 & +- & 0,110 \\
\hline efeito ensaio & $-0,140$ & +- & 0,110 \\
\hline efeito secagem & & & \\
\hline INTERAÇÕES DOIS FATORES & & +- & 0,110 \\
\hline efeito ens $x$ sec & $-0,092$ & + & \\
\hline
\end{tabular}

A Tabela 5.4 comprova a análise de que nenhuma variável considerada é significante às respostas de absorção. Desta forma, fica estatisticamente provado que a secagem por pano ou microondas são iguais quanto à obtenção da resposta de absorção de amostras de agregados de RCD reciclados de alta porosidade.

Os mesmos cálculos foram realizados para as respostas de perda de massa, chegando-se ao erro experimental de 0,015 demonstrado na Tabela 5.5, e comparando-o aos efeitos das variáveis sobre as respostas de perda de massa, na Tabela 5.6.

Tabela 5.5 - Determinação erro experimental do planejamento para as respostas de perda de massa.

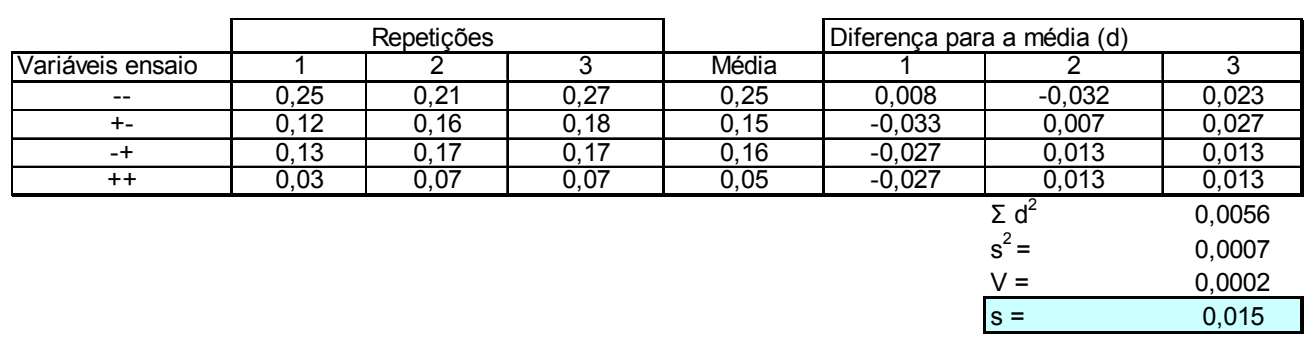


Tabela 5.6 - Estudo de significância das variáveis do planejamento para as respostas de perda de massa.

\begin{tabular}{l|lcc|}
\hline \multicolumn{1}{|l|}{ Perda massa (\%) } & Efeito & & Erro padrão \\
\hline média & 0,151 & +- & 0,008 \\
\hline EFEITOS PRINCIPAIS & & & \\
\hline efeito ensaio & $-0,101$ & +- & 0,015 \\
\hline efeito secagem & $-0,093$ & +- & 0,015 \\
\hline INTERAÇOES DOIS FATORES & & & \\
\hline efeito ens $x$ sec & $-0,003$ & +- & 0,015 \\
\hline
\end{tabular}

Observa-se, na Tabela 5.6, que se comprova estatisticamente a significância das variáveis a) repetição do ensaio e b) método de secagem sobre as respostas de perda de massa, em níveis bem superiores ao erro experimental. Assim, o uso do microondas melhora o ensaio em relação ao uso do pano, em níveis maiores do que os encontrados no planejamento experimental do capítulo 4, principalmente no que diz respeito ao primeiro ensaio executado sobre uma determinada amostra. Isto comprova a hipótese levantada de que as partículas dos agregados apresentam, em sua camada exterior, altos níveis iniciais de desagregação, o que se deve em parte ao processo de britagem sofrido na usina de reciclagem. Assim, nos primeiros ensaios realizados com uma amostra de agregados reciclados, esta camada externa desprendese com maior facilidade, o que gera maiores índices de perda de massa. Os próximos ensaios são marcados por diminuição das perdas de massa medidas.

Há ainda que se notar que os valores de perda de massa das amostras, como visualizado na Tabela 5.5, variaram entre 0,12 e 0,18\% nos segundos ensaios com pano, e entre 0,03 e $0,07 \%$ nos segundos ensaios com microondas. Estes valores são menores do que as faixas de variação da perda de massa das amostras obtidas no planejamento do capítulo 4, que foram de 0,20 a $0,30 \%$ para o pano e de 0,09 a $0,19 \%$ para o microondas, resultados também não obtidos nos primeiros ensaios das amostras e sim em repetições de ciclos molhagem-secagem. $\mathrm{O}$ fato dos ensaios do presente capítulo terem apresentado menor perda de massa do que os resultados do capítulo 4 explica-se porque naquele foi utilizada amostra de agregados de RCD reciclados de faixa de densidade $<1,9 \mathrm{~kg} / \mathrm{dm}^{3}$, enquanto agora as amostras eram da faixa $1,9<\mathrm{d}<2,2 \mathrm{~kg} / \mathrm{dm}^{3}-$ menos porosas, apresentando menores níveis de perda de massa. Assim, também pode se concluir que a perda de massa diminui conforme o aumento da densidade, e vice-versa.

Para o planejamento experimental realizado, não há sentido em se realizar cheque estatístico de curvatura do modelo, pois as duas variáveis (repetição do ensaio e meio de secagem) são qualitativas. O mesmo vale para o passo ascendente - etapa de cálculo de novas configurações de ensaios visando otimização das respostas. 


\subsection{CONCLUSÕES DO CAPÍTULO}

Sobre o planejamento experimental realizado neste capítulo com agregados de RCD reciclados faixa de densidade $1,9<\mathrm{d}<2,2 \mathrm{~kg} / \mathrm{dm}^{3}$, visando a análise dos fatores de influência real sobre a perda de massa das amostras durante os ensaios, concluiu-se que:

1) As respostas de MEA e MER podem ser obtidas com sucesso em qualquer combinação de variáveis utilizada, no primeiro ou segundo ensaio sobre a amostra, e com pano ou microondas para secagem - sua determinação independe das variáveis;

2) Nenhuma das duas variáveis estudadas - repetição do ensaio ou método de secagem influenciou as medidas de absorção das amostras, o que era esperado, uma vez que o presente planejamento teve o intuito de analisar as influências de variáveis sobre as respostas de perda de massa das amostras e não sobre as respostas de absorção, que já haviam sido suficientemente estudadas no capítulo 4;

3) A perda de massa foi influenciada de forma significativa pelo número do ensaio, atingindo valores maiores nos primeiros ensaios em relação aos segundos, independentemente da secagem por pano ou por microondas, para todas as amostras;

4) A perda de massa foi influenciada de forma significativa pelo método de secagem, atingindo valores maiores nos ensaios com pano em relação aos ensaios com microondas, independentemente de ser o primeiro ou o segundo ensaio de cada amostra, o que comprova o fato de que a secagem por microondas diminui o desgaste superficial da amostra;

5) O primeiro ensaio com pano apresentou maior perda de massa em relação ao segundo com pano, e em relação ao primeiro com microondas. Analogamente, o segundo ensaio com microondas apresentou menor perda de massa em relação ao primeiro com microondas, e também em relação ao segundo com pano. O primeiro ensaio com microondas apresentou perda de massa de mesma ordem de grandeza em relação ao segundo ensaio com pano. Assim, se comprovou a teoria da maior perda de massa no primeiro ensaio sobre uma amostra, e também a da menor perda de massa da amostra quando da substituição da secagem por pano (NM 53) pela secagem em microondas, sem prejuízos às medições de absorção e MEA. 


\section{COMPARAÇÃO ENTRE DETERMINAÇÃO DA MASSA SECA EM ESTUFA E MICROONDAS}

Os capítulos 4 e 5 estudaram possibilidades de modificações nos procedimentos da norma NM 53 para sua aplicação sobre agregados de alta porosidade, buscando: 1) aumentar a saturação dos poros das amostras (aumento da precisão); 2) diminuir o tempo do ensaio; e 3 ) diminuir a perda de massa da amostra, obtendo sucesso para os itens 1 e 2 através da saturação a vácuo por 30 min em substituição à saturação à pressão ambiente por $24 \mathrm{~h}$, e para o item 3 através da secagem por microondas em substituição à secagem por pano. Porém, o procedimento de determinação da massa seca da amostra continuou a ser executado de acordo com a NM 53, requerendo, por secagem em estufa, no mínimo 24 horas, tempo inadequado ao uso em uma central de reciclagem de RCD para a caracterização de lotes de agregados.

O presente capítulo busca, assim, analisar a viabilidade da determinação da $\mathrm{M}_{\mathrm{s}} \mathrm{em}$ microondas em substituição à secagem em estufa, procedimento que pode diminuir o tempo do ensaio em até 20 horas.

\subsection{Planejamento eXPERIMENTAL, MATERIAIS E MÉtodos}

Como demonstrado nos capítulos 4 e 5, a secagem em microondas substituiu de forma eficiente a secagem com pano para a determinação da $\mathrm{M}_{\mathrm{sss}}$ de amostras de agregados porosos, trazendo resultados de absorção estatisticamente iguais e perda de massa das amostras em nível significativamente menor. A determinação da $\mathrm{M}_{\mathrm{s}}$, porém, continuou sendo realizada através de secagem da amostra em estufa a $+-105^{\circ} \mathrm{C}$ por $24 \mathrm{~h}$. Como a secagem em microondas apresentou-se útil em substituição à secagem por pano e também muito rápida para a retirada da umidade livre das amostras, é possível que o ensaio de secagem em microondas possa determinar $\mathrm{a}_{\mathrm{s}}$ da amostra em tempo muito inferior às 24 horas da estufa.

Nos planejamentos dos capítulos 4 e 5, este estudo não pôde ser executado concomitantemente às análises sobre as variáveis consideradas porque os ensaios em microondas não puderam ser levados ao extremo, retirando toda a umidade possível, pois não se sabia se este procedimento poderia causar destruição da amostra, gerado um erro na medição da $M_{s}$ final do conjunto - determinada após secagem em estufa por 24h após o fim do ensaio. Esta $\mathrm{M}_{\mathrm{s}}$ final medida poderia ser menor do que seu valor real devido à possível 
destruição da amostra, com conseqüente erro sobre as determinações dos valores de perda de massa do conjunto, que seriam maiores do que o real. Deste modo, os ensaios eram interrompidos antes da umidade total da amostra chegar a patamares próximos a $0 \%$.

O presente planejamento experimental estudou, portanto, a diferença entre as $M_{s}$ medidas de uma mesma amostra: 1) na estufa após 24h de secagem; e 2) no microondas após secagem até estabilização da massa.

\subsubsection{ARRANJO EXPERIMENTAL}

A Tabela 6.1 apresenta o planejamento fatorial $2^{1}$ utilizado para as verificações sobre a massa seca da amostra, segundo modelo de Box; Hunter; Hunter (1978). A variável do planejamento foi o método de determinação da $M_{s}$, sendo o ponto (-1) a determinação por secagem em estufa por $24 \mathrm{~h}$, e o ponto $(+1)$ a determinação por microondas. Com as respostas obtidas tornou-se possível analisar: 1) a diferença entre as $M_{s}$ medidas na estufa e no microondas; e 2) a diferença entre as absorções medidas com ambas as $M_{s}$, pois foram determinadas no mesmo ensaio, possibilitando o cálculo de dois resultados de absorção em cada ensaio para serem comparados, um para cada $\mathrm{M}_{\mathrm{s}}$ e mantendo-se os demais dados fixos.

Tabela 6.1 - Planejamento fatorial $2^{1}$ completo dos ensaios sobre agregados reciclados densidade $1,9<\mathrm{d}<2,2 \mathrm{~kg} / \mathrm{dm}^{3}$.

\begin{tabular}{|c|c|c|}
\cline { 2 - 3 } \multicolumn{1}{c|}{} & VARIAVEIS CODIFICADAS & \multicolumn{1}{c|}{} \\
\hline ENSAIO & MASSA SECA & AMOSTRA \\
\hline 2.4 .1 & - & A1 \\
\hline 2.4 .2 & + & A2 \\
\hline 2.4 .3 & - & \\
\hline 2.4 .4 & + & $\mathrm{A} 3$ \\
\hline 2.4 .5 & - & \\
\hline 2.4 .6 & + & $\mathrm{A} 4$ \\
\hline 2.4 .7 & - & \\
\hline 2.4 .8 & + & \\
\hline
\end{tabular}

O planejamento $2^{1}$, como visto na tabela 6.1 , foi repetido quatro vezes, com o intuito de se determinar o erro experimental, sendo, para cada repetição, uma amostra distinta. Assim se evitou a repetição de ensaios sobre uma mesma amostra, pois, conforme demonstrado no capítulo 5, no primeiro ensaio a perda de massa é maior, o que faz com que repetições de ensaios sobre amostras sejam prejudiciais a este planejamento pelo fato de que poderiam subestimar as diferenças das $\mathrm{M}_{\mathrm{s}}$ do microondas e da estufa.

A determinação da $\mathrm{M}_{\mathrm{sss}}$ foi realizada por secagem em microondas, de acordo com as conclusões do capítulo 5. Detalhes desta forma de secagem estão descritos no capítulo 4. A saturação da amostra foi realizada sob depressão de vácuo $-500 \mathrm{mmHg}$ por 30 minutos, método mais rápido e eficiente do que a saturação $24 \mathrm{~h}$ à pressão ambiente (norma NM 53), como comprovado no capítulo 4 . 


\subsubsection{MATERIAIS}

Foram adotados agregados de RCD reciclados de densidade $1,9<\mathrm{d}<2,2 \mathrm{~kg} / \mathrm{dm}^{3}$, (alta porosidade), analogamente ao capítulo 5. As amostras estudadas neste trabalho são as mesmas utilizadas por Angulo (2005) e Carrijo (2005). Maiores detalhes são descritos no capítulo 4.

\subsubsection{EQUIPAMENTOS}

Os ensaios deste planejamento utilizaram-se dos mesmos equipamentos descritos nos capítulos 4 e 5, pois os ensaios foram idênticos em termos de execução.

\subsubsection{Procedimentos de ensaio e cálculos}

Os ensaios foram realizados de acordo com os passos da Figura 6.1.
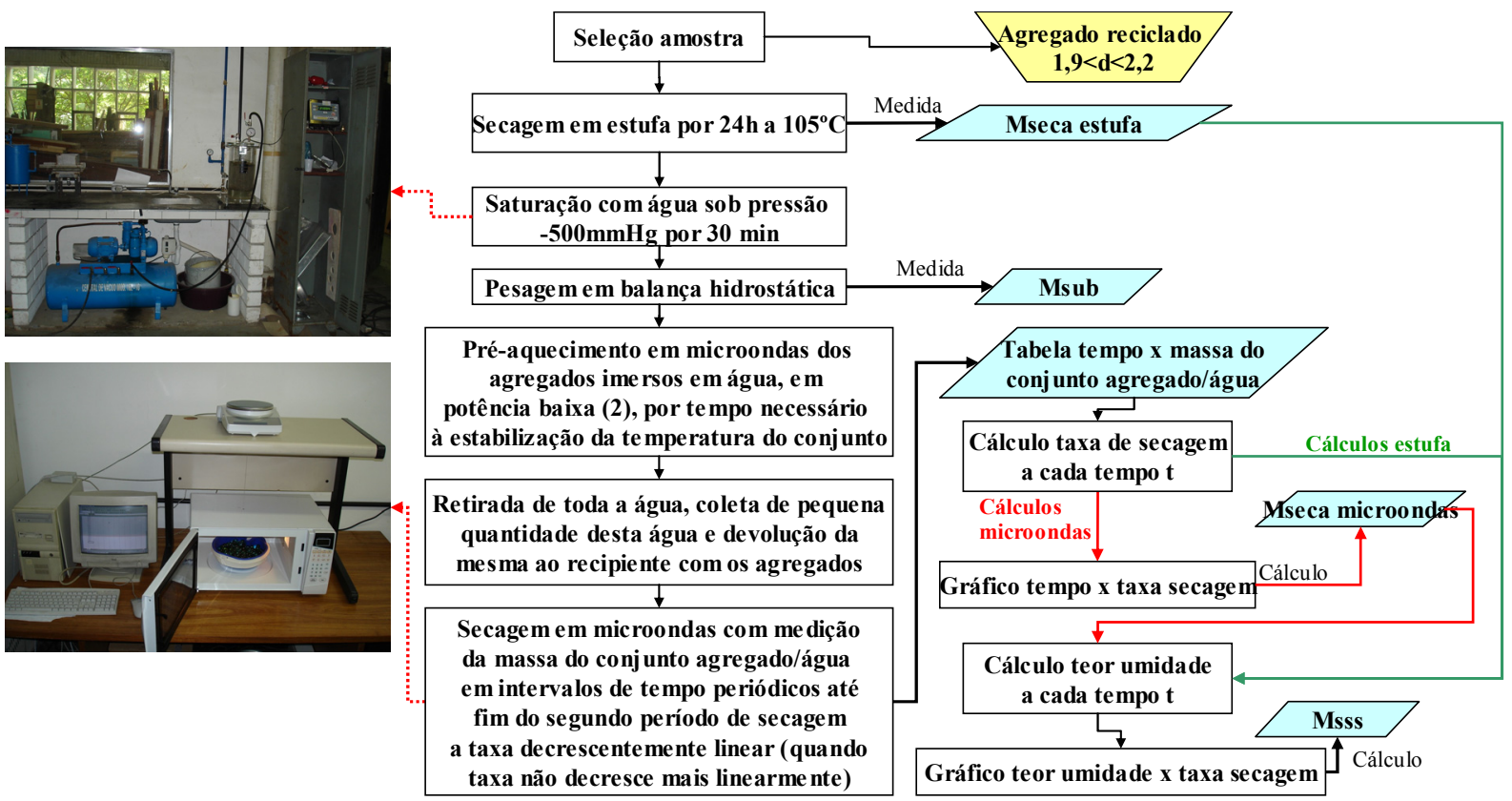

Figura 6.1 - Fluxograma de ensaio do planejamento experimental dos agregados reciclados densidade $1,9<\mathrm{d}<2,2 \mathrm{~kg} / \mathrm{dm}^{3}$.

Os ensaios em microondas seguiram os mesmos cuidados e sistemas de aquisição de dados descritos no item 4.1.6 do capítulo 4. Os cálculos das respostas de absorção, MER e MEA também foram realizados de forma análoga ao capítulo 4, com uma modificação: o meio de obtenção da $\mathrm{M}_{\mathrm{s}}$, determinada através do gráfico de secagem em microondas.

$A M_{s}$ determinada pela secagem em microondas poderia, a princípio, ser realizada de duas formas: 1) levando o ensaio de secagem até a estabilização da massa (retirada de toda a umidade livre), e adotando este valor como o da $\mathrm{M}_{\mathrm{s}}$; ou 2) por cálculo de regressão linear.

Optou-se por utilizar a segunda forma, pois nos ensaios exploratórios a primeira secagem até estabilização da massa - demorou e as massas estabilizadas, por sua vez, 
apresentaram valores da ordem de $2 \%$ inferiores às $M_{s}$ obtidas na estufa, para a mesma amostra. $\mathrm{O}$ fato comprova que a secagem em microondas, levada ao extremo, aumenta a perda de massa de agregados de RCD reciclados.

Assim, para a determinação da $\mathrm{M}_{\mathrm{s}}$ através dos dados de secagem em microondas, plotou-se um gráfico do tempo de ensaio (eixo x) x taxa de secagem (eixo y), de forma semelhante aos gráficos para determinação da absorção, que apresentavam teor de umidade (eixo $\mathrm{x}$ ) $\mathrm{x}$ taxa de secagem (eixo y). Um modelo esquemático dos gráficos obtidos nos ensaios realizados está apresentado na Figura 6.2. Observou-se em todos os resultados obtidos experimentalmente que, na secagem em microondas levada ao extremo, ocorrem dois períodos de secagem a taxa decrescentemente linear: um primeiro (II), logo após o final da taxa de secagem constante (I); e um segundo (III), de maior inclinação, quando a taxa de secagem passa a diminuir em maior velocidade com o passar dos instantes $t$, devido à menor diminuição da massa do conjunto.

Foram então detectados os períodos numerados no gráfico: $\mathrm{I}_{0}$ ) inicial; I) taxa de secagem constante; II) primeiro trecho de taxa decrescente linear; III) segundo trecho de taxa decrescente linear; e IV) diminuição não mais linear da queda da taxa de secagem, até estabilização em zero. Estes períodos eram esperados de acordo com a teoria de secagem de sólidos descrita no capítulo 2 .

O segundo período de secagem (III), em taxa decrescentemente linear de maior inclinação, começou a ocorrer quando a taxa de secagem chegava a patamares próximos a zero, de forma que se pode deduzir que a amostra chegava à sua $\mathrm{M}_{\mathrm{s}}$. Em determinado momento deste período, porém, esta taxa de secagem começou a apresentar tendência a diminuir em menor velocidade, o que foi expresso no gráfico por uma curva (período IV), espaçando a queda da velocidade da taxa de secagem em relação aos instantes t.

Quando a queda da taxa de secagem começa a diminuir sensivelmente, perdendo o aspecto de reta, pode-se considerar que a $\mathrm{M}_{\mathrm{s}}$ do material está muito próxima de ser atingida, pois a taxa de secagem torna-se quase constante sob valores próximos a zero. Assim, para a determinação da $M_{s}$ no microondas calculou-se a equação da reta do segundo período de secagem decrescentemente linear (III), e, por regressão, esta foi extrapolada matematicamente ao ponto em que $\mathrm{y}=0$ (taxa de secagem $=0)$, obtendo-se, no eixo $\mathrm{x}$, o tempo $\mathrm{t}$ em que a $\mathrm{M}_{\mathrm{s}}$ ocorreu, conforme representado graficamente pela linha verde da Figura 6.2. A massa medida no instante $\mathrm{t}$ foi considerada $\mathrm{a}_{\mathrm{s}}$ da amostra determinada pelo microondas. 


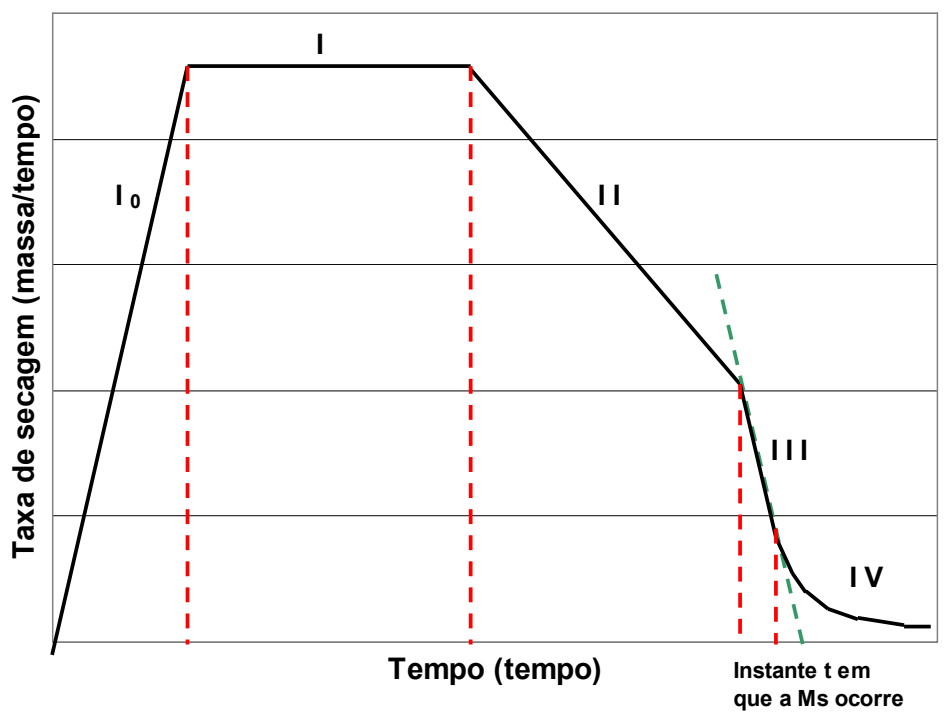

Figura 6.2 - Esquema dos períodos de secagem obtidos através dos dados de secagem em microondas (linhas vermelhas) e do método de determinação da $\mathrm{M}_{\mathrm{s}}$ (linha verde)

Com $M_{s}$ (estufa), $M_{s}$ (microondas), $M_{\text {sss }}$ e $M_{\text {sub}}$, calcula-se as propriedades absorção (A), massa específica aparente (MEA) e massa específica real (MER):

$$
\begin{aligned}
& A(\%)=\frac{M_{s s s}-M_{\sec a}}{M_{\sec a}} \times 100 \\
& M E A=\frac{M_{\sec a}}{M_{s s s}-M_{s u b}} \\
& M E R=\frac{M_{\sec a}}{M_{\sec a}-M_{s u b}}
\end{aligned}
$$

Para não haver influência das diferenças de execução entre diferentes ensaios, em cada ensaio foram determinadas as duas $\mathrm{M}_{\mathrm{s}}$ - em estufa e em microondas. A absorção foi calculada duas vezes em cada experimento, uma para cada $\mathrm{M}_{\mathrm{s}}$.

Como no capítulo 4, aqui os ensaios foram realizados sob umidade relativa do ar controlada em 50+-4\%, pelos motivos descritos no item 4.1.6. A padronização das condições de umidade relativa do ar evita que ocorra retirada de teores distintos de umidade em ensaios diferentes, o que poderia incutir em erro experimental, de acordo com McCabe (1987).

\subsection{Resultados}

As Figuras 6.3 e 6.4 apresentam os gráficos de tempo $\mathrm{t} \times$ taxa de secagem dos ensaios deste planejamento, utilizados preliminarmente para a determinação da $M_{s}$ das 
amostras através dos dados do microondas, conforme explicação da Figura 6.2. O segundo período de secagem em taxa linearmente decrescente é extrapolado por regressão ao instante $\mathrm{t}$ onde a taxa de secagem é zero. Este é o instante em que ocorreu a $\mathrm{M}_{\mathrm{s}}$ da amostra. Os dados utilizados para a confecção dos gráficos e para os cálculos dos resultados estão no apêndice I.

É importante ressaltar que os ensaios foram realizados por tempos bem superiores aos indicados nas Figuras 6.3 e 6.4, chegando a até 700 instantes t de 20 segundos cada. Após o período de taxa decrescente linear 2, marcado nos gráficos, confirma-se a tendência de decréscimo da taxa de secagem de forma não linear ao longo do tempo, até se atingir o valor zero. Os gráficos não foram plotados considerando-se os instantes até 700 para facilitar a visualização da projeção do período de taxa decrescente linear 2 ao eixo x, que, conforme a explicação da Figura 6.2, foi o método utilizado para a determinação da $\mathrm{M}_{\mathrm{s}}$ pelo microondas.
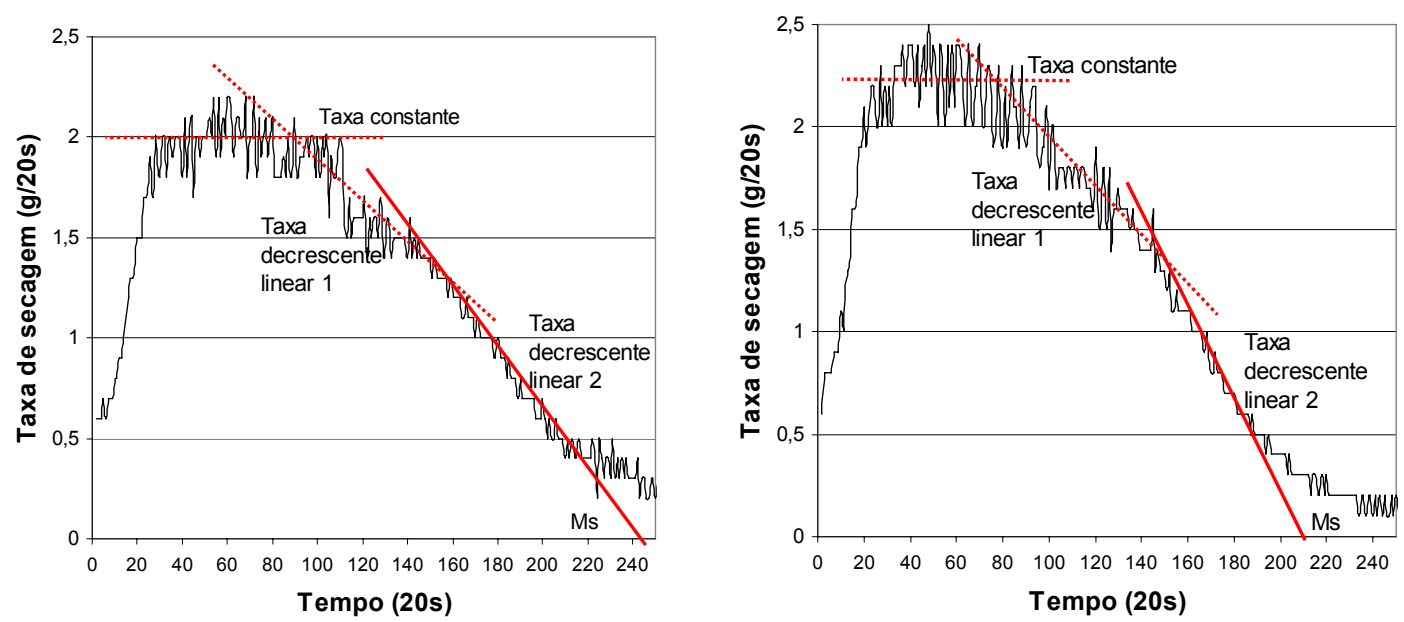

Figura 6.3 - Determinação da $\mathrm{M}_{\mathrm{s}}$ através dos dados de secagem em microondas, para a amosta: a) A1; e b) A2.
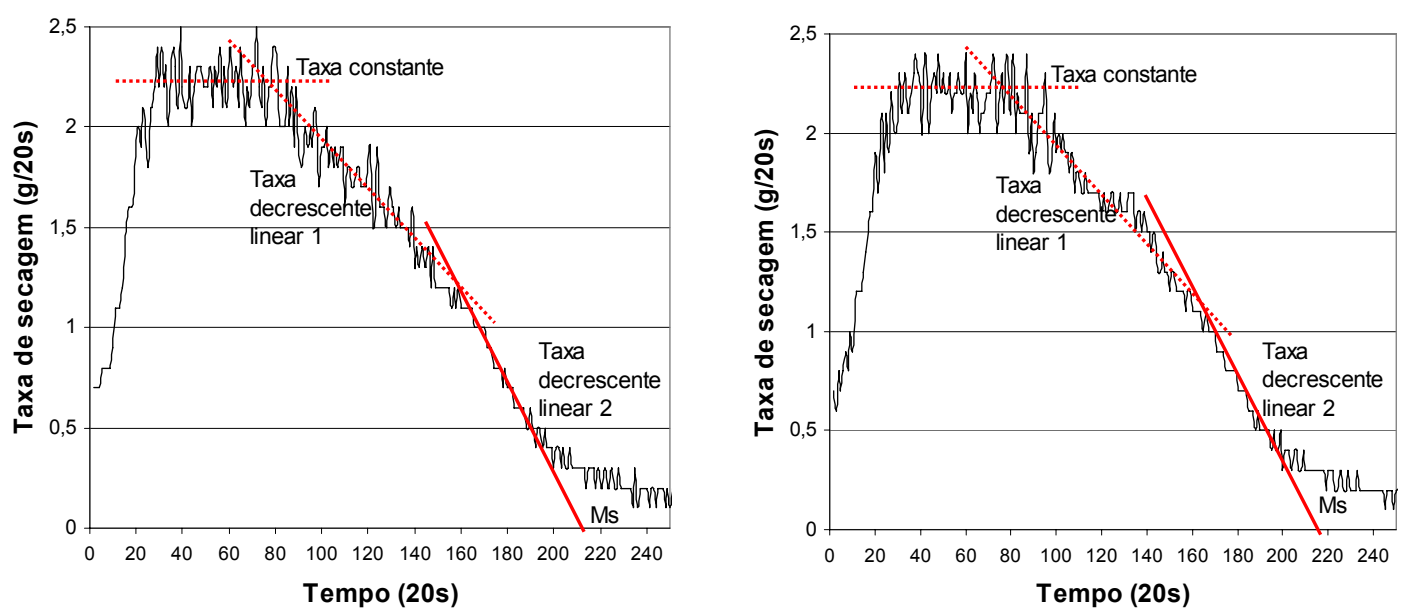

Figura 6.4 - Determinação da $\mathrm{M}_{\mathrm{s}}$ através dos dados de secagem em microondas, para a amosta: a) A3; e b) A4. 
Com as $\mathrm{M}_{\mathrm{s}}$ assim determinadas, pôde-se fazer os gráficos de secagem, do modo já estudado nos capítulos 4 e 5. Estes estão apresentados nas Figuras 6.5 a 6.8 .
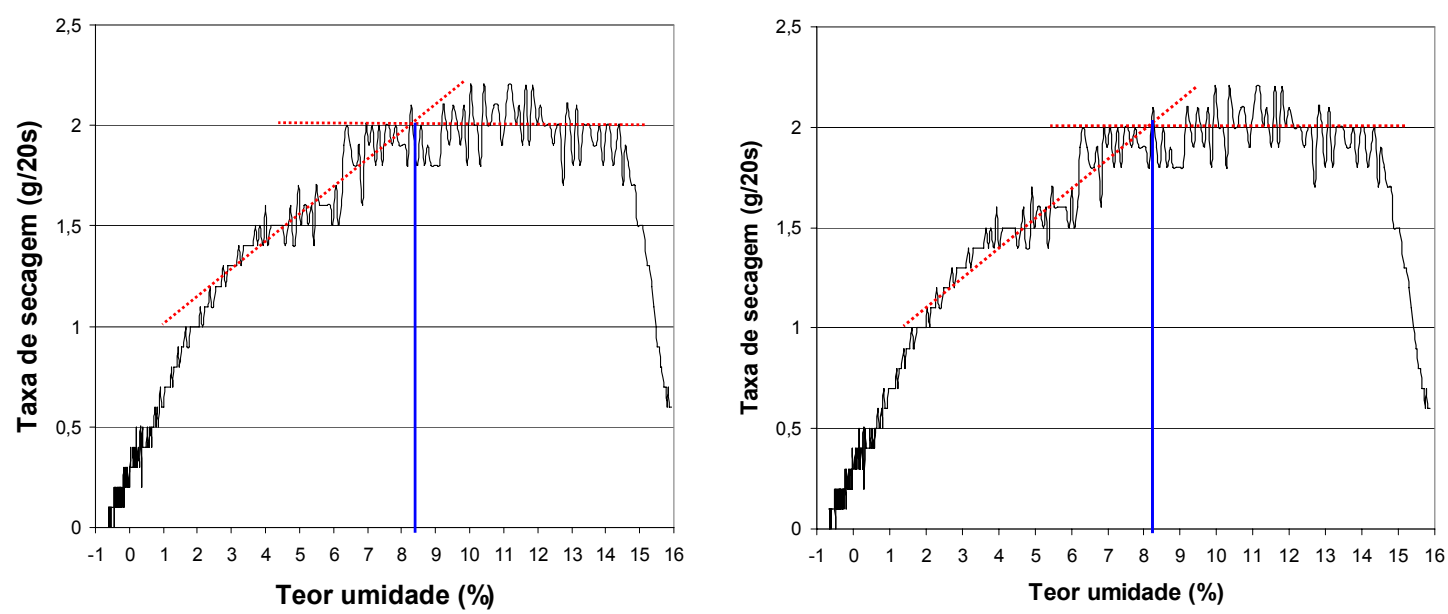

Figura 6.5 - Ensaios de secagem da amosta A1, considerando a $M_{s}$ obtida em: a) estufa (-1); e b) microondas (+1).
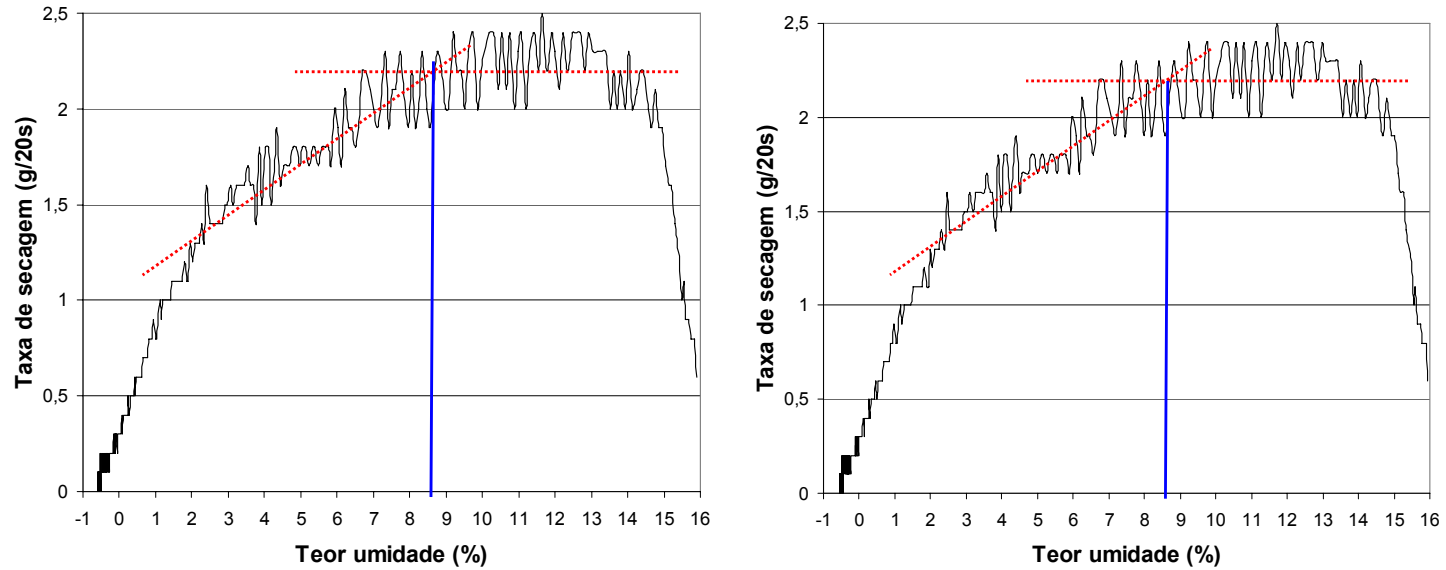

Figura 6.6 - Ensaios de secagem da amosta A2, considerando a $M_{\mathrm{s}}$ obtida em: a) estufa (-2); e b) microondas (+2).
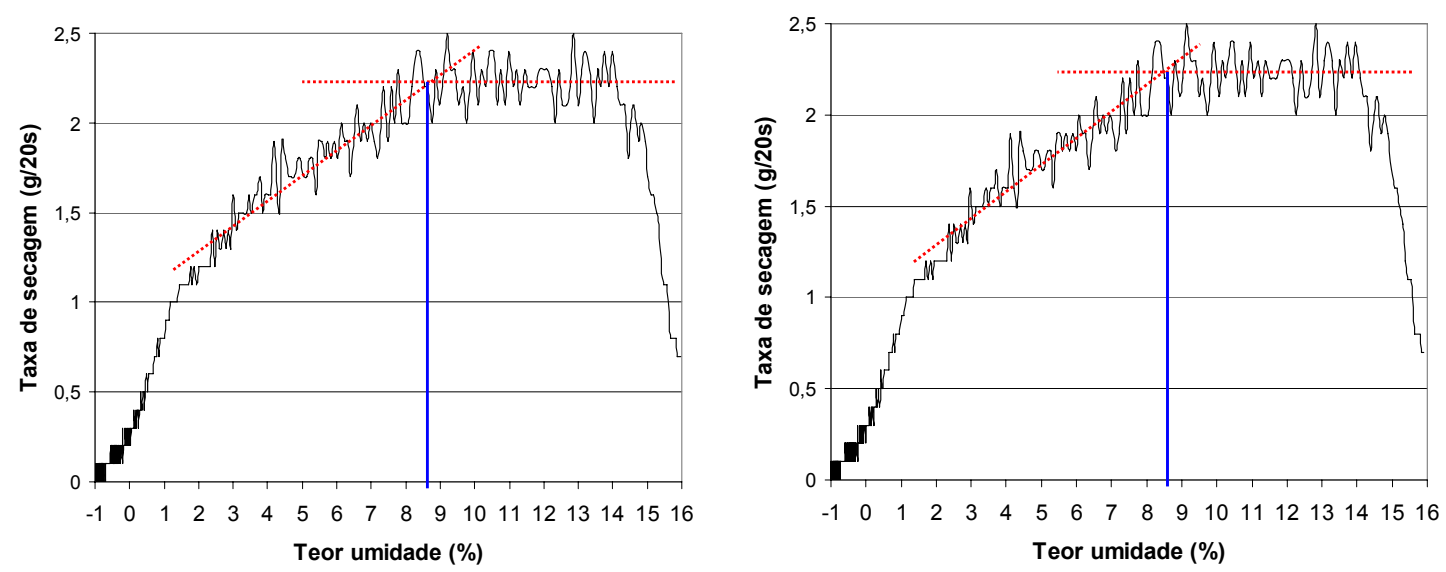

Figura 6.7 - Ensaios de secagem da amosta A3, considerando a $M_{s}$ obtida em: a) estufa (-3); e b) microondas (+3). 

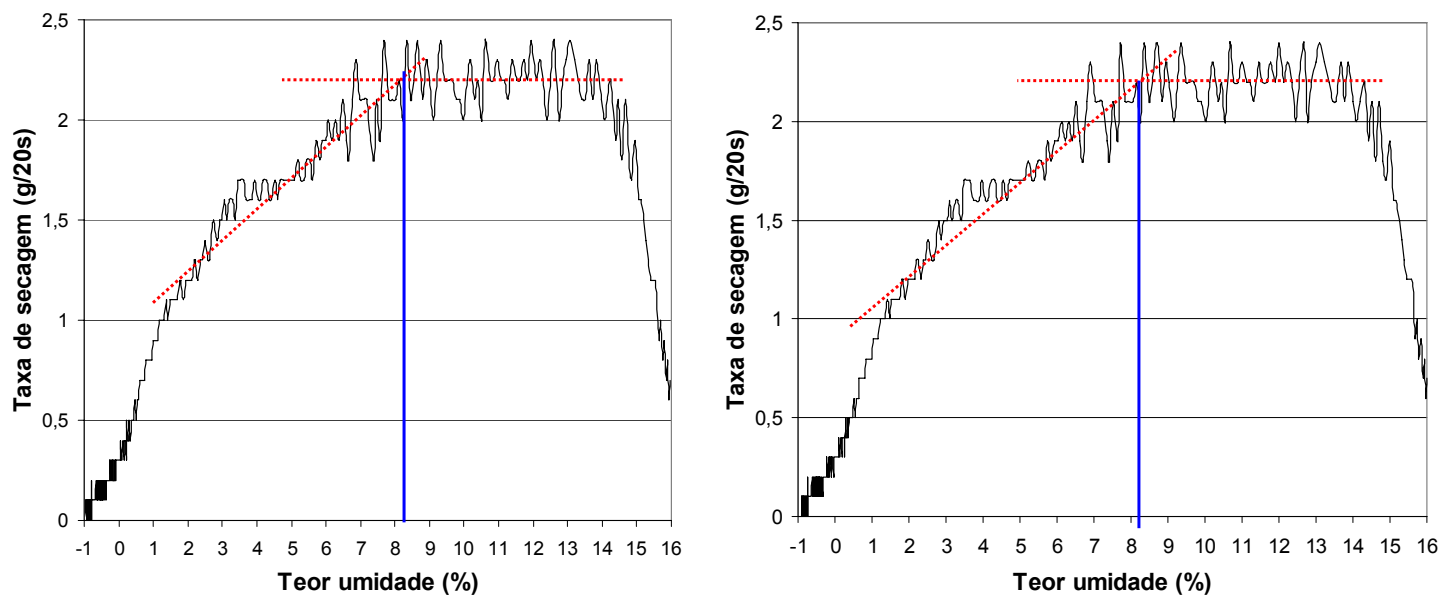

Figura 6.8 - Ensaios de secagem da amosta A4, considerando a $\mathrm{M}_{\mathrm{s}}$ obtida em: a) estufa (-4); e b) microondas (+4).

A reta vertical indica a umidade que corresponde ao ponto de $\mathrm{M}_{\mathrm{sss}}$, calculada com regressão por mínimos quadrados do ponto de transição da taxa de secagem constante para a linearmente decrescente. A seleção dos dados correspondentes aos períodos de secagem constante e decrescentemente linear, utilizados nos cálculos de regressão, foi realizada de forma análoga à descrita no item 4.2 do capítulo 4 .

Para análise dos resultados por modelos estatísticos DOE fatorial completo, a sua disposição foi realizada na Tabela 6.2.

Tabela 6.2 - Resultados do planejamento $2^{1}$ realizado sobre agregados reciclados $1,9<\mathrm{d}<2,2 \mathrm{~kg} / \mathrm{dm}^{3}$.

\begin{tabular}{|c|c|c|c|c|c|c|}
\hline & VARIÁVEL & \multicolumn{4}{|c|}{ RESPOSTAS } & \\
\hline ENSAIO & OBTENÇÃO Ms & Absorção (\%) & $\operatorname{MEA}\left(\mathrm{kg} / \mathrm{dm}^{3}\right)$ & MER $\left(\mathrm{kg} / \mathrm{dm}^{3}\right)$ & Ms (g) & AMOSTRA \\
\hline 2.4 .1 & - & 8,23 & 2,12 & 2,57 & 2003,1 & $\bar{A} 1$ \\
\hline 2.4 .2 & + & 8,20 & 2,12 & 2,56 & 2004,1 & \\
\hline 2.4 .3 & - & 8,69 & 2,09 & 2,56 & 2002,8 & $\mathrm{~A} 2$ \\
\hline 2.4 .4 & + & 8,72 & 2,09 & 2,56 & 2002,0 & \\
\hline 2.4 .5 & - & 8,65 & 2,10 & 2,57 & 2002,3 & A3 \\
\hline 2.4 .6 & + & 8,64 & 2,10 & 2,56 & 2003,1 & \\
\hline 2.4 .7 & - & 8,16 & 2,12 & 2,56 & 2002,2 & A4 \\
\hline 2.4 .8 & + & 8,16 & 2,12 & 2,56 & 2001,4 & \\
\hline
\end{tabular}

\subsection{ANÁLISE DOS RESULTADOS}

As análises de dados foram baseadas nos modelos de Box; Hunter; Hunter (1978), com auxílio dos softwares Excel e Minitab 14. As análises físicas e estatísticas do efeito da variável estudada sobre as respostas foram feitas pelas médias dos ensaios quadruplicados. $\mathrm{O}$ cálculo do erro do planejamento, por sua vez, foi realizado a partir dos desvios entre os ensaios repetidos, lembrando que foram repetidos sobre amostras distintas. Deste modo, o erro expressa a variabilidade entre as diferentes amostras mas de mesma faixa de porosidade (densidade $1,9<\mathrm{d}<2,2 \mathrm{~kg} / \mathrm{dm}^{3}$ ). 
As resposta de MEA, como ocorrido no planejamento do capítulo 4, atingiram valores muito próximos em todos os ensaios, variando entre 2,09 e 2,12kg/dm ${ }^{3}$ (grande precisão), independentemente de alterações das amostras ou da variável meio de obtenção da massa seca - ou seja, são estatisticamente iguais. O mesmo pode-se dizer em relação à MER, que variou entre 2,56 e $2,57 \mathrm{~kg} / \mathrm{dm}^{3}$. Assim, os efeitos da variável sobre a MEA e a MER não serão avaliados, pois se pode afirmar que tanto a determinação da $\mathrm{M}_{\mathrm{s}}$ em estufa como no microondas são válidas para a medição da MEA e MER de agregados de RCD reciclados.

As Figuras 6.9(a) e 6.9(b) apresentam a correlação entre a variável método de obtenção da massa seca $\left(\mathrm{M}_{\mathrm{s}}\right)$ com as respostas de absorção e $\mathrm{M}_{\mathrm{s}}$, respectivamente.
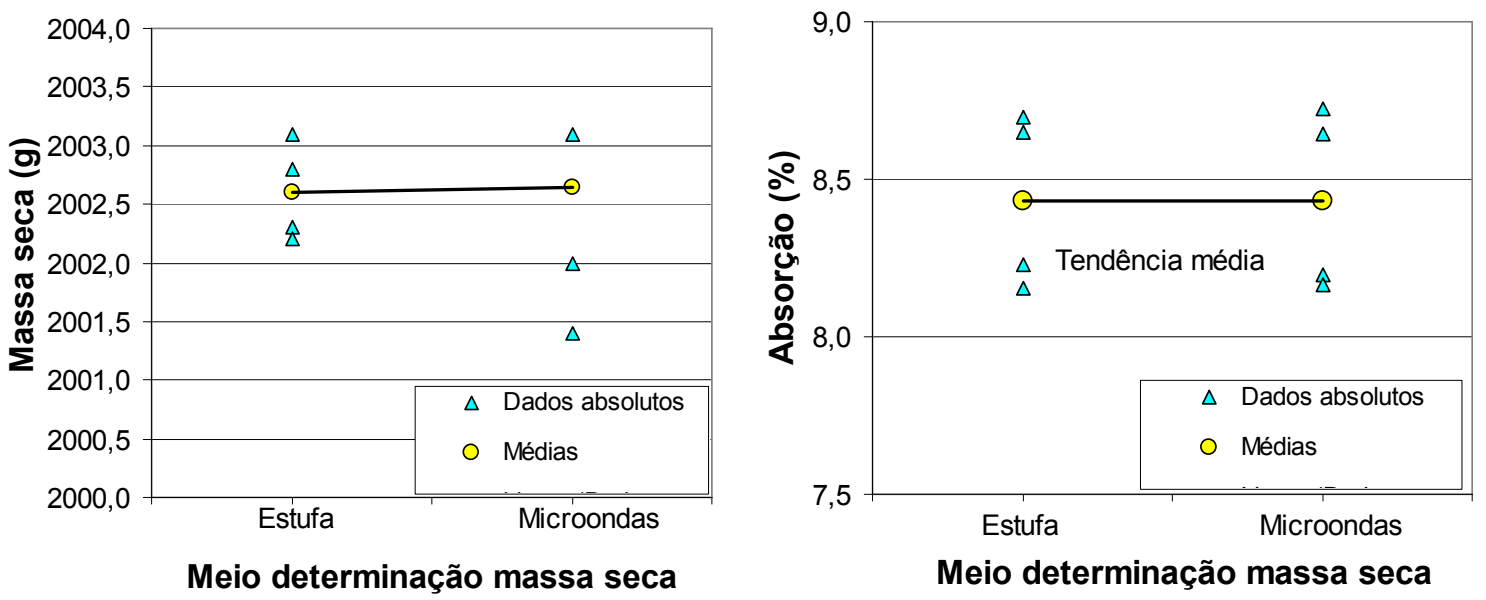

Figura 6.9 - Efeito da variável método de obtenção da massa seca sobre as respostas de: a) massa seca; e b) absorção.

A Figura 6.9(a) demonstra que não há tendência de aumento ou diminuição das massas secas das amostras em função da variação do método de obtenção da massa seca estufa ou microondas. Este fato traz, como conseqüência, também uma falta de tendência de alteração das respostas de absorção em função da variação do método de obtenção da $\mathrm{M}_{\mathrm{s}}$, como expressa o gráfico da Figura 6.9(b), uma vez que as respostas de absorção dependem diretamente das respostas de massa seca.

Assim, pelos ensaios deste trabalho constatou-se que, utilizando-se secagem de agregados reciclados em estufa por 24 horas ou em microondas por 2,5 horas em média, obtém-se medidas de $M_{s}$ (e conseqüentemente absorção) estatisticamente iguais, fato importante pela possibilidade de economia média de tempo de 21,5 horas no ensaio.

Para comprovar estatisticamente estas análises, calcula-se o erro experimental pelos desvios encontrados entre as quadruplicatas dos ensaios, chegando-se ao valor de 0,777 para as respostas de $\mathrm{M}_{\mathrm{s}}$, conforme Tabela 6.3. Importa notar que as quatro repetições dos ensaios 
foram realizadas sobre amostras distintas, por motivos discutidos no planejamento, de forma que o erro também inclui diferenças entre as amostras. Calculado o erro, procede-se à sua comparação com os efeitos da variável sobre as respostas de massa seca, na Tabela 6.4, de acordo com Box; Hunter; Hunter (1978).

Tabela 6.3 - Determinação do erro experimental do planejamento para as respostas de massa seca.

\begin{tabular}{|c|c|c|c|c|c|c|c|c|c|}
\hline & \multicolumn{3}{|c|}{ Repetiçōes } & \multicolumn{6}{|c|}{ Diferença para a média (d) } \\
\hline Variáveis ensaio & 1 & 2 & 3 & 4 & Media & 1 & 2 & 3 & 4 \\
\hline- & 2003,1 & 2002,8 & 2002,3 & 2002,2 & 2002,6 & 0,500 & 0,200 & $-0,300$ & $-0,400$ \\
\hline \pm & 2004,1 & 2002,0 & 2003,1 & 2001,4 & 2002,7 & 1,450 & $-0,650$ & 0,450 & $-1,250$ \\
\hline & & & & & & & & $\begin{array}{l}\sum d^{2} \\
s^{\alpha}= \\
V=\end{array}$ & $\begin{array}{l}4,830 \\
1,207 \\
0,604\end{array}$ \\
\hline & & & & & & & & $\mathrm{s}=$ & 0,777 \\
\hline
\end{tabular}

Tabela 6.4 - Estudo de significância das variáveis do planejamento para as respostas de massa seca.

\begin{tabular}{l|ccc|}
\hline Massa seca $(\mathrm{g})$ & Efeito & & Erro padrão \\
\hline média & 2002,63 & +- & 0,389 \\
\hline EFEITO PRINCIPAL & & & \\
\hline efeito metodo obtençāo Ms & 0,05000 & +- & 0,777 \\
\hline
\end{tabular}

A Tabela 6.4 comprova a análise de que a variável considerada não é significante às respostas de massa seca. Desta forma, fica estatisticamente provado que a determinação da massa seca por estufa ou microondas não são diferentes para amostras de agregados de RCD reciclados de alta porosidade. Deve-se contudo sugerir que, para aplicação prática do método de determinação da $M_{s}$ através do microondas, seja realizada calibração periódica, confrontando valores de $\mathrm{M}_{\mathrm{s}}$ obtidos pela secagem de amostras neste equipamento com resultados de $\mathrm{M}_{\mathrm{s}}$ obtidos em estufa, para a garantia de que as respostas estejam compatíveis.

Os mesmos cálculos foram realizados para as respostas de absorção, chegando-se ao erro experimental de 0,248 demonstrado na Tabela 6.5, e comparando-o aos efeitos da variável sobre as respostas de absorção, na Tabela 6.6.

Tabela 6.5 - Determinação erro experimental do planejamento para as respostas de absorção.

\begin{tabular}{|c|c|c|c|c|c|c|c|c|c|}
\hline & \multicolumn{3}{|c|}{ Repetições } & \multicolumn{6}{|c|}{ Diferença para a média (d) } \\
\hline Variáveis ensaio & & 2 & 3 & 4 & Média & 1 & 2 & 3 & 4 \\
\hline- & 8,23 & 8,69 & 8,65 & 8,16 & 8,43 & $-0,205$ & 0,263 & 0,218 & $-0,276$ \\
\hline 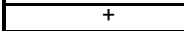 & 8,20 & 8,72 & 8,64 & 8,16 & 8,43 & $-0,236$ & 0,292 & 0,213 & $-0,269$ \\
\hline & & & & & & & & $\sum \mathrm{d}^{2}$ & 0,493 \\
\hline & & & & & & & & $s^{2}=$ & 0,123 \\
\hline & & & & & & & & $V=$ & 0,062 \\
\hline & & & & & & & & $\mathrm{s}=$ & 0,248 \\
\hline
\end{tabular}

Tabela 6.6 - Estudo de significância das variáveis do planejamento para as respostas de absorção.

\begin{tabular}{l|cccc|}
\hline Absorção (\%) & Efeito & & Erro padrão \\
\hline média & 8,43 & +- & 0,124 \\
\hline EFEITO PRINCIPAL & & & \\
\hline efeito método obtenção Ms & $-0,00038$ & +- & 0,248 \\
\hline
\end{tabular}


De acordo com a Tabela 6.6, também fica estatisticamente comprovado que a determinação da massa seca por estufa ou microondas são iguais para os cálculos de absorção de amostras de agregados de RCD reciclados de alta porosidade.

Para este planejamento experimental, não há sentido em se realizar cheque de curvatura, pois a variável é qualitativa. O mesmo vale para o passo ascendente.

\subsection{Conclusões do CAPÍtulo}

Sobre o planejamento experimental realizado neste capítulo com agregados de RCD reciclados faixa de densidade $1,9<\mathrm{d}<2,2 \mathrm{~kg} / \mathrm{dm}^{3}$, visando a análise da diferença entre as massas secas medidas em estufa e microondas, concluiu-se que:

1) As respostas de MEA e MER são independentes da variável estudada, podendo ser calculadas com qualquer massa seca determinada - estufa ou microondas;

2) A variável estudada - método de obtenção da massa seca - não influenciou as medidas de massa seca das amostras, de forma que sua determinação por estufa após 24 horas, ou por secagem em microondas após 2,5 (em média) horas são estatisticamente iguais;

3) A variável estudada - método de obtenção da massa seca - não influenciou as respostas de absorção das amostras, que são estatisticamente iguais se calculadas com a $M_{s}$ determinada em estufa após 24 horas ou a $\mathrm{M}_{\mathrm{s}}$ determinada em microondas em 2,5 horas;

4) Devido à igualdade estatística para as determinações da massa seca por estufa ou microondas, a determinação pelo segundo método é de grande vantagem, pois ocorre após secagem de duração de, em média, 2,5 horas. Comparando-se este tempo à determinação por estufa, que é realizada após 24 horas, tem-se um ganho de aproximadamente 21,5 horas na duração da execução do ensaio. 


\section{Proposta de MÉtodo}

Após a execução dos experimentos descritos nos capítulos 3, 4, 5 e 6, sobre agregados de vidro, argila expandida e RCD reciclados em diferentes faixas de densidade, este capítulo descreve o método de ensaio que, de acordo com os resultados experimentais encontrados, possui precisão e rapidez para caracterizar agregados de RCD reciclados.

Como se observou nas análises comparativas, os procedimentos para determinar absorção de água e densidades real e aparente propostos neste trabalho dão resultados equivalentes ao da NM 53. Foram também confirmados muitos dos problemas detectados em bibliografia quando se utiliza a NM 53 para caracterização de agregados reciclados, como: a) baixa saturação de poros das amostras nas $24 \mathrm{~h}$; b) perda de massa durante o ensaio; e c) altos tempos de caracterização. Conseguiu-se comprovar estatisticamente que: 1) para aumentar a saturação dos poros e ao mesmo tempo acelerar o ensaio, a saturação à pressão ambiente por 24 horas pode ser substituída pela saturação sob vácuo $-500 \mathrm{mmHg}$ por 30 minutos; e 2) para diminuir a perda de massa durante o ensaio, acelerando-o e obtendo resultados de absorção iguais, a secagem por pano pode ser substituída pela secagem por microondas, com eliminação da etapa inicial de determinação da $\mathrm{M}_{\mathrm{s}}$ após secagem em estufa por 24 horas, pois o mesmo procedimento de secagem (microondas) pode determinar a $\mathrm{M}_{\mathrm{sss}}$ e a $\mathrm{M}_{\mathrm{s}}$ da amostra.

\subsection{OBJETIVO}

Assim, o objetivo deste capítulo é apresentar uma proposta de método de ensaio para determinação rápida das seguintes propriedades físicas de agregados reciclados: absorção de água, massa específica real (MER) e massa específica aparente (MEA).

Este método pode ser facilmente adaptado para medir estas propriedades em outros grãos, pois a teoria de secagem de sólidos sobre a qual ele se baseia vale para materiais porosos em geral. Os ensaios sobre argila expandida realizados no capítulo 4 comprovaram isto na prática, pois as propriedades físicas medidas sobre este material também foram estatisticamente iguais às determinações realizadas com pano (NM 53).

\subsection{EQUIPAMENTOS}

Os ensaios deste método utilizam-se de: 
$\Rightarrow$ Balança digital com capacidade $4 \mathrm{~kg}$ ou maior e precisão de $0,1 \mathrm{~g}$, dotada de dispositivo para medições de massa submersa e saída digital para interface com microcomputador;

$\Rightarrow$ Recipientes para estocagem, secagem, saturação e medição da $\mathrm{M}_{\text {sub }}$ dos agregados bacias e cesto metálico com capacidade de ser pendurado em gancho;

$\Rightarrow$ Central de vácuo com capacidade de aplicar pressão constante de vácuo de pelo menos $500 \mathrm{mmHg}$ durante todo o ensaio, dotada de manômetro com precisão de $10 \mathrm{mmHg}$;

$\Rightarrow$ Cilindro de acrílico com espessura 10mm e tampa de acrílico com espessura 20mm, calculado para suportar pressão interna, dentro do qual a amostra sofrerá a pressão de vácuo, que permite verificar a presença eventual de bolhas de ar remanescentes;

$\Rightarrow$ Mangueiras $\varnothing=5 / 16$ " e conexões de diâmetros compatíveis, para gases sob pressão;

$\Rightarrow$ Forno de microondas de cozinha com potência de 20\% (baixa) a 100\% (alta) (foi usado um Panasonic, modelo NN S-65, 35 litros, potência máxima de 1000W), com furo na face superior para realizar o ensaio de massa versus tempo de secagem, calibrado (tempo e potência) para fornecer secagem equivalente à obtida com pano pelo método NM 53;

$\Rightarrow$ Microcomputador terminal para aquisição de dados de massa da balança, dotado de software e cabos compatíveis com o padrão de comunicação da balança.

\subsection{Procedimentos de ensalo e cálculos}

A seqüência de ensaio está apresentada no fluxograma da Figura 7.1:

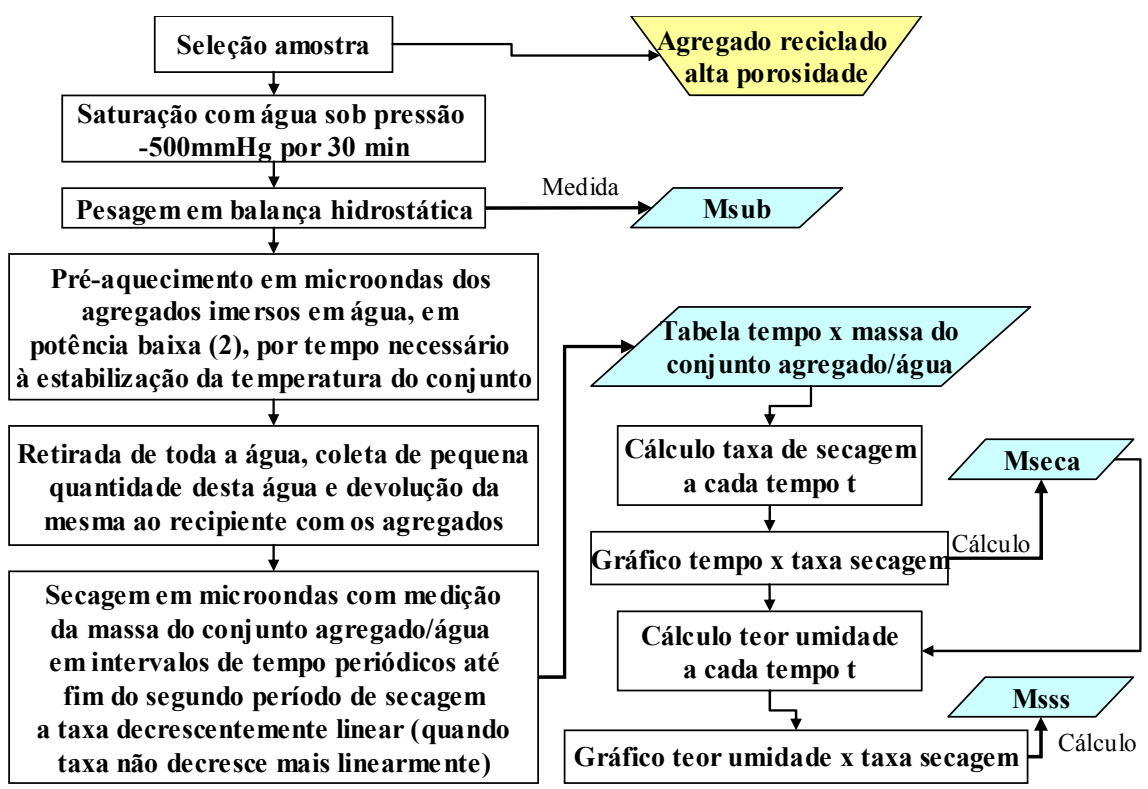

Figura 7.1 - Fluxograma do ensaio criado para medição de propriedades físicas de agregados reciclados de alta porosidade.

O procedimento de ensaio envolve as seguintes etapas: 
1) Definição de lote e retirada de amostra representativa a ser ensaiada. Este procedimento pode ser realizado de acordo com a teoria de Pierre Gy, conforme descrição de Angulo (2005);

2) Saturação da amostra: em água, realizada sob depressão de vácuo $-500 \mathrm{mmHg}$, por 30 minutos, conforme ilustrado na Figura 7.2. Durante este procedimento o vácuo deve ser retirado após 1, 3, 5, 10 e 15 minutos do início do ensaio, a amostra retirada e reimersa na água e o vácuo reaplicado imediatamente. Este procedimento retira as bolhas de ar que se formam na superfície do cesto metálico e dos próprios agregados;

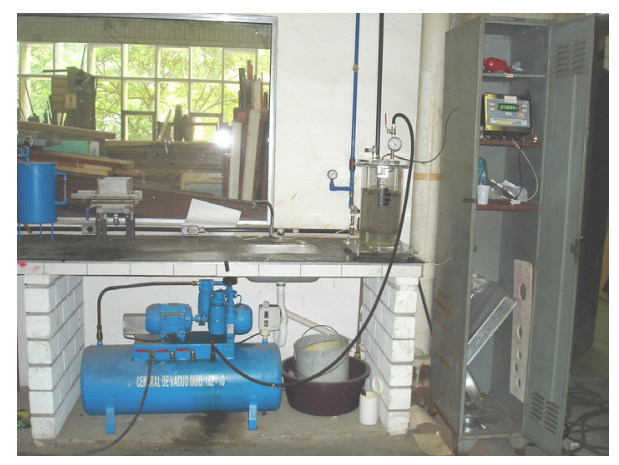

Figura 7.2 - Ilustração dos equipamentos e procedimento utilizados para saturação das amostras.

3) Pesagem da amostra saturada em balança hidrostática, para determinação da massa submersa $\left(\mathrm{M}_{\text {sub }}\right)$ em água;

4) Pré-aquecimento no forno de microondas, em recipiente apropriado, dos agregados totalmente imersos em água, pelo tempo necessário à estabilização da máxima temperatura atingida da massa agregado/água, que nos ensaios deste trabalho esteve em torno de $70^{\circ} \mathrm{C}$. Com a estabilização da temperatura antes do início do ensaio, evita-se que os agregados sejam expostos a períodos de secagem (perdendo água por evaporação) ainda sob baixas taxas de secagem, que não são relevantes ao ensaio. No caso deste trabalho, o tempo necessário à realização da etapa de pré-aquecimento foi de aproximadamente 45 minutos, e a potência do microondas utilizada, de $20 \%$. A utilização de potência baixa deveu-se ao fato de que, conforme visto experimentalmente no capítulo 3, altas potências geram taxas de secagem muito altas, que acarretam em perda de sensibilidade dos resultados de "teor de umidade e taxa de secagem", fundamentais às determinações das propriedades estudadas através do método de secagem. Altas potências também aumentam a velocidade do ensaio, diminuindo porém a quantidade de tempo dos períodos de secagem, o que traz maior imprecisão aos cálculos necessários para a determinação das propriedades do material, que dependem da identificação dos momentos de mudança de velocidade de secagem; 
5) Drenagem da água livre, mantendo-se apenas uma pequena quantidade desta água aquecida. Neste trabalho, a quantidade de água aquecida coletada e devolvida ao recipiente com os agregados foi de $120 \mathrm{~g}$, para amostras de $2000 \mathrm{~g}$ de massa seca $(6 \%$ do valor em massa). Esta água é importante para criar um breve período de taxa de secagem constante no ensaio, fundamental à determinação da absorção, que se dá na diferenciação deste período em relação ao de taxa de secagem linearmente decrescente, conforme a teoria de secagem;

6) Reinício da secagem, conforme ilustração da Figura 7.3, com medida da massa do conjunto agregado/água em intervalos de tempo definidos e constantes, sob a mesma potência utilizada na etapa de pré-aquecimento (neste estudo, 20\%), até o fim do segundo período de secagem a taxa linearmente decrescente (momentos próximos à estabilização da massa do conjunto). Estas medições geram uma tabela contendo os tempos t (período de leitura dos dados) e a massa do conjunto agregado/água relativa a cada instante t. Os intervalos usados para as medições, neste trabalho, foram de 20 segundos, pois se mostraram adequados à obtenção de taxas de secagem variando de 1,6 a $2 \mathrm{~g} /$ intervalo em média, taxas estas que permitiram boa visualização das mudanças de regimes de secagem, sem, contudo, perder muita precisão como ocorreria com taxas altas. Notou-se, ainda, que a temperatura atingida ao final desta etapa é bem superior à estabilizada na etapa de pré-saturação, pois a quantidade de água é menor e os agregados apresentam-se descobertos nas proximidades do final do ensaio, atingindo até $170^{\circ} \mathrm{C}$ nos experimentos deste estudo;

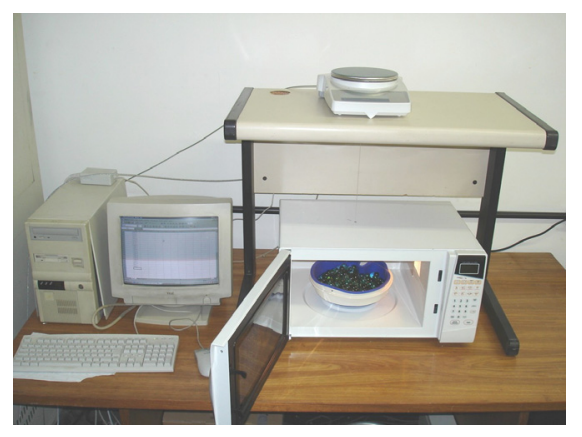

Figura 7.3 - Ilustração dos equipamentos e procedimento utilizados para secagem das amostras em microondas.

7) Cálculo da taxa de secagem a cada instante t, de acordo com a equação:

$\operatorname{TaxaSecagem}(t)($ massa $/$ tempo $)=\frac{\left[M_{\text {conj.agreg } / \text { água }(t-1)}\right]-\left[M_{\text {conj.agreg } / \text { água }(t)}\right]}{(t)-(t-1)}$

8) Confecção do gráfico tempo (no eixo x) versus taxa de secagem (eixo y);

9) Determinação da massa seca $\left(\mathbf{M}_{\mathbf{s}}\right)$ : no gráfico tempo versus taxa de secagem, identifica-se os períodos de secagem em taxa constante e em taxa decrescentemente linear. 
Como demonstrado esquematicamente na figura 7.4, ocorrem dois períodos de secagem em taxa linear decrescente - I e II -, e o segundo (II), no qual a taxa cai em maior velocidade, ocorre próximo aos valores da $\mathrm{M}_{\mathrm{s}}$ do material, quando a massa cai com grande dificuldade. Por regressão, extrapola-se este segundo período de taxa decrescentemente linear ao ponto, no eixo $\mathrm{x}$ (tempo), em que a taxa de secagem seria zero $(\mathrm{y}=0)$. Este é o instante $t$ em que ocorre a $\mathrm{M}_{\mathrm{s}}$ do material, sendo possível então determiná-la;

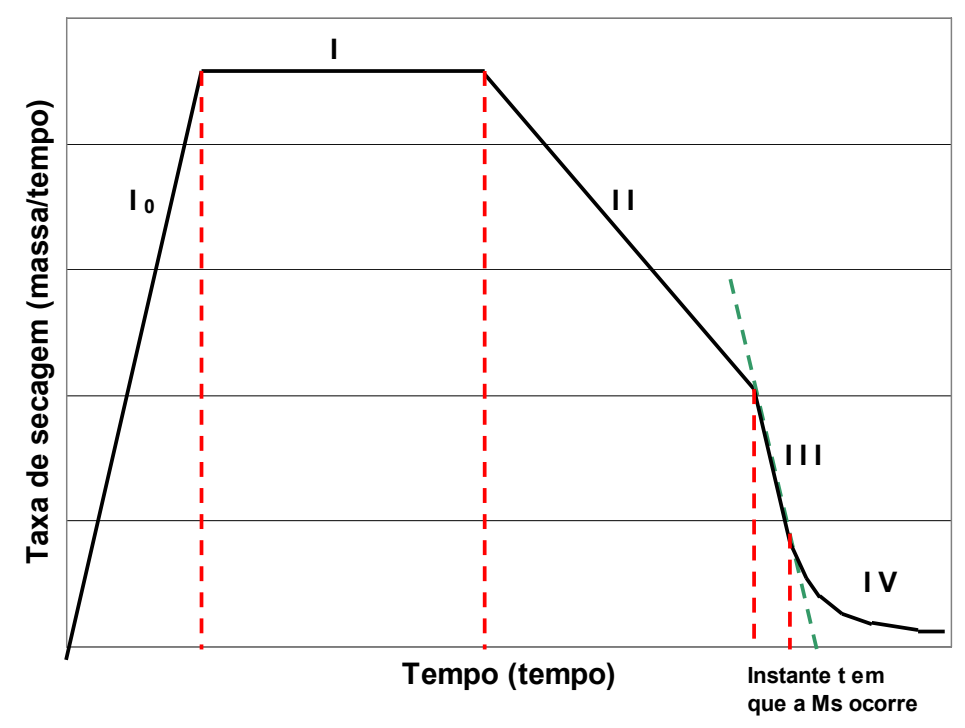

Figura 7.4 - Esquema dos períodos de secagem obtidos através dos dados de secagem em microondas (linhas vermelhas) e do método de determinação da $\mathrm{M}_{\mathrm{s}}$ (linha verde)

10) Cálculo do teor de umidade a cada instante t, pela equação 20 , já que, de acordo com o passo 9, a massa seca $\left(\mathrm{M}_{\mathrm{s}}\right)$ é agora conhecida:

$\operatorname{TeorUmidade}(t)(\%)=\frac{M_{\text {conj.agreg } / \text { água }(t)}-M_{\mathrm{sec} a}}{M_{\mathrm{sec} a}} \times 100$

11) Confecção do gráfico teor de umidade (eixo $\mathrm{x}$ ) versus taxa de secagem correspondente (eixo y);

12) Determinação da massa saturada superfície seca $\left(\mathbf{M}_{\mathrm{sss}}\right)$ : no gráfico teor de umidade versus taxa de secagem, conforme ilustrado esquematicamente na figura 7.5, identifica-se os períodos de secagem em taxa constante (I) e o primeiro período de secagem em taxa decrescentemente linear (II), que se inicia logo após o final da taxa constante. Calcula-se, por regressão, o ponto onde a equação do período de secagem em taxa decrescente linear atinge, no eixo y, o valor da taxa de secagem constante média calculada, e a projeção vertical deste ponto no eixo $\mathrm{x}$ indica a absorção do agregado (teor de umidade quando a 
secagem passa a ocorrer dentro dos poros do material, conforme a teoria de secagem do capítulo 2). Com o valor de absorção determinado, volta-se aos dados de massa coletados nos instantes $\mathrm{t}=1$ até $\mathrm{t}=\infty$ e verifica-se, no instante $(\mathrm{t})$ em que esta absorção (teor de umidade) ocorreu, a massa do conjunto agregado/água correspondente, que é a $\mathrm{M}_{\mathrm{sss}}$;

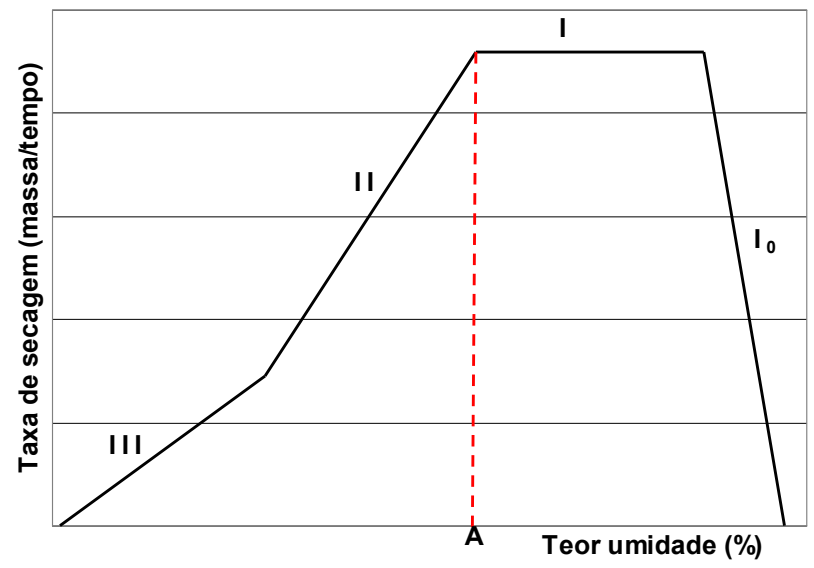

Figura 7.5 - Esquema da determinação da absorção (A) no ponto de intersecção entre fases de secagem I e II.

13) Cálculo da absorção (A), massa específica real (MER) e massa específica aparente (MEA): com $\mathrm{M}_{\mathrm{s}}, \mathrm{M}_{\mathrm{sss}}$ e $\mathrm{M}_{\text {sub }}$ determinados, calcula-se as propriedades físicas buscadas, através das mesmas equações da NM 53:

$$
\begin{aligned}
& A(\%)=\frac{M_{s s s}-M_{\sec a}}{M_{\sec a}} \times 100 \\
& M E A=\frac{M_{\sec a}}{M_{s s s}-M_{s u b}} \\
& M E R=\frac{M_{\sec a}}{M_{\sec a}-M_{s u b}}
\end{aligned}
$$




\section{CONCLUSÕES}

Como discutido na introdução deste trabalho, o objetivo proposto é averiguar a viabilidade da caracterização de propriedades físicas de agregados graúdos de RCD reciclados através da NM 53 (norma atual), estudando sistematicamente, por comparação, novos procedimentos possíveis de realizar esta tarefa de forma mais rápida e precisa. Métodos mais rápidos e precisos para determinação das propriedades físicas de agregados graúdos de RCD reciclados podem ser úteis para separar lotes de agregados de baixa porosidade e alta resistência de lotes de agregados de maior porosidade.

Os resultados experimentais apresentados nos capítulos 3 a 6 demonstram que o novo método de ensaio proposto no capítulo 7 reduz o tempo dispensado para a caracterização dos agregados reciclados, apresentando resultados similares. Neste novo método realiza-se: 1) saturação da amostra com aplicação de depressão de vácuo por 30 minutos; 2) préaquecimento em microondas da amostra imersa em água, antes do início da coleta dos dados de secagem, até estabilização da temperatura, por tempo aproximado de 45 minutos; e 3) secagem em microondas, com medições periódicas da massa do conjunto água/agregado, por tempo que, nos ensaios deste estudo, foram de 2,5 horas em média. O novo ensaio, portanto, é realizado no máximo em 4 horas, o que reduz em aproximadamente 44 horas o tempo de execução em relação à NM 53. Esta norma utiliza 48 horas no mínimo, sendo 24 horas de secagem da amostra em estufa para obtenção da $\mathrm{M}_{\mathrm{S}}$ e mais 24 horas de saturação em água sob pressão ambiente para obtenção da $\mathrm{M}_{\text {sss }}$, através de secagem por pano.

Ao mesmo tempo em que é mais rápido, o novo método traz maior precisão, pois se comprovou que houve aumento significativo da saturação dos poros da amostra pela atuação do vácuo $-500 \mathrm{mmHg}$ por 30 minutos, em substituição à saturação sob pressão ambiente por 24 horas utilizada pela NM 53, resultando em medidas de absorção maiores. Deve-se, porém, ressaltar que não foi atingida saturação total, mesmo após ensaios com 72 horas de saturação sob vácuo $-500 \mathrm{mmHg}$.

O novo método ainda diminui a perda de massa da amostra pela utilização da secagem em microondas para a determinação da $\mathrm{M}_{\mathrm{s}}$ e $\mathrm{M}_{\mathrm{sss}}$ no mesmo procedimento, em substituição às secagens por estufa $\left(\mathrm{M}_{\mathrm{s}}\right)$ e pano $\left(\mathrm{M}_{\mathrm{sss}}\right)$ usadas pela NM 53 .

Há ainda que se lembrar que o método criado utiliza-se de equipamentos de baixos custos e manuseio simples, o que aumenta seu potencial para aplicação real em usinas de 
reciclagem. Um forno de microondas, uma balança, uma bomba capaz de gerar vácuo $500 \mathrm{mmHg}$, um recipiente de acrílico que suporte vácuo, um microcomputador e um software para captação de dados, com seus respectivos acessórios - além de recipientes para medições de massas em diversas circunstâncias - são suficientes para a aplicação do ensaio.

Porém, o método não apresentou resultados consistentes quando aplicado a agregados de argila expandida, devido à grande quantidade de poros não-permeáveis presente em sua estrutura. Ressalta-se que a impossibilidade da caracterização precisa da argila foi detectada para qualquer método que use saturação com água e não realize moagem do material. Deste modo, o método criado não se aplica à caracterização de qualquer agregado poroso e sim especificamente a agregados de RCD reciclados de alta porosidade, mas pode ser adaptado para medir a absorção e massa específica de outros grãos (dependendo de sua estrutura porosa), já que se baseia em teoria de secagem válida a sólidos porosos em geral.

A grande variabilidade intrínseca dos agregados de RCD reciclados, quando não controlada, limita sua aplicabilidade em concretos, restringindo seus mercados e diminuindo seu valor. Em conseqüência, são desestimulados processos de demolição de edifícios que segreguem as fases minerais.

Um ensaio mais rápido e preciso para caracterização de propriedades físicas de agregados de RCD reciclados foi idealizado e ajustado neste trabalho, e sua eficiência foi comprovada. Acredita-se que este seja o elo que possa ligar interesses de demolidores e potenciais compradores de agregados reciclados, pois sua caracterização rápida e eficiente ainda na central de reciclagem pode trazer um produto de qualidade e custos reduzidos, gerando aumento da procura. Este aumento, por sua vez, pode gerar nos demolidores maior interesse econômico pelas frações minerais dos edifícios, iniciando-se a implantação de sistemas de demolição seletiva ou desconstrução, pois separando as fases ainda em canteiro a variabilidade diminui e o valor aumenta. Lotes de menor variabilidade e bem caracterizados, por sua vez, apresentariam maior campo de utilização, ampliando os mercados dos agregados de RCD reciclados e livrando o planeta de alguns milhares de toneladas destes resíduos.

\section{RECOMENDAÇÕES}

Como temas para pesquisas futuras sobre o método proposto no capítulo 7 sugere-se: 1) estudo interlaboratorial, visando sua normatização; 2) análise da sua aplicabilidade frente a variações de características dos agregados, como granulometria, densidade e origem; e 3) possibilidade de caracterização de agregados miúdos de RCD reciclados através do método. 


\section{REFERÊNCIAS}

ASSOCIAÇÃO BRASILEIRA DE NORMAS TÉCNICAS. NBR 9935: agregados terminologia. Rio de Janeiro, 1987. 6 p.

ALAEJOS, P. G. et al. Draft of Spanish regulations for the use of recycled aggregate in the production of structural concrete. In: INTERNATIONAL RILEM CONFERENCE ON THE USE OF RECYCLED MATERIALS IN BUILDINGS AND STRUCTURES, 2004, Barcelona. Proceedings... Bagneux, França: RILEM, 2004. v.1, p. 511-525.

ALMEIDA, R. P.; REZENDE, M. E.; DIAS, J. F. Propriedades do agregado reciclado de telha. Uberlândia: Programa Especial de Treinamento - PET, Faculdade de Engenharia Civil, Universidade Federal de Uberlândia, abril 2003. (Relatório de Pesquisa).

ANGULO, S. C. Variabilidade de agregados graúdos de resíduos de construção e demolição reciclados. 2000. 155 p. Dissertação (Mestrado) - Escola Politécnica, Universidade de São Paulo, São Paulo, 2000.

ANGULO, S. C. et al. Desenvolvimento de novos mercados para a reciclagem massiva de RCD. In: SEMINÁRIO DE DESENVOLVIMENTO SUSTENTÁVEL E A RECICLAGEM NA CONSTRUÇÃO CIVIL, 5., 2002, São Paulo. Anais... São Paulo: IBRACON/IPEN, 2002. p. 293-307.

ANGULO, S. C.; JOHN, V. M. Normalização de agregados graúdos de resíduos de construção e demolição reciclados para concretos e a variabilidade. In: ENCONTRO NACIONAL DE TECNOLOGIA DO AMBIENTE CONSTRUÍDO, 9., 2002, Foz do Iguaçu. Anais... Paraná: ANTAC, 2002. p. 1613-1624.

ANGULO, S. C. et al. Metodologia de caracterização de resíduos de construção e demolição. In: SEMINÁRIO DE DESENVOLVIMENTO SUSTENTÁVEL E A RECICLAGEM NA CONSTRUÇÃO CIVIL, 6., 2003, São Paulo. Anais... São Paulo: IBRACON/IPEN, 2003a. CD-ROM.

ANGULO, S. C. et al. Characterization and recyclability of construction and demolition waste in Brazil. In: INTERNATIONAL CONFERENCE ON THE ENVIRONMENTAL AND TECHNICAL IMPLICATIONS WITH ALTERNATIVE MATERIALS, 5., 2003, San Sebastian. Proceedings... Espanha: ISCOWA/INASMET, 2003b. p. 209-218.

ANGULO, S. C.; JOHN, V. M. Variabilidade dos agregados graúdos de resíduos de construção e demolição reciclados. Revista de Ciência e Tecnologia de Materiais de Construção Civil, Santa Catarina, v. 1, n. 1, p. 22-32, 2004. 
ANGULO, S. C. et al. Caracterização de agregados de resíduos de construção e demolição reciclados separados por líquidos densos. In: ENCONTRO NACIONAL DE TECNOLOGIA DO AMBIENTE CONSTRUÍDO, 10., 2004, São Paulo. Anais... São Paulo: ANTAC, 2004. 1 CD-ROM.

ANGULO, S. C. Caracterização de agregados de resíduos de construção e demolição reciclados e a influência de suas características no comportamento de concretos. 2005. 167 p. Tese (Doutorado) - Escola Politécnica, Universidade de São Paulo, São Paulo, 2005.

ASKELAND, D. R. The science and engineering of materials. London: Chapman \& Hall, 1990. $880 \mathrm{p}$.

AMERICAN SOCIEY OF TESTING MATERIALS. C 125: terminology relating to concrete and concrete aggregates. Washington, 2003. 5p.

C 127: standard test method for density, relative density (specific gravity) and absorption of coarse aggregate. Washington, 2004. 6p.

C 642: test method for density, absorption, and voids in hardened concrete. Washington, 1997.3p.

E 456: standard terminology for relating to quality and statistics. Washington, 1996.

$8 \mathrm{p}$.

E 691: standard practice for conducting an interlaboratory study to determine the precision of a test method. Washington, 1999. 22p.

BAROGHEL-BOUNY, V. et al. Characterization and identification of equilibrium and transfer moisture properties for ordinary and high-performance cementitious materials. Cement and Concrete Research, Elmsford, n. 29, p. 1225-1238, 1999.

BOUGUERRA, A. et al. Isothermal moisture properties of wood-cementitious composites. Cement and Concrete Research, Elmsford, n. 29, p. 339-347, 1999.

BOX, G. E. P.; HUNTER, W. G.; HUNTER, J. S. Statistics for experimenters: an introduction to design, data analysis, and model building. New York: John Wiley \& Sons, 1978. $653 \mathrm{p}$. 
BROWN, G. G et al. Operaciones básicas de la ingeniería química. Barcelona: Manuel Marín \& CIA, 1965. 629 p.

CALLISTER, W. D. Materials science and engineering: an introduction. New York: John Wiley \& Sons, 2000. 871 p.

CARNEIRO, A. P.; CASSA, J. C. S.; BRUM, I. A. S. (Org.). Reciclagem de entulho para produção de materiais de construção (Projeto Entulho Bom). Salvador: EDUFBA, 2001. $311 \mathrm{p}$.

CARRIJO, P. M. Análise da influência da massa específica de agregados graúdos provenientes de resíduos de construção e demolição no desempenho mecânico do concreto. 2005. 129 p. Dissertação (Mestrado) - Escola Politécnica, Universidade de São Paulo, São Paulo, 2005.

CHEN, H.; YEN, T.; CHEN, K. Use of building rubbles as recycled aggregates. Cement and Concrete Research, Elmsford, n. 33, p. 125-132, 2003.

MINISTÉRIO DO MEIO AMBIENTE. Conselho Nacional do Meio Ambiente. Estabelece diretrizes, critérios e procedimentos para a gestão dos resíduos da construção civil. Resolução $n^{\circ}$ 307, de 5 de julho de 2002. Diário Oficial da União, Brasília, DF, 17 jul. 2002.

COSTA NETO, P. L. Estatística. São Paulo: Edgard Blucher, 1977. 264 p.

CROWTHER, P. Developing an inclusive model for design for deconstruction. In: CHINI, A. R. Deconstruction and material reuse: technology, economy and policy. Florida: CIB, 2001. p. 1-27. (CIB Publication 266).

DAMINELI, B. L. et al. Comparação entre métodos de caracterização de propriedades físicas de agregados graúdos de resíduos de construção e demolição reciclados. In: SEMINÁRIO DE DESENVOLVIMENTO SUSTENTÁVEL E A RECICLAGEM NA CONSTRUÇÃO CIVIL, 7., 2006, São Paulo. Anais... São Paulo: IBRACON/IPEN, 2006. 1 CD-ROM.

DANTATA, N.; TOURAN, A.; WANG, J. An analysis of cost and duration for deconstruction and demolition of residential buildings in Massachusetts. Resources, Conservation and Recycling, Amsterdam, n. 44, p. 1-15, Apr. 2005.

DIAS, J. F.; AGOPYAN, V. Determinação da absorção de agregados minerais reciclados porosos. In: ENCONTRO NACIONAL DE TECNOLOGIA DO AMBIENTE CONSTRUÍDO, 10., 2004, São Paulo. Anais... São Paulo: ANTAC, 2004. 1 CD-ROM. 
DIAS, J. F.; AGOPYAN, V.; SILVA, T. J. da. Proposta de procedimento para determinação da absorção de agregados reciclados de resíduos sólidos da construção civil para emprego em concreto. In: CONGRESSO BRASILEIRO DO CONCRETO, 47., 2005, Olinda. Anais... São Paulo: IBRACON, 2005. 1 CD-ROM.

FARIA, L. J. G. Análise experimental do processo de secagem de urucum (Bixa Orellana L.) em leito fixo. 1998. 274 p. Tese (Doutorado) - Universidade de Campinas, Campinas, 1998.

FATTA, D. et al. Generation and management of construction and demolition waste in Greece: an existing challenge. Resources, Conservation and Recycling, Amsterdam, n. 40, p. 81-91, Dec. 2003.

FAUST, T.; BECK, M. Pore structure of different LWAs. LACER, n. 4, p. 123-132, 1999.

FEDERAÇÃO DAS INDÚSTRIAS DO ESTADO DE SÃO PAULO. Agenda de política para a cadeia produtiva da construção civil. São Paulo: FIESP, 2004. 73 p. (Referências FIESP; 7).

FERRAZ, G. R. et al. Estações de classificação e transbordo na cidade de São Paulo. In: SEMINÁRIO DE DESENVOLVIMENTO SUSTENTÁVEL E A RECICLAGEM NA CONSTRUÇÃO CIVIL, 4., 2001, São Paulo. Anais... São Paulo: IBRACON/IPEN, 2001. p. $75-86$.

GUY, B. Building deconstruction assessment tool. In: CHINI, A. R. Deconstruction and material reuse: technology, economy and policy. Florida: CIB, 2001. p. 125-137. (CIB Publication 266).

HAGYMASSY JR, J. et al. Pore structure analysis by water vapor adsorption: 3 analysis of hydrated calcium silicates and Portland cements. Journal of Colloid and Interface Science, New York, v. 38, n. 1, p. 20-34, 1972.

HALLIDAY, D. Física básica. Rio de Janeiro: Livros Técnicos e Científicos, 1991. 280 p. HELENE, P. R. L.; TERZIAN, P. R. Manual de dosagem e controle do concreto. São Paulo: PINI, 1992. 349 p.

HELENE, P. R. L.; TERZIAN, P. R. Manual de dosagem e controle do concreto. São Paulo: PINI, 1992. 349p. 
HENDRIKS, C. F. The building cycle. Holanda: Aeneas, 2000. 231 p.

HENDRIKS, C. H.; PIETERSEN, H. S. Concrete: durable, but also sustainable? In: DHIR, R. K.; HENDERSON, N. A.; LIMBACHIYA, M. C. (Ed.). Sustainable construction: use of recycled concrete aggregate. London: Thomas Telford, 1998. p. 1-18.

HENDRIKS, C.; XING, W. Quality improvements of granular wastes by separation techniques. In: INTERNATIONAL RILEM CONFERENCE ON THE USE OF RECYCLED MATERIALS IN BUILDINGS AND STRUCTURES, 2004, Barcelona. Proceedings... França: Elsevier, 2004. v.1, p. 142-149.

HOBBS, G.; HURLEY, J. Deconstruction and reuse of construction materials. In: CHINI, A. R. Deconstruction and material reuse: technology, economy and policy. Florida: CIB, 2001. p. 98-124. (CIB Publication 266).

HOLM, T. A; OOI, O. S.; BREMMER, T. W. Moisture dynamics in lightweight aggregate and concrete. Salt Lake City: Expanded Shale Clay \& Slate Institute (ESCSI), 2004. 12 p. (Publication 9340).

JOHN, V. M. Reciclagem de resíduos na construção civil: contribuição à metodologia de pesquisa e desenvolvimento. 2000. 102 p. Tese (Livre Docência) - Escola Politécnica, Universidade de São Paulo, São Paulo, 2000.

JOHN, V. M.; ANGULO, S. C. Metodologia para o desenvolvimento de reciclagem de resíduos. In: JOHN, V. M.; ROCHA, J. C. Utilização de resíduos na construção habitacional. Porto Alegre: ANTAC, 2003. v.4, p. 8-71.

JOHN, V. M. et al. Strategies for innovation in construction and demolition waste management in Brazil. In: CIB WORLD BUILDING CONGRESS, 2004, Toronto. Proceedings... Canadá: National Research Council of Canada, 2004. 1 CD-ROM.

KEEY, R. B. Drying: principles and practice. Hungary: Pergamon Press, 1972. 358 p.

KIBERT, C. J.; CHINI, A. R. Introdution: deconstruction as an essential component of sustainable construction. In: KIBERT, C. J.; CHINI, A. R. Deconstruction and material reuse: technology, economy and policy. Florida: CIB, 2000. p. 6-13. (CIB Report Publication 252). 
KLANG, A.; VIKMAN, P.; BRATTEB, H. Sustainable management of demolition waste: an integrated model for the evaluation of environmental, economic and social aspects. Resouces, Conservation and Recycling, n. 38, p. 317-334, Jul. 2003.

KOWALCZYK, T. State of the art of deconstruction in the Netherlands. In: KIBERT, C. J.; CHINI, A. R. Deconstruction and material reuse: technology, economy and policy. Florida: CIB, 2000. p. 95-143. (CIB Publication 252).

KROPP, J. Bestimmung der Kernfeuchte wassergesättigter: Bauschuttrezyklate anhand des Trocknungsverhaltens. Amtliche Materialprüfungsanstalt Bremen. 2005. 12 p. Disponível em: <http://www.uni-weimar.de/Bauing/aufber/veranstaltungen.html $>$. Acesso em: $18 \mathrm{abr}$. 2006.

LEITE, M. B. Avaliação das propriedades mecânicas de concretos produzidos com agregados reciclados de resíduos de construção e demolição. 2001. 270 p. Tese (Doutorado) - Universidade Federal do Rio Grande do Sul, Porto Alegre, 2001.

LEVY, S. M. Reciclagem do entulho de construção civil, para utilização como agregado de argamassas e concretos. 1997. 146 p. Dissertação (Mestrado) - Escola Politécnica, Universidade de São Paulo, São Paulo, 1997.

LIMA, J. A. R. Proposição de diretrizes para produção e normalização de resíduo de construção reciclado e de suas aplicações em argamassas e concretos. 1999. 204 p. Dissertação (Mestrado) - Escola de Engenharia de São Carlos, Universidade de São Paulo, São Carlos, 1999.

LIMBACHIA, M. C; LEELAWAT, T; DHIR, R. K. Use of recycled concrete aggregate in high-strength concrete. Materials and Structures, Paris, n.33, p. 574-580, Nov. 2000.

LO, Y; GAO, X. F.; JEARY, A. P. Microstructure of pre-wetted aggregate on lightweight concrete. Building and Environment, Oxford, n. 34, p. 759-764, 1999.

LÜTHI, T. Infrared thermography. Materials and Structures, Paris, n.31, p. 188-189, Apr. 1998.

McCABE, W. L.; SMITH, J. C.; HARRIOTT, P. Unit operations of chemical engineering. $4^{\text {th }}$ ed. São Paulo: McGraw-Hill do Brasil, 1987. 960 p.

MEHTA, P. K; MONTEIRO, P. J. M. Concreto: estrutura, propriedade e materiais. São Paulo: PINI, 1994. 573 p. 
MORAVIA, W. G. et al. Caracterização microestrutural da argila expandida para aplicação como agregado em concreto estrutural leve. Cerâmica, São Paulo, n. 52, p. 193-199, 2006. NAIK, T. R.; RAMME, B. W. Determination of the water content of concrete by the microwave method. Cement and Concrete Research, Elmsford, n.17, p. 927-938, 1987.

NEVILLE, A. M. Properties of concrete. London: Longman, 1995. 844 p.

NONHEBEL, G.; MOSS, A. A. H. Drying of solids in the chemical industry. London: Butterworth \& Co., 1971. 301 p.

NORMA MERCOSUL. NM 53: agregado graúdo: determinação da massa específica, massa específica aparente e absorção de água. Rio de Janeiro, 2003. 8 p.

PEDROZO, P. H.; LEITE, M. B.; DAL MOLIN, D. C. C. Technical viability study of the use of construction and demolition waste to concrete production. In: CIB SYMPOSIUM ON CONSTRUCTION \& ENVIRONMENT: THEORY INTO PRACTICE, 1., 2000, São Paulo. Proceedings... São Paulo: EPUSP/CIB, 2000. 1 CD-ROM.

PINTO, T. P. Metodologia para a gestão diferenciada de resíduos sólidos da construção urbana. 1999. 189 p. Tese (Doutorado) - Escola Politécnica, Universidade de São Paulo, São Paulo, 1999.

POON, C. S. et al. Influence of moisture states of natural and recycled aggregates on the slump and compressive strength of concrete. Cement and Concrete Research, Elmsford, n. 34, p. 31-36, 2004.

RAMALHO, P. C. et al. Caracterização das propriedades físicas de agregados graúdos reciclados pelo método da massa submersa x tempo. 2004. 36p. Relatório final (Bolsa PIBIq/CNPq) - Escola Politécnica, Universidade de São Paulo. São Paulo, 2004.

RILEM RECOMMENDATION. Specification for concrete with recycled aggregates. Materials and Structures, Paris, n. 27, p. 557-559, 1994.

SCHADLER, N.; KAST, W. Experimental studies and mathematical modelling on convective drying of porous bodies. In: MUJUMDAR, A. S. Drying of solids: recent international developments. New Delhi: Wiley, 1986. p. 29-40.

SCHERER, G. W. Theory of drying. Journal of the American Ceramic Society, Easton, n. 73, p. 3-14, 1990. 
SCHOUENBORG, B. et al. Test methods adapted for alternative and recycled, porous aggregate materials: part 3: water absorption: NORDTEST Project No. 1531-01. Boras: SP Swedish National Testing and Research Institute, 2003. 20 p. (SP Report 2003:24).

SCHULTMANN, F. The state of deconstruction in Germany. In: KIBERT, C. J.; CHINI, A. R. Deconstruction and material reuse: technology, economy and policy. Florida: CIB, 2000. p. 45-74. (CIB Publication 252).

SCHULTMANN, F. et al. Methodologies and guidelines for deconstruction in Germany and France. In: CHINI, A. R. Deconstruction and material reuse: technology, economy and policy. Florida: CIB, 2001. p. 27-43. (CIB Publication 266).

SINDICATO DAS EMPRESAS REMOVEDORAS DE ENTULHO DO ESTADO DE SÃO PAULO. Panorama do mercado de remoção dos resíduos da construção. In: RESÍDUOS DA CONSTRUÇÃO CIVIL - NOVA POLÍTICA E INCENTIVO A NOVOS NEGÓCIOS, 2003, São Paulo. São Paulo: SINDUSCON-SP/Prefeitura de SP/SIERESP, 2003. 1 CD-ROM.

STAMENKOVIC, H. Determination of absorbed water in lightweight aggregate and quantities of ingredients in lightweight concrete. Matériaux et Constructions, Paris, v.3, n. 13, p. 45-51, 1970.

STRONGIN, V.; BORDE, I. Theoretical prediction of moisture transfer by connective drying for a flat plate. In: MUJUMDAR, A. S. Drying of solids: recent international developments. New Delhi: Wiley, 1986. p. 22-28.

STRUMILLO, C.; KUDRA, T. Drying: principles, applications and design. Glasgow: Gordon and Breach Science Publishers, 1986. 448 p.

TANAKA, K.; KURUMISAWA, K. Developments of technique for observing pores in hardened cement paste. Cement and Concrete Research, Elmsford, n. 33, p. 1435-1441, 2002.

TAYLOR, H. F. W. Cement chemistry. London: Academic, 1992. 475 p.

VAN VLACK, L. H. Princípios de ciência dos materiais. São Paulo: Edgard Blucher, 1970. $427 \mathrm{p}$.

VASILIU, D. The characteristic water of aggregate testing and applications. Matériaux et Constructions, Paris, v.15, n.87, p. 185-194, 1982. 
VÁZQUEZ, E.; BARRA, M. Recycling of aggregates in the construction industry. In: CIB SYMPOSIUM ON CONSTRUCTION \& ENVIRONMENT: THEORY INTO PRACTICE, 1., 2000, São Paulo. Proceedings... São Paulo: EPUSP/CIB, 2000. 1 CD-ROM.

VIEIRA, C. M. F.; FEITOSA, H. S.; MONTEIRO, S. N. Avaliação da secagem de cerâmica vermelha através da curva de Bigot. Cerâmica Industrial, São Paulo, n. 8, p. 42-46, jan./fev. 2003.

VUOLO, J. H. Introdução à teoria de erros. São Paulo: IF/USP, 1999. 68 p.

WAENY, J. C. C. Controle total da qualidade em metrologia. São Paulo: Makron Books, 1992. $152 \mathrm{p}$.

WANG, J. et al. A systems analysis tool for construction and demolition wastes management. Waste Management, n.24, p. 989-997, 2004.

WASSERMAN, R.; BENTUR, A. Interfacial interactions in lightweight aggregate concretes and their influence on the concrete strength. Cement and Concrete Composites, Essex, n.18, p. 67-76, 1996.

ZORDAN, S. E. A utilização do entulho como agregado, na confecção do concreto. 1997. 140 p. Dissertação (Mestrado) - Faculdade de Engenharia Civil, Universidade Estadual de Campinas, Campinas, 1997. 